\title{
Blattwasserzustand und Wasserumsatz von vier Buchenwäldern entlang eines Niederschlagsgradienten in Mitteldeutschland
}

\author{
Dissertation \\ zur Erlangung des Doktorgrades \\ der Mathematisch-Naturwissenschaftlichen Fakultäten \\ der Georg-August-Universität zu Göttingen
}

vorgelegt von

\section{Florian Schipka}

aus Würzburg

Göttingen, 16.12.2002 
D 7

Referent: $\quad$ Prof. Dr. Ch. Leuschner

Korreferent: Prof. Dr. M. Runge

Tag der mündlichen Prüfung: 29.1.2003 


\section{Inhaltsverzeichnis}

1 Einleitung

2 Beschreibung der Standorte und Untersuchungsbestände

2.1 Topographische Lage der Untersuchungsflächen ............................................................. 3

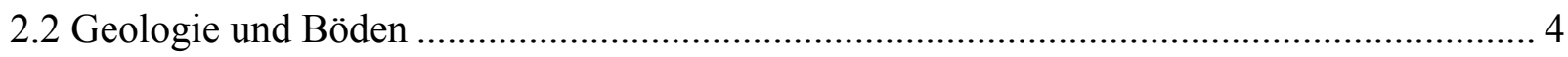

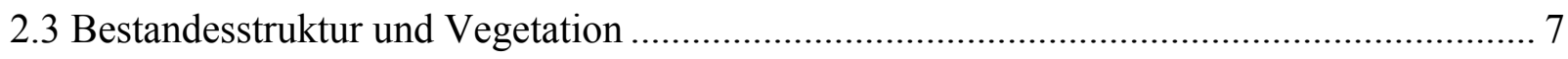

2.4 Regionalklima und Witterung in den Untersuchungsjahren........................................... 9

2.4.1 Regionalklima der Untersuchungsgebiete ........................................................ 9

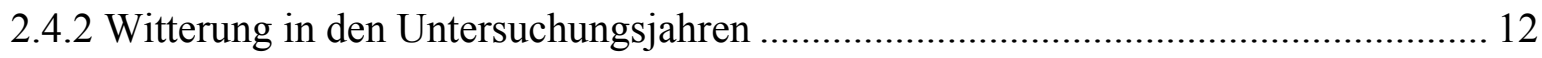

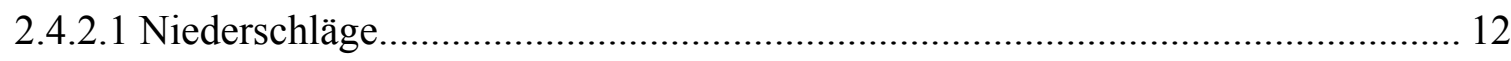

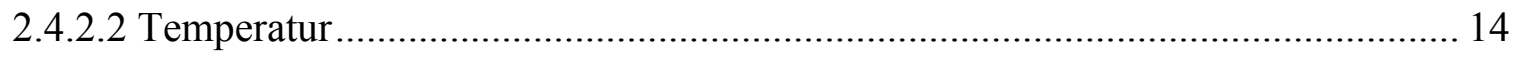

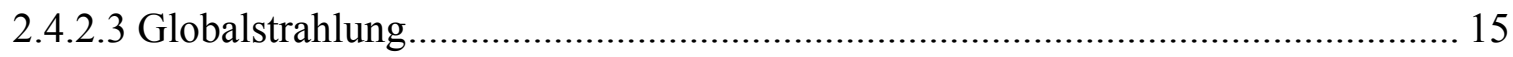

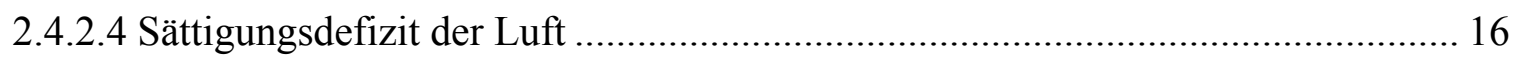

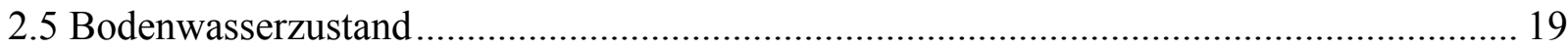

2.5.1 Volumetrische Bodenwassergehalte und Bodenmatrixpotentiale ........................... 19

2.5.2 Matrixpotential-Wassergehaltsbeziehungen (Feld-pF-Kurven) ............................... 28

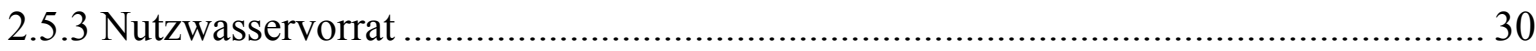

3 Material und Methoden $\quad 34$

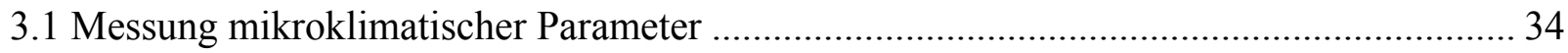

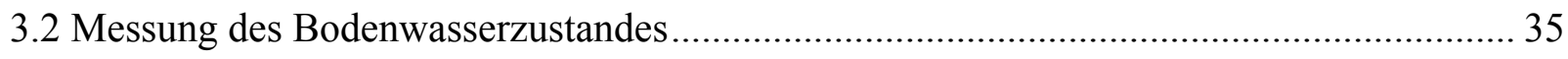

3.2.1 Messung von Bodenmatrixpotential und volumetrischem Bodenwassergehalt ......... 35

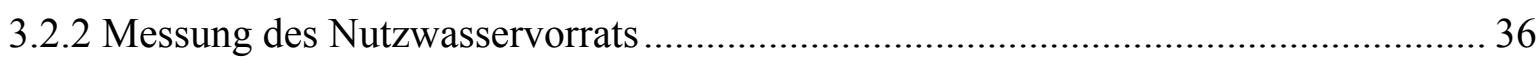

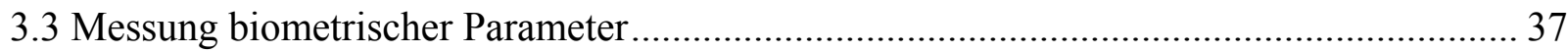

3.3.1 Messung von Blattflächenindex, Bestandesblattmasse und morphologischen

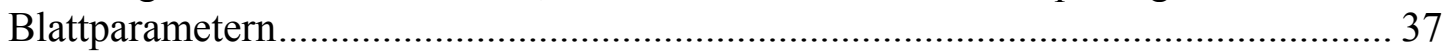

3.3.2 Messung des Holz-Volumenzuwachses und Bestimmung des Holzvorrats ............... 38

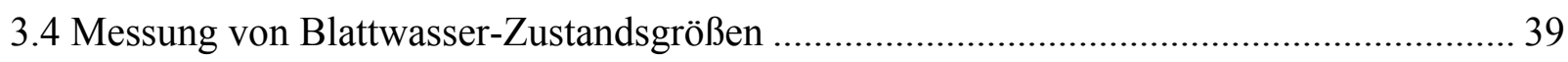

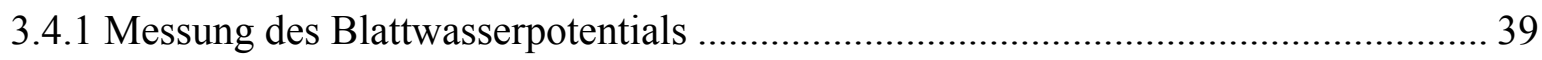

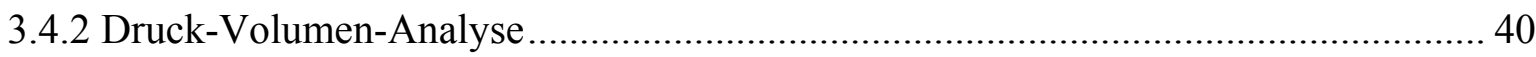

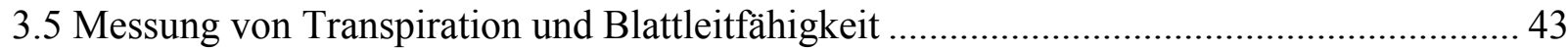

3.5.1 Porometrische Messung von Transpiration und Blattleitfähigkeit ............................ 43

3.5.2 Xylem-Saftflußmessung und Bestimmung der Bestandestranspiration ..................... 44 
4.1 Blattflächenindex, Bestandesblattmasse und morphologische Blattparameter ................. 48

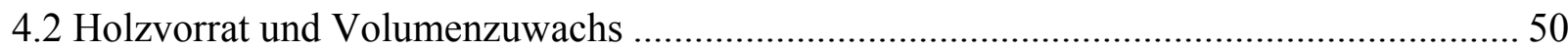

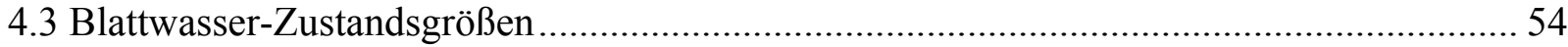

4.3.1 Osmotisches Potential bei Wassersättigung und bei Grenzplasmolyse ...................... 54

4.3.2 Relativer Wassergehalt bei Grenzplasmolyse.......................................................... 57

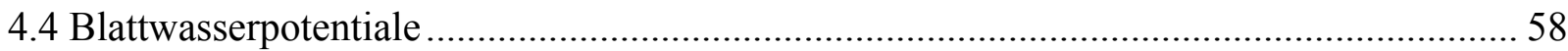

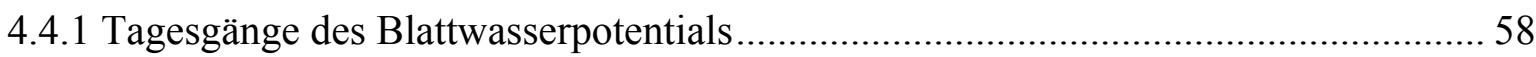

4.4.2 Tagesmaxima und Tagesminima des Blattwasserpotentials..................................... 59

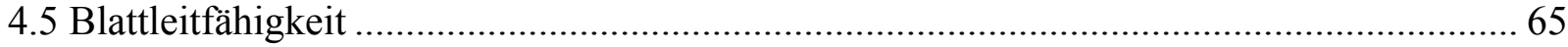

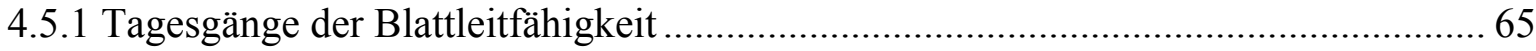

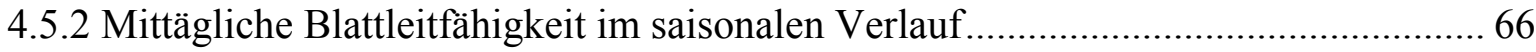

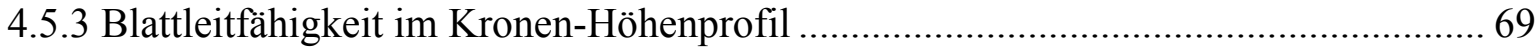

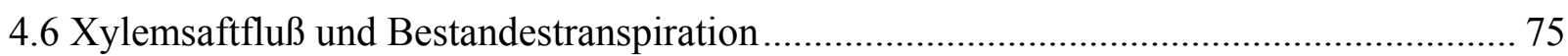

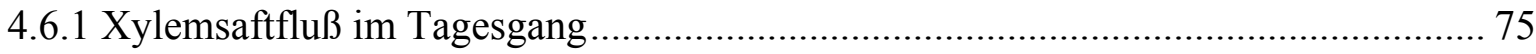

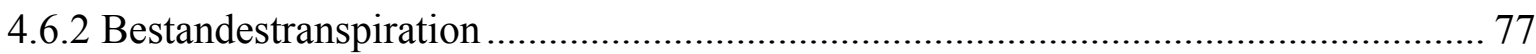

5 Diskussion $\quad 83$

5.1 Die standörtlichen Wasserhaushaltsbedingungen: Unterschiede in der klimatisch-

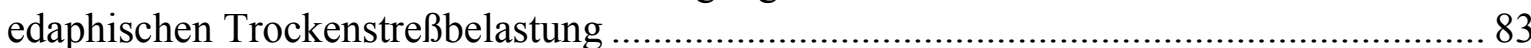

5.1.1 Der Klimagradient zwischen den untersuchten Beständen und die klimatische Trockenstreßbelastung in den Untersuchungsjahren .............................................. 83

5.1.2 Unterschiede und Gemeinsamkeiten in der Bodenwasserversorgung der untersuchten Bestände

5.2 Blattwasserzustand und Blattleitfähigkeit der untersuchten Buchenbestände..................... 94

5.2.1 Gibt es ,osmotic adjustment' bei Fagus sylvatica? .................................................. 94

5.2.2 Blattleitfähigkeiten und Blattwasserpotentiale bei unterschiedlicher

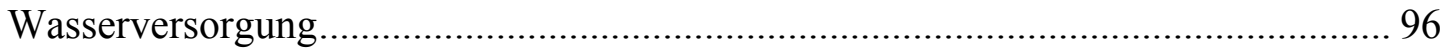

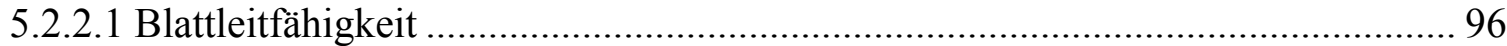

5.2.2.2 Schwellenwerte des Blattwasserpotentials ......................................................... 98

5.2.2.3 Pre-dawn-Werte des Blattwasserpotentials ..................................................... 101

5.3 Der Wasserumsatz der untersuchten Buchenbestände..................................................... 103

5.3.1 Bestimmung der Bestandestranspiration: Methoden und Kritik.............................. 103

5.3.2 Die Jahressummen der Bestandestranspiration unter dem Einfluß von

Niederschlagsregime und morphologisch-strukturellen Bestandesmerkmalen ........ 106 
5.4 Bestandestranspiration und Bestandesleitfähigkeit in ihrer Reaktion auf das aktuelle Wasserhaushaltsregime.....

5.4.1 Die Bestandestranspiration in Abhängigkeit von abiotischen Einflußgrößen des Wasserhaushalts.

5.4.2 Reaktionsmuster der Bestandesleitfähigkeit bei unterschiedlicher Trockenstreßbelastung

5.5 Zuwachsverhalten: Die Bedeutung von Trockenstreß und Phänomene der TrockenstreßAnpassung.

6 Zusammenfassung

Verzeichnis der Tabellen und Abbildungen im Text I

Abkürzungsverzeichnis VI 


\section{Einleitung}

Buchenwälder nehmen heute etwa ein Viertel der bewaldeten Fläche Deutschlands ein (BMELF 1999) und spielen in weiten Teilen Mitteleuropas auch in der potentiellen natürlichen Vegetation eine dominierende Rolle (ELLENBERG 1996, LEUSCHNER 1998a). So wären ohne anthropogenen Einfluß rund $75 \%$ der Fläche der alten Bundesländer von buchenbeherrschten Wäldern bedeckt (LEUSCHNER 1998a). Diese beachtliche Dominanz belegt eine Konkurrenzkraft der Buche, die RöHRIG (1991) als ,von keinem anderen Laubbaum der nördlichen Hemisphäre, vielleicht sogar der ganzen Welt erreicht" beschreibt.

Einen großen Konkurrenzvorteil gegenüber anderen Arten erlangt die Buche durch ihr starkes Durchsetzungsvermögen im Kronenraum mit hoher Schattenerzeugung bei zugleich ausgeprägter Schattentoleranz (LEUSCHNER 1994, HAGEMEIER 2002). Ein weiterer wesentlicher Grund für die enorme Konkurrenzkraft der Buche liegt sicher in ihrer großen Plastizität gegenüber klimatischen und edaphischen Standortfaktoren. Buchenwälder kommen über das gesamte Niederschlags- und Bodenreaktions-Spektrum Mitteleuropas vor (460 bis $>2000 \mathrm{~mm}$ Jahresniederschlag, $\mathrm{pH}(\mathrm{KCl}) 2.6$ bis > 7) (LEUSCHNER et al. 1993, LEUSCHNER 1998a).

Die Buche gilt gemeinhin als ozeanische und relativ trockenempfindliche Art (RÖHRIG 1991, ELLENBERG 1996), deren natürliches Verbreitungsgebiet bereits GRISEBACH (1872) als „vollkommensten Ausdruck für den Einfluß des Seeklimas in Europa“ bezeichnete und anhand deren Klimaoptimum KÖPPEN (1901) ein „Buchenklima“ auch in anderen Erdteilen abgrenzte. Dennoch erreicht die Buche ihre Arealgrenze im Norden als Baumart des Tieflands erst in Südskandinavien (60 30') und im Süden als Baumart der Gebirge bis in Höhen von $2300 \mathrm{~m}$ in Sizilien (37 30') (RUBNer 1960, PAUle 1992). Am östlichen Rand des Verbreitungsgebiets in der Ukraine stehen Buchenwälder in direktem Kontakt mit Steppengesellschaften und in Südeuropa erreichen sie meist in einer Höhe von $800-900 \mathrm{~m}$ ihre untere Verbreitungsgrenze (STOJKO 1991, PAUle 1992). Neben Spätfrostschäden in kontinental geprägten Klimaten gilt im Osten und Süden des Buchenareals vor allem Sommertrockenheit als begrenzender Faktor (RUBNER 1960, ELLENBERG 1996).

Damit erhebt sich die Frage, welche Faktoren den Wasserhaushalt von Buchenbeständen entscheidend beeinflussen und mit welchen Reaktionsmustern die Buche in der Lage ist, unterschiedlichen Wasserhaushaltsbedingungen zu begegnen. Wie plastisch ist die Buche in der Anpassung an Wassermangel, und wodurch können Vitalität und Konkurrenzkraft so stark eingeschränkt werden, daß auch in Mitteleuropa Grenzen der Anpassungsfähigkeit und damit der Verbreitung erreicht werden? Vor dem Hintergrund weltweiter Klimaveränderungen gewinnen Fragen zur Reaktion wichtiger Waldbaumarten auf veränderte Wasserhaushaltsbedingungen an Bedeutung (OverdiECK \& Forstreuther 1994, SCHUlze et al. 1994, PEUKE et al. 2002).

In zahlreichen Untersuchungen wurden diverse Parameter des pflanzlichen Wasserhaushalts an Buchen bestimmt, häufig jedoch nur an Schößlingen und in Form von Topfexperimenten 
(Overdieck \& Forstreuther 1994, Tognetti et al. 1995, Thomas 2000, Peuke et al. 2002). Eine Reihe von Arbeiten zum Wasserhaushalt einzelner Buchenaltbestände beschränkte sich vorwiegend auf die Ebene des Wasserumsatzes im Bestand (BENECKE 1984, BÜCKING \& KREBS 1986, GERKE 1987, HEIL 1996). Wenige Untersuchungen bezogen zugleich intensiv Parameter des pflanzlichen Wasserhaushalts ein (ROBERTS \& ROSIER 1994, BACKES 1996, GRANIER et al. 2000). Eine entsprechend umfassende Untersuchung, die mehrere mitteleuropäische Waldbestände derselben Art über einen weiten Gradienten des so bedeutenden Standortfaktors der Niederschlags- bzw. Bodenwasserversorgung (WoODWARD 1987, PigOTT \& PigOTT 1993) vergleicht, wurde bisher nicht durchgeführt.

In der vorliegenden Studie wurden Parameter des Wasserhaushalts von vier Buchenbeständen entlang eines Niederschlagsgradienten in Mitteldeutschland untersucht. Die Standortbedingungen der untersuchten Buchenbestände umfassen bei langjährigen Mitteln des Jahresniederschlags von $520 \mathrm{~mm}$ - $1040 \mathrm{~mm}$ und subkontinentaler bis subozeanisch-montaner Klimatönung einen weiten Bereich des Klimaspektrums mitteleuropäischer Buchenstandorte. Bestandestranspiration, stomatäre Leitfähigkeit und Parameter des Blattwasserzustands der Bestände werden auf ihren Zusammenhang mit mikroklimatischen Parametern, Bodenwasserversorgung und Unterschieden in Blattmorphologie und Bestandesaufbau hin untersucht. Einblicke in das Zusammenspiel dieser Faktoren können Aufschluß geben über Wasserumsatz und Reaktionsmuster der Wasserhaushaltsregulation bei standörtlich unterschiedlichen Wasserhaushaltsbedingungen der untersuchten Buchenbestände. Eine zusätzliche Betrachtung der Zuwachsreaktion erlaubt schließlich eine Einordnung der Auswirkung unterschiedlicher Trockenstreßbelastung auf die Vitalität und Konkurrenzkraft der untersuchten Buchenbestände. 


\section{Beschreibung der Standorte und Untersuchungsbestände}

\subsection{Topographische Lage der Untersuchungsflächen}

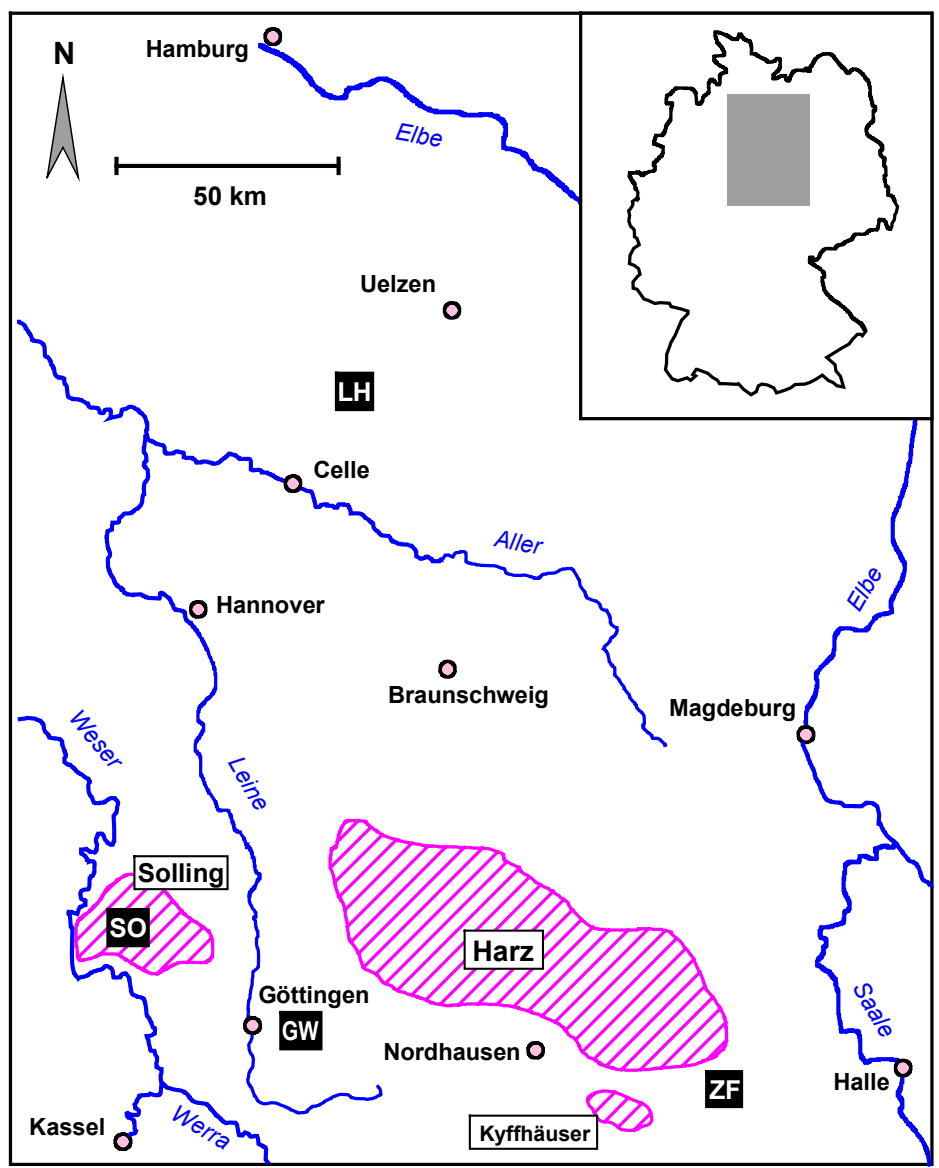

Abb. 2-1: Topographische Lage der Untersuchungsflächen:

Ziegelrodaer Forst (ZF)

Göttinger Wald (GW)

Lüneburger Heide (LH)

Solling (SO)

Es wurden vier Untersuchungsflächen entlang eines Niederschlagsgradienten in Mitteldeutschland ausgewählt, auf denen in Alter und Bestandesstruktur vergleichbare Buchenwälder stocken (Abb. 2-1):

\section{Ziegelrodaer Forst}

Der Untersuchungsbestand im Ziegelrodaer Forst befindet sich etwa $50 \mathrm{~km}$ westlich von Halle und $3 \mathrm{~km}$ südöstlich von Allstedt $\left(51^{\circ} 23^{\prime} \mathrm{N}, 11^{\circ} 26^{\prime} \mathrm{E}\right)$ auf einem Höhenzug im südöstlichen Harzvorland. Der Buchenbestand liegt in einer Höhe von $280 \mathrm{~m}$ ü. M. und gehört zum Forstamt Allstedt / Ziegelroda (Abt. 118). Der Kernbereich der Untersuchungsfläche ist eben und geht im nordwestlichen Flächenteil über in einen bis maximal $6^{\circ}$ nach Nordwesten abfallenden Oberhang. 


\section{Göttinger Wald}

Der Buchenbestand im Göttinger Wald befindet sich auf der Untersuchungsfläche des ehemaligen Sonderforschungsbereiches 0135 der Universität Göttingen. Der Bestand liegt auf dem Plateau einer Schichtstufe $7 \mathrm{~km}$ östlich von Göttingen $\left(51^{\circ} 31^{\prime} \mathrm{N}, 10^{\circ} 03^{\prime} \mathrm{E}\right)$ in einer Höhe von $420 \mathrm{~m}$ ü. M. und gehört zum Forstamt Reinhausen (Abt. 166).

\section{Lüneburger Heide}

Der untersuchte Mischbestand aus Buchen und Traubeneichen befindet sich in der südlichen Lüneburger Heide zwischen Celle und Uelzen, ca. $2 \mathrm{~km}$ westlich von Unterlüß $\left(52^{\circ} 45^{\prime} \mathrm{N}\right.$, $\left.10^{\circ} 30^{\prime} \mathrm{E}\right)$. Der Bestand liegt im nordwestdeutschen Tiefland in einer Höhe von $115 \mathrm{~m}$ ü. M. auf einem flachen Höhenrücken, der sich bis auf $170 \mathrm{~m}$ ü. M. erhebt. Die Fläche ist eben bis schwach nach Nordosten geneigt.

\section{Solling}

Untersucht wurde ein Buchenbestand im Solling, einem etwa $30 \mathrm{~km}$ nordwestlich Göttingen gelegenen Mittelgebirgszug an der Weser. Die Untersuchungsfläche befindet sich etwa $3 \mathrm{~km}$ südöstlich des Ortes Silberborn ( $\left.51^{\circ} 46^{\prime} \mathrm{N}, 9^{\circ} 35^{\prime} \mathrm{E}\right)$ und wurde unter der Bezeichnung B1 bereits seit über 30 Jahren im Rahmen des „Solling-Projekts“ (ELLENBERG et al. 1986) intensiv untersucht. Die weitgehend ebene Fläche liegt in einer Höhe von $510 \mathrm{~m}$ ü. M. im Bereich des Forstamtes Neuhaus (Abt. 50).

\subsection{Geologie und Böden}

\section{Ziegelrodaer Forst}

Der Höhenzug des Ziegelrodaer Forstes ist aus dem unteren und mittleren Buntsandstein der Trias aufgebaut. Auf dem Höhenrücken steht im Bereich der Untersuchungsfläche der mittleren Buntsandstein an, welcher hier durch eine kleinräumig unterschiedlich mächtige Lößschicht von einigen Zentimetern überdeckt ist.

Ausgangsmaterial der Bodenbildung stellte somit neben einer geringmächtigen Sandlößauflage überwiegend der tiefgründig verwitterte mittlere Buntsandstein dar. Im Untersuchungsbestand liegt mit der Horizontabfolge $A_{h}-B_{v}-C_{v}$ eine schwach saure Braunerde vor. Über dem Mineralboden befindet sich eine nur geringmächtige organische Auflage, die mit den Horizonten $\mathrm{O}_{\mathrm{f}}(1 \mathrm{~cm})$ und $\mathrm{O}_{1}(2 \mathrm{~cm})$ einen typischen F-Mull bildet. Der 5 - $8 \mathrm{~cm}$ mächtige $A_{h}$-Horizont aus lehmigem Sand ist stark humos. Während der $20-30 \mathrm{~cm}$ mächtige $\mathrm{B}_{\mathrm{v}}$-Horizont als Bodenart schwach schluffigen Sand aufweist, wechseln im $\mathrm{Cv}$ Horizont Lagen schluffigen Sandes mit fast reinem Feinsand, die teilweise von geringmächtigen Tonbändern durchzogen werden. Im $\mathrm{B}_{\mathrm{v}^{-}}$und $\mathrm{C}_{\mathrm{v}}$-Horizont, der bis $1.4 \mathrm{~m}$ erschlossen wurde, befinden sich einige Zentimeter bis einige Dezimeter große Platten und Blöcke wenig verwitterten Ausgangsgesteins. Der Skelettanteil übersteigt jedoch $15 \%$ nicht (MuHS 1997). 
Bodenchemisch überraschend ist der trotz des nährstoff- und carbonatarmen Ausgangsmaterials in allen Bodentiefen relativ hohe $\mathrm{pH}(\mathrm{KCl})$ von etwa 3.6. Der Boden befindet sich somit nach der Klassifizierung von ULRICH (1981) noch im Übergang vom Austauscher- zum Aluminium-Pufferbereich. Die Kationenaustauschkapazität $\left(\mathrm{Ak}_{\mathrm{e}}\right)$ ist mit

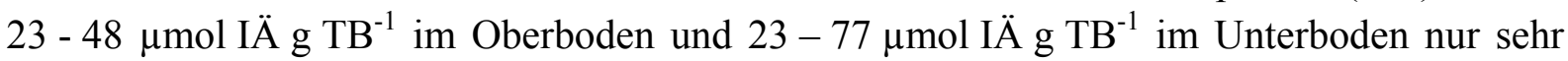
gering. Der Summenanteil von $\mathrm{K}-\mathrm{Ca}$ - und $\mathrm{Mg}$-Ionen an der $\mathrm{Ak}_{\mathrm{e}}$, ist mit etwa $45 \%$ im Oberboden und 20 - $30 \%$ im Unterboden wiederum vergleichsweise hoch (Tab. 2-1).

\section{Göttinger Wald}

Die Untersuchungsfläche Göttinger Wald liegt auf dem Hochplateau einer Schichtstufe des unteren Muschelkalks. Dieser wird aus einer wechselnden Folge von dünnplattig-schichtigem Wellenkalk und dickbankigeren Kalksteinen gebildet (LAVAHUN 1981).

Auf der Untersuchungsfläche hat sich aus einer periglazialen Muschelkalk-Frostschuttdecke eine flachgründige Rendzina mit den Horizonten $A_{h}-C_{v}$ entwickelt (MEIWES \& BEESE 1988). Daneben sind sehr kleinräumig und stark heterogen verteilt noch die in der Entwicklungsreihe hin zur Braunerde folgenden Bodentypen Terra fusca - Rendzina und Terra fusca zu beobachten. Das Feinbodenmaterial des Oberbodens besteht aus tonigem Schluff und ist unregelmäßig mit plattigen Kalksteinen von etwa $1-10 \mathrm{~cm}$ Durchmesser durchsetzt. So steigt im Mittel der Skelettanteil im Ah bis in $25 \mathrm{~cm}$ Tiefe auf etwa $20 \%$ an und erreicht im $\mathrm{C}_{\mathrm{v}}$ rasch Werte von 50 - 70 \%. Der Übergang zum anstehenden Wellenkalk erfolgt etwa in $1 \mathrm{~m}$ Tiefe. Eine organische Auflage findet sich nur in Form eines dünnen $\mathrm{O}_{\mathrm{l}}$-Horizonts, so daß die Humusform als L-Mull zu beschreiben ist.

Bodenchemisch unterscheidet sich der Bestand Göttinger Wald durch das nährstoff- und tonreiche Ausgangsgestein des unteren Muschelkalks stark von den anderen Untersuchungsbeständen. Der pH $\left(\mathrm{CaCl}_{2}\right)$ liegt im neutralen Bereich und der Boden befindet sich nach der Klassifizierung von ULRICH (1981) im Carbonat-Pufferbereich. Die Kationenaustauschkapazität liegt mit Werten um $740 \mu$ mol IÄ g TB ${ }^{-1}$ um ein Vielfaches höher als in den Böden der anderen Untersuchungsflächen (Tab. 2-1); ebenso der Summenanteil der K-, Ca- und Mg-Ionen, der nur wenig unter $100 \%$ bleibt.

\section{Lüneburger Heide}

Die Lüneburger Heide ist eine Altmoränenlandschaft, deren geologische Formen vor allem durch Ablagerungen des Saale-Glazials geprägt worden sind (WOLDSTEDT \& DUPHORN 1974). Das Untersuchungsgebiet erstreckt sich im Übergangsbereich zwischen den Lüßbergen, die als Endmoränen aus geschiebeführendem Material geformt wurden, und den anschließenden Sanderflächen aus geschichteten Schmelzwassersanden. Während der letzten großen Vereisung, der Weichseleiszeit, befand sich das Untersuchungsgebiet im Periglazialraum. So überdecken auf der Untersuchungsfläche einige Zentimeter Flugsand und eine etwa $50-70 \mathrm{~cm}$ mächtige Schicht aus Geschiebedecksand die glazialen Schmelzwassersande. Lokal sind dazwischen noch bis zu $50 \mathrm{~cm}$ mächtige Steinsohlen aus Schmelzwasserkies eingelagert (MARGRAF 1989).

Die Bodenart des Feinbodenmaterials reicht von schwach lehmigen Mittelsanden bis zu lehmigen Grobsanden. Aus dem silikatreichen und nährstoffarmen Ausgangsmaterial haben 
sich im Untersuchungsbestand mäßig bis stark podsolige Braunerden entwickelt. Diese weisen je nach Podsolierungsgrad unterschiedlich deutlich ausgeprägte Eluvial- und Illuvialhorizonte auf, die oft unscharf ineinander übergehen. Die typische Horizontfolge ist $\mathrm{A}_{\mathrm{he}}-\mathrm{B}_{\mathrm{sv}}-\mathrm{B}_{\mathrm{v}}-\mathrm{C}_{\mathrm{v}}$. Das Bodenskelett variiert auf der Untersuchungsfläche stark und besteht aus Kies und Geröll unterschiedlichster Durchmesser. Der Skelettanteil bleibt im Oberboden zwar meist unter $10 \%$, kann im Unterboden im Bereich lokaler Steinsohlen jedoch bis auf $30 \%$ ansteigen. In den Schmelzwassersanden des $\mathrm{C}_{\mathrm{v}}$ wiederum bleibt er meist sehr gering (Margraf 1989, Rode \& Heinken 1993). Auf dem Mineralboden hat sich eine etwa $8-10 \mathrm{~cm}$ mächtige organische Auflage gebildet, die als rohhumusartiger Moder einzuordnen ist. Die Auflagehorizonte $\mathrm{O}_{1-} \mathrm{O}_{\mathrm{f}-} \mathrm{O}_{\mathrm{h}}$ besitzen etwa die Mächtigkeiten $2 \mathrm{~cm}-6 \mathrm{~cm}-2 \mathrm{~cm}$ (GÖRLITZ 1992).

Die Untersuchungsfläche weist mit $\mathrm{pH}(\mathrm{KCl})$-Werten um 3.0 im Oberboden und noch niedrigeren Werten in der organischen Auflage die am stärksten versauerten Bodenhorizonte aller Untersuchungsbestände auf (Tab. 2-1). Der Oberboden befindet sich der Klassifizierung von UlRICH (1981) zufolge im Eisen-Pufferbereich, der Unterboden noch im AluminiumPufferbereich. Die Kationenaustauschkapazität liegt mit Werten zwischen 10 und $35 \mu \mathrm{mol}$ I $\ddot{\mathrm{g}} \mathrm{TB}^{-1}$ extrem niedrig. Der Summenanteil von K-, Ca- und Mg-Ionen an der $\mathrm{Ak}_{\mathrm{e}}$ bleibt mit $4-8 \%$ ebenfalls sehr gering.

\section{Solling}

Die Untersuchungsfläche Solling befindet sich auf einem Verebnungsareal des Sollinggewölbes, das aus Schichten des mittleren Buntsandsteins aufgebaut ist und sich als 200 - 300 m mächtige Schichtstufe aus dem Umland erhebt.

Der auf der Untersuchungsfläche vorliegende Boden wurde aus zwei wechselnd mächtigen Fließerdeschichten gebildet. Die obere besteht vorwiegend aus umgelagertem Löß und ist durch die Bodenart lehmiger Schluff charakterisiert. Die untere Fließerdeschicht ist aus dem ab etwa $1.5 \mathrm{~m}$ Tiefe anstehenden, wechselnd tonigen Schluffstein hervorgegangen und kann als toniger Lehm eingestuft werden. Der auf der Untersuchungsfläche vorliegende Bodentyp ist eine schwach bis mäßig podsolige und schwach pseudovergleyte Braunerde mit der Horizontfolge $A_{(e) h}-B_{v}-C_{v}$. Dabei bleibt der Skelettraum in $A_{h}$ und $B_{v}$ unter $5 \%$ und liegt im $\mathrm{C}_{\mathrm{v}}$ bei etwa $30 \%$ (BREDEMEIER \& WiEDEY 1990). Den Mineralboden bedeckt eine etwa 4 - $6 \mathrm{~cm}$ dicke organische Auflage mit den Horizonten $\mathrm{O}_{1}-\mathrm{O}_{\mathrm{f}}-\mathrm{O}_{\mathrm{h}}$, deren Mächtigkeiten etwa $2 \mathrm{~cm}-2 \mathrm{~cm}-1 \mathrm{~cm}$ betragen. Humusform ist ein typischer Moder.

Der $\mathrm{pH}\left(\mathrm{CaCl}_{2}\right)$ liegt im Oberboden mit Werten um 3.0 ähnlich niedrig wie auf der Untersuchungsfläche Lüneburger Heide (Tab. 2-1). Nach der Klassifizierung von ULRICH (1981) befindet sich der Boden im Aluminium-Pufferbereich. Die Kationenaustauschkapazität ist mit $68-108 \mu \mathrm{mol} \mathrm{IÄ} \mathrm{g} \mathrm{TB}{ }^{-1}$ im Oberboden und 47 - $70 \mu \mathrm{mol}$ IÄ g TB ${ }^{-1}$ im Unterboden zwar relativ niedrig, damit aber immer noch deutlich höher als in der Lüneburger Heide und im Ziegelrodaer Forst. Der Summenanteil von K-, Caund $\mathrm{Mg}$-Ionen an der $\mathrm{Ak}_{\mathrm{e}}$ bleibt mit Werten um 4-6\% jedoch wie in der Lüneburger Heide sehr gering. 
Tab. 2-1: Bodenchemische Kennwerte der vier Untersuchungsflächen nach eigenen Messungen sowie nach Angaben von STROBEL (1997) für den Ziegelrodaer Forst (ZF), von MEIWES \& BEESE (1988) für den Göttinger Wald (GW), von MARGRAF (1989) und DANNER (1990) für die Lüneburger Heide (LH) und von MATZNER (1988) für den Solling (SO).

\begin{tabular}{|c|c|c|c|c|c|c|c|c|c|c|c|c|}
\hline \multirow[t]{2}{*}{$\begin{array}{l}\text { Auflagehorizont } \\
\text { Mineralboden- } \\
\text { tiefe [cm] }\end{array}$} & \multicolumn{4}{|c|}{$\mathrm{pH}\left(\mathrm{KCl} / \mathrm{CaCl}_{2}\right)$} & \multicolumn{4}{|c|}{$\begin{array}{c}\text { Effektive Austausch- } \\
\text { kapazität } \mathrm{Ak}_{\mathrm{e}} \\
{\left[\mu \mathrm{mol} \mathrm{IÄ} \mathrm{g} \mathrm{TB}^{-1}\right]}\end{array}$} & \multicolumn{4}{|c|}{$\begin{array}{l}\text { Summenanteil } \\
\mathrm{K}^{+}-, \mathrm{Ca}^{2+}-\text { und } \mathrm{Mg}^{2+}- \\
\text { Ionen am } \\
\text { Austauscher [\%] }\end{array}$} \\
\hline & $\mathbf{Z F}$ & GW & $\mathbf{L H}$ & SO & $\mathbf{Z F}$ & GW & $\mathbf{L H}$ & SO & $\mathbf{Z F}$ & GW & LH & SO \\
\hline Of & 3.8 & - & 2.7 & 3.3 & - & - & - & - & - & - & - & - \\
\hline Oh & - & - & 2.6 & - & - & - & - & - & - & - & - & - \\
\hline $0-5$ & 3.6 & 6.7 & 2.9 & 2.9 & 48.1 & 738 & 35.1 & 108 & 45.9 & 98.9 & 8.2 & 6.1 \\
\hline $5-10$ & 3.4 & 6.7 & 3.1 & 3.2 & 32.6 & 732 & - & 108 & & 95.1 & - & 6.1 \\
\hline $10-25$ & 3.7 & 7.1 & 3.4 & 3.7 & 23.3 & 745 & 33.4 & 68 & 20.4 & 99.4 & 3.9 & 5.3 \\
\hline $25-50$ & 3.8 & - & 4.0 & 4.1 & 23.1 & - & 14 & 47 & 19.2 & - & 4.7 & 5.7 \\
\hline $50-100$ & & - & 4.1 & 3.9 & 30.4 & - & - & 70 & 31.4 & - & - & 4.2 \\
\hline $100-150$ & 3.8 & - & 4.1 & 3.9 & 77.1 & - & 9.1 & 50 & 56.2 & - & 7.4 & 5.7 \\
\hline
\end{tabular}

\subsection{Bestandesstruktur und Vegetation}

\section{Ziegelrodaer Forst}

Der Buchenbestand im Ziegelrodaer Forst fällt im Vergleich der vier Untersuchungsbestände durch die höchste Stammzahl der herrschenden Bäume auf und nimmt bei den BHD eine Mittelstellung ein. Er ist mit einem Alter der herrschenden Baumschicht von etwa 120 Jahren den anderen Beständen jedoch vergleichbar und weist keine großen Bestandeslücken auf. Die herrschenden Buchen haben eine mittlere Höhe von $28 \mathrm{~m}$ und sind zu einem sehr geringen Anteil der Stammzahl mit einzelnen Traubeneichen durchsetzt. Eine Strauchschicht aus Rubus idaeus, Sambucus nigra, und Jungwuchs von Sorbus aucuparia, Acer platanoides, Acer pseudoplatanus und Fraxinus excelsior tritt nur in lichteren Bereichen auf. Die ebenfalls nur sehr ungleichmäßig ausgebildete Krautschicht besitzt einen mittleren Deckungsgrad von etwa $30 \%$ und bildet ein kleinräumiges Mosaik mit sehr heterogener Artenzusammensetzung. So treten beispielsweise die säuretoleranten Arten Luzula luzuloides, Calamagrostis arundinacea, Vaccinium myrtillus, Dryopteris carthusiana, Dryopteris dilatata und Athyrium filix-femina in unmittelbarer Nachbarschaft von calcicolen Arten wie Maianthemum bifolium, Polygonatum multiflorum, Anemone ranunculoides, Viola reichenbachiana und Lilium martagon auf. Neben einer Reihe unspezifischerer Arten der Krautschicht wie Poa nemoralis, Anemone nemorosa, Stellaria holostea und Moehringia trinerva sind aber auch Arten mit besonders hohem Stickstoffanspruch wie Urtica dioica, Epilobium angustifolium oder Sambucus nigra zu finden. 
Dies spiegelt eine untypische Ausprägung von bodenchemischen Parametern wider (vgl. Tab. 2-1) und bedingt, daß der Bestand pflanzensoziologisch nur schwer einzuordnen ist, am ehesten aber wohl dem Galio-Fagetum zugeordnet werden kann.

\section{Göttinger Wald}

Im Göttinger Wald bildet der etwa 110 - 125 Jahre alte und mit bis zu $35 \mathrm{~m}$ deutlich höchste untersuchte Baumbestand einen weitgehend geschlossenen Buchen-Hallenwald. Dieser weist die geringste Stammzahl herrschender Bäume sowie einen hohen mittleren BHD auf. In den Buchenbestand sind mit etwa $6 \%$ der Stammzahl vereinzelt Fraxinus excelsior, Acer platanoides und Acer pseudoplatanus sowie Quercus robur, Quercus petraea und Ulmus glabra (mit in der Reihung abnehmender Bedeutung) eingestreut (GERKE 1987, MEIWES \& BEESE 1988). Jungbäume dieser Arten, und hier vornehmlich die beiden Acer-Arten, sowie Fraxinus bilden stellenweise eine Strauchschicht.

Nach DieRSCHKE \& SONG (1982) handelt es sich um einen subozeanisch-submontanen Kalkbuchenwald, der pflanzensoziologisch als Hordelymo-Fagetum einzuordnen ist und damit der potentiellen natürlichen Vegetation entspricht (ELLENBERG 1996).

In der artenreichen Krautschicht mit hohem Deckungsgrad treten zahlreiche nährstoffliebende Arten auf, darunter Carex sylvatica, Hordelymus europaeus, Milium effusum, Lathyrus vernus, Allium ursinum, Anemone nemorosa, Mercurialis perennis, Hepatica nobilis, Galium odoratum, Lamiastrum galeobdolon, Pulmonaria officinalis, Asarum europeaeum, Hedera helix, Viola reichenbachiana, Polygonatum multiflorum, Aconitum vulparia, Euphorbia amygdaloides, Dentaria bulbifera.

\section{Lüneburger Heide}

Der Bestand Lüneburger Heide ist der einzige hier untersuchte Buchen-Mischbestand mit relevantem Anteil einer Nebenbaumart. Hier treten Fagus sylvatica und Quercus petraea in einem Stammzahlverhältnis von 10:1 im Gesamtbestand und von 4:1 in der herrschenden Baumschicht auf. Die Traubeneichen haben mit ca. 190 Jahren ein deutlich höheres mittleres Alter als die herrschenden Buchen mit etwa 100 Jahren. Im Vergleich der Untersuchungsflächen erreicht der Bestand durch einen hohen Anteil von Jungbäumen im Unterstand die deutlich höchste Gesamtbestand-Stammzahl und weist bei den Buchen zugleich die geringsten mittleren BHD auf. Die Stammzahl der herrschenden Bäume bleibt jedoch im Rahmen der anderen Untersuchungsbestände. Die in Gruppen oder einzeln stehenden Traubeneichen mit oft sehr hohem BHD werden hier zum Teil von umstehenden Buchen im Kronenraum stark bedrängt und zeigen dann häufig absterbende Äste und eine eingeschränkte Vitalität. Der Bestand ist aber nahezu vollständig geschlossen und mit einer mittleren Höhe der herrschenden Bäume von $28 \mathrm{~m}$ mit den anderen Beständen vergleichbar.

Eine Strauchschicht fehlt, und auch eine Krautschicht ist nicht flächenhaft ausgebildet. Hier treten nur vereinzelt Avenella flexuosa sowie Carex pilulifera auf. Dicranella heteromalla, Polytrichum formosum und Hypnum cupressiforme bilden jedoch stellenweise Moosbewuchs (LeusChner 1994). So ordnet HeinKen (1993) den Bestand einer Tieflandform des LuzuloFagetum (Meusel) zu. 
Tab. 2-2: Bestandesstruktur der Untersuchungsbestände Ziegelrodaer Forst (ZF), Göttinger Wald (GW), Lüneburger Heide (LH) und Solling (SO). Angaben jeweils für die herrschende Baumschicht, (in Klammern: Angaben für den Gesamtbestand).

Nach Bestandesaufnahmen auf allen Untersuchungsflächen 1995 (ULRICH SCHMITT, unveröff.) sowie nach MEIWES \& BEESE (1988) für den Göttinger Wald, LEUSCHNER (1994) für Lüneburger Heide und nach Bestandesaufnahme der Niedersächsischen Forstlichen Versuchsanstalt 1996 im Solling.

\begin{tabular}{|c|c|c|c|c|c|c|c|}
\hline $\begin{array}{c}\text { Be- } \\
\text { stand }\end{array}$ & $\begin{array}{c}\text { Haupt- } \\
\text { Baumart(en) }\end{array}$ & $\begin{array}{l}\text { herrschende } \\
\text { Altersstufe }\end{array}$ & $\begin{array}{c}\text { mittl. } \\
\text { Höhe [m] }\end{array}$ & $\begin{array}{c}\text { Stammzahl } \\
{\left[\mathrm{ha}^{-1}\right]}\end{array}$ & $\begin{array}{l}\text { mittlerer } \\
\text { BHD }[\mathrm{cm}]\end{array}$ & $\begin{array}{c}\text { Grundfläche } \\
{\left[\mathrm{m}^{2} \mathrm{ha}^{-1}\right]}\end{array}$ & $\begin{array}{c}\text { Anteil } \\
\text { Fremdart(en) }\end{array}$ \\
\hline $\mathbf{Z F}$ & Buche & 120 & 28 & $237(370)$ & $40(31)$ & $31.9(34.8)$ & $4 \%(4 \%)$ \\
\hline GW & Buche & 120 & 34 & $181(235)$ & $47(41)$ & $32.9(34.7)$ & $4 \%(6 \%)$ \\
\hline LH & $\begin{array}{c}\text { Buche } \\
\text { Traubeneiche }\end{array}$ & $\begin{array}{l}100 \\
190\end{array}$ & 28 & $212(522)$ & $\begin{array}{l}34(19) \\
53(53)\end{array}$ & $\begin{array}{l}15.2(18.5) \\
12.3(12.3)\end{array}$ & $25 \%(10 \%)$ \\
\hline SO & Buche & 150 & 29 & $193(217)$ & $47(45)$ & $34.7(36.6)$ & - \\
\hline
\end{tabular}

\section{Solling}

Der einzige reine Buchenbestand der vier Untersuchungsflächen ist mit einem Alter von ca. 150 Jahren auch der älteste Bestand und zeigt an einigen Stellen durch das Absterben von Kronenteilen oder ganzen Altbäumen erste Anzeichen des Zusammenbrechens. Der Bestand Solling besitzt eine dem Göttinger Wald vergleichbare Stammzahl und weist noch einen etwas höheren mittleren BHD als dieser auf. Mit 29 m erreicht der Bestand eine mittlere Höhe der herrschenden Bäume wie im Ziegelrodaer Forst und in der Lüneburger Heide. Eine Strauchschicht fehlt. Die Krautschicht tritt nur mit sehr geringem Deckungsgrad auf und setzt sich aus wenigen Arten, neben Luzula luzuloides und Avenella flexuosa noch aus Oxalis acetosella sowie Dryopteris carthusiana, zusammen. Dafür bilden Dicranella heteromalla, Polytrichum formosum und Hypnum cupressiforme teils eine Moosschicht. EllENBERG et al. (1986) weisen diesen Bestand pflanzensoziologisch als Luzulo-Fagetum-typicum aus.

\subsection{Regionalklima und Witterung in den Untersuchungsjahren}

\subsubsection{Regionalklima der Untersuchungsgebiete}

\section{Ziegelrodaer Forst}

Der Ziegelrodaer Forst befindet sich im Bereich des mitteldeutschen Trockengebietes und besitzt ein subkontinental getöntes kühl-gemäßigtes Klima, das wesentlich von der Lage im Regenschatten des Harzes geprägt ist. Die Untersuchungsfläche Ziegelrodaer Forst liegt zwischen der $2 \mathrm{~km}$ entfernten Meßstelle des DWD (Deutscher Wetterdienst) am Forstamt Ziegelroda mit $548 \mathrm{~mm}$ Jahresniederschlag und der in unmittelbarer Nähe des Bestandes verlaufenden $500 \mathrm{~mm}$-Isohydre auf der Karte der potentiellen natürlichen Vegetation von Sachsen-Anhalt (Angaben nach DWD, Wetteramt Leipzig und LANDESAMT SACHS.-ANH. 2000). Für den Untersuchungsbestand kann man also ein langjähriges Mittel des Jahresniederschlags von etwa $520 \mathrm{~mm}$ annehmen (Tab. 2-3). Der Bestand im Ziegelrodaer Forst 
weist somit den deutlich geringsten Jahresniederschlag der vier Untersuchungsflächen auf und ist darüber hinaus der einzige Bestand, dessen langjährige Niederschlagsverteilung über das Jahr nur ein Maximum erkennen läßt. Der kontinentalen Prägung entsprechend tritt hier nur im Sommerhalbjahr (etwa Mai bis August) ein Niederschlagsmaximum auf, das zudem stärker ausgeprägt ist als auf den anderen Untersuchungsflächen (Abb. 2-2). In der Vegetationsperiode fallen durchschnittlich $53 \%$ des Jahresniederschlags.

Temperaturwerte der DWD-Meßstelle des Forstamtes Ziegelroda zeigen, daß die langjährigen Monatsmittel der Temperatur auf der Untersuchungsfläche etwa denjenigen der nächstgelegenen Wetterstation Artern entsprechen (Abb. 2-2). Mit $8.1^{\circ} \mathrm{C}$ liegt im Ziegelrodaer Forst eine Jahresmitteltemperatur vor, die derjenigen der anderen beiden nicht montanen Untersuchungsbestände vergleichbar ist. Die Jahresamplitude der Monatsmittel der Temperatur im Ziegelrodaer Forst ist mit $18.3 \mathrm{~K}$ jedoch um fast $2 \mathrm{~K}$ größer als die Jahresamplitude aller anderen Untersuchungsflächen. Zudem ist die Mitteltemperatur der Vegetationsperiode von $15.2^{\circ} \mathrm{C}$ die höchste der untersuchten Bestände (Tab. 2-4). Dies unterstreicht den subkontinental-sommerwarmen und -sommertrockenen Charakter des Regionalklimas im Ziegelrodaer Forst.

\section{Göttinger Wald}

Die Untersuchungsfläche Göttinger Wald befindet sich im Übergangsbereich von einem subozeanisch zu einem subkontinental geprägten kühl-gemäßigten Klima. Niederschlagsmessungen der Niedersächsischen Forstlichen Versuchsanstalt auf dem Kerstlingeröder Feld nahe dem Untersuchungsbestand Göttinger Wald in etwa gleicher Höhenlage ergeben einen mittleren Jahresniederschlag von ca. $710 \mathrm{~mm}$ (Tab. 2-3). Dabei entspricht die Verteilung der Jahresniederschlagssumme auf die einzelnen Monate dem langjährigen Mittel der Wetterstation Göttingen mit $647 \mathrm{~mm}$ Jahresniederschlag (Abb. 2-2). Die Niederschlagsverteilung zeigt zwei Maxima: Ein relativ ausgeprägtes und lang andauerndes Maximum von Mai bis August mit besonders hohen Niederschlägen im Juni sowie ein wesentlich schwächer konturiertes Maximum von November bis Januar. Durchschnittlich fallen $49 \%$ des Jahresniederschlags in der Vegetationsperiode.

Das langjährige Jahresmittel der Temperatur der Station Göttingen $(167 \mathrm{~m})$ liegt bei $8.7^{\circ} \mathrm{C}$. Wie Temperaturmessungen in den Vegetationsperioden der Untersuchungsjahre zeigen, ist es auf der 250 m höher gelegenen Untersuchungsfläche im Mittel jedoch um $1.2 \mathrm{~K}$ kälter. So kann für den Untersuchungsbestand eine langjährige Mitteltemperatur der Vegetationsperiode von etwa $13.9^{\circ} \mathrm{C}$ angenommen werden (Tab. 2-4).

\section{Lüneburger Heide}

Die Untersuchungsfläche Lüneburger Heide besitzt durch ihre Lage in der norddeutschen Tiefebene ein subozeanisch geprägtes kühl-gemäßigtes Klima. Der Untersuchungsbestand weist durch seine Lage im Bereich eines bis $169 \mathrm{~m}$ ü. M. reichenden Höhenzugs gegenüber der Umgebung etwas höhere Niederschläge sowie niedrigere Temperaturen auf. Niederschlagsmessungen der nahe dem Bestand gelegenen Station Unterlüß des Deutschen Wetterdienstes weisen ein langjähriges Mittel des Jahresniederschlags von $801 \mathrm{~mm}$ aus, 
wovon $44 \%$ in der Vegetationsperiode von Mai bis September fallen. Die subozeanische Klimaprägung kommt vor allem in der Niederschlagsverteilung zum Ausdruck, die zwei nur relativ schwach ausgeprägte Maxima zeigt: im Sommer von Juni bis August sowie im Winterhalbjahr von November bis Januar (Abb. 2-2).

Die langjährige Jahresmitteltemperatur der Station Unterlüß von $8.1{ }^{\circ} \mathrm{C}$ entspricht der im Forstamt Ziegelroda gemessenen. Die Untersuchungsfläche Lüneburger Heide unterscheidet sich jedoch durch eine deutlich geringere Jahresamplitude der Monatsmittel der Temperatur sowie eine niedrigere Mitteltemperatur der Vegetationsperiode von $14.6{ }^{\circ} \mathrm{C}$ (Tab. 2-4).
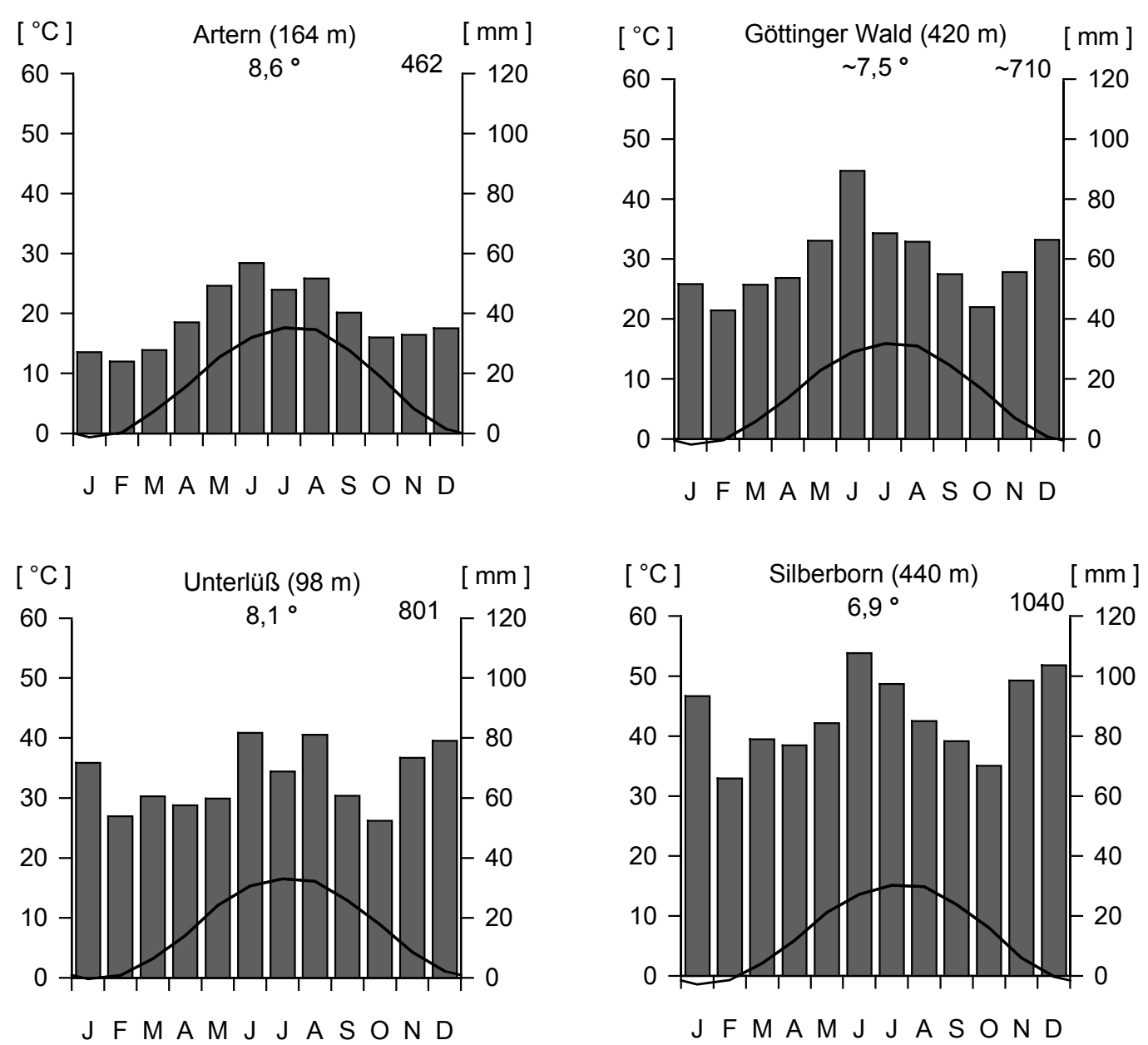

Abb. 2-2: Monatliche Temperaturen und Niederschläge im langjährigen Mittel der Wetterstationen Artern (Ziegelrodaer Forst), Unterlüß (Lüneburger Heide) und Silberborn (Solling) nach Angaben des DEUTSCHEN WETTERDIENSTES. Angaben für den Göttinger Wald basierend auf mehrjährigen Klimadaten der Niedersächsischen Forstlichen Versuchsanstalt für das Kerstlingeröder Feld nahe der Untersuchungsfläche im Göttinger Wald und langjährigen Mittelwerten der Wetterstation (Göttingen).

\section{Solling}

Die im Hochsolling gelegene Untersuchungsfläche besitzt ein subozeanisches und kühlgemäßigtes Klima. Die montane Lage am Nordrand der deutschen Mittelgebirgslandschaft bewirkt hier wesentlich niedrigere Temperaturen und höhere Niederschläge als auf den tiefer gelegenen Untersuchungsflächen. So weist der Untersuchungsbestand Solling mit einem 
langjährigen Mittel von $1040 \mathrm{~mm}$ (Station Silberborn) den deutlich höchsten Jahresniederschlag der vier Untersuchungsflächen auf. Vermutlich sind die Niederschläge auf der $510 \mathrm{~m}$ hoch gelegenen Untersuchungsfläche im Durchschnitt noch etwas höher als die jeweiligen langjährigen Mittelwerte der tiefer gelegenen Station Silberborn (440 m). Die Niederschlagsverteilung über das Jahr zeigt zwei etwa gleich hohe Maxima: ein Sommermaximum mit besonders hohen Niederschlägen im Juni und Juli sowie ein Wintermaximum von November bis Januar (Abb. 2-2). Im langjährigen Mittel fallen im Solling wie im Bestand Lüneburger Heide $44 \%$ des Jahresniederschlages in der Vegetationsperiode.

Der Hochsolling weist im langjährigen Mittel der Station Silberborn mit $6.9^{\circ} \mathrm{C}$ die niedrigste mittlere Jahrestemperatur auf und auch die Vegetationsperiode ist mit $13.2{ }^{\circ} \mathrm{C}$ im Mittel hier deutlich kühler als in den tiefer gelegenen Untersuchungsbeständen. In den Vegetationsperioden der Untersuchungsjahre wurden auf der Untersuchungsfläche sogar noch um im Mittel $0.6^{\circ} \mathrm{K}$ niedrigere Temperaturen als in der etwas tiefer gelegenen Station Silberborn gemessen (Tab. 2-4).

\subsubsection{Witterung in den Untersuchungsjahren}

\subsubsection{Niederschläge}

\section{Ziegelrodaer Forst}

In den beiden Untersuchungsjahren dieses Bestandes 1996 und 1997 wurde die mittlere Jahresniederschlagssumme etwas überschritten (Tab. 2-3).

Der mittlere Niederschlag in der Vegetationsperiode von $269 \mathrm{~mm}$ wurde 1996 mit $304 \mathrm{~mm}$ merklich überschritten, lag 1997 jedoch im Durchschnitt. Die auffälligste Besonderheit der Vegetationsperioden 1996 und 1997 stellen die jeweils ungewöhnlich niederschlagsreichen Hochsommerperioden mit $190 \%$ bzw. $260 \%$ der mittleren Juli-Niederschläge bei etwa durchschnittlichen Niederschlägen im August dar.

\section{Göttinger Wald}

In allen drei Untersuchungsjahren wurde die mittlere Jahresniederschlagssumme im Göttinger Wald unterschritten; 1995 und 1996 merklich, 1997 nur wenig (Tab. 2-3).

Die Niederschläge in der Vegetationsperiode lagen 1995 und 1996 etwas unter dem langjährigen Mittel von 345 mm, im Jahr 1997 geringfügig darüber. Die Hochsommermonate Juli und August waren 1995 deutlich niederschlagsärmer, 1996 und 1997 deutlich niederschlagsreicher als im langjährigen Mittel.

\section{Lüneburger Heide}

In allen drei Untersuchungsjahren erreichte der Jahresniederschlag des Bestandes Lüneburger Heide nicht das langjährige Niederschlagsmittel (Tab. 2-3).

Besonders treten hier die auffällig niederschlagsarmen Vegetationsperioden 1995 und 1996 hervor, in denen jeweils nur $80 \%$ bzw. $68 \%$ des langjährig für den Zeitraum Mai bis 
September ermittelten Niederschlags fielen. 1995 und vor allem 1996 blieb dabei auch die Niederschlagsmenge der Hochsommermonate Juli und August mit 74 \% bzw. 56 \% weit unter dem langjährigen Mittel. So war 1996 im Bestand Lüneburger Heide mit nur $239 \mathrm{~mm}$ die niederschlagsärmste Vegetationsperiode und mit $83 \mathrm{~mm}$ im Juli und August der niederschlagsärmste Hochsommer aller Untersuchungsflächen und aller Untersuchungsjahre zu beobachten. 1997 traten in der Vegetationsperiode etwa durchschnittliche, im Juli und August sogar überdurchschnittlich hohe Niederschläge auf.

\section{Solling}

Der Untersuchungsbestand Solling mit dem deutlich höchsten mittleren Jahresniederschlag der vier Untersuchungsflächen wies auch in allen drei Untersuchungsjahren durchwegs um etwa $50-100 \%$ höhere Jahresniederschläge auf als die anderen Bestände (Tab. 2-3). Dabei wich nur der Jahresniederschlag 1995 deutlich vom langjährigen Mittel ab und überstieg dieses vor allem durch einen außergewöhnlich niederschlagsreichen Jahresbeginn.

Anders als bei den Jahresniederschlägen lagen die Niederschläge in den Vegetationsperioden im Solling 1995 und 1996 nur um etwa 25 - 50 \% über denjenigen der anderen Bestände. In der im Solling auffällig niederschlagsarmen Vegetationsperiode 1997 überstiegen die Niederschläge hier sogar nur diejenigen des trockensten Bestandes im Ziegelrodaer Forst wesentlich. Die Niederschläge im Juli und August wichen im Solling nur 1995 durch eine besonders trockene Hochsommerperiode deutlich vom langjährigen Mittel ab.

Tab. 2-3: Niederschlagssummen auf den Untersuchungsflächen angegeben für das Jahr, die Vegetationsperiode (Mai - September) und den Hochsommer (Juli - August) im langjährigen Mittel sowie in den Untersuchungsjahren.

\begin{tabular}{|c|ccc|ccc|ccc|ccc|}
\hline Niederschlag & \multicolumn{4}{|c|}{ Ziegelrodaer Forst } & \multicolumn{3}{|c|}{ Göttinger Wald } & \multicolumn{3}{c|}{ Lüneburger Heide } & \multicolumn{3}{c|}{ Solling } \\
[ mm ] & Jahr & Vegp. & J - A & Jahr & Vegp. & J - A & Jahr & Vegp. & J - A & Jahr & Vegp. & J - A \\
\hline langj. & $\mathbf{5 2 0}$ & $\mathbf{2 6 9}$ & $\mathbf{1 0 7}$ & $\mathbf{7 1 0}$ & $\mathbf{3 4 5}$ & $\mathbf{1 3 4}$ & $\mathbf{8 0 1}$ & $\mathbf{3 5 2}$ & $\mathbf{1 4 9}$ & $\mathbf{1 0 4 0}$ & $\mathbf{4 5 2}$ & $\mathbf{1 8 2}$ \\
1995 & - & - & - & 595 & 317 & 87 & 721 & 282 & 111 & 1246 & 479 & 127 \\
1996 & 581 & 304 & 157 & 593 & 313 & 175 & 584 & 239 & 83 & 933 & 387 & 178 \\
1997 & 576 & 268 & 176 & 654 & 359 & 186 & 697 & 336 & 175 & 1016 & 348 & 195 \\
\hline
\end{tabular}

Tab. 2-4: Mittlere Temperatur auf den Untersuchungsflächen angegeben für das Jahr, die Vegetationsperiode (Mai - September) und den Hochsommer (Juli - August) im langjährigen Mittel sowie in den Untersuchungsjahren.

\begin{tabular}{|c|ccc|ccc|cccc|ccc|}
\hline Temperatur & \multicolumn{3}{|c|}{ Ziegelrodaer Forst } & \multicolumn{3}{|c|}{ Göttinger Wald } & \multicolumn{3}{c|}{ Lüneburger Heide } & \multicolumn{3}{c|}{ Solling } \\
[ $^{\circ} \mathbf{C}$ ] & Jahr & Vegp. & J - A & Jahr & Vegp. & J - A & Jahr & Vegp. & J - A & Jahr & Vegp. & J - A \\
\hline langj. & $\mathbf{8 . 1}$ & $\mathbf{1 5 . 2}$ & $\mathbf{1 7 . 2}$ & $\mathbf{7 . 5}$ & $\mathbf{1 3 . 9}$ & $\mathbf{1 5 . 7}$ & $\mathbf{8 . 1}$ & $\mathbf{1 4 . 6}$ & $\mathbf{1 6 . 3}$ & $\mathbf{6 . 5}$ & $\mathbf{1 2 . 6}$ & $\mathbf{1 4 . 4}$ \\
1995 & - & - & - & 7.8 & 14.0 & 17.4 & 8.8 & 15.7 & 19.5 & 7.0 & 13.3 & 17.4 \\
1996 & 6.9 & 14.3 & 16.9 & 5.8 & 12.5 & 14.9 & 6.9 & 13.9 & 16.8 & 5.3 & 11.7 & 14.3 \\
1997 & 8.7 & 16.1 & 18.8 & 7.7 & 14.3 & 17.1 & 8.8 & 15.8 & 18.7 & 7.3 & 13.7 & 16.6 \\
\hline
\end{tabular}




\subsubsection{Temperatur}

Während die Niederschläge auf den einzelnen Untersuchungsflächen zum Teil auf sehr unterschiedliche Weise vom langjährigen Mittel abwichen, verliefen die Abweichungen der Monatsmittel der Temperatur vom langjährigen Mittel in allen Beständen weitgehend ähnlich (Tab. 2-4).

1995 war dementsprechend auf allen drei in diesem Jahr untersuchten Flächen die Jahresmitteltemperatur etwas höher als im langjährigen Mittel, ebenso die mittlere Temperatur der Vegetationsperiode. Im Mittel der drei Untersuchungsflächen lag das Jahresmittel 1995 um $+0.5 \mathrm{~K}$, das Mittel der Vegetationsperiode um $+0.6 \mathrm{~K}$ über der langjährigen Mitteltemperatur. Dabei zeigte in der Vegetationsperiode der Bestand Göttinger Wald mit $+0.1 \mathrm{~K}$ die geringste, der Bestand Lüneburger Heide mit $+1.1 \mathrm{~K}$ die stärkste Abweichung.

Nach einem sehr milden Winter fiel im Temperaturverlauf der Vegetationsperiode 1995 vor allem der außergewöhnlich warme Hochsommer auf. Im Mittel der Untersuchungsflächen wich der Juli um $+3.0 \mathrm{~K}$ und der August um $+2.0 \mathrm{~K}$ gegenüber den langjährigen Monatsmitteltemperaturen ab. Mai und September erreichten etwa durchschnittliche Monatsmittel der Temperatur, und nur der Juni war merklich kühler als im langjährigen Mittel.

1996 kann sowohl das gesamte Jahr als auch die Vegetationsperiode für alle vier Untersuchungsflächen als vergleichsweise kalt charakterisiert werden. Die Jahresmitteltemperatur wich 1996 im Mittel der Untersuchungsflächen um - 1.3 K vom langjährigen Mittel ab, die Mitteltemperatur der Vegetationsperiode um - 0.9 K. Dabei wich die Mitteltemperatur der Vegetationsperiode im Bestand Göttinger Wald mit - $1.3 \mathrm{~K}$ am stärksten, im Bestand Lüneburger Heide mit - 0.6 K am geringsten vom langjährigen Mittel ab.

Der Winter 1995/1996 war außergewöhnlich kalt. Die mittlere Abweichung der Temperaturen aller Untersuchungsflächen gegenüber dem langjährigen Mittel von Dezember bis Februar betrug - 3.2 K. Die Vegetationsperiode 1996 war in allen Beständen von Mai bis Juli durchweg merklich kühler und nur im August etwas wärmer als im langjährigen Mittel und endete mit einem außergewöhnlich kalten September.

1997 lag sowohl die Jahresmitteltemperatur als auch die Mitteltemperatur der Vegetationsperiode auf allen Untersuchungsflächen über den langjährigen Mittelwerten; im Mittel der Untersuchungsflächen um $+0.6 \mathrm{~K}$ bzw. $+0.9 \mathrm{~K}$. Dabei war für den Bestand Göttinger Wald mit $+0.4 \mathrm{~K}$ die geringste, für den Bestand Lüneburger Heide mit $+1.2 \mathrm{~K}$ die stärkste Abweichung vom langjährigen Mittel der Temperatur in der Vegetationsperiode zu beobachten.

Der Winter 1996/1997 war durch einen kalten Winterbeginn und einen darauf folgenden sehr milden Spätwinter geprägt. Die relativ hohen Mitteltemperaturen der Vegetationsperiode 1997 sind in allen Beständen vorwiegend auf einen außergewöhnlich heißen August mit einer mittleren Abweichung der Bestände von $+3.5 \mathrm{~K}$ gegenüber dem langjährigen Monatsmittel zurückzuführen. Von Mai bis Juli sowie im September herrschten dagegen meist nur wenig überdurchschnittliche, im Bestand Göttinger Wald sogar etwas unterdurchschnittliche Temperaturen. 


\subsubsection{Globalstrahlung}

Die für die Vegetationsperioden 1995 - 1997 bestimmten Monatssummen der Globalstrahlung unterschieden sich zwischen den Untersuchungsflächen meist nur geringfügig. Die Globalstrahlungssummen über den Zeitraum Juni bis September wichen sogar durchweg nur um $\leq 6 \%$ voneinander ab (Tab. 2-5). Die ermittelten Unterschiede des Globalstrahlungsregimes zwischen den Untersuchungsflächen überstiegen damit nicht oder nur sehr wenig den Fehlerbereich der Meßgenauigkeit der eingesetzten Globalstrahlungsgeber von $3-5 \%$. Die Globalstrahlungswerte für die Fläche Ziegelrodaer Forst wurden aus den Werten der dort über Bestand gemessenen PAR berechnet (vgl. Kap. 3.1). Auch diese infolge Extrapolation aus der PAR vermutlich mit einem größeren Fehler behafteten Globalstrahlungswerte des Bestandes Ziegelrodaer Forst wichen nicht stärker von den direkt gemessenen Globalstrahlungssummen der anderen Bestände ab als diese untereinander. Es konnte in den Untersuchungsjahren auch im saisonalen Verlauf kein wesentlicher Unterschied des Globalstrahlungsregimes zwischen den Untersuchungsbeständen festgestellt werden (Abb. 2-3).

Tab. 2-5: Monatssummen der Globalstrahlung auf den Untersuchungsflächen in den Vegetationsperioden 1995-1997 sowie Summen über die gesamte Vegetationsperiode (Mai - September) und den Zeitraum Juni - August. Mehrjährige Mittelwerte der Monatssummen der Globalstrahlung in den Beständen Göttinger Wald (7 Jahre im Zeitraum 1982 - 1997) und Solling (9 Jahre im Zeitraum 1967 - 1997), gebildet aus den Werten der Untersuchungsjahre und Daten aus EHRHARDT 1988 und ELLENBERG \& WILMERS 1986.

\begin{tabular}{|c|c|c|c|c|c|c|c|c|c|c|c|c|c|}
\hline & \multicolumn{3}{|c|}{$\begin{array}{c}\text { Globalstrahlg. } 1995 \\
{\left[\mathrm{MJ} \mathrm{m}^{-2}\right]}\end{array}$} & \multicolumn{4}{|c|}{$\begin{array}{c}\text { Globalstrahlung } 1996 \\
{\left[\mathrm{MJ} \mathrm{m}^{-2}\right]}\end{array}$} & \multicolumn{4}{|c|}{$\begin{array}{c}\text { Globalstrahlung } 1997 \\
{\left[\mathrm{MJ} \mathrm{m}^{-2}\right]}\end{array}$} & \multicolumn{2}{|c|}{$\begin{array}{l}\text { mehrj. Ø } \\
{\left[\mathbf{M J ~ m}^{-2}\right]}\end{array}$} \\
\hline & GW & LH & SO & $\mathbf{Z F}$ & GW & LH & SO & $\mathbf{Z F}$ & GW & LH & SO & GW & SO \\
\hline Mai & 48 & 56 & 54 & 4 & 38 & 415 & 399 & 546 & 549 & 530 & 542 & 455 & 496 \\
\hline Juni & 521 & 547 & 532 & 479 & 512 & 500 & 540 & 583 & 600 & 610 & 616 & 531 & 546 \\
\hline Juli & 639 & 653 & 639 & 507 & 511 & 499 & 50 & 505 & 520 & 537 & 517 & 568 & 562 \\
\hline Augus & 510 & 572 & 556 & 453 & 455 & 483 & 469 & 560 & 506 & 544 & 580 & 477 & 491 \\
\hline September & 276 & 301 & 271 & 254 & 278 & 314 & 287 & 384 & 375 & 352 & 391 & 304 & 314 \\
\hline Mai-Sept. & 2433 & 2633 & 2600 & 2087 & 2136 & 2211 & 2199 & 2578 & 2550 & 2573 & 2646 & 2336 & 2408 \\
\hline Juni-Aug. & 1670 & 1772 & 1781 & 1439 & 1478 & 1482 & 1513 & 1648 & 1626 & 1691 & 1713 & 1576 & 1598 \\
\hline
\end{tabular}

Deutlichere Unterschiede der Globalstrahlungssummen der Vegetationsperioden traten zwischen den Untersuchungsjahren auf. Hier fiel vor allem die besonders strahlungsarme Vegetationsperiode 1996 auf, in der im Mittel der Untersuchungsflächen nur 84 \% der Globalstrahlungssumme der strahlungsreichsten Vegetationsperiode 1997 erreicht wurden. Die Vegetationsperiode 1995 war mit einer im Mittel der Untersuchungsflächen nahezu gleichen Strahlungsmenge wie 1997 ebenfalls vergleichsweise strahlungsreich (Tab. 2-5). Im saisonalen Verlauf unterschied sich die Vegetationsperiode 1995 deutlich von denjenigen der Untersuchungsjahre 1996 und 1997. Auf eine Phase besonders geringer Globalstrahlung Ende Mai bis Ende Juni 1995 folgte der strahlungsreichste Hochsommer der drei Untersuchungsjahre, während daraufhin in diesem Jahr der strahlungsärmste September beobachtet wurde (Abb. 2-3). 
Eine längerfristige Einordnung des Strahlungsregimes der drei Untersuchungsjahre wird möglich durch einen Vergleich der im Bestand Solling bestimmten Globalstrahlungssummen mit einem aus insgesamt 9 Meßjahren im Zeitraum 1967 - 1997 (ELLENBERG \& WILMERS 1986) gebildeten Mittelwert für diesen Bestand bzw. für den Bestand Göttinger Wald mit einem Mittelwert aus dort 7 Meßjahren im Zeitraum 1982 - 1997 (EHRHARDT 1988). Hier zeigt sich, daß auch im längerfristigen Vergleich die Vegetationsperiode 1995 einen außergewöhnlich strahlungsreichen Hochsommer aufwies und nur der September auffällig strahlungsarm war. Die Globalstrahlungssumme der gesamten Vegetationsperiode 1995 überstieg daher das mehrjährige Mittel um etwa $8 \%$ im Bestand Solling bzw. $4 \%$ im Bestand Göttinger Wald. In der Vegetationsperiode 1996 waren alle Monate strahlungsärmer als im mehrjährigen Mittel, mit den besonders strahlungsarmen Monaten Mai und Juli. Die Globalstrahlungssumme dieser Vegetationsperiode blieb im Göttinger Wald und im Solling etwa $9 \%$ unter dem mehrjährigen Mittel. Die Vegetationsperiode 1997 war in allen Monaten außer im Juli vergleichsweise strahlungsreich und erreichte so von Mai bis September eine Globalstrahlungssumme, die im Bestand Solling etwa $10 \%$ bzw. im Bestand Göttinger Wald $8 \%$ über dem mehrjährigen Mittel lag. Dabei fielen vor allem die außergewöhnlich strahlungsreichen Monate August und September auf.
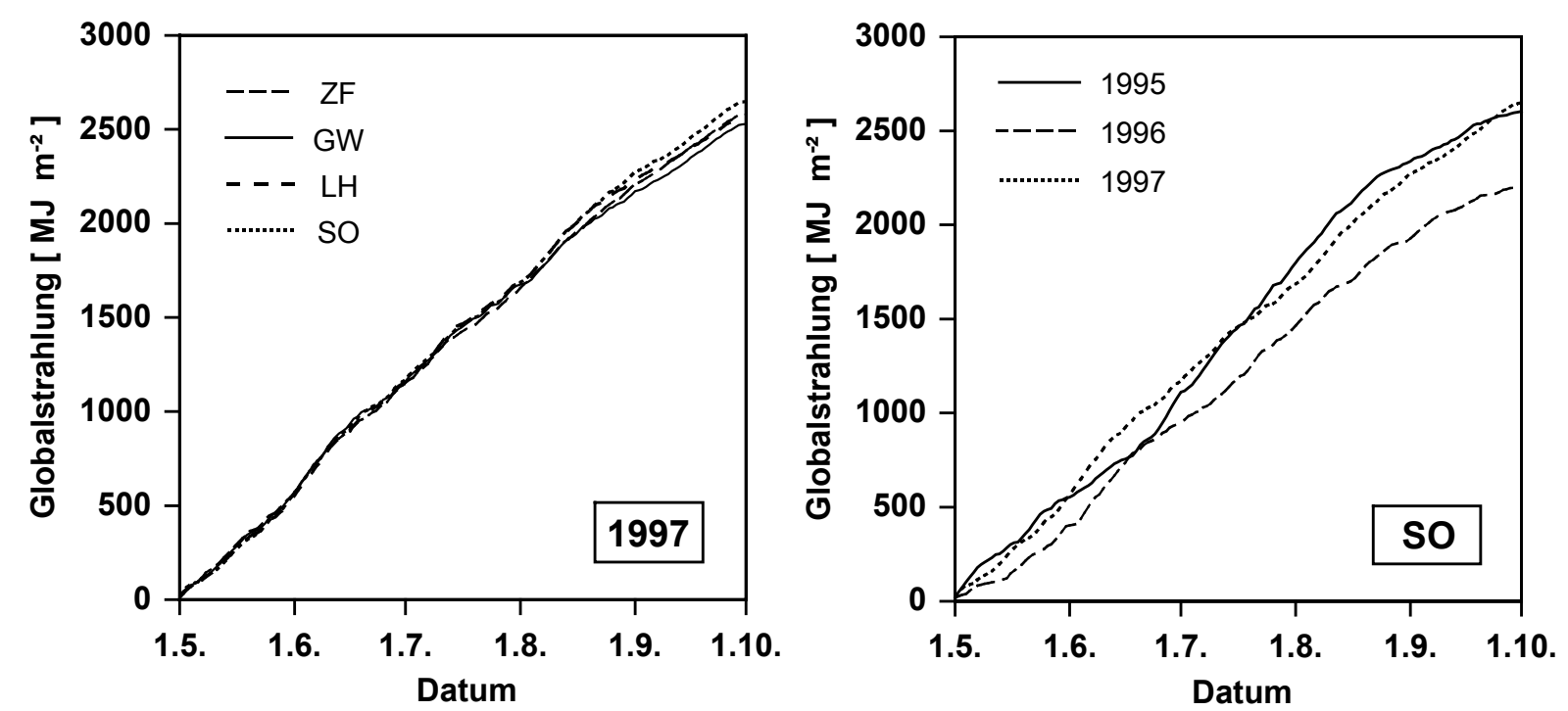

Abb. 2-3: Globalstrahlung auf den Untersuchungsflächen in der Vegetationsperiode 1997 sowie im Vergleich der untersuchten Vegetationsperioden für den Bestand Solling. Dargestellt sind die kumulativ aufgetragenen Tagessummen der Stundenmittelwerte.

\subsubsection{Sättigungsdefizit der Luft}

Mittels Luftfeuchte- und Temperaturmessungen wurde auf den Untersuchungsflächen das Wasserdampf-Sättigungsdefizit der Luft bestimmt. Auf den mit einem Gerüstturm ausgestatteten Flächen wurde über Bestand gemessen, im Ziegelrodaer Forst in $25 \mathrm{~m}$ Höhe im oberen Kronenbereich. Aufgrund zum Teil häufiger Ausfälle vor allem der Luftfeuchtemessung liegen nicht für alle Untersuchungsflächen über den gesamten Untersuchungszeitraum Werte des Wasserdampf-Sättigungsdefizits vor. Fehlende Werte konnten zum Teil 
mit Hilfe der stets eng korrelierten Feuchte- und Temperaturwerte aus anderen Höhenstufen im selben Bestand rekonstruiert werden. Bei völligem Meßwertausfall in einem Bestand wurden, wo dies vertretbar erschien, einzelne fehlende Tageswerte durch Mittelung aus den zeitlich nächsten Tagessummen im selben Bestand oder durch Mittelung der Tagessummen auf den anderen Untersuchungsflächen rekonstruiert. Auch die direkt durch Messungen ermittelten Werte des Wasserdampf-Sättigungsdefizits unterliegen jedoch vermutlich einem vergleichsweise hohen Fehler, da nicht immer eindeutig abzugrenzen war, wann die Luftfeuchtefühler nicht exakt arbeiteten.

Tab. 2-6 gibt Monatssummen des Sättigungsdefizits an, gebildet aus den Stundenmittelwerten der Tageshellphasen (Globalstrahlung $>5 \mathrm{~J} \mathrm{~m}^{-2} \mathrm{~s}^{-1}$ ). Die Monatssummen des Sättigungsdefizits unterschieden sich zwischen den Untersuchungsflächen zumeist wenig. Dabei war auch kein einheitlicher Gradient zwischen den Untersuchungsflächen zu erkennen.

Tab. 2-6: Monatssummen des Wasserdampf-Sättigungsdefizits der Luft auf den Untersuchungsflächen in den Vegetationsperioden 1995 - 1997 sowie Summen über die gesamte Vegetationsperiode (Mai - September) und den Zeitraum Juni - August. Die Summenwerte des Sättigungsdefizits wurden gebildet aus den Stunden-Mittelwerten der Tages-Hellphasen (Globalstrahlung $>5 \mathrm{~J} \mathrm{~m}^{-2} \mathrm{~s}^{-1}$ ).

\begin{tabular}{cccccccccccc}
\hline & \multicolumn{1}{c}{$\begin{array}{c}\text { Sättigungsdefizit 1995 } \\
\text { [ kPa ] }\end{array}$} & \multicolumn{3}{c}{ Sättigungsdefizit 1996 } & \multicolumn{4}{c}{ Sättigungsdefizit 1997 } \\
& $\mathbf{3}$ [ $\mathbf{~ R P a}]$ \\
& GW & LH & SO & ZF & GW & LH & SO & ZF & GW & LH & SO \\
\hline Mai & 225 & - & 232 & & 119 & 149 & 150 & 276 & 264 & 249 & 218 \\
Juni & 203 & - & 204 & & 199 & 218 & 250 & 323 & 307 & 330 & 295 \\
Juli & 397 & - & 384 & & 204 & 203 & 210 & 245 & 245 & 222 & 236 \\
August & 357 & - & 399 & 291 & 257 & 252 & 249 & 399 & 406 & 314 & 365 \\
September & 108 & - & 94 & 105 & 85 & 113 & 90 & 214 & 219 & 163 & 188 \\
\hline Mai-Sept. & $\mathbf{1 2 9 0}$ & - & $\mathbf{1 3 1 3}$ & - & $\mathbf{8 6 4}$ & $\mathbf{9 3 5}$ & $\mathbf{9 4 9}$ & $\mathbf{1 4 5 7}$ & $\mathbf{1 4 4 1}$ & $\mathbf{1 2 7 8}$ & $\mathbf{1 3 0 2}$ \\
Juni-Aug. & $\mathbf{9 5 7}$ & - & $\mathbf{9 8 7}$ & - & $\mathbf{6 6 0}$ & $\mathbf{6 7 3}$ & $\mathbf{7 0 9}$ & $\mathbf{9 6 7}$ & $\mathbf{9 5 8}$ & $\mathbf{8 6 6}$ & $\mathbf{8 9 6}$ \\
\hline
\end{tabular}

1996 wurde sowohl für die gesamte Vegetationsperiode als auch für den Zeitraum Juni bis August im Bestand Göttinger Wald ein etwas geringeres Sättigungsdefizit bestimmt als in den Beständen Lüneburger Heide und Solling. In der Vegetationsperiode 1997 waren dagegen in den Beständen Lüneburger Heide und Solling etwas niedrigere Werte des Sättigungsdefizits zu beobachten als in den Beständen Ziegelrodaer Forst und Göttinger Wald, die sehr ähnliche Monatssummen aufwiesen. Diese Unterschiede zwischen den Untersuchungsflächen betrugen jedoch sowohl über die gesamte Vegetationsperiode als auch im Zeitraum der höchsten Sättigungsdefizite von Juni bis August in der Regel $<10 \%$. Dabei war stets auch ein in allen Untersuchungsbeständen eng übereinstimmender saisonaler Verlauf des Sättigungsdefizits zu beobachten (Abb. 2-4).

Im Vergleich zwischen den Untersuchungsjahren fielen die durchwegs geringen Sättigungsdefizitwerte der Vegetationsperiode 1996 auf. In diesem vergleichsweise kühlen Jahr waren mit Summenwerten der Vegetationsperiode um $900 \mathrm{kPa}$ deutlich geringere Sättigungsdefizite zu beobachten als in den Vegetationsperioden 1995 und 1997 mit Werten 
im Bereich von 1300 - $1450 \mathrm{kPa}$. Dabei blieben 1996 vor allem die Monatssummen im Mai, Juli und August deutlich hinter denen von 1995 und 1997 zurück. 1995 wurden für die gesamte Vegetationsperiode wie auch im Zeitraum Juni bis August ähnlich hohe Summen des Sättigungsdefizits ermittelt wie 1997. Dabei traten im Juli und August 1995 sowie im August 1997 besonders hohe Monatssummen des Sättigungsdefizits von 300 - $400 \mathrm{kPa}$ auf. Die Vegetationsperiode 1997 zeichnete sich darüber hinaus durch die im Vergleich der Untersuchungsjahre höchsten September-Summenwerte des Sättigungsdefizits aus. Somit unterschied sich wie schon bei der Globalstrahlung auch beim Sättigungsdefizit der Luft die Vegetationsperiode 1995 im saisonalen Verlauf deutlich von denjenigen der Untersuchungsjahre 1996 und 1997. Auf eine Phase besonders geringer Sättigungsdefizitwerte Ende Mai bis Ende Juni 1995 folgte in diesem Jahr der Hochsommer mit dem höchsten Sättigungsdefizit der drei Untersuchungsjahre, während daraufhin ein Spätsommer mit besonders geringen Sättigungsdefizitwerten zu beobachten war (Abb. 2-4).
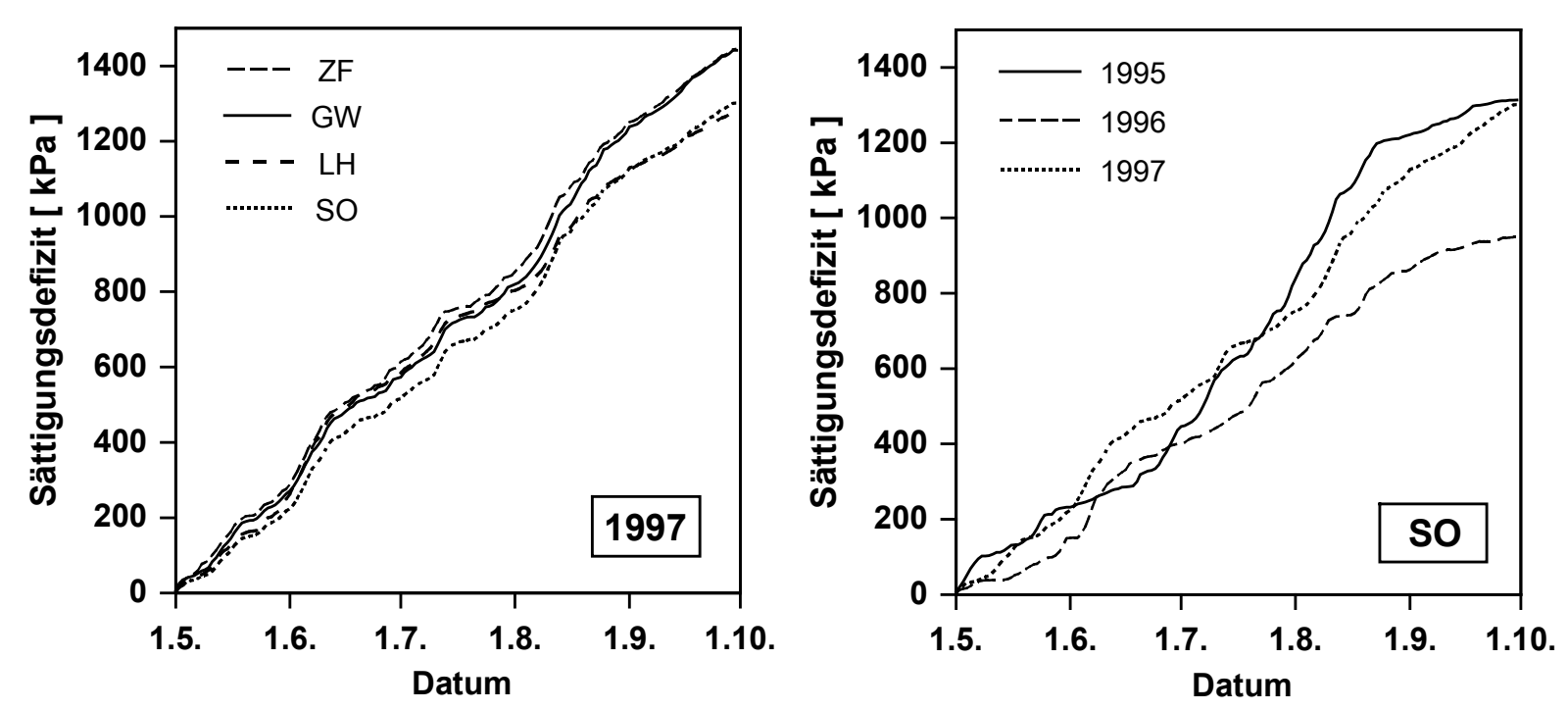

Abb. 2-4: Wasserdampf-Sättigungsdefizit der Luft im Vergleich zwischen den Untersuchungsbeständen für die Vegetationsperiode 1997 sowie im Vergleich der untersuchten Vegetationsperioden für den Bestand Solling. Dargestellt sind die kumulativ aufgetragenen Tagessummen der Stundenmittelwerte während der Tageshellphase (Globalstrahlung $>5 \mathrm{~J} \mathrm{~m}^{-2} \mathrm{~s}^{-1}$ ). 


\subsection{Bodenwasserzustand}

\subsubsection{Volumetrische Bodenwassergehalte und Bodenmatrixpotentiale}

\section{5}

In der Vegetationsperiode 1995 herrschte in den Untersuchungsbeständen durch ausgeglichene Niederschlagsverhältnisse bis in den Frühsommer eine gute Bodenwasserversorgung. So wurden in der Lüneburger Heide bis Ende Juni, im Solling bis Mitte Juli durchwegs Matrixpotentiale $>-200 \mathrm{hPa}$ bestimmt. Für den Göttinger Wald liegen für diesen Zeitraum bis Anfang August leider keine Meßwerte vor. Nach einer mäßigen Austrocknung des Bodens Anfang Juli mit Matrixpotentialen um - $600 \mathrm{hPa}$ in der Lüneburger Heide erfolgte dort wie auch im Solling Mitte Juli eine starke Wiederbefeuchtung. Dabei wurden Bodenwassergehalte nahe dem Sättigungszustand und Matrixpotentiale $>-100 \mathrm{hPa}$ erreicht (Abb. 2-6).

Mit dem Einsetzen einer etwa vierwöchigen ausgeprägten Hitze- und Trockenperiode um den 20. Juli begann in den drei Untersuchungsbeständen des Jahres 1995 eine Phase intensiver und langanhaltender Bodenaustrocknung. So sanken im Bestand Lüneburger Heide wie auch im Solling vom Bodenwasserzustand nahe Sättigung ausgehend binnen zwei Wochen bis Anfang August die volumetrischen Wassergehalte bis $20 \mathrm{~cm}$ Bodentiefe um $8-10 \mathrm{Vol} \%$. Im gleichen Zeitraum fielen die Bodenmatrixpotentiale in $10 \mathrm{~cm}$ Bodentiefe im Solling auf - $400 \mathrm{hPa} \mathrm{ab}$ und erreichten im Bestand Lüneburger Heide mit $-800 \mathrm{hPa}$ die Meßbereichsgrenze der Tensiometer. Diese wurde bis Mitte August auch im Bestand Göttinger Wald im gesamten mit Tensiometern erfaßbaren Bereich, also bis $25 \mathrm{~cm}$ Tiefe unterschritten. Dagegen wurden im Solling auch auf dem Höhepunkt der Bodenaustrocknung Matrixpotentiale von $-600 \mathrm{hPa}$ nicht unterschritten. Im Göttinger Wald sank der Bodenwassergehalt in $10 \mathrm{~cm}$ Tiefe bis zum 13. August auf nur noch $14 \mathrm{Vol} \% \mathrm{ab}$, den weitaus niedrigsten dort gemessenen Wert in allen drei Untersuchungsjahren. Geringfügige Niederschläge Mitte August konnten diese extreme Bodenwasserverknappung dort nur sehr wenig abmildern. Im Bestand Lüneburger Heide war ebenfalls im August eine fortdauernde extreme Bodenaustrocknung $\mathrm{zu}$ beobachten, an deren Ende am 22. August minimale Bodenwassergehalte von nur noch $6-13 \mathrm{Vol} \%$ bis $35 \mathrm{~cm}$ Tiefe gemessen wurden. Auch in der Lüneburger Heide wurden damit zu diesem Zeitpunkt die niedrigsten Bodenfeuchten bestimmt, die in den drei Untersuchungsjahren dort gemessen werden konnten.

Ende August bis Anfang September erfolgte in allen Untersuchungsbeständen eine intensive Wiederbefeuchtung des Bodens. Gegen Ende der Vegetationsperiode herrschten infolgedessen Matrixpotentiale $>-200 \mathrm{hPa}$ vor, und die Bodenwassergehalte erreichten in etwa wieder das relativ hohe Niveau wie vor der extremen hochsommerlichen Trockenperiode. Dabei war auch im September im Solling der entspannteste Bodenwasserhaushalt mit Matrixpotentialen nahe dem Sättigungszustand zu beobachten. Der Göttinger Wald dagegen fiel als einziger Bestand durch ein nochmaliges Absinken der Matrixpotentiale Mitte September auf Werte deutlich unter - $200 \mathrm{hPa}$ auf.

Der volumetrische Wassergehalt der organischen Auflage erreichte in der Lüneburger Heide nach einer fortschreitenden Austrocknung im Juni und Juli ebenfalls im August seinen Tiefpunkt (Abb. 2-5). Bereits Anfang August 1995, also noch zwei Wochen vor Ende der 
extremen Trockenperiode wurde mit $9 \mathrm{Vol} \%$ die geringste dort in den drei Untersuchungsjahren gefundene Streufeuchte bestimmt. Ende August bis Ende September stieg der volumetrische Wassergehalt der Streuauflage dann wieder auf Werte um 30 Vol.\% wie zu Beginn der Vegetationsperiode an.

\section{6}

Auf allen Flächen war 1996 nach einer ersten vierwöchigen kontinuierlichen Austrocknungsphase im Juni erst Anfang Juli eine starke Wiederbefeuchtung zu beobachten. Anfang August wurde ein Maximum der Bodentrockenheit erreicht (Abb. 2-7 und 2-8). Im Göttinger Wald und im Solling stieg die Bodenfeuchte daraufhin bis zum Ende der Vegetationsperiode wieder merklich an. In der Lüneburger Heide wurde nach nur kurzen hochsommerlichen Feuchtephasen erst Ende August der geringste Bodenwassergehalt erreicht. Der Bestand im Ziegelrodaer Forst wich hier von den anderen Beständen deutlich ab und zeigte eine nahezu kontinuierliche Bodenaustrocknung über die gesamte Vegetationsperiode, die nur durch eine dreiwöchige Feuchtephase im Juli merklich unterbrochen wurde. So wurde dort erst im September die maximale Bodentrockenheit erreicht und hielt auf diesem niedrigen Niveau noch fast den ganzen Monat an. Anfang Oktober beendeten ergiebige Niederschläge auf allen Untersuchungsflächen die sommerliche Bodenaustrocknung.

Auffällig in der Vegetationsperiode 1996 sind die meist nur 2 - 3 Wochen dauernden, eher kurzfristigen Austrocknungsperioden und starken Feuchteschwankungen in den Beständen Lüneburger Heide und Göttinger Wald. Weniger dynamische Bodenfeuchteänderungen zeigt demgegenüber der Bestand im Solling mit einem weitgehend stabil hohen Bodenfeuchteniveau sowie der Ziegelrodaer Forst mit nahezu kontinuierlich abnehmenden Bodenwassergehalten.

Auf allen Untersuchungsflächen waren dabei im Mineralboden bis etwa $30 \mathrm{~cm}$ Tiefe stets von oben nach unten abnehmende Bodenwassergehalte zu beobachten. Erst darunter nahm die Bodenfeuchte mit der Tiefe wieder zu, so daß in allen Beständen durchwegs etwa bei $20-40 \mathrm{~cm}$ Bodentiefe die geringsten Bodenwassergehalte gemessen werden konnten (Abb. 2-7). Die sandigen Mineralböden der Bestände Ziegelrodaer Forst und Lüneburger Heide wiesen dabei mit Werten im Bereich von 10 - 30\% deutlich niedrigere volumetrische Wassergehalte auf als die lehmigen Böden im Solling mit 20 - 35\% und im GW mit 30 - 50\%. Im Vergleich der beiden Bestände mit stark entwickelter organischer Auflage waren im Solling in der Streuauflage mit etwa 20-40\% stets wesentlich höhere volumetrische Wassergehalte zu beobachten als in der Lüneburger Heide mit nur 10 - 25\% (Abb. 2-5).

Die saisonale Entwicklung der Bodenmatrixpotentiale auf den ab 1996 vier Untersuchungsflächen spiegelte stets deutlich die Veränderung der jeweiligen Bodenwassergehalte wider. Unterschiedliche Bodenarten sowohl zwischen den Beständen als auch in verschiedenen Bodentiefen eines Bestandes bedingten jedoch bei gleichen Bodenwassergehalten zum Teil stark unterschiedliche Bodenwasserpotentiale (Abb. 2-8). 

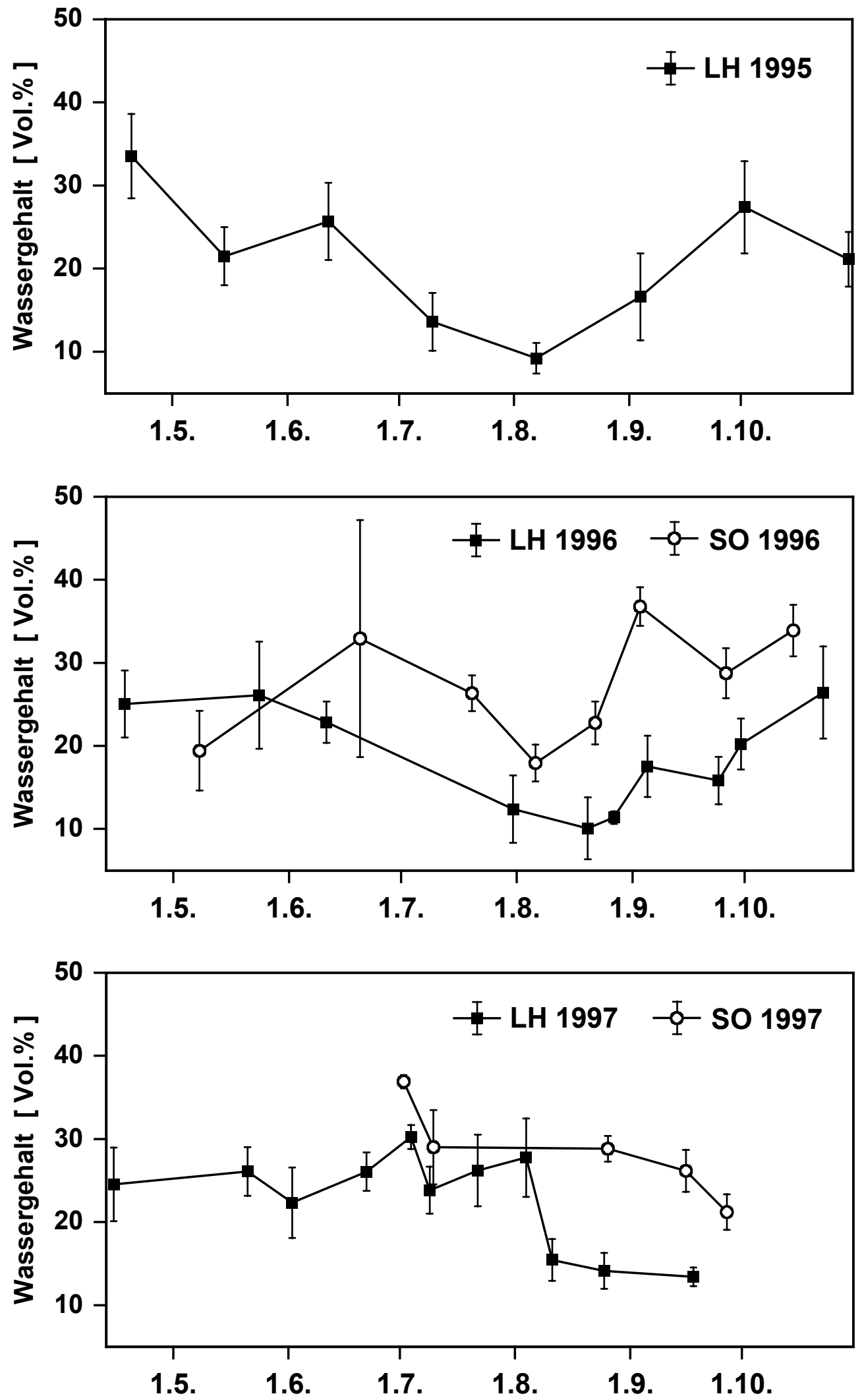

Abb. 2-5: Volumetrischer Wassergehalt der Streuauflage auf den Untersuchungsflächen Lüneburger Heide (LH) und Solling (SO) in den Vegetationsperioden 1995 - 1997. 

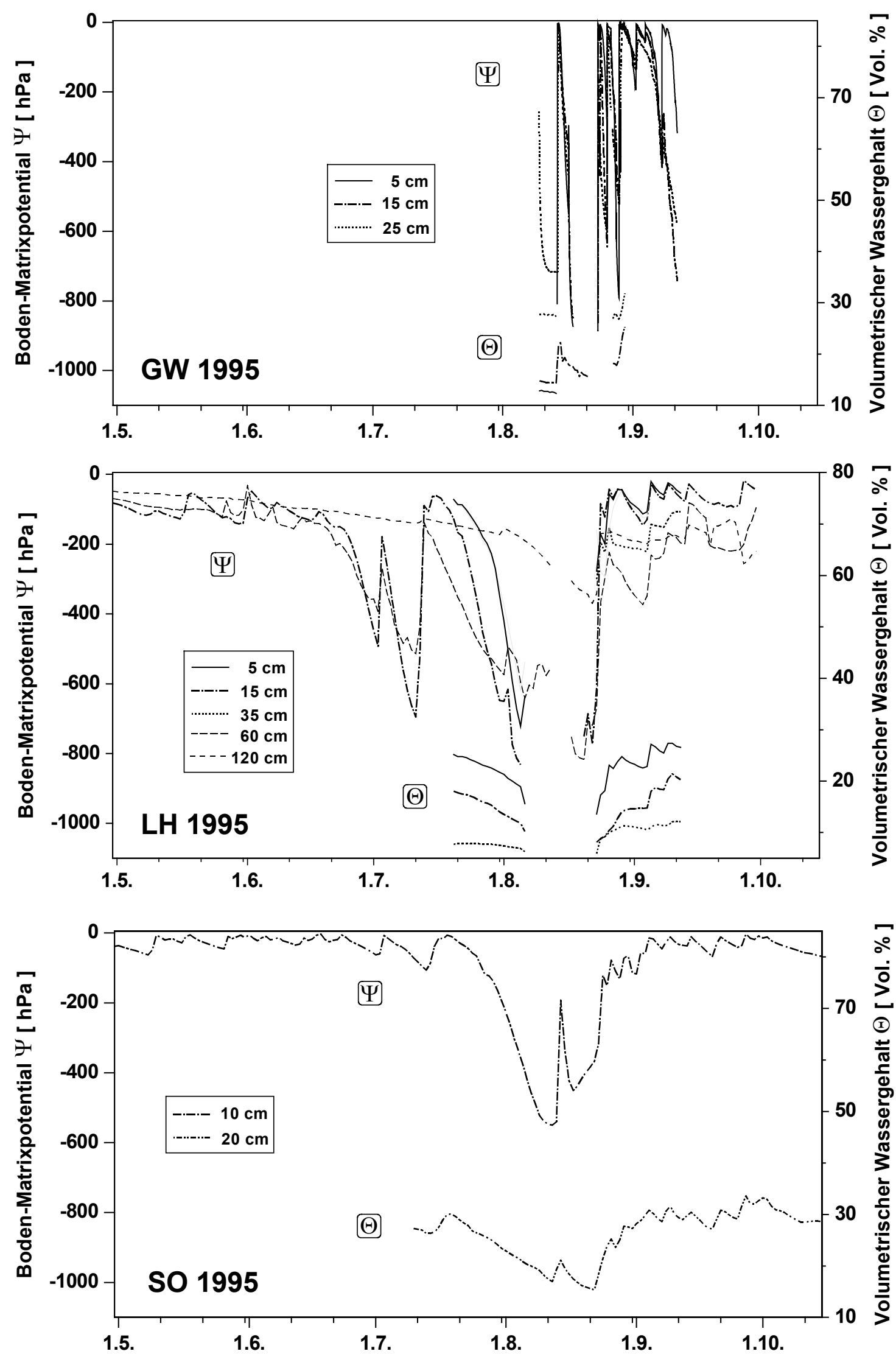

Abb. 2-6: Bodenmatrixpotential $(\Psi)$ und volumetrischer Bodenwassergehalt $(\Theta)$ auf den Untersuchungsflächen Göttinger Wald (GW), Lüneburger Heide (LH) und Solling (SO) in der Vegetationsperiode 1995. 

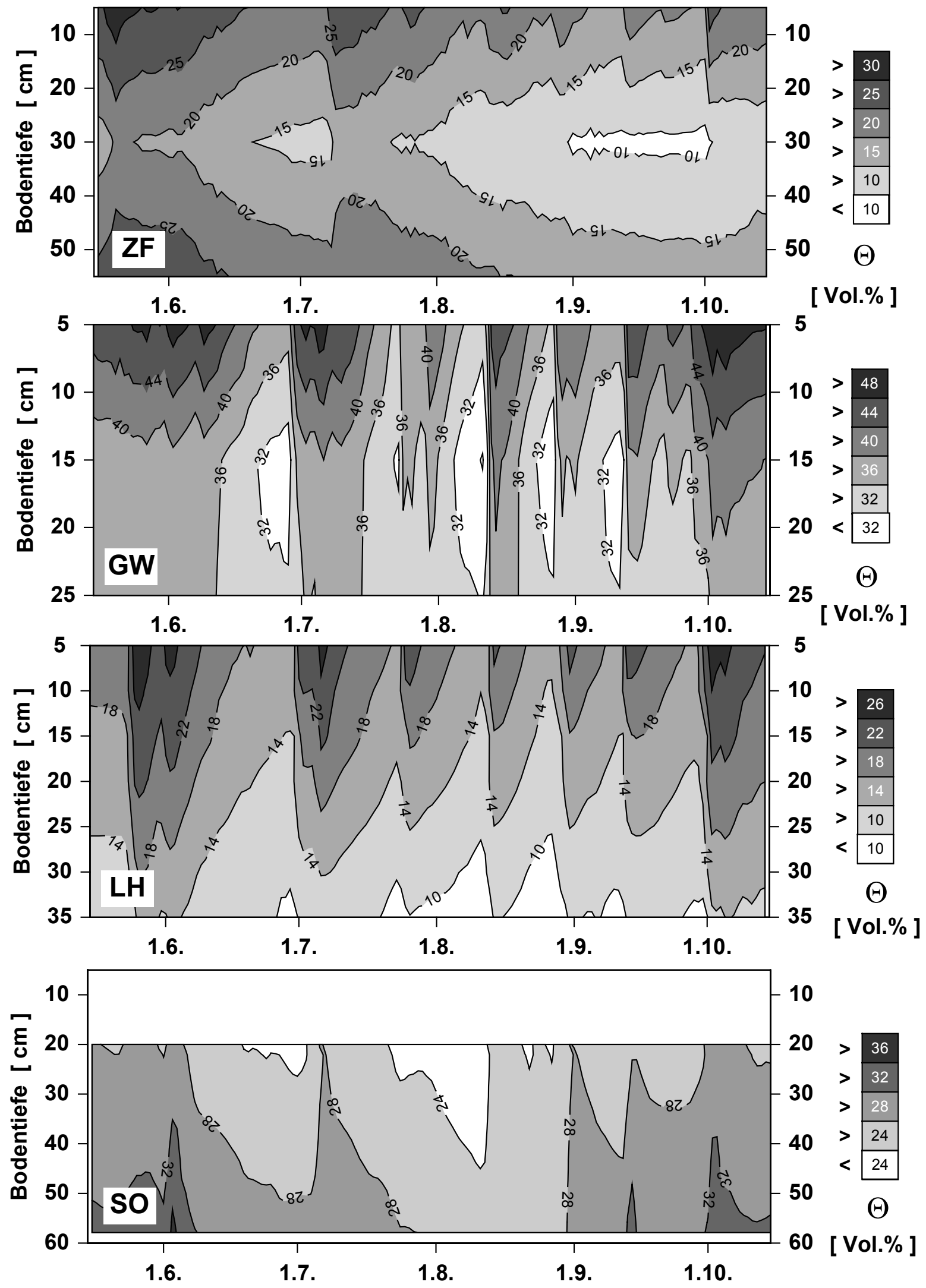

Abb. 2-7: Volumetrischer Bodenwassergehalt $(\Theta)$ auf den Untersuchungsflächen Ziegelrodaer Forst (ZF), Göttinger Wald (GW), Lüneburger Heide (LH) und Solling (SO) in der Vegetationsperiode 1996. 

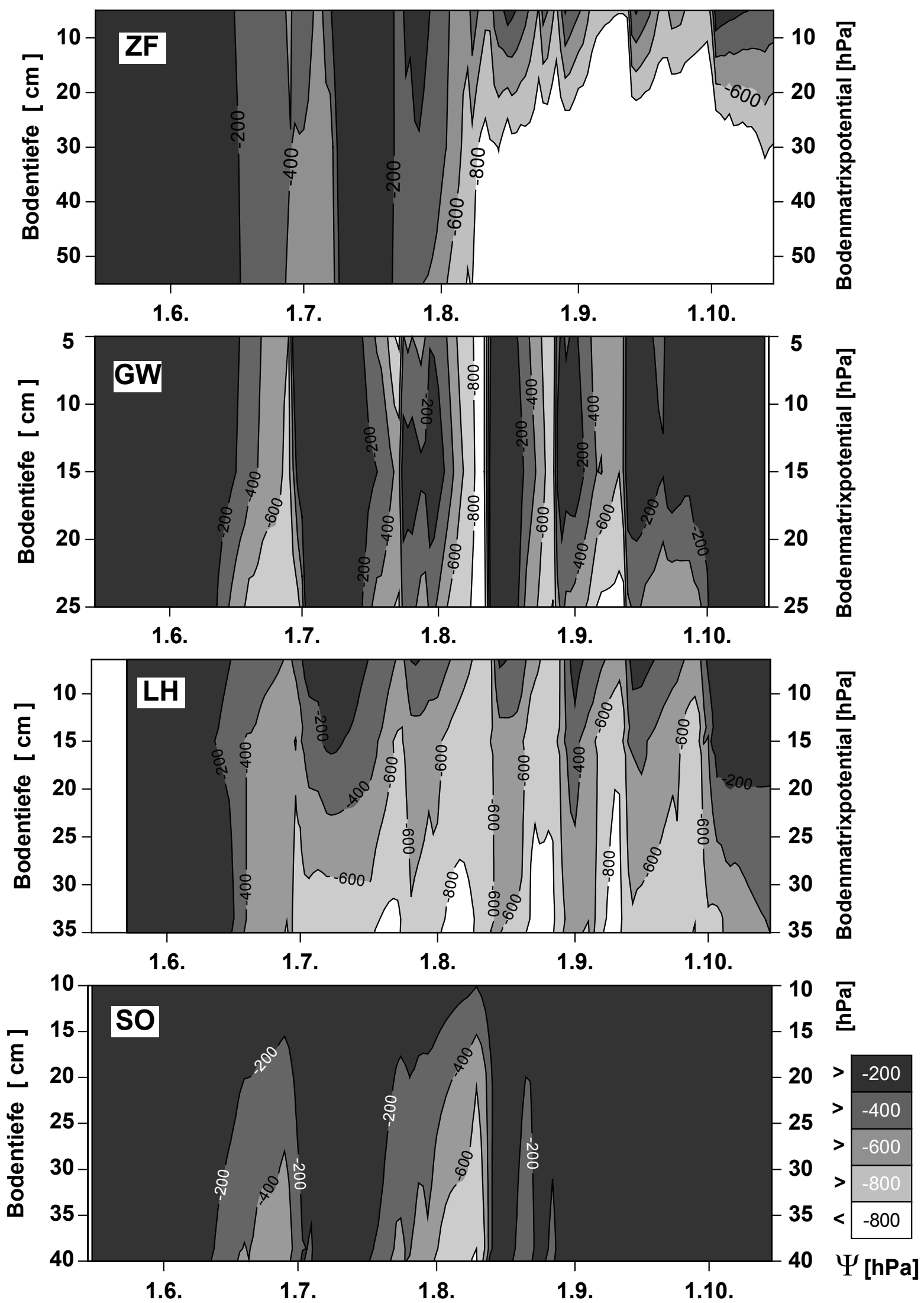

Abb. 2-8: Bodenmatrixpotential $(\Psi)$ auf den Untersuchungsflächen Ziegelrodaer Forst (ZF), Göttinger Wald (GW), Lüneburger Heide (LH) und Solling (SO) in der Vegetationsperiode 1996. 

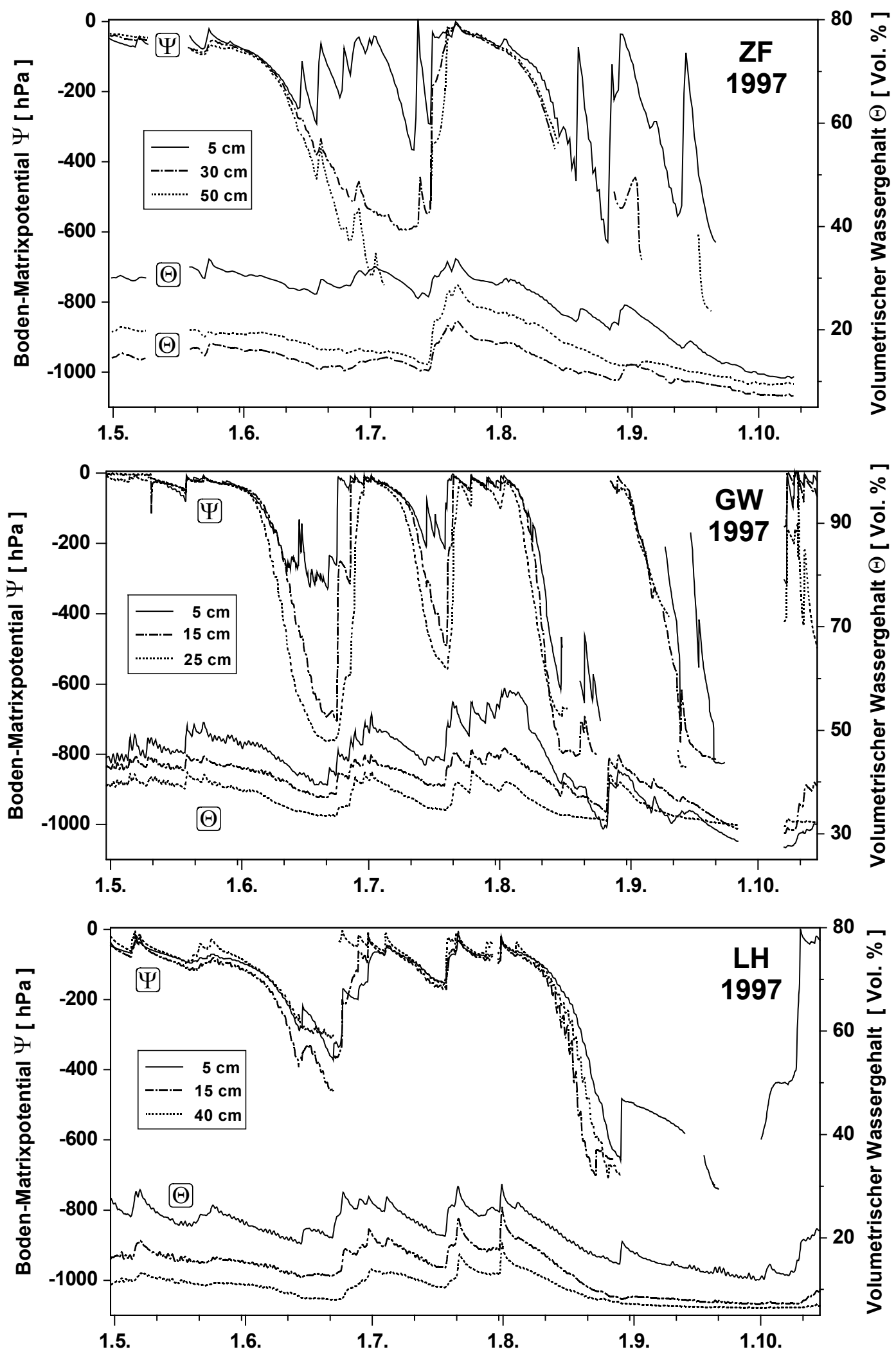

Abb. 2-9: Bodenmatrixpotential ( $\Psi)$ und volumetrischer Bodenwassergehalt $(\Theta)$ auf den Untersuchungsflächen Ziegelrodaer Forst (ZF), Göttinger Wald (GW) und Lüneburger Heide (LH) in der Vegetationsperiode 1997. 

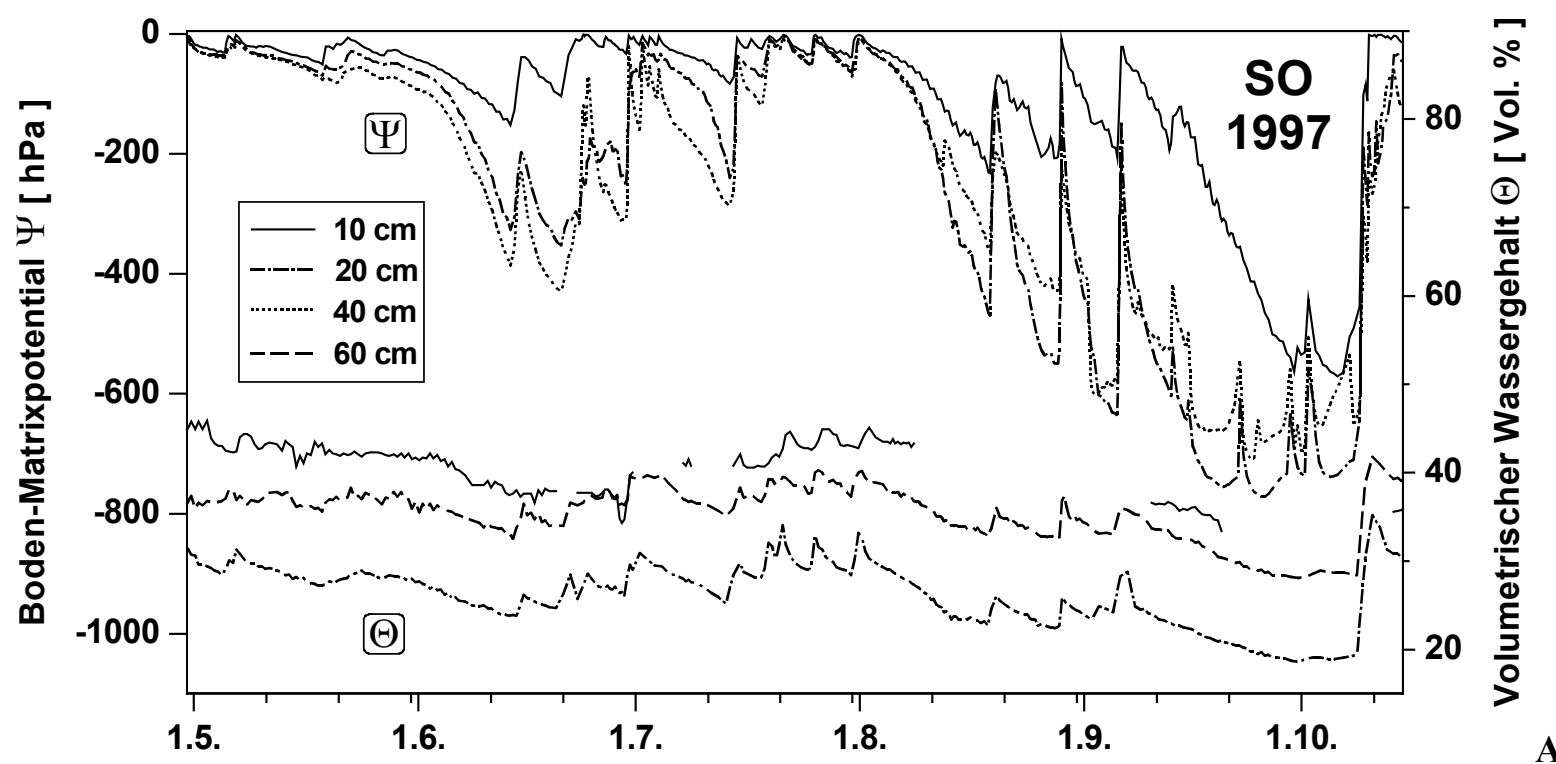

Abb. 2-10: Bodenmatrixpotential $(\Psi)$ und volumetrischer Bodenwassergehalt $(\Theta)$ auf der Untersuchungsflächen Solling (SO) in der Vegetationsperiode 1997.

Dennoch traten in den Beständen mit den deutlich niedrigsten volumetrischen Wassergehalten des Bodens auch die negativsten Bodenmatrixpotentialwerte auf.

So wurde im schluffig-sandigen Boden des Ziegelrodaer Forstes 1996 schon ab Anfang August im Unterboden und ab September großteils auch im Oberboden der MatrixpotentialMeßbereich der Tensiometer bis etwa - $800 \mathrm{hPa}$ unterschritten. Dieser Wert wurde erst durch die starke Wiederbefeuchtung Anfang Oktober wieder überschritten. Demgegenüber sank in den Sanden des Bestandes Lüneburger Heide bei ähnlich niedrigen volumetrischen Wassergehalten das Matrixpotential im Oberboden nur in zwei kurzen Phasen maximaler Trockenheit im August unter $-600 \mathrm{hPa}$ ab. Nur im Unterboden in $20-40 \mathrm{~cm}$ Tiefe und nur in Trockenphasen im Hoch- und Spätsommer fiel es hier unter den Meßbereich der Tensiometer von etwa - $800 \mathrm{hPa}$. Im Göttinger Wald waren Matrixpotentiale unter $-600 \mathrm{hPa}$ jeweils nur sehr kurz am Ende von kleinen Trockenperioden und dann besonders im Unterboden zu beobachten. Potentiale unter $-800 \mathrm{hPa}$ traten über größere Bodentiefebereiche nur an 2-3 Tagen zum Zeitpunkt maximaler Trockenheit Anfang August auf. Auf dem bodenfeuchtesten Standort Solling sank das Matrixpotential bis zu einer Mineralbodentiefe von $10 \mathrm{~cm}$ niemals unter $-200 \mathrm{hPa}$ und erreichte die niedrigsten Werte mit -600 bis - 800 hPa nur während der kurzen Trockenperiode Anfang August unterhalb $20 \mathrm{~cm}$ Tiefe.

Wie bei den Wassergehalten wurde auch bei den Matrixpotentialen die Tendenz zu einer von der Mineralbodenoberfläche bis etwa $40 \mathrm{~cm}$ Tiefe zunehmenden Bodentrockenheit deutlich. Das Bodenmatrixpotential nahm auf allen Untersuchungsflächen in der Regel zunächst von oben nach unten ab und erreichte in etwa 30-40 cm Tiefe ein Minimum. Unterhalb etwa $50 \mathrm{~cm}$ Bodentiefe konnten im Solling und in der Lüneburger Heide vor allem während Trockenperioden mit zunehmender Tiefe wieder deutlich ansteigende Bodenwasserpotentiale gemessen werden (LEUSCHNER 1994, BENECKE 1984). Im Ziegelrodaer Forst war bis zur maximalen Meßtiefe von $55 \mathrm{~cm}$ zu keinem Zeitpunkt ein länger andauernder Wiederanstieg des Bodenwasserpotentials mit zunehmender Tiefe zu beobachten, sondern allenfalls ein 
kurzfristiges und sehr seltenes Vordringen von Wasserfronten bei Starkregenereignissen. Die flachgründige Lehmrendzina des Bestandes GW stellte bezüglich des Tiefenverlaufs des Bodenmatrixpotentials eine Ausnahme dar. Hier wurde nur selten die Tendenz zu einem Tiefengradienten des Bodenwasserpotentials erkennbar. Zumeist herrschten über die gesamte nur geringe Tiefe des skelettarmen Mineralbodens etwa gleiche hohe Matrixpotentiale vor. Das bedeutet, daß in diesem Boden sowohl eine Bodenaustrocknung über den gesamten Oberboden etwa gleichmäßig stattfand als auch, daß bei Infiltrationsereignissen nach stärkerer Austrocknung das Matrixpotential in allen Tiefen fast gleichzeitig stark anstieg und von 0 - 30cm Tiefe schnell Werte über - $200 \mathrm{hPa}$ erreichte.

\section{7}

Auf allen Untersuchungsflächen trat 1997 nach hoher Bodenfeuchte im Mai ab Anfang Juni eine länger andauernde Phase der Bodenaustrocknung auf (Abb. 2-9 und 2-10). Diese konnte durch vereinzelte geringe Niederschläge ab Mitte Juni nur oberflächennah und nur zum Teil kompensiert werden, während im Unterboden ein fortgesetzter Rückgang der volumetrischen Wassergehalte und Matrixpotentiale zu beobachten war. Eine nachhaltige Wiederbefeuchtung durch länger andauernde Niederschläge trat erst wieder Ende Juni / Anfang Juli ein, wobei auch tiefere Bodenschichten erreicht wurden. Eine Ausnahme stellte hierbei jedoch der Bestand Ziegelrodaer Forst dar, in dem die Anfang Juli eindringende Wasserfront schon eine Tiefe von $30 \mathrm{~cm}$ nicht mehr erreichte. Nach einer erneuten kurzen Austrocknungsphase war schließlich im Zeitraum Mitte Juli bis Anfang August durch wiederholte Niederschläge ein zum Teil starker Wiederanstieg der volumetrischen Wassergehalte auf Werte wie zu Beginn der Vegetationsperiode oder sogar darüber (Göttinger Wald) zu beobachten. Dabei wurde in allen Beständen zumindest im Oberboden ein Zustand nahe der Wassersättigung erreicht. Dieser dauerte in den Beständen Göttinger Wald und Solling mit etwa 15 - 20 Tagen bis Anfang August am längsten an, wurde in der Lüneburger Heide und im Ziegelrodaer Forst jedoch nur für wenige Tage erreicht und war dort schon am 31. Juli bzw. 23. Juli beendet. Auf den Bodenwasserzustand nahe Sättigung folgte in allen Beständen während einer etwa dreiwöchigen ausgeprägten Hitze- und Trockenperiode ab Anfang August eine Phase schneller und intensiver Bodenaustrocknung. Dabei wurde auf allen Untersuchungsflächen außer im Solling der Meßbereich der Tensiometer mit Matrixpotentialen zwischen $-650 \mathrm{hPa}$ und $-800 \mathrm{hPa}$ erreicht oder unterschritten. Der zuvor stärker durchfeuchtete Oberboden trocknete auch hierbei meist deutlich weniger stark aus als tiefere Bodenschichten. So waren gegen Ende der Hitze- und Trockenperiode um den 25. August Bodenwassergehalte von 23 - 35 Vol. \% im Solling, $30-35$ Vol. \% im Göttinger Wald, $7-14$ Vol. \% in der Lüneburger Heide und $10-20 \mathrm{Vol}$ \% im Ziegelrodaer Forst zu beobachten. Diese sanken nach einer kurzen Erholung der Bodenwasservorräte Ende August im Laufe des Septembers kontinuierlich noch weiter ab. So traten schließlich Ende September die Minimalwerte der Vegetationsperiode auf mit Werten im Oberboden von etwa 30 Vol. \% im Solling und im Göttinger Wald und um $10 \mathrm{Vol}$ \% in den Beständen Lüneburger Heide und Ziegelrodaer Forst. Dabei lagen die Matrixpotentiale vor allem in den Meßtiefen des Unterbodens in der Lüneburger Heide und im Ziegelrodaer Forst von Ende August bis Anfang Oktober langfristig unterhalb des Meßbereichs der Tensiometer $(<-800 \mathrm{hPa})$. Im Göttinger Wald war dies nur in 
zwei kurzen Phasen Ende August und Ende September der Fall. Im Solling wurden erst in der zweiten Septemberhälfte Bodenmatrixpotentiale von - $600 \mathrm{hPa}$ unterschritten. Nach der ausgeprägten spätsommerlichen Austrocknungsphase setzte auf allen Untersuchungsflächen erst Mitte Oktober eine deutliche Wiederbefeuchtung ein.

Der volumetrische Wassergehalt der organischen Auflagen in der Lüneburger Heide und im Solling zeigte 1997 wie in den vorangegangenen Untersuchungsjahren im wesentlichen einen den Feuchten im oberen Mineralboden parallelen Verlauf (Abb. 2-5). So vollzog sich in der Lüneburger Heide auch in der Streuauflage Anfang August ein rapider Austrocknungsprozeß mit einem Rückgang des volumetrischen Wassergehalts von $28 \mathrm{Vol} \%$ auf $15 \mathrm{Vol} \%$ innerhalb einer Woche. Nach Werten im Bereich von 20 - 30 Vol.\% im Zeitraum Mai bis Juli wurde im September 1997 mit 13 Vol. \% hier ein etwas höherer Minimalwert der Streufeuchte ermittelt als 1995 und 1996. Anders als in der Lüneburger Heide war der Wassergehalt der Streuauflage im Solling Ende August mit 29 Vol. \% nicht wesentlich niedriger als nach der Feuchtephase Anfang Juli. Auch der Ende September erreichte niedrigste volumetrische Wassergehalt der Streuauflage lag mit 21 Vol. \% im Solling deutlich höher als in der Lüneburger Heide.

\subsubsection{Matrixpotential-Wassergehaltsbeziehungen (Feld-pF-Kurven)}

Die kontinuierliche Aufzeichnung von Matrixpotential und Wassergehalt im Gelände ermöglicht die Darstellung der Wasserhaushaltscharakteristik der Böden auf den Untersuchungsflächen in Form von Feld-pF-Kurven (Abb. 2-11). Bedingt durch den begrenzten Meßbereich von Tensiometern kann mit Feld-pF-Kurven jedoch nur ein Ausschnitt ( $\mathrm{pF} 1.8-\mathrm{pF} \sim 2.9$ ) des gesamten Bereichs der nutzbaren Feldkapazität von $\mathrm{pF} 1.8-\mathrm{pF} 4.2$ erfaßt werden.

In der Matrixpotential-Wassergehaltsbeziehung unterscheiden sich die tonig-schluffigen bis lehmigen Böden im Göttinger Wald und Solling grundlegend von den sandigen Böden der Bestände Ziegelrodaer Forst und Lüneburger Heide. Die Feld-pF-Kurven weisen für die beiden Sandböden im Ziegelrodaer Forst und in der Lüneburger Heide im mit Tensiometern erfaßbaren Bereich von pF 1.8 bis pF 2.9 im Oberboden $(0-10 \mathrm{~cm})$ etwa $10 \mathrm{Vol} \%$ und im Unterboden $(25-35 \mathrm{~cm}) 6 \mathrm{Vol} \%$ pflanzenverfügbares Wasser aus. Der tonig-schluffige Boden im Göttinger Wald verfügt in diesem Matrixpotentialbereich entsprechend über 18 Vol. \% bzw. 8 Vol. \% pflanzenverfügbares Wasser. Für den lehmig-schluffigen Boden im Bestand Solling kann trotz der in dieser Untersuchung etwas abweichenden Meßtiefen anhand einer Labor-pF-Kurve des gleichen Bodens (BENECKE 1984) für den Matrixpotentialbereich bis pF 2.9 etwa 15 Vol.\% pflanzenverfügbares Wasser im Oberboden und 8 Vol.\% im Unterboden angenommen werden. 

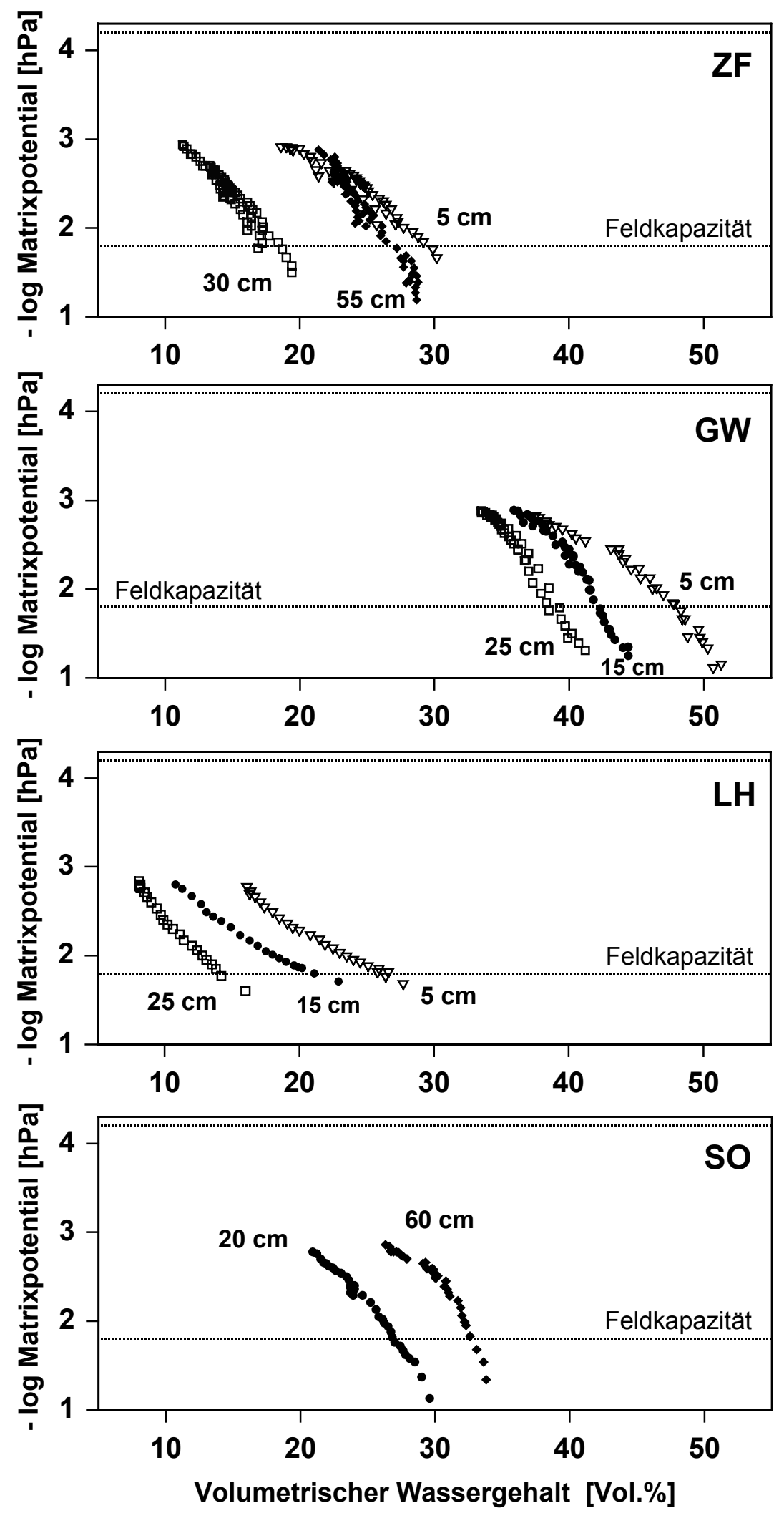

Abb. 2-11: Matrixpotential-Wassergehalts-Beziehungen (Feld-pF-Kurven) in unterschiedlichen Mineralbodentiefen auf den Untersuchungsflächen Ziegelrodaer Forst (ZF), Göttinger Wald (GW), Lüneburger Heide (LH) und Solling (SO). In die dargestellten Kurven gingen Werte des Bodenmatrixpotentials und des Volumetrischen Wassergehalts aus jeweils 2 - 3 Desorptionsphasen ein. 


\subsubsection{Nutzwasservorrat}

Als aktueller pflanzenverfügbarer Wasservorrat oder Nutzwasservorrat eines Bodens wird allgemein die Wassermenge definiert, die mit Matrixpotentialen zwischen $-15000 \mathrm{hPa}$ ( $\mathrm{pF}$ 4.2) und etwa $-60 \mathrm{hPa}(\mathrm{pF} 1.8)$ im Wurzelraum gebunden ist. Wasser, das mit Potentialen $<-15000 \mathrm{hPa}$ an die Bodenmatrix gebunden ist, gilt als für Pflanzen nicht mehr aufnehmbares Totwasser. Wasser mit Matrixpotentialen $>-60 \mathrm{hPa}(\mathrm{pF} 1.8)$ wird als Sickerwasser betrachtet, das nicht dauerhaft gegen die Schwerkraft im Boden gehalten werden kann. Die Nutzwasserkapazität gibt den maximal möglichen Nutzwasservorrat eines Bodens an. Dieser kann bei bekanntem Nutzwasseranteil des Feinbodens und unter Berücksichtigung des jeweiligen Skelettanteils unterschiedlicher Bodenschichten für einen betrachteten Bodentiefebereich ermittelt werden (Tab. 2-7).

Tab. 2-7: Feldkapazität (Nutzwasseranteil) und Nutzwasserkapazität unter Berücksichtigung des Skelettanteils der Böden auf den Untersuchungsflächen. Nach eigenen Untersuchungen sowie Daten von GERKE 1987 und MEIWES \& BEESE 1988 für den Göttinger Wald, von BENECKE 1984 für den Solling sowie von LEUSCHNER 1994 für die Lüneburger Heide.

\begin{tabular}{|c|c|c|c|c|c|c|c|c|c|c|c|c|}
\hline \multirow[t]{2}{*}{$\begin{array}{c}\text { Horizont/ } \\
\text { Bodentiefe }\end{array}$} & \multicolumn{4}{|c|}{$\begin{array}{c}\text { Skelettanteil } \\
\text { [Vol. \% ] }\end{array}$} & \multicolumn{4}{|c|}{$\begin{array}{c}\text { Feldkapazität } \\
{[\text { Vol. \% ] }}\end{array}$} & \multicolumn{4}{|c|}{$\begin{array}{c}\text { Nutzwasser- } \\
\text { kapazität [ mm ] }\end{array}$} \\
\hline & $\mathbf{Z F}$ & GW & $\mathbf{L H}$ & SO & $\mathbf{Z F}$ & GW & LH & SO & $\mathbf{Z F}$ & GW & LH & SO \\
\hline $0-10 \mathrm{~cm}$ & 3 & 3 & 5 & 3 & 29 & 46 & 31 & 38 & 16 & 22 & 21 & 19 \\
\hline$-20 \mathrm{~cm}$ & 5 & 5 & 17 & 3 & 23 & 40 & 22 & 33 & 13 & 17 & 16 & 16 \\
\hline$-40 \mathrm{~cm}$ & 10 & 30 & 23 & 3 & 17 & 27 & 13 & 30 & 20 & 26 & 17 & 28 \\
\hline$-70 \mathrm{~cm}$ & 10 & 53 & 17 & 3 & 22 & 13 & 12 & 30 & 39 & 24 & 25 & 33 \\
\hline$-100 \mathrm{~cm}$ & 15 & 80 & 14 & 30 & - & - & - & - & - & - & - & - \\
\hline org. Aufl. & - & - & - & - & 35 & - & 40 & 40 & - & - & 21 & 14 \\
\hline $0-40 \mathrm{~cm}$ & 7 & 17 & 17 & 3 & 21 & 35 & 16 & 33 & 49 & 65 & 56 & 63 \\
\hline $0-70 \mathrm{~cm}$ & 8 & 32 & 17 & 3 & 22 & 26 & 13 & 32 & 88 & 89 & 81 & 96 \\
\hline Aufl. $-70 \mathrm{~cm}$ & & & & & & & & & 88 & 89 & 102 & 110 \\
\hline
\end{tabular}

Abbildung 2-12 gibt für das Untersuchungsjahr 1996 die saisonale Entwicklung des Nutzwasservorrats auf den Untersuchungsflächen bis $40 \mathrm{~cm}$ Mineralbodentiefe wider. Dies entspricht in allen Untersuchungsbeständen gut dem am intensivsten von Feinwurzeln erschlossenen Bodenbereich (HERTEL 1999). Die saisonalen Änderungen des Nutzwasservorrats folgten auf allen Untersuchungsflächen eng dem saisonalen Verlauf von Matrixpotential und volumetrischem Wassergehalt, anhand derer der Nutzwasservorrat ermittelt wurde (vgl. Abb.2-7 und 2-8).

Der Nutzwasservorrat bis $40 \mathrm{~cm}$ Mineralbodentiefe im Bestand Ziegelrodaer Forst nahm bis auf eine kurze Erholung Mitte Juli über die gesamte Vegetationsperiode 1996 kontinuierlich 

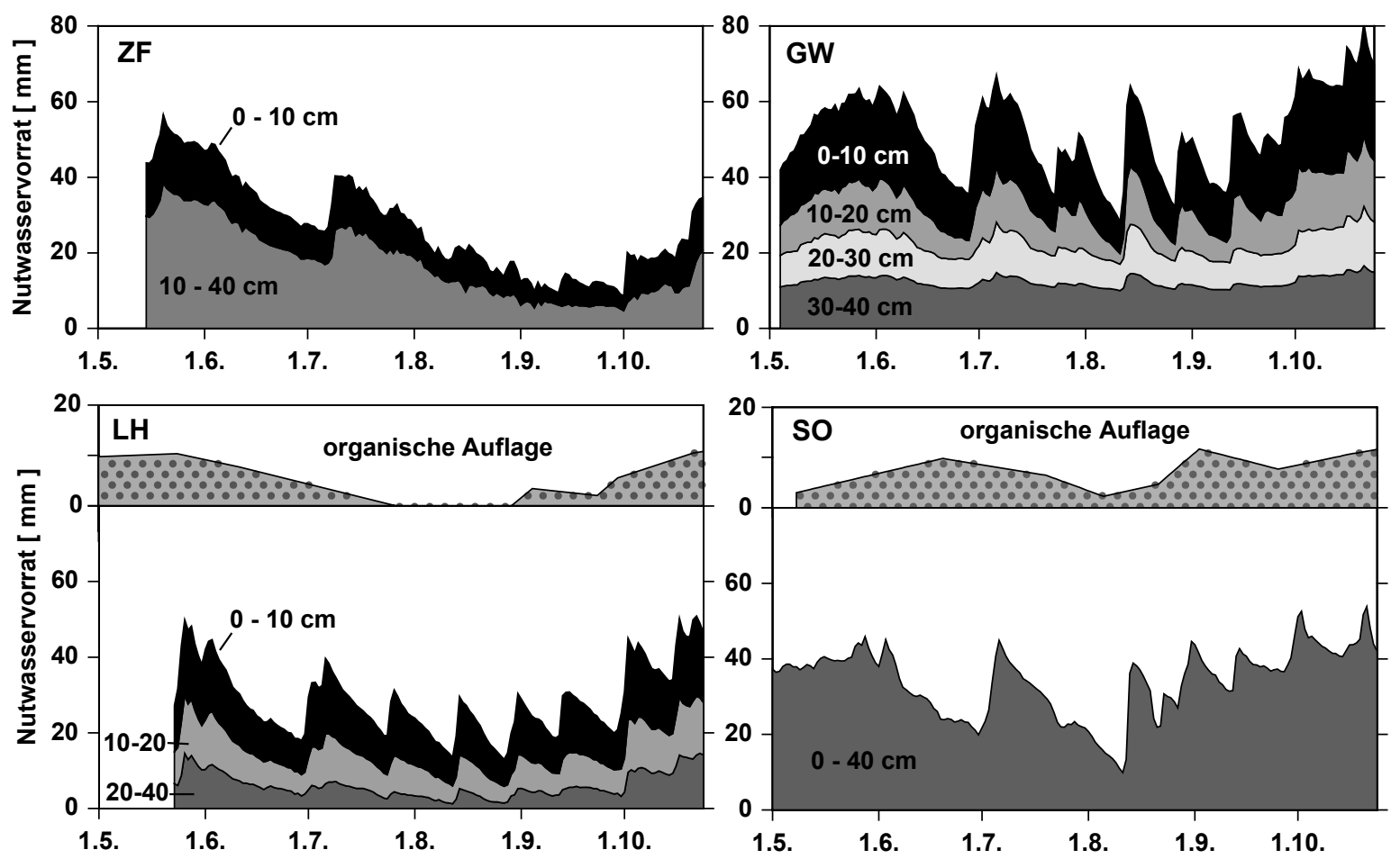

Abb. 2-12: Nutzwasservorrat in Mineralboden $(0-40 \mathrm{~cm})$ und organischer Auflage auf den Untersuchungsflächen Ziegelrodaer Forst (ZF), Göttinger Wald (GW), Lüneburger Heide (LH) und Solling (SO) während der Vegetationsperiode 1996.

ab. Nach etwa $50 \mathrm{~mm}$ Ende Mai erreichte er den Tiefststand im September mit Werten um $10 \mathrm{~mm}$ und stieg erst im Oktober wieder merklich an.

Dabei waren $\mathrm{zu}$ jedem Zeitpunkt der Vegetationsperiode in den obersten $10 \mathrm{~cm}$ des Mineralbodens mindestens $30-40 \%$ des Nutzwasservorrats bis $40 \mathrm{~cm}$ Tiefe lokalisiert. Gegen Ende der Vegetationsperiode, zum Zeitpunkt minimaler Nutzwasservorräte von deutlich unter $20 \mathrm{~mm}$ bis $40 \mathrm{~cm}$ Profiltiefe, stieg der Anteil in den obersten $10 \mathrm{~cm}$ Mineralboden sogar auf 40-60\% an. Tiefere Bodenschichten $(40-70 \mathrm{~cm}$, ohne Abb.) trugen im Verlauf der Vegetationsperiode 1996 zunächst in etwa gleicher Größenordnung zum Nutzwasservorrat bei wie der Bereich 0 - $40 \mathrm{~cm}$. Ab August überstieg jedoch dieser Nutzwasservorrat unterhalb $40 \mathrm{~cm}$ Bodentiefe denjenigen oberhalb $40 \mathrm{~cm}$ etwa um den Faktor 1.5 - 2. Der gesamte Wasservorrat der sehr geringmächtigen und nur von wenigen Wurzeln erschlossene Streuauflage im Bestand Ziegelrodaer Forst betrug über die Vegetationsperiode nur 1-4 mm. Angesichts des zudem noch hohen Totwasseranteils in organischen Auflagehorizonten aus Buchenstreu (LEUSCHNER 1994) konnte die Streuauflage somit sicher zu keinem Zeitpunkt nennenswert zum Nutzwasservorrat des Bestandes beitragen.

Die Nutzwasserkapazität bleibt im Ziegelrodaer Forst mit nur $49 \mathrm{~mm}$ bis $40 \mathrm{~cm}$ Profiltiefe gering. Erst tiefer liegende Bodenschichten mit günstigeren Wasserspeichereigenschaften ergeben für 0 - $70 \mathrm{~cm}$ Bodentiefe mit $88 \mathrm{~mm}$ eine ähnliche Nutzwasserkapazität wie in den anderen Beständen (Tab. 2-7). 
Der Bodenwasservorrat im Bestand Göttinger Wald ist aufgrund des heterogenen Materials im Oberboden und durch den kaum erfaßbaren Skelettanteil im klüftigen Kalkgestein des $\mathrm{C}_{\mathrm{v}^{-}}$ Horizonts schwer zu bestimmen. Trotz eines relativ hohen Totwasseranteils des tonigen Oberbodens von etwa $30 \mathrm{Vol} \%$ weist dieser durch intensive Gefügebildung aber ein mit 50 - 60 Vol. \% sehr hohes Porenvolumen und somit einen dennoch hohen Nutzwasseranteil um 25 Vol. \% auf (Abb. 2-11) (vgl. GERKE 1987). Dadurch resultiert trotz des im Unterboden stark zunehmenden Skelettanteils für den Bereich $0-40 \mathrm{~cm}$ Bodentiefe eine vergleichsweise hohe Nutzwasserkapazität von $65 \mathrm{~mm}$, die bis $70 \mathrm{~cm}$ Bodentiefe auf $89 \mathrm{~mm}$ ansteigt (Tab. 2-7).

Der Nutzwasservorrat bis $40 \mathrm{~cm}$ Mineralbodentiefe im Göttinger Wald unterlag in der gesamten Vegetationsperiode 1996 häufigen, starken und kurzfristigen Schwankungen zwischen Werten von etwa $30 \mathrm{~mm}$ und $60 \mathrm{~mm}$ (Abb. 2-12). Über weite Strecken der Vegetationsperiode befanden sich dabei in den obersten $20 \mathrm{~cm}$ des Mineralbodens etwa $50-65 \%$ des Nutzwasservorrats bis $40 \mathrm{~cm}$ Bodentiefe. Nur in kurzen Phasen starker Bodenaustrocknung sank dieser Anteil deutlich unter 50\%. Der Nutzwasservorrat im Oberboden unterlag darüber hinaus erheblich stärkeren Schwankungen als im Bereich unterhalb $20 \mathrm{~cm}$ Bodentiefe.

Frühere Tensiometermessungen im Bestand Lüneburger Heide zeigten, daß in diesem Sandboden auch mit Matrixpotentialen $>-60 \mathrm{hPa}(\mathrm{pF} 1.8)$ gebundenes Wasser längerfristig im Profil verbleibt und somit nicht als Sickerwasser sondern als unmittelbar pflanzenverfügbar betrachtet werden kann (LEUSCHNER 1994). Daher wird hier Wasser im Potentialbereich von $-20 \mathrm{hPa}(\mathrm{pF} 1.3)$ bis $-15000 \mathrm{hPa} \quad(\mathrm{pF} 4.2)$ als potentiell pflanzenaufnehmbar betrachtet und dem aktuellen Nutzwasservorrat sowie der Nutzwasserkapazität zugerechnet.

Der Nutzwasservorrat bis $40 \mathrm{~cm}$ Mineralbodentiefe zeigte im Bestand Lüneburger Heide ähnlich wie im Göttinger Wald häufige und kurzfristige Schwankungen, ließ dabei jedoch anders als im Göttinger Wald eine bis Ende August fallende Tendenz erkennen (Abb. 2-12). Nach einer nur leichten Erholung im September wurde der Nutzwasservorrat erst im Oktober wieder aufgefüllt. Im Bestand Lüneburger Heide ist ein großer Teil der pflanzenaufnehmbaren Wasservorräte in den obersten $20 \mathrm{~cm}$ des Mineralbodens lokalisiert. Dort sind auch die weitaus stärksten saisonalen Veränderungen des Nutzwasservorrats zu beobachten. So befinden sich je nach Befeuchtungszustand im saisonalen Verlauf allein in den obersten $10 \mathrm{~cm}$ des Mineralbodens $35-55 \%$, in den obersten $20 \mathrm{~cm}$ des Mineralbodens sogar $60-90 \%$ des Nutzwasservorrats von organischer Auflage und Mineralboden bis $40 \mathrm{~cm}$ Bodentiefe. Tiefere Bodenschichten mit meist geringen Wassergehalten und z.T. hohem Skelettanteil sowie die organische Auflage mit einem hohen Totwasseranteil und niedrigen Nutzwassergehalten tragen nur relativ wenig zur Wasserversorgung des Bestandes bei (vgl. LEUSCHNER 1994). Ihr relativer Anteil am Nutzwasservorrat sinkt zudem bei zunehmender Bodenwasserverknappung. So stellt die Streuauflage nach ausgiebigen Niederschlägen mit einem Nutzwasservorrat von etwa $10 \mathrm{~mm}$ zwar jeweils einen Anteil von etwa 15 - $20 \%$ des gesamten Nutzwasser-Vorrats bis $40 \mathrm{~cm}$ Bodentiefe zur Verfügung. In Phasen ausgeprägter Trockenheit jedoch kann die Streuauflage mit Matrixpotentialen unter $-15000 \mathrm{hPa}$ nicht mehr zur Wasserversorgung des Bestandes beitragen (Abb. 2-12). 
Die Nutzwasserkapazität der organischen Auflage beträgt $21 \mathrm{~mm}$. Die Nutzwasserkapazität des Mineralbodens bleibt im Bereich intensiver Durchwurzelung $(0-40 \mathrm{~cm}$ Tiefe $)$ mit $56 \mathrm{~mm}$ vergleichsweise niedrig und steigt infolge relativ hoher Skelettanteile auch bis $70 \mathrm{~cm}$ Tiefe nur auf $81 \mathrm{~mm}$ an (Tab. 2-7).

Für die Untersuchungsfläche Solling lagen über die saisonale Entwicklung des volumetrischen Wassergehalts nur Werte aus $20 \mathrm{~cm}$ und $60 \mathrm{~cm}$ Tiefe vor. Dies erlaubte keine differenzierte Bestimmung des Nutzwasservorrates in verschiedenen Tiefenstufen des Mineralbodenbereiches $0-40 \mathrm{~cm}$ wie auf den anderen Untersuchungsflächen. Eine Extrapolation des in $20 \mathrm{~cm}$ Tiefe gemessenen volumetrischen Wassergehalts für die Mineralboden-Profiltiefe 0 - $40 \mathrm{~cm}$ ließ für weite Teile der Vegetationsperiode 1996 auf einen Nutzwasservorrat zwischen 25 und $35 \mathrm{~mm}$ schließen, der nur wenige Tage Anfang August auf Werte unter $20 \mathrm{~mm}$ absank. (Abb. 2-12)

Die organische Auflage stellte mit 2 - $12 \mathrm{~mm}$ Nutzwasservorrat durchschnittlich etwa $20 \%$ $(9-30 \%)$ des gesamten Nutzwasservorrats bis $40 \mathrm{~cm}$ bzw. etwa $11 \%(5-16 \%)$ des gesamten Nutzwasservorrats bis $80 \mathrm{~cm}$ Profiltiefe zur Verfügung.

Die organische Auflage im Solling besitzt eine Nutzwasserkapazität von etwa $14 \mathrm{~mm}$. Die Nutzwasserkapazität des Mineralbodens bis $40 \mathrm{~cm}$ Tiefe ist mit $63 \mathrm{~mm}$ vergleichsweise hoch und erreicht bis $70 \mathrm{~cm}$ Tiefe den im Flächenvergleich höchsten Wert von 96 mm (Tab. 2-7). 


\section{Material und Methoden}

\subsection{Messung mikroklimatischer Parameter}

\section{Niederschlag}

Im Ziegelrodaer Forst wurde der Freilandniederschlag mit einem Hellmann-Trichter auf einem etwa $200 \mathrm{~m}$ vom Bestand entfernten kleinen Gerüstturm in etwa $5 \mathrm{~m}$ Höhe über einer Fichtenschonung gesammelt und in ein- bis dreiwöchigem Abstand gemessen. Diese Daten wurden bezüglich der zeitlichen Verteilung mit täglichen Niederschlagsmessungen des etwa $2 \mathrm{~km}$ entfernten Forstamtes Ziegelroda abgeglichen. Darüber hinaus wurde in diesem Untersuchungsbestand in den gleichen Zeitabständen wie der Freilandniederschlag auch die Kronentraufe bestimmt. Dazu waren 20 Niederschlagsmesser in einem 5 x 5 m - Raster auf einem Meßfeld von 20 x 15 m in 1 m Höhe aufgestellt worden.

Für die Bestände Göttinger Wald, Lüneburger Heide und Solling konnte auf Niederschlagswerte zurückgegriffen werden, die von der Niedersächsischen forstlichen Versuchsanstalt durch wöchentliche Messungen des Freilandniederschlages auf den Untersuchungsflächen erhoben und zur Verfügung gestellt wurden.

\section{Globalstrahlung, PAR, Lufttemperatur, Luftfeuchte}

Im Ziegelrodaer Forst wurden die photosynthetisch aktive Strahlung (PAR) mit einem Quantum-Sensor der Firma LI-COR (Lincoln NE, USA) gemessen. Dieser wurde mit einer in der Krone einer Buche senkrecht befestigten $6 \mathrm{~m}$ langen Aluminiumstange in einer Höhe von $32 \mathrm{~m}$ und somit also etwa $1 \mathrm{~m}$ oberhalb des Kronendaches angebracht. Lufttemperatur und relative Luftfeuchte wurden mit einem elektronischen Luftfühler des Typs YA-100 F Hygrometer (Firma Rotronic, Ettlingen Deutschland) bestimmt. Dieser war in $24 \mathrm{~m}$ Höhe im Kronenraum befestigt und durch ein nach unten offenes Stahlgehäuse gegen Strahlung und Regen abgeschirmt. Ein weiterer Temperatursensor in Form eines NTC-Widerstandes befand sich in 17 m Höhe. Diese Klima-Meßinstrumente wurden mit dem gleichen Daten-Logger wie die Bodenmeßstation angesteuert (Modell CR 10, Firma Campbell Scientific, Logan, Utah, USA). Messungen von Globalstrahlung, Lufttemperatur und relativer Luftfeuchte erfolgten im Minuten-Takt und wurden jeweils als 15-Minuten-Mittelwerte abgespeichert.

Die Ermittlung der Globalstrahlungswerte für den Bestand Ziegelrodaer Forst erfolgte anhand der dort gemessenen PAR-Strahlungswerte. In einer mehrjährigen Untersuchung des Strahlungshaushalts im Bestand Göttinger Wald stellte EHRHARDT (1988) für den Zeitraum der Vegetationsperiode ein weitgehend konstantes Verhältnis von PAR zu Globalstrahlung fest $\left(\mathrm{PAR}\left[\mathrm{mol} \mathrm{m}^{-2}\right] / \mathrm{G}\left[\mathrm{MJ} \mathrm{m}^{-2}\right]=1.85+/-0.06\right)$. Anhand dessen wurde das Globalstrahlungsregime des Bestandes Ziegelrodaer Forst für die Vegetationsperioden 1996 und 1997 aus den dort gemessenen PAR-Werten berechnet (vgl. Abb. 2-3 und Tab. 2-5).

Auf den anderen Untersuchungsflächen wurden Globalstrahlung, Lufttemperatur und Luftfeuchte auf den Meßtürmen über dem Bestand in $39 \mathrm{~m}$ (Göttinger Wald) bzw. 
$37 \mathrm{~m}$ (Lüneburger Heide) und $29 \mathrm{~m}$ Höhe (Solling) gemessen. Die entsprechenden Daten wurden durch das Institut für Bioklimatologie, Fakultät für Forstwissenschaften und Waldökologie der Universität Göttingen erhoben und zur Verfügung gestellt.

\section{Wasserdampf-Sättigungsdefizit der Luft}

Das Wasserdampf-Sättigungsdefizit der Luft (VPD) wurde aus den Werten der Lufttemperatur und der relativen Luftfeuchte mit der Magnus-Formel (G1. 3-1) berechnet:

$$
\begin{array}{ll}
\mathrm{VPD}=\mathrm{e}_{\mathrm{s}}-\mathrm{e}_{\mathrm{a}} \\
\text { mit } \quad \mathrm{e}_{\mathrm{s}}=610.8 \cdot 10^{(7.5 \cdot \mathrm{T}) /(237.3+\mathrm{T})} \quad \text { und } \quad \mathrm{e}_{\mathrm{a}}=\frac{\mathrm{e}_{\mathrm{s}} \cdot \mathrm{rF}}{100}
\end{array}
$$

VPD = Wasserdampf-Sättigungsdefizit der Luft [ Pa ]

$\mathrm{e}_{\mathrm{s}} \quad=$ Sättigungsdampfdruck bei gegebener Temperatur $[\mathrm{Pa}]$

$\mathrm{e}_{\mathrm{a}} \quad=$ aktueller Dampfdruck [ Pa ]

$\mathrm{T}=$ Temperatur $\left[{ }^{\circ} \mathrm{C}\right]$

$\mathrm{rF} \quad=$ relative Luftfeuchte $[\%]$

Für einen Vergleich von Klima- und Wasserhaushaltsparametern auf Tagesebene wurden Tagessummen der Globalstrahlung $\left[\mathrm{MJ} \mathrm{m}^{-2} \mathrm{~d}^{-1}\right]$ gebildet und für das WasserdampfSättigungsdefizit die Stundenmittelwerte der Tageshellphase (Globalstrahlung $>5 \mathrm{~J} \mathrm{~m}^{-2} \mathrm{~s}^{-1}$ ) zu Tageswerten $[\mathrm{kPa}]$ addiert.

\subsection{Messung des Bodenwasserzustandes}

\subsubsection{Messung von Bodenmatrixpotential und volumetrischem Boden- wassergehalt}

Als wichtige Kenngrößen des Bodenwasserhaushalts wurden das Bodenmatrixpotential $\left(\Psi_{\text {Boden }}\right)$ und der volumetrische Bodenwassergehalt $(\Theta)$ bestimmt. Auf den Untersuchungsflächen Ziegelrodaer Forst, Göttinger Wald und Lüneburger Heide wurde jeweils eine Bodenmeßstation in der Nähe eines Xylemsaftfluß-Meßbaumes installiert. Dazu wurde in $2 \mathrm{~m}$ Entfernung vom Stammfuß eines Meßbaumes ein etwa $2 \mathrm{mx} 1 \mathrm{~m}$ großes Meßfeld eingerichtet.

Das Bodenmatrixpotential wurde mit selbstgefertigten Druckaufnehmer-Tensiometern bestimmt, in denen ein piezoelektrischer Drucksensor über eine wasserbefüllte Keramikkerze $(2 \mathrm{~cm}$ x $5 \mathrm{~cm})$ mit den Bodenkapillaren in Kontakt steht. Auf jedem Boden-Meßfeld wurden insgesamt 10 Tensiometer in drei verschiedenen Meßtiefen eingebracht, in der geringsten Meßtiefe 4, in den größeren Meßtiefen je 3 Tensiometer. Die Tensiometer einer Meßtiefe hatten dabei jeweils einen Abstand von etwa 1-2 m. Um einen guten Kontakt der Keramikkerze zur Bodenmatrix zu gewährleisten ohne den Boden an der Kontaktstelle stark zu verändern, wurde die Höhlung für die Keramikkerze mit einem geschärften Rohr von gleichem Durchmesser aus dem Boden ausgestochen. Die Drucksensoren wurden vor Beginn der Messungen durch Anlegen einer Wassersäule geeicht. 
Der volumetrische Bodenwassergehalt des Mineralbodens wurde mit der TDR-Methode (time-domaine-reflectrometry) bestimmt (TOPP et al. 1980, HEIMOVAARA 1993). Dabei werden Metallstäbe in den Boden eingestochen, an denen elektromagnetische Impulse entlanglaufen. Gemessen wird die Laufgeschwindigkeit der Impulse, die von der Dielektrizitätskonstante des umgebenden Mediums abhängig ist. Da die Dielektrizitätskonstante von Wasser erheblich höher ist als die Dielektrizitätskonstanten von Luft und Bodenpartikeln, kann über die Impulsgeschwindigkeit der volumetrische Wassergehalt des Bodens ermittelt werden. Gemessen wurde mit einem TDR-System der Firma Imko (Ettlingen, Deutschland), dessen TDR-Sonden mit $10 \mathrm{~cm}$ langen Metallstäben ausgestattet waren. Dazu wurde jeweils an der baumabgewandten Seite der Boden-Meßfelder ein Profil gegraben und in die Profilwand 6 TDR-Sonden einstochen, je 2 Sonden in drei verschiedenen Meßtiefen. Die Sonden einer Meßtiefe hatten dabei jeweils einen Abstand von etwa $1 \mathrm{~m}$.

Meßwerte von Bodenmatrixpotential und volumetrischem Bodenwassergehalt wurden halbstündlich mit einem Daten-Logger (Modell CR 10, Firma Campbell Scientific, Logan, Utah, USA) aufgezeichnet.

Der volumetrische Bodenwassergehalt der organischen Auflage wurde gravimetrisch ermittelt. Dazu wurden entlang eines Transekts in 25-cm-Schritten von $0.5-2.25 \mathrm{~m}$ Abstand vom Stammfuß einer Buche 8 Parallelproben mit einem Wurzelbohrer (Durchmesser $5.5 \mathrm{~cm}$ ) bis zur Mineralbodengrenze ausgestochen. Anschließend wurde die Mächtigkeit der Streuauflageproben ermittelt, das Gewicht vor und nach Trocknung ( $48 \mathrm{~h}$ bei $105^{\circ} \mathrm{C}$ ) bestimmt und die Differenz als Wasservolumen auf das Probenvolumen bezogen.

Für die Untersuchungsfläche B1 im Solling konnte auf Meßwerte von Bodenmatrixpotential und volumetrischem Bodenwassergehalt zurückgegriffen werden, die durch das Institut für Bodenkunde und Waldernährung an der Forstlichen Fakultät der Universität Göttingen und die Niedersächsische Forstliche Versuchanstalt dort erhoben worden waren.

\subsubsection{Messung des Nutzwasservorrats}

Eine Bestimmung bzw. Abschätzung des Nutzwasseranteils der Böden auf den Untersuchungsflächen erfolgte soweit möglich (Meßbereich der Tensiometer) anhand der in Abb. 2-11 dargestellten Feld-pF-Kurven. Für den Bereich niedrigerer Matrixpotentiale wurde auf in diesem Abschnitt zuverlässig erscheinende Labor-pF-Kurven (BENECKE 1984, GERKE 1987, LEUSCHNER 1994) zurückgegriffen sowie auf Literaturangaben zur Charakteristik der Matrixpotential-Wassergehalts-Beziehungen verschiedener Bodenarten und daraus resultierenden Tot- und Nutzwasseranteilen (ARYA \& PARIS 1981, HAVERKAMP \& Parlange 1986, Kern 1995, SchaAp 1996, Scheffer \& Schachtschabel 1998, Fiedler 2001). 


\subsection{Messung biometrischer Parameter}

\subsubsection{Messung von Blattflächenindex, Bestandesblattmasse und morphologischen Blattparametern}

Durch das Aufstellen von 10 Streufangkübeln mit einer Öffnung von jeweils $0.28 \mathrm{~m}^{2}$ in einem Abstand von je $10 \mathrm{~m}$ entlang eines Transekts im geschlossenen Bestand konnte für alle Untersuchungsbestände jährlich der Blattflächenindex (LAI) erfaßt werden. Zusätzlich wurden morphologische Blattparameter vergleichend bestimmt.

Die Bestimmung der Einzelblattflächen erfolgte in den Jahren 1995 und 1996 mittels Blattflächen-Meßgerät 3050A/4 der Firma LI-COR bzw. 1997 durch Einscannen von Blättern und anschließender Analyse der Blattflächenparameter mit dem Programm Win Folia der Firma Regents Instruments Inc., Canada. Dabei wurden jeweils 50 zufällig ausgewählte Blätter aus jedem Streusammler, also 500 Blätter pro Bestand und Jahr vermessen. Durch anschließende Trocknung bei $105^{\circ} \mathrm{C}$ konnte über das Trockengewicht und die Blattflächen der Probeblätter das spezifische Blattgewicht berechnet werden. Das Auswiegen der Trockenmassen aller Blätter aus den Streusammlern erlaubte dann mit 10 Parallelen die Bestimmung der Bestandesblattmasse pro $\mathrm{m}^{2}$ Bodenfläche und mit Hilfe des spezifischen Blattgwichts die Ermittelung des LAI.

1997 wurde in den drei Untersuchungsbeständen mit Meßturm mit dem optischen Meßgerät LAI-2000 Canopy Analyzer der Firma LI COR die vertikale Zunahme des Blattflächenindex über den Kronenbereich gemessen. Das Meßgerät LAI-2000 unterschätzt in Laubwaldbeständen allerdings regelmäßig den tatsächlich vorhandenen absoluten LAI, wie zahlreiche Vergleichsmessungen des LAI über Streufänger mit anschließender Messung der Einzelblattflächen zeigen (FOETZKI 1998, VOß 1998, PRSKAwETZ \& LeXER 2000). Daher wurden die per LAI 2000 gemessenen LAI-Werte nur zur Bestimmung der relativen vertikalen Zunahme des Blattflächenindex über den Kronenbereich herangezogen und in ihrem absoluten Wert auf den als zuverlässig betrachteten per Streufänger bestimmten LAIGesamtwert korrigiert (CHASON et al. 1991, DUFRÊNE \& BRÉDA 1995).

Zur Bestimmung der vertikalen Änderung des LAI im Kronenraum wurde der Meßkopf des LAI 2000 mit einer $2.5 \mathrm{~m}$ langen Latte von den vier Seiten des Meßturms aus waagerecht in den Kronenraum gehalten und in jeder Position je 10 Parallelmessungen durchgeführt. Dies geschah im oberen Kronenraum in Höhenstufen von 1-2 m Abstand, im unteren Kronenraum z.T. in größeren Abständen. Dabei wurde der Winkel des optisch erfaßten Bereiches so eingeschränkt, daß ein Störeinfluß durch den Turmschatten sowie durch Kronenauflichtungen im Turmbereich weitgehend ausgeschlossen werden konnte. Auf der obersten Turmplattform über dem Bestand befand sich ein zweites, gleich geeichtes, gleich eingestelltes und gleich ausgerichtetes Gerät, von dem zu jedem Meßzeitpunkt synchron die Referenz-Beleuchtungsstärke des Himmels ohne Einfluß des Kronendachs gemessen wurde. Die Messungen wurden mittags bei gleichmäßig bewölktem Himmel und somit diffusem Licht durchgeführt. 


\subsubsection{Messung des Holz-Volumenzuwachses und Bestimmung des Holzvorrats}

Zur Bestimmung des Stammholzzuwachses wurden in jedem Untersuchungsbestand auf einer bestandesrepräsentativen Teilfläche von 0.3 - 1.0 ha die Brusthöhendurchmesser (BHD) aller Stämme durch Umfangmessung erfaßt. Nach Einteilen der Stämme in BHD-Klassen mit einer Klassenweite von $4 \mathrm{~cm}$ konnten anhand der Durchmesserklassenverteilung jedes Bestandes repräsentative Zuwachs-Meßklassen ausgewählt werden. Die ausgewählten Meßklassen deckten einen Anteil von 38-47\% aller vorhandenen Durchmesserklassen bzw. $41-56 \%$ der Stammzahl in den vier Untersuchungsbeständen ab.

Proportional dem Stammzahlanteil jeder ausgewählten Meßklasse am Gesamtbestand wurde an je 2 - 5 Bäumen der jeweiligen Durchmesserklasse in 1.3 m Höhe ein Zuwachsmaßband angebracht. Die Zuwachsmaßbänder aus Kunststoff mit geringem Temperaturausdehnungskoeffizienten saßen im gesamten Untersuchungszeitraum durch den Zug einer Feder stets gleichmäßig fest gespannt am Stamm und erlaubten mittels eines Nonius eine Meßgenauigkeit von $0.25 \mathrm{~mm}$ Umfangsänderung. Zur Vermeidung des Einflusses von Quellungseffekten der Rinde wurden die Zuwachswerte bis auf wenige Ausnahmen nur bei trockenen Stammoberflächen bestimmt. Um den saisonalen Verlauf des Stammholzzuwachses verfolgen zu können, wurden die Maßbänder während der Vegetationsperiode im Mittel alle 3 Wochen abgelesen.

Die Zuwächse der Durchmesserklassen, für die keine Maßbänder installiert waren, konnten durch lineare Regressionen mit jeweils hohem Bestimmtheitsmaß aus den Zuwächsen der Meßbaumklassen errechnet werden.

Aus den Brusthöhendurchmessern und Umfangsänderungen der Stämme auf den bestandesrepräsentativen Teilflächen konnten nun die Bestandesgrundfläche (Querschnittsfläche aller Stämme in $1.3 \mathrm{~m}$ Höhe) sowie der saisonale Grundflächenzuwachs pro ha berechnet werden.

Die Berechnung der Derbholz-Holzvolumina der Bestände erfolgte stammweise über Baumgrundfläche und Baumhöhe mittels der von BERGEL (1973) empirisch abgeleiteten Derbholz-Formzahl für Buche (Gl. 3-2).

(G1. 3-2) $\quad \mathrm{V}_{\mathrm{d}}=\mathrm{GF} \cdot \mathrm{h} \cdot \mathrm{F}_{\mathrm{d}}$

mit

$F_{d}=\left[0.4039-118.19 \cdot \mathrm{BHD}^{-3}+4.2 \cdot 10^{-6} \cdot \mathrm{BHD}^{2}+1.1267 \cdot \mathrm{h}^{-1}+1.7335 \cdot 10^{-3}\right]$

$\mathrm{V}_{\mathrm{d}} \quad=$ Derbholz-Volumen $\left[\mathrm{m}^{3}\right]($ Volumen Holz mit $\mathrm{d}>7 \mathrm{~cm})$

$\mathrm{GF}=$ Grundfläche $\left[\mathrm{m}^{2}\right]$ (Querschnittsfläche in $1.3 \mathrm{~m}$ Höhe)

$\mathrm{h}=$ Baumhöhe $[\mathrm{m}]$

$\mathrm{F}_{\mathrm{d}} \quad=$ Derbholz-Formzahl für Buche nach Bergel (1973)

$\mathrm{BHD}=$ Brusthöhendurchmesser [cm]

Die Baumhöhen wurden mit dem Höhenmesser PM-5/1520 der Firma Suunto, Finnland gemessen. Die Bestimmung von Baumhöhen im Bestand ist oft schwierig und daher vergleichsweise aufwendig. Andererseits besteht in der Regel eine enge Beziehung zwischen 
BHD und Höhe eines Baumes. Daher wurde in jedem Bestand an etwa 30 repräsentativ ausgewählten Bäumen außer dem BHD auch die Höhe bestimmt.

Aus diesen Daten lassen sich Funktionen zur Beschreibung sogenannter Bestandeshöhenkurven berechnen, wie sie von verschiedenen Autoren entwickelt wurden. Für die untersuchten Buchenbestände zeigte die Gleichung für Bestandeshöhenkurven nach Prodan (Gl. 3-3) (in KRAMER \& AKCA 1995) die beste Anpassung an die gemessenen Werte (NAGEL et al. 2000).

$$
\text { (Gl. 3-3) Gleichung nach PRODAN } \quad \mathrm{h}=1.3+\frac{\mathrm{BHD}^{2}}{\mathrm{a}+\mathrm{b} \cdot \mathrm{BHD}+\mathrm{c} \cdot \mathrm{BHD}^{2}}
$$

Mit den aus der Bestandeshöhenkurve abgeleiteten Baumhöhen konnten nun die DerbholzVolumina aller Einzelstämme auf den jeweils vermessenen Teilflächen berechnet werden (G1. 3-2). Das so bestimmte Derbholz-Volumen der repräsentativen Teilflächen erlaubte schließlich eine Hochrechnung des Derbholz-Volumens auf Bestandesebene in $\mathrm{m}^{3} \mathrm{ha}^{-1}$.

Mit dem Derbholz-Volumen wird nur Holz mit Durchmessern $>7 \mathrm{~cm}$ erfaßt. Auch das Reisholz $(\mathrm{d}<7 \mathrm{~cm})$ der Kronen nimmt jedoch einen nicht $\mathrm{zu}$ vernachlässigenden Teil des gesamten oberirdischen Holzvolumens eines Buchenbestandes ein (BURGER 1939, GARELKOV 1973, Ellenberg et al. 1986, Pellinen 1986). Strobel (in Vorber.) leitete aus biometrischen Daten von 29 im Rahmen des Internationalen Biologischen Programms (EllenBerg et al. 1986) im Solling geernteten Probebäumen und einem Probebaum aus dem Göttinger Wald eine Funktion zur Berechnung des Reisholzanteils bei Buchen her. Mit Hilfe dieser Funktion kann aus dem BHD eines Baumes der damit hoch korrelierte Reisholzanteil berechnet werden. Mit dem so ermittelten Reisholzanteil konnte bei bekanntem Derbholzvolumen schließlich der gesamte oberirdische Holzvorrat bzw. -zuwachs jedes Bestandes mit hinreichender Genauigkeit bestimmt werden.

\subsection{Messung von Blattwasser-Zustandsgrößen}

\subsubsection{Messung des Blattwasserpotentials}

Das Blattwasserpotential $\Psi$ wurde mit der Druckbombenmethode nach Scholander bestimmt (SCHOlAnder \& HAMmEl 1964, ScholANDER et al. 1965). Diese bietet die Möglichkeit, im Freilandeinsatz einfach und mit hinreichender Genauigkeit das Gesamtwasserpotential von Zweigen oder Blättern zu bestimmen (TURNER 1988).

Bei der Scholander-Methode wird das Druckpotential des Xylemwassers, also apoplastischen Wassers, in einem Pflanzenteil gemessen. Das osmotische Potential wie auch das Matrixpotential des Apoplasten sind in der Regel vernachlässigbar klein (TYREE \& JARVIS 1982). Unter der Annahme, daß sich beim Abschneiden eines Zweiges ein neues thermodynamisches Gleichgewicht zwischen den Wasserpotentialen im Symplasten und im Apoplasten einstellt, entspricht das gemessene Druckpotential des Xylemwassers demzufolge in guter Näherung dem symplastischen Gesamtwasserpotential (KOIDE et al. 1989). 
Zur Messung der Blattwasserpotentiale wurden aus verschiedenen Bereichen der Sonnenkrone Zweige mit 2 - 6 Blättern von den Meßtürmen aus mit einer scharfen Klinge abgetrennt. Im Bestand Ziegelrodaer Forst war es nur durch freies Klettern in der Krone und mit Hilfe eines speziell konstruierten, gut geschärften Zweigschneiders an einer Teleskopstange möglich, vergleichbare Proben aus dem Außenbereich der Sonnenkrone zu entnehmen.

Beim Abschneiden zieht sich aufgrund des Unterdrucks im Xylem gegenüber dem nun einwirkenden Atmosphärendruck die Wassersäule im Xylem zurück. Sofort nach dem Abschneiden wurden die Zweige in die Druckkammer der Scholanderbombe (PMSInstruments, Corvallis, USA) eingespannt. Daraufhin wurde der Druck in der Kammer mit Preßluft um etwa 0.1-0.2 $\mathrm{MPa} \mathrm{s}^{-1}$ langsam erhöht und die aus der Kammer ragende Schnittfläche währenddessen mit einer Lupe beobachtet. Der Kammerdruck, bei dem der wieder ansteigende Xylemsaft die Schnittfläche befeuchtete, wurde mit negativem Vorzeichen dem Blattwasserpotential gleichgesetzt.

Die pre-dawn-Werte des Blattwasserpotentials $\Psi_{\max }$ wurden kurz vor Dämmerungsbeginn gemessen. Die Tagesminima des Blattwasserpotentials $\Psi_{\min }$ wurden mittags zwischen 11.30 und 14.00 Uhr Ortszeit bestimmt.

\subsubsection{Druck-Volumen-Analyse}

Zur Bestimmung von Parametern des Blattwasserstatus in einer Druck-Volumen-Analyse wird mit der Druckbombe nach Scholander in ansteigenden Druckstufen sukzessive Wasser aus einer Pflanzenprobe gepreßt (SCHOLANDER et al. 1965, TYREE \& HAMMEL 1972). Wird dabei mit zunehmender Menge ausgepreßten Wassers der Turgornullpunkt überschritten, ist das Gesamtwasserpotential der Pflanzenprobe jenseits des Zustands der Grenzplasmolyse gleich dem osmotischen Potential.

Die Druck-Volumen-Beziehungen wurden an je vier am Vortag aus der Sonnenkrone genommenen Zweigproben mit 4-8 Blättern parallel gemessen. Die unter Wasser nachgeschnittenen Zweige konnten sich über Nacht aufsättigen. Vor Beginn der Messungen wurden die Zweige erneut angeschnitten und das Frischgewicht bestimmt. Um den Wasserverlust durch Transpiration in der Druckkammer während der Messungen zu minimieren, wurden die Zweige mit Plastikfolie dicht umhüllt. Die erfolgreiche Aufsättigung wurde durch eine erste Blattwasserpotentialmessung überprüft und Zweige mit $\Psi>-0.2 \mathrm{MPa}$ als gesättigt angenommen.

Daraufhin wurden die Proben 10 min lang einem Anfangsdruck von 0.4 MPa ausgesetzt und das an der Schnittfläche austretende Wasser in Plastikröhrchen mit Zellstoff aufgefangen und anschließend gewogen. Nach dem Auspreß-Vorgang wurde der Druck in der Kammer so weit abgesenkt, daß kein Wasser mehr austrat. In diesem Zustand konnte sich dann weitere 10 min lang ein neues Gleichgewicht zwischen apoplastischem und symplastischem Wasser einstellen.

Das durch den verminderten Wassergehalt veränderte Blattwasserpotential der Probe wurde nun in Form des Gleichgewichtsdruckes bestimmt, der bei nachfolgender Druckerhöhung im Moment erneut austretenden Wassers herrschte. Daraufhin wurde die nächste Druckstufe 
eingestellt und wiederum wie beschrieben verfahren. Zwischen dem Anfangsdruck von 0.4 MPa und 2.5 MPa wurde der Druck in Stufen von 0.3 MPa erhöht, danach in Stufen von $0.2 \mathrm{MPa}$, um durch eine höhere Auflösung die Bestimmung des Übergangs vom nichtlinearen in den linearen Abschnitt der Druck-Volumen-Kurve zu erleichtern. Die Messungen wurden bei einem Enddruck von 4.1 MPa beendet bzw. bei einem geringeren Druck, falls zuvor schon eine mechanische Schädigung der Probe erkennbar wurde.

Schließlich wurde die Probe erneut gewogen, um den gesamten Gewichtsverlust im Verlauf der Messung festzustellen. Aus der Differenz zwischen dem Gewichtsverlust der Probe und der Summe des ausgepreßten Wassers ergibt sich der Wasserverlust durch Transpiration während der Messung. Dieser wurde als gleichmäßig auf alle Druckstufen verteilt angenommen und dementsprechend den durch Auspressen in jeder Druckstufe entstandenen Wasserverlusten zugeschlagen. Abschließend wurden die Proben bei $105^{\circ} \mathrm{C}$ bis zur Gewichtskonstanz getrocknet. Über das Trockengewicht wurde schließlich der Gesamtwassergehalt $\mathrm{V}_{\mathrm{t}}$ der zu Beginn der Messung wassergesättigten Probe ermittelt.

Die Druck-Volumen-Kurve wird durch Auftragen des Kehrwerts der für die Druckstufen bestimmten Gleichgewichtsdrücke (= Gesamtwasserpotentiale) gegen die kumulative Menge ausgepreßten symplastischen Wassers $\mathrm{V}_{\mathrm{e}}$ erstellt (Abb. 3-1). Bis zum Turgornullpunkt wird das Gesamtwasserpotential $(\Psi)$ außer vom osmotischen Potential $\left(\Psi_{\Pi}\right)$ auch noch vom Turgor $\left(\Psi_{\mathrm{P}}\right)$ und somit von den elastischen Eigenschaften der Zellwand beeinflußt (Gl. 3-4). In diesem Bereich verläuft die Kurve nicht linear.

$$
\Psi=\Psi_{\Pi}+\Psi_{P}
$$

Jenseits des Turgornullpunktes entspricht das Gesamtwasserpotential dem osmotischen Potential des symplastischen Wassers. Der weitere Kurvenverlauf ist linear und läßt sich mit der Geradengleichung (3-5) beschreiben:

$$
\begin{aligned}
& \text { (Gl. 3-5) } \quad-\frac{1}{\Psi}=-\frac{1}{\Psi_{\Pi}}=\left(\mathrm{V}_{\mathrm{e}}-\mathrm{V}_{0}\right) \cdot \frac{1}{N \cdot R \cdot T}\left[\mathrm{MPa}^{-1}\right] \\
& \mathrm{V}_{0} \quad=\text { symplastisches Wasservolumen bei Sättigung [ml] } \\
& \mathrm{V}_{\mathrm{e}} \quad=\text { ausgepreßtes Wasservolumen [ml] } \\
& \mathrm{N} \quad=\text { Anzahl Mole gelöster osmotisch wirksamer Substanz [mol] } \\
& \left.\mathrm{R} \quad=\text { ideale Gaskonstante [MPa ml mol } \mathrm{K}^{-1}\right] \\
& \mathrm{T} \quad=\text { Temperatur [K] }
\end{aligned}
$$

Aus der Druck-Volumen-Kurve lassen sich eine Vielzahl von Wasserzustandsparametern ableiten (TYREE \& HAMMEL 1972, TYREE \& JARVIS 1982). In dieser Untersuchung wurden mit folgenden Analyseschritten aus den Druck-Volumen-Kurven Kennwerte des Blattwasserstatus ermittelt: 


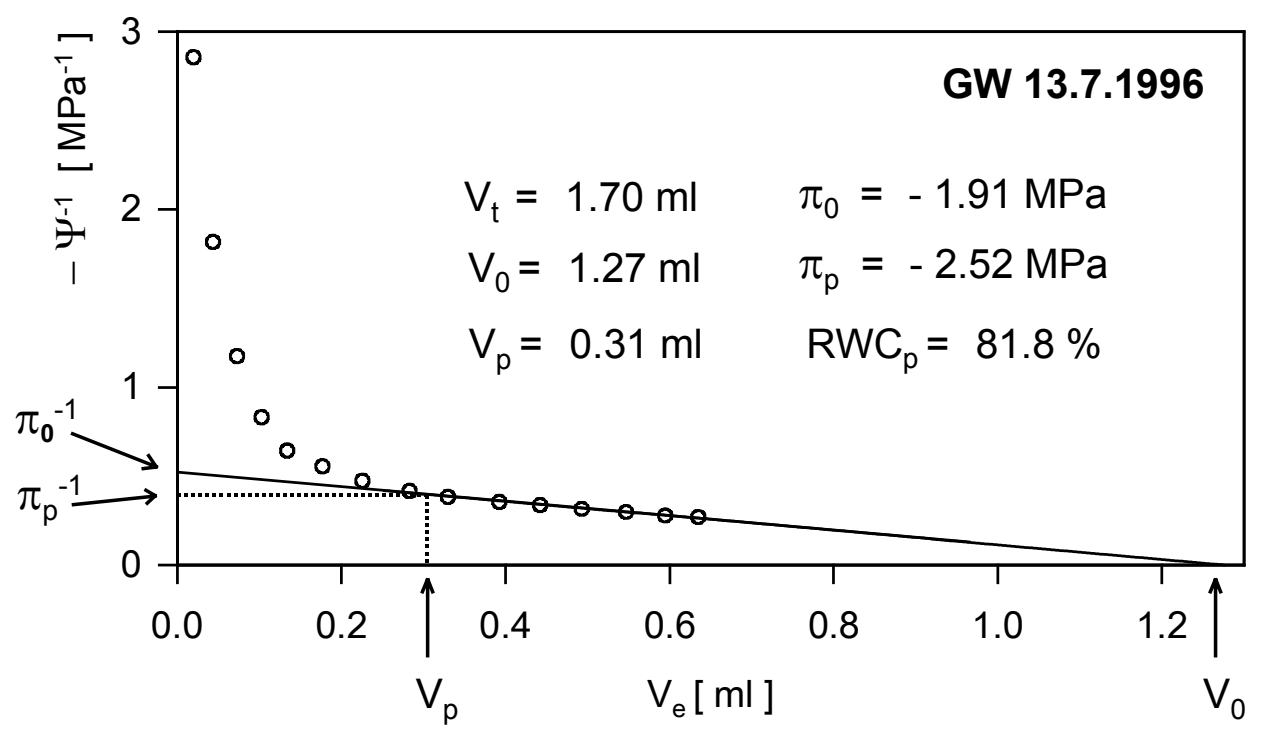

Abb. 3-1: $\quad$ Beispielkurve der Druck-Volumen-Analyse für eine Probe vom 13.7.1996 aus dem Bestand Göttinger Wald.

- Durch Extrapolation des linearen Kurvenabschnitts bis zum Schnittpunkt mit der Ordinate kann dort das osmotische Potential bei Wassersättigung $\pi_{0}$ abgelesen werden.

- Der beim Übergang vom nicht-linearen in den linearen Kurventeil herrschende Gleichgewichtsdruck entspricht dem osmotischen Potential bei Grenzplasmolyse $\pi_{\mathbf{p}}$.

- Mit der bis zur Grenzplasmolyse ausgepreßten Menge Wasser $V_{p}$ und dem Gesamtwassergehalt der Probe $V_{t}$ kann nach Gleichung (3-6) der relative Wassergehalt bei Grenzplasmolyse RWCp bestimmt werden.

$$
\text { RWCp }=1-\frac{V_{p}}{V_{t}}
$$

Um die Grenze zwischen dem nicht-linearen und dem linearen Kurvenabschnitt zu ermitteln, wurden lineare Regressionen berechnet. Dabei wurde ausgehend von den letzten drei Punkten der Kurve sukzessive jeweils ein weiterer Punkt in die Regressionsrechnung mit einbezogen. Nach WiLLERT et al. (1995) wird mit dem zuletzt hinzugenommenen Datenpaar dann der nicht-lineare Kurventeil erreicht, wenn der Korrelationskoeffizient der neuen Regression signifikant von demjenigen der vorherigen abweicht.

Die ausschließlich anhand dieser Kriterien durchgeführte Identifikation des linearen und des nicht-linearen Kurvenabschnitts war jedoch dann zum Teil offensichtlich falsch oder unmöglich, wenn die Punkte eine starke Streuung um die berechneten Geraden aufwiesen und die Irrtumswahrscheinlichkeiten der linearen Regressionen somit vergleichsweise hoch waren. Hier erschien es sinnvoll, auf eine optische Beurteilung des Kurvenverlaufs und der linearen Anpassungen zurückzugreifen. Nach WILLERT et al. (1995) erlaubt dies in der Regel jedoch ebenfalls eine hinreichende Genauigkeit. 


\subsection{Messung von Transpiration und Blattleitfähigkeit}

\subsubsection{Porometrische Messung von Transpiration und Blattleitfähigkeit}

Die Blatttranspirationsraten und Blattleitfähigkeiten für Wasserdampf wurden mit einem Steady-State-Porometer LI 1600M (Firma LI-COR, Lincoln NE, USA) bestimmt.

Vor Beginn der eigentlichen Messung am Blatt wird zunächst mit dem Feuchtefühler in einer offenen und ventilierten Meßkammer die Außenluftfeuchte gemessen. Die Außenluftfeuchte wird als Sollwert, der in der folgenden Messung in der Meßkammer aufrechterhalten wird, elektronisch gespeichert. Mittels einer Klemme kann nun ein Blatt dicht auf die Öffnung der Meßkammer gespannt werden. Da Buchenblätter hypostomatisch sind, wird hierbei die Blattunterseite der Meßkammer zugewandt. Der aus dem Blatt transpirierende Wasserdampf führt zunächst zu einer Erhöhung der Luftfeuchte in der Meßkammer, die jedoch durch einen regulierbaren Zustrom trockener Luft kompensiert werden kann. Die zuströmende trockene Luft ist Außenluft, die zuvor beim Durchströmen von Silicagel ihre Feuchtigkeit abgegeben hat. So können mit Hilfe des Feuchtefühlers in der Meßkammer Steady-State-Bedingungen mit Außenluftfeuchte und Außentemperatur eingestellt werden.

Die Blatttranspirationsrate wird bestimmt durch die Messung der Menge einströmender Trockenluft, die eine entsprechende der Blatttranspiration entstammende Menge Wasserdampf aus der Meßkammer verdrängen und dort somit eine konstante Luftfeuchte aufrechterhalten kann (Gl. 3-7).

$$
\mathrm{E}=\frac{\mathrm{N}_{\mathrm{tr}} \cdot \mathrm{e}}{\mathrm{t} \cdot \mathrm{P} \cdot \mathrm{A}}
$$

$\mathrm{E}=$ Transpirationsrate $\left[\mathrm{mmol} \mathrm{m} \mathrm{m}^{-2} \mathrm{~s}^{-1}\right]$

$\mathrm{N}_{\mathrm{tr}} \quad=$ Menge in die Meßkammer strömende Trockenluft [ mmol ]

e $\quad=$ Wasserdampf-Partialdruck der Außenluft [ $\mathrm{Pa}$ ]

$\mathrm{t} \quad=$ Zeit $[\mathrm{s}]$

$\mathrm{P} \quad=$ aktueller Luftdruck [ $\mathrm{Pa}$ ]

$\mathrm{A} \quad=$ Blattfläche in Kontakt mit dem Meßkammer-Innenraum $\left[\mathrm{m}^{-2}\right]$

Dabei ist $\mathrm{zu}$ beachten, daß die Temperatur in der Meßkammer, die dort von einem Thermoelement gemessen wird, der Außenlufttemperatur entspricht. Eine Strahlungsabschirmung sowie eine äußere Ventilation der Meßkammer gewährleisten dies weitgehend. Die Blattleitfähigkeit für Wasserdampf kann nun mit Hilfe der WasserdampfPartialdruck-Differenz zwischen dem Blattinneren und der umgebenden Luft $(\Delta \mathrm{w})$ ermittelt werden (Gl. 3-8).

$$
\mathrm{g}=\frac{\mathrm{E}}{\Delta \mathrm{w}} \quad \text { mit } \quad \Delta \mathrm{w}=\frac{\mathrm{e}_{\text {Blatt }}-\mathrm{e}}{\mathrm{P}}
$$

$$
\begin{array}{ll}
\mathrm{g} & =\text { Blattleitfähigkeit für Wasserdampf }\left[\mathrm{mmol} \mathrm{m}^{-2} \mathrm{~s}^{-1}\right] \\
\Delta \mathrm{W} & =\text { Wasserdampf-Partialdruck-Differenz Blattinneres/Umgebungsluft }[\mathrm{Pa}] \\
\mathrm{e}_{\text {Blatt }} & =\text { Wasserdampf-Partialdruck in den Blattinterzellularen [ Pa }] \\
\mathrm{e} & =\text { Wasserdampf-Partialdruck der Außenluft [ Pa }] \\
\mathrm{P} & =\text { aktueller Luftdruck [ } \mathrm{Pa}]
\end{array}
$$


Der Wasserdampf-Partialdruck in den Blattinterzellularen ergibt sich wiederum aus der Annahme wasserdampfgesättigter Luft im Blattinneren (WILLERT et al. 1995) und der Blattemperatur, die während der Transpirationsmessung mit einem Thermoelement an der Blattoberfläche bestimmt wird.

Das Meßgerät besitzt nach Herstellerangabe in der Meßkammer einen konstante Grenzschicht-Leitfähigkeit von $6.7 \mathrm{~cm} \mathrm{~s}^{-1}$. Eine Korrektur um diese GrenzschichtLeitfähigkeit findet bei dem in den Messungen eingesetzten Geräte-Typ M des Porometers LI-1600 nicht statt. Die konstante Grenzschicht-Leitfähigkeit ist jedoch in der Regel um ein bis zwei Größenordnungen höher als die stomatäre Leitfähigkeit. Zugleich übersteigt die stomatäre Leitfähigkeit die kutikuläre Leitfähigkeit eines Blattes um mehrere Größenordnungen (SCHREIBER et al. 1996). Daher kann die gemessene Blattleitfähigkeit in guter Näherung der stomatären Leitfähigkeit gleichgesetzt werden und als Maß für die mittlere Öffnungsweite der Stomata eines Blattes gelten (WILLERT et al. 1995, LÖSCH 2001).

Die Bestimmung der Blatt-Transpirationsraten und Blattleitfähigkeiten erfolgte jeweils an 4 - 6 Blättern als Parallelen. Wurden zusätzlich auch Blattwasserpotentiale bestimmt (vgl. Kap. 3.4.1), geschah dies direkt nach den porometrischen Messungen an denselben Blättern.

\subsubsection{Xylem-Saftflußmessung und Bestimmung der Bestandestranspiration}

Zur Bestimmung der Bestandestranspiration wurden Xylem-Saftflußmessungen mit der Tissue Heat Balance (THB) Methode nach CERMAK et al. (1973 und 1976) durchgeführt. Diese erlaubt eine kontinuierliche Massenfluß-Messung des Xylemsaftes im Stamm und damit die Bestimmung der vom Baum durch Transpiration abgegebenen Wassermenge.

Bei der Installation des eingesetzten Meßsystems P 690.3 (Fa. EMS, Brno, Tschech. Rep.) werden 5 Plattenelektroden im Abstand von jeweils $2 \mathrm{~cm}$ parallel zueinander so tief in den Stamm eingeschlagen, daß sie das leitende Splintholz möglichst vollständig durchdringen. Die Insertionstiefe ist dabei nach einem für die Installation entwickelten Schema zur Abschätzung der Splintholziefe abhängig von Ring- oder Zerstreutporigkeit der untersuchten Art, Baumalter und Stammdurchmesser zu wählen. Sie betrug dementsprechend in dieser Untersuchung 28 - 56 mm Splintholztiefe plus Phloem- und Borkenstärke.

An die Elektroden wird eine Wechselspannung $(1 \mathrm{kHz})$ angelegt. Das zwischen den Elektroden liegende Xylem fungiert als Heizwiderstand und wird mit einer konstanten Heizleistung von $1 \mathrm{~W}$ erwärmt. Fließt Xylemsaft durch das Heizfeld zwischen den Elektroden, nimmt dieser Wärmenergie auf und transportiert sie nach oben ab. Eine von CERMAK \& KUCERA (1981) entwickelte Anordnung von 8 Thermoelementen ermittelt die Differenz zwischen der Temperatur des unbeheizten Xylems unterhalb des Heizfeldes und der Maximaltemperatur des Xylems in dem erzeugten Wärmefeld, gemessen an der Oberkante des Heizfeldes zwischen den Elektroden. Bei konstanter Heizleistung ist unter diesen Voraussetzungen die von den Thermoelementen in Form einer Thermospannung gemessene Temperaturdifferenz umgekehrt proportional zur Saftflußrate im Xylem. Aus Heizleistung, Temperaturdifferenz und der spezifischen Wärmekapazität von Wasser kann so der Massenfluß des Xylemsaftes nach Gleichung (3-9) berechnet werden. 


$$
\mathrm{Q}=\frac{\mathrm{P} \cdot 3600}{\mathrm{dT} \cdot \mathrm{cw} \cdot(\mathrm{n}-1) \cdot \mathrm{d}} \quad \text { mit } \quad \mathrm{dT}=\frac{\mathrm{U}}{\mathrm{k}_{T E}}
$$

$\mathrm{Q} \quad=$ Saftflußrate pro $\mathrm{cm}$ Xylemumfang $\left[\mathrm{kg} \mathrm{h}^{-1} \mathrm{~cm}^{-1}\right]$

$\mathrm{P} \quad=$ Heizleistung $(1 \mathrm{~W})$

$\mathrm{cW} \quad=$ spezif. Wärmekapazität Wasser $\left(4187 \mathrm{~J} \mathrm{~kg}^{-1} \mathrm{~K}^{-1}\right)$

$\mathrm{n} \quad=$ Anzahl Heizelektroden (5)

$\mathrm{d}=$ Abstand zwischen den Heizelektroden $(2 \mathrm{~cm})$

$\mathrm{dT}=$ Temperaturdifferenz beheiztes / unbeheiztes Xylem [ $\mathrm{K}$ ]

$\mathrm{k}_{T E}=$ Temperaturkoeffizient der Thermoelement-Anordnung $\left(80 \mu \mathrm{V} \mathrm{K}^{-1}\right)$

$\mathrm{U} \quad=$ Thermospannung $[\mu \mathrm{V}]$

Ein eventueller Massenfluß im Phloem ist dabei aufgrund seiner minimalen Größenordnung gegenüber dem Xylem-Saftfluß vernachlässigbar.

Der Datalogger in der zentralen Steuereinheit des Meßsystems erfaßte jede Minute die an den Thermoelementen eines Meßpunktes gemessene Thermospannung und speicherte jeweils Mittelwerte über 15 Minuten ab. Mit Hilfe eines zum Meßsystem gehörigen ComputerProgrammes (EMS P63) konnten die Thermospannungs-Rohdaten ausgelesen und daraus direkt (Gl. 3-9) die auf den Xylemumfang bezogenen spezifischen Saftflußraten $\left[\mathrm{kg} \mathrm{h}^{-1} \mathrm{~cm}^{-1}\right]$ berechnet werden. Die Multiplikation dieser spezifischen Saftflußrate mit dem Xylemumfang (aus Stammradius abzüglich Rindenstärke) des Baumes in Höhe des Meßpunktes ergibt schließlich die Saftflußrate des Meßbaumes $\left[\mathrm{kg} \mathrm{h}^{-1}\right]$. Die so ermittelte apparente Saftflußrate muß jedoch noch um den Betrag eines fiktiven Flusses korrigiert werden. Dieser kommt zustande durch saftflußunabhängige Wärmeverluste an die Umgebung des Meßpunktes. Die Nullinie in Form dieses fiktiven Flusses kann durch die Thermospannung bestimmt werden, die gemessen wird, wenn in der Nacht nach Wiederaufsättigung des Baumes oder in Perioden langanhaltender Niederschläge der Saftfluß zum Stillstand kommt.

Die Saftflußdichten im Xylem können sich auf verschiedenen Seiten desselben Stammes erheblich unterscheiden (LANG 1999). Daher wurden an jedem Meßbaum zwei Meßpunkte auf gegenüberliegenden Stammseiten installiert und aus den beiden Saftflußraten ein Mittelwert für den Meßbaum gebildet. Es wurden sowohl Ost-West als auch Nord-Süd orientierte Meßpunktpaare angebracht. Dabei wurden Unregelmäßigkeiten von Holz und Rinde wie etwa Frostrisse oder Totäste im Bereich des Meßfeldes vermieden.

Die Meßsysteme wurden in 2-3 m Höhe installiert. Dadurch werden untypische Xylemausbildungen und der besonders große natürliche Temperaturgradient des Xylemsafts im Stammfußbereich sowie starke Temperaturschwankungen in Bodennähe ausgeschlossen. Um von außen induzierten Temperaturschwankungen entgegenzuwirken, wurden zudem die Stämme in einem etwa 1m mächtigen Bereich um die Meßpunkte mit Schaumstoffmatten isoliert und durch Aluminiumbleche bis zum Stammfuß gegen Strahlungseinwirkung geschützt. Eine mit Harz um den Stamm abgedichtete Polyethylenfolie verhinderte das Eindringen von Regen und Stammabflußwasser.

Auf jeder Untersuchungsfläche wurden 6 die Durchmesserklassenverteilung des Bestandes möglichst gut repräsentierende Bäume ausgewählt und mit je zwei Saftfluß-Meßpunkten versehen. Bei Ausfällen einzelner Meßpunkte für einige Tage etwa infolge von Mäusen durchnagter Kabel, Blitzschlag oder Solarenergiemangel konnten die fehlenden Daten gut aus 
den Meßwerten des jeweils gegenüberliegenden Meßpunktes rekonstruiert werden. Die Saftflußraten gegenüberliegender Meßpunkte eines Baumes sind auf Ebene von Tagessummen über lineare Beziehungen hoch korreliert. Beim Ausfall beider Meßpunkte eines Baumes erfolgte in einigen Fällen in analoger Weise auch eine Datenrekonstruktion über die Meßwerte von Bäumen der nächstliegenden BHD-Klassen.

Zur Extrapolation der Saftfluß-Tagessummen der Einzelbäume auf den Bestand wurde nach CERMAK \& KuCERA (1986) die Grundfläche der jeweils 6 Meßbäume zu der Grundfläche des Bestandes in Beziehung gesetzt (vgl. Kap. 2.3). Dazu wurden für jeden Monat der Vegetationsperiode die mittleren Saftflußraten der 6 Meßbäume berechnet und über eine lineare Regression auf deren Stammquerschnittsflächen (Grundflächen) bezogen. Diese Beziehungen waren in der Regel hoch korreliert $(r=0.75$ bis $r=0.99)($ Abb. 3-2).
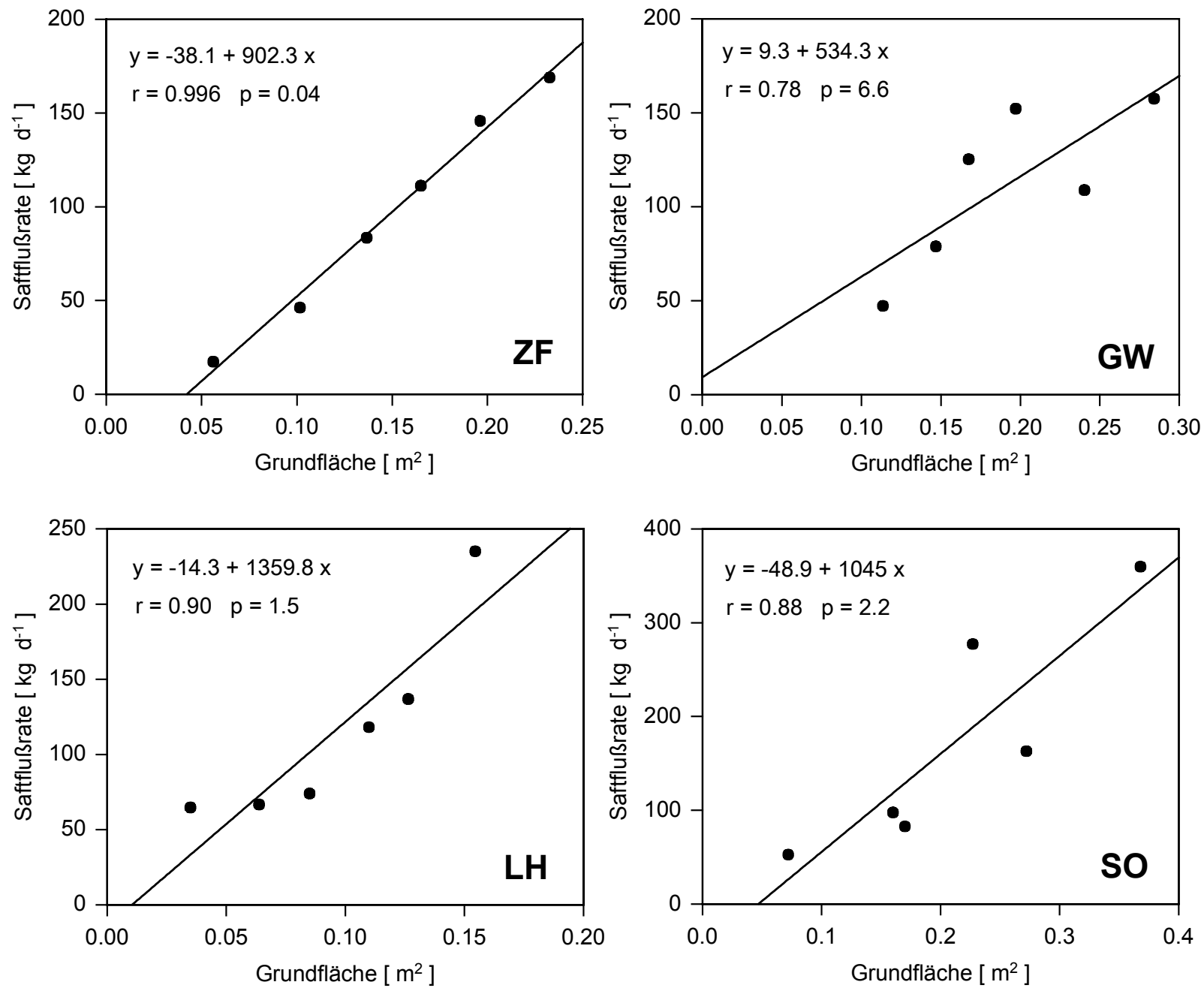

Abb. 3-2: Beziehungen der mittleren monatlichen Saftflußraten zu den Grundflächen der Meßbäume für die Hochrechnung der Einzelbaum-Saftflußraten auf Bestandesebene. Hier exemplarisch für Juli 1996 in den Beständen Ziegelrodaer Forst (ZF), Göttinger Wald (GW), Lüneburger Heide (LH) und Solling (SO).

Mithilfe dieser Korrelation konnten auch die mittleren Saftflußraten für die Bäume derjenigen BHD-Klassen berechnet werden, die nicht durch Saftfluß-Meßbäume repräsentiert waren. 
Eine solche Herleitung der nicht direkt gemessenen mittleren Saftflußraten über die Korrelation mit den Baum-Grundflächen führte für Bäume sehr geringer Durchmesser jedoch bisweilen zu negativen Saftflußraten. Diese wurden dann trotz eines nur sehr geringen Einflusses auf das Ergebnis in die weitere Berechnung der Bestandestranspiration nicht einbezogen.

Die Multiplikation der für die einzelnen BHD-Klassen eines Bestandes ermittelten grundflächenbezogenen Saftflußraten mit den Grundflächen der jeweiligen BHD-Klassen pro Hektar ergibt die Saftflußraten der BHD-Klassen pro Hektar. Die Summe der Saftflüsse aller BHD-Klassen des Bestandes entspricht schließlich der Transpiration des Gesamtbestandes.

\subsection{Statistische Auswertung der Daten}

Die Parameter einfacher linearer Regressionen und quadratischer Kurvenanpassungen wurden mit dem Computerprogramm Xact (Firma SciLab, Hamburg) bestimmt. Multiple lineare Regressionen wurden mit dem Computerprogramm SAS durch schrittweises Einbeziehen derjenigen Parameter, die die erklärbare Varianz in einem Modell signifikant erhöhen konnten, berechnet.

SAS wurde auch für weitergehende statistische Testverfahren verwendet. Dazu wurde zunächst mit dem Anpassungstest nach Shapiro und Wilk geprüft, ob bei den zu testenden Meßdaten Normalverteilung vorlag. Um signifikante Unterschiede zwischen Mittelwerten zu bestimmen, wurde bei normalverteilten, unabhängigen Stichproben der Test nach Scheffé durchgeführt. Lag keine Normalverteilung vor, wurden die verteilungsunabhängigen Testverfahren nach van der Waerden für abhängige, bzw. der Wilcoxon-U-Test nach Mann und Whitney für unabhängige Stichproben durchgeführt. 


\section{Ergebnisse}

\subsection{Blattflächenindex, Bestandesblattmasse und morphologische Blatt- parameter}

Die vier untersuchten Buchenbestände wiesen zum Teil deutliche Unterschiede im Blattflächenindex (LAI) und in den morphologischen Blattparametern auf. Die Unterschiede dieser Parameter innerhalb eines Bestandes zwischen verschiedenen Meßjahren blieben dagegen zumeist gering (Tab 4-1).

Tab. 4-1: Blattflächenindices und morphologische Blattparameter in den Untersuchungsbeständen Ziegelrodaer Forst (ZF), Göttinger Wald (GW), Lüneburger Heide (LH) und Solling (SO) für die Untersuchungsjahre 1995 - 1997. Angaben für Solling 1995 und 1996 nach HEIMANN (unveröffentlicht).

In Mischbeständen wurden jeweils die Summe der LAI-Werte von Buche und anderen Laubbaumarten sowie die Summe der Bestandes-Blattmassen von Buche und anderen Laubbaumarten angegeben; Einzelblattflächen sowie spezifisches Blattgewicht nur für Buchenblätter angegeben. Unterschiedliche Großbuchstaben kennzeichnen signifikante Unterschiede zwischen Untersuchungsjahren, unterschiedliche Kleinbuchstaben kennzeichnen signifikante Unterschiede zwischen Untersuchungsbeständen (Mittelwertsvergleich nach Scheffé, $\mathrm{p}<0.05)$.

LAI (leaf area index): $\mathrm{m}^{2}$ Blattfläche je $\mathrm{m}^{2}$ Bodenfläche

spezifisches Blattgewicht: g Trockengewicht je $\mathrm{m}^{2}$ Blattfläche

Bestandes-Blattmasse: $\quad$ g Trockengewicht je $\mathrm{m}^{2}$ Bodenfläche

\begin{tabular}{|c|c|c|c|c|c|}
\hline & & ZF & GW & LH & so \\
\hline $\begin{array}{c}\text { LAI }\left[\mathrm{m}^{2} \mathrm{~m}^{-2}\right] \\
\text { (Gesamtbestand) }\end{array}$ & $\begin{array}{l}95 \\
96 \\
97 \\
\varnothing\end{array}$ & $\begin{array}{c}\mathrm{A} 9.0 \pm 1.0^{\mathrm{a}} \\
{ }^{\mathrm{A}} 8.3 \pm 1.5^{\mathrm{e}} \\
\mathrm{A}^{\mathrm{A}} 8.5 \pm 1.2^{\mathrm{j}} \\
\mathbf{8 . 6} \pm \mathbf{0 . 4}\end{array}$ & $\begin{array}{c}{ }^{\mathrm{A}} 6.2 \pm 0.6^{\mathrm{b}} \\
{ }^{\mathrm{A}} 6.3 \pm 0.4^{\mathrm{f}} \\
{ }^{\mathrm{A}} 6.8 \pm 0.8^{\mathrm{k}} \\
6.4 \pm \mathbf{0 . 3}\end{array}$ & $\begin{array}{l}{ }^{\mathrm{A}} 6.7 \pm 1.5^{\mathrm{b}} \\
{ }^{\mathrm{A}} 7.2 \pm 0.8{ }^{\mathrm{f}} \\
{ }^{\mathrm{A}} 6.8 \pm 0.8 \mathrm{k} \\
\mathbf{6 . 8} \pm \mathbf{0 . 3}\end{array}$ & $\begin{array}{l}{ }^{A} 7.0 \\
{ }^{A} 6.5 \pm 0.9 \\
{ }^{A} 6.5 \pm 0.5 \\
6.7 \pm 0.3\end{array}$ \\
\hline $\begin{array}{c}\text { Blattgröße }\left[\mathrm{cm}^{2}\right] \\
\text { (nur Buchen) }\end{array}$ & $\begin{array}{l}95 \\
96 \\
97 \\
\varnothing\end{array}$ & 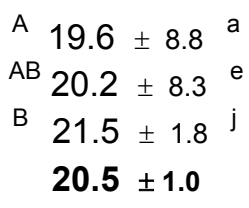 & $\begin{array}{c}A 16.5 \pm 7.2 \\
A B \\
A 7.5 \pm 6.3 \\
B \quad 18.9 \pm 1.8 \\
17.6 \pm 1.2\end{array}$ & 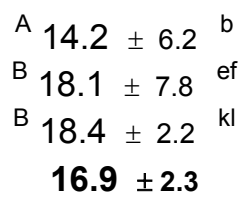 & $\begin{array}{c}- \\
\text { A } 14.3 \pm 7.8 \\
A 14.7 \pm 1.1 \\
14.5 \pm 0.3\end{array}$ \\
\hline $\begin{array}{c}\text { spezifisches } \\
\text { Blattgew. }\left[\mathrm{g} \mathrm{m}^{-2} \text { ] }\right. \\
\text { (nur Buchen) }\end{array}$ & $\begin{array}{l}95 \\
96 \\
97 \\
\varnothing\end{array}$ & $\begin{array}{c}{ }^{A} 37.9 \pm 4.0 \\
{ }^{B} 45.5 \pm 4.7 \\
{ }^{B} 42.3 \pm 4.2 \\
41.9 \pm 3.8\end{array}$ & $\begin{array}{c}{ }^{A} 45.0 \pm 2.8^{b} \\
{ }^{B} 51.0 \pm 1.5^{f} \\
{ }^{B} 50.4 \pm 4.1^{k} \\
48.8 \pm 3.3\end{array}$ & $\begin{array}{c}{ }^{A} 49.4 \pm 6.2 \\
{ }^{B} 41.5 \pm 2.3 \\
{ }^{B} 42.5 \pm 6.1 \\
44.5 \pm 4.3\end{array}$ & $\begin{array}{c}- \\
\mathrm{A} 48.9 \pm 2.6 \\
\mathrm{~A} 50.2 \pm 3.7 \\
\mathbf{4 9 . 6} \pm \mathbf{0 . 9}\end{array}$ \\
\hline $\begin{array}{c}\text { Blattmasse } \\
{\left[\mathrm{g} \mathrm{m}^{-2}\right]} \\
\text { (Gesamtbestand) }\end{array}$ & $\begin{array}{l}95 \\
96 \\
97 \\
\varnothing\end{array}$ & $\begin{array}{r}A 33 \pm 36 \\
{ }^{A} 380 \pm 78 \\
{ }^{A} 358 \pm 28 \\
360 \pm 19\end{array}$ & $\begin{array}{c}A 277 \pm 17^{\mathrm{b}} \\
\mathrm{B}^{\mathrm{B}} 321 \pm 23^{\mathrm{f}} \\
\mathrm{B} 338 \pm 24^{\mathrm{jk}} \\
312 \pm 32\end{array}$ & $\begin{array}{c}\mathrm{A}_{350} \pm 50 \mathrm{a} \\
\mathrm{A}_{335} \pm 53 \text { ef } \\
\mathrm{A}_{318} \pm 30 \mathrm{k} \\
336 \pm 14\end{array}$ & $\begin{array}{c}- \\
A_{317 \pm 43}^{f} \\
A^{A} 27 \pm 24 \\
322 \pm 7\end{array}$ \\
\hline
\end{tabular}


Bei einem Vergleich der Blattflächenindices 1995 - 1997 fiel der Bestand Ziegelrodaer Forst in allen Untersuchungsjahren durch die deutlich höchste Blattfläche pro Bodenfläche auf und erreichte im Mittel einen LAI von 8.5. Die anderen Untersuchungsbestände zeigten mit mittleren LAI-Werten von 6.4 - 6.8 Blattflächenindices auf einem einheitlichen und deutlich niedrigeren Niveau. Für den Bestand Ziegelrodaer Forst wurde in den Jahren 1996 und 1997 mit einer mittleren Blattgröße von $20.9 \mathrm{~cm}^{2}$ auch die im Mittel größte Einzelblattfläche bestimmt. Demgegenüber fiel der Bestand Solling bei einer mittleren Blattgröße von $14.5 \mathrm{~cm}^{2}$ durch die deutlich kleinsten Blätter auf. Die Bestände Göttinger Wald und Lüneburger Heide nahmen mit mittleren Blattgrößen von $18.1 \mathrm{~cm}^{2}$ bzw. $18.3 \mathrm{~cm}^{2}$ eine Mittelstellung ein. Der Bestand Ziegelrodaer Forst besaß zudem im Mittel der Jahre 1996 und 1997 mit 43.8 g Trockengewicht pro $\mathrm{m}^{2}$ ein vergleichsweise geringes spezifisches Blattgewicht ebenso wie der Bestand Lüneburger Heide mit $42.0 \mathrm{~g} \mathrm{TG} \mathrm{m}^{-2}$. Die Bestände Göttinger Wald und Solling wiesen mit $50.7 \mathrm{~g} \mathrm{TG} \mathrm{m}^{-2}$ und $51.4 \mathrm{~g} \mathrm{TG} \mathrm{m}^{-2}$ ähnlich hohe spezifische Blattgewichte auf.

Im Mittel der Jahre 1996 und 1997 erreichten die Bestände Göttinger Wald, Lüneburger Heide und Solling mit Werten um $330 \mathrm{~g} \mathrm{TG} \mathrm{m}^{-2}$ sehr ähnliche mittlere Bestandesblattmassen. Hiervon wich wie schon beim LAI nur der Bestand Ziegelrodaer Forst mit einer höheren mittleren Bestandesblattmasse von $362 \mathrm{~g} \mathrm{TG} \mathrm{m}^{-2} \mathrm{ab}$.

1997 wurde in den drei mit einem Meßturm ausgestatteten Untersuchungsbeständen die vertikale Zunahme des Blattflächenindex über den Kronenbereich bestimmt. Dabei zeigte sich an allen untersuchten Standorten im Kronenraum ein ähnliches Muster der kumulativen Zunahme des LAI mit abnehmender Höhe (Abb. 4-1).
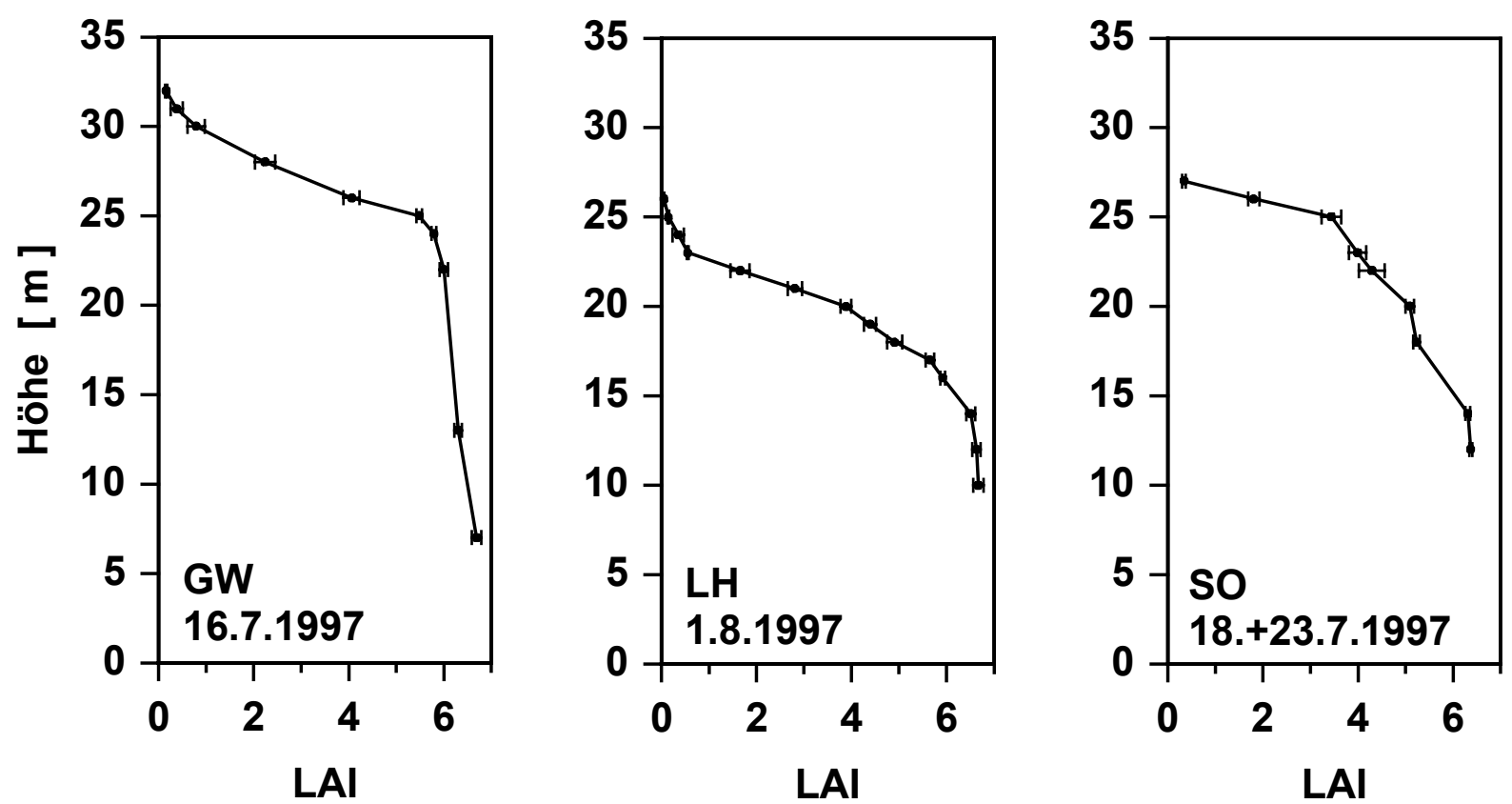

Abb. 4-1: Kronenraum-Höhenprofil des kumulativen Blattflächenindex im Hochsommer 1997 für die Untersuchungsbestände Göttinger Wald (GW), Lüneburger Heide (LH) und Solling (SO).

Auf einen Bereich bis etwa $2-3 \mathrm{~m}$ unterhalb der Kronenspitzen, in dem der LAI nur mäßig auf einen Wert von etwa 0.5 - 1 ansteigt, folgt eine etwa 6-8 m mächtige Schicht mit einer starken nahezu linearen Zunahme des LAI auf einen kumulativen Wert um 6. Darunter erstreckt sich 
nach einer nur 2-3 m mächtigen relativ abrupten Übergangszone ein Bereich äußerst geringer LAI-Zunahme. Bereits etwa $10 \mathrm{~m}$ über der Bodenoberfläche erreicht der LAI nahezu den maximalen Endwert.

In dem zum Teil schon zusammenbrechenden Bestand Solling sind diese optisch bestimmten Zonen unterschiedlicher Dynamik der Zunahme des kumulativen LAI weniger deutlich abzugrenzen als in den noch völlig geschlossenen Beständen Göttinger Wald und Lüneburger Heide. Dies ist zurückzuführen auf Auflichtungen des Kronendachs und dadurch teilweise starken Störlichteinfall in einigen Kronenbereichen des Bestandes Solling.

\subsection{Holzvorrat und Volumenzuwachs}

Die Untersuchungsbestände Ziegelrodaer Forst und Solling (je $\sim 575 \mathrm{~m}^{3} \mathrm{ha}^{-1}$ ) sowie Göttinger Wald $\left(\sim 675 \mathrm{~m}^{3} \mathrm{ha}^{-1}\right)$ besitzen in etwa vergleichbare Holzvolumina. Diese Bestände weisen zudem nahezu gleich hohe Reisholzanteile um 9.5\% auf (Tab. 4-2). Eine Ausnahme bildet der Bestand Lüneburger Heide, der mit etwa $350 \mathrm{~m}^{3} \mathrm{ha}^{-1}$ ein erheblich geringeres Holzvolumen bei einem zugleich höheren Reisholzanteil von $12.4 \%$ besitzt.

Tab. 4-2: Holzvolumenvorrat der vier Untersuchungsbestände in den Untersuchungsjahren $\left[\mathrm{m}^{3} \mathrm{ha}^{-1} \mathrm{a}^{-1}\right]$, Volumenzuwachs im Zeitraum 1995 - 1996 bzw. 1995 - 1997 absolut $\left[\mathrm{m}^{3} \mathrm{ha}^{-1} \mathrm{a}^{-1}\right]$ und in Prozent des Ausgangsvolumens sowie Reisholzanteil $(\mathrm{d}<7 \mathrm{~cm})$ in Prozent des Gesamt-Holzvolumens. In den Mischbeständen Ziegelrodaer Forst und Göttinger Wald mit einem nur sehr geringen Anteil Fremdarten gingen diese wie Buchen gleichen Durchmessers in die Volumenberechnung ein. Im Bestand Lüneburger Heide wurde eine 0.28 ha große Teil-Aufnahmefläche mit nur $2 \%$ Eichenanteil zur Hochrechnung des Holzvolumens eines fast reinen Buchenbestandes $\mathrm{zu}$ Grunde gelegt und dieser sehr geringe Fremdartenanteil ebenfalls nicht differenziert.

\begin{tabular}{ccccc}
\hline$\left[\mathbf{m}^{\mathbf{3}} \mathbf{h a}^{-1} \mathbf{a}^{-1}\right]$ & ZF & GW & LH & SO \\
\hline Ende 1994 & - & 668.5 & 343.3 & 565.1 \\
Ende 1995 & 571.2 & 674.9 & 349.5 & 571.2 \\
Ende 1996 & 577.4 & 678.5 & 353.7 & 573.6 \\
Ende 1997 & 590.0 & 689.6 & 362.4 & 580.6 \\
Zuwachs 95 - 97 & - & $21.1(3.2 \%)$ & $19.1(5.6 \%)$ & $15.5(2.7 \%)$ \\
Zuwachs 96-97 & $18.8(3.3 \%)$ & $14.6(2.2 \%)$ & $12.9(3.0 \%)$ & $9.4(1.7 \%)$ \\
Reisholzanteil & $9.7 \%$ & $9.3 \%$ & $12.4 \%$ & $9.4 \%$ \\
\hline
\end{tabular}

Ein Vergleich der Holzzuwächse aller Untersuchungsbestände und -jahre zeigt, daß in allen Beständen 1997 der deutlich höchste $\left(7.0-12.5 \mathrm{~m}^{3} \mathrm{ha}^{-1}\right)$ und 1996 der deutlich geringste Holzzuwachs $\left(2.4-6.2 \mathrm{~m}^{3} \mathrm{ha}^{-1}\right)$ erfolgte, während 1995 ein Zuwachs auf mittlerem Niveau $\left(\sim 6 \mathrm{~m}^{3} \mathrm{ha}^{-1}\right)$ zu beobachten war (Abb. 4-2). Dabei erreichte in den Jahren 1996 und 1997, in denen auf allen vier Untersuchungsflächen der Holzzuwachs ermittelt wurde, der Bestand Ziegelrodaer Forst die höchste Zuwachsleistung. Im Solling wurde dagegen stets der niedrigste Holzzuwachs bestimmt. Die Bestände Göttinger Wald und Lüneburger Heide zeigten jeweils zwischen diesen Extremen liegende Zuwachsleistungen in ähnlicher Höhe. 


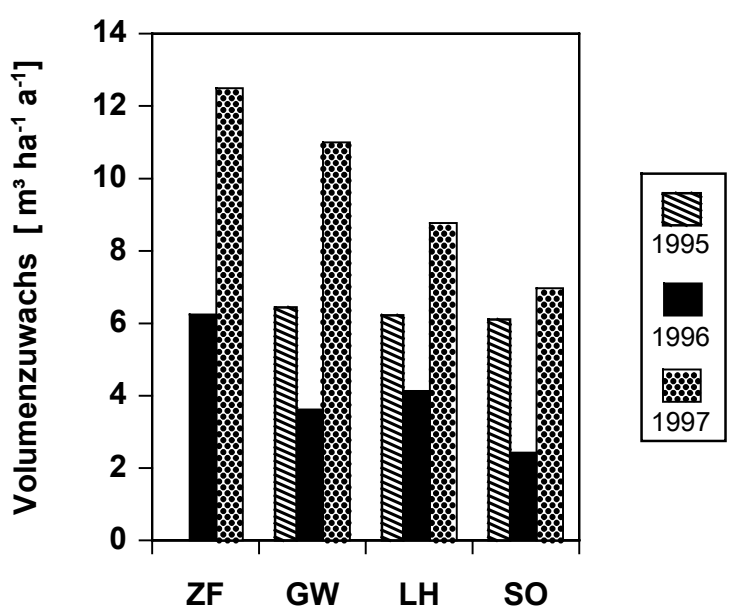

Abb. 4-2: Holzvolumenzuwachs der Untersuchungsbestände Ziegelrodaer Forst (ZF), Göttinger Wald (GW), Lüneburger Heide (LH) und Solling (SO) in den Untersuchungsjahren 1995 - 1997.

Die Abbildung 4-3 zeigt kumulativ den saisonalen Verlauf des mittleren relativen Durchmesserzuwachses der mit Zuwachsmaßbändern versehenen Durchmesserklassen der Untersuchungsbestände, bezogen auf die jeweils in einer Vegetationsperiode bis Anfang November erreichte Zuwachsleistung.

Im Vergleich der Bestände fällt auf, daß in allen drei Untersuchungsjahren der Bestand Lüneburger Heide über weite Strecken der Vegetationsperiode bis September jeweils den höchsten bereits erreichten relativen Anteil des Zuwachses zeigt. Demgegenüber weist der Bestand Göttinger Wald in allen Untersuchungsjahren fast $\mathrm{zu}$ jedem Zeitpunkt der Vegetationsperiode die niedrigste erreichte relative Zuwachsleistung auf. Dadurch wurde im Göttinger Wald das gleiche Niveau der relativen Zuwachsleistung meist erst 20 - 50 Tage später als in der Lüneburger Heide erreicht. Die Bestände Ziegelrodaer Forst und Solling nehmen hier eine Mittelstellung ein.

Eine besonders starke Spreizung des erreichten Zuwachsniveaus zwischen den Untersuchungsbeständen war $1996 \mathrm{zu}$ beobachten (Abb. 4-3). In diesem Jahr setzte das Dickenwachstum in den Beständen Göttinger Wald und Solling deutlich später ein als im Bestand Lüneburger Heide und auch später als in den Untersuchungsjahren 1995 und 1997 (Abb. 4-3). Die ausgeprägteste Zuwachsverzögerung trat jedoch im Bestand Ziegelrodaer Forst auf, in dem das Dickenwachstum im Jahr 1996 erst Mitte Juni begann, ca. 50 Tage später als in der Vegetationsperiode 1997.

Abbildung 4-4 zeigt die mittleren relativen Zuwachsraten aller Durchmesserklassen eines Bestandes in den Vegetationsperioden 1995 -1997, gibt also die saisonale Änderung der Zuwachsdynamik im Bestandesvergleich wider. Generell stiegen die Zuwachsraten von Mai bis etwa Anfang Juli stark an. Danach war bis Ende September stets eine abnehmende Tendenz zu beobachten. Vor allem 1996, aber auch 1997 fiel der Bestand Ziegelrodaer Forst jeweils im Juli und August durch die höchsten relativen Zuwachsraten auf. In beiden Untersuchungsjahren nahm die Zuwachsrate in diesem Bestand jedoch von Juli bis September stark ab, bis sie Ende September fast Null betrug, und fiel so hinter diejenige der anderen Bestände zurück. Eine noch ausgeprägtere saisonale Änderung der Zuwachsdynamik zeigte der Bestand Lüneburger Heide in den Untersuchungsjahren 1995 und 1996. Hier trat jeweils von Ende Juli bis Mitte August ein extrem starker Abfall der Zuwachsrate auf. 

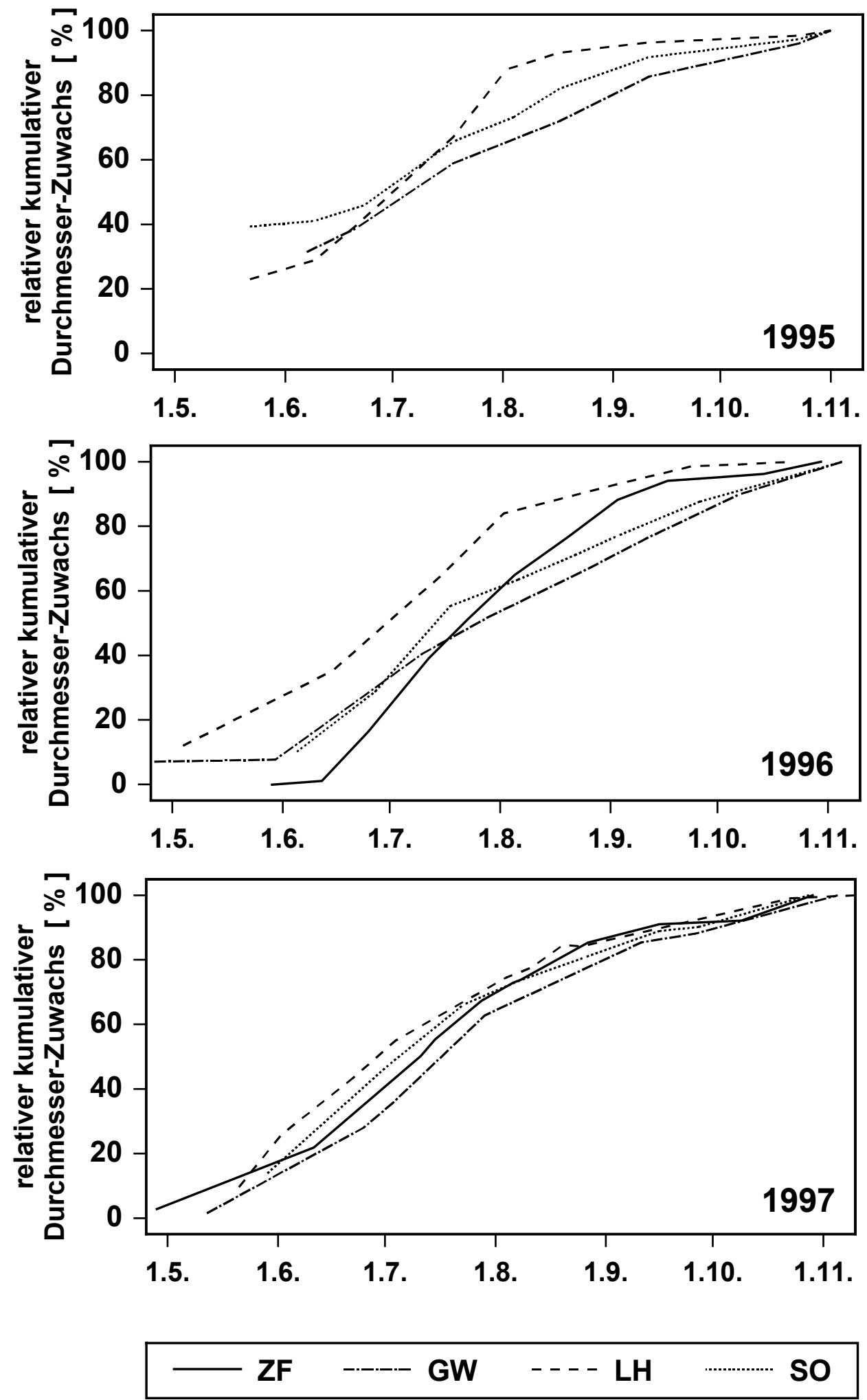

Abb. 4-3: Mittlerer relativer Durchmesserzuwachs in den Untersuchungsbeständen Ziegelrodaer Forst (ZF), Göttinger Wald (GW), Lüneburger Heide (LH) und Solling (SO) im Verlauf der Vegetationsperioden 1995 - 1997. Bezugsgröße des kumulativ dargestellten relativen Durchmesserzuwachses ist die bis Anfang November erreichte Durchmesser-Zuwachsleistung. 

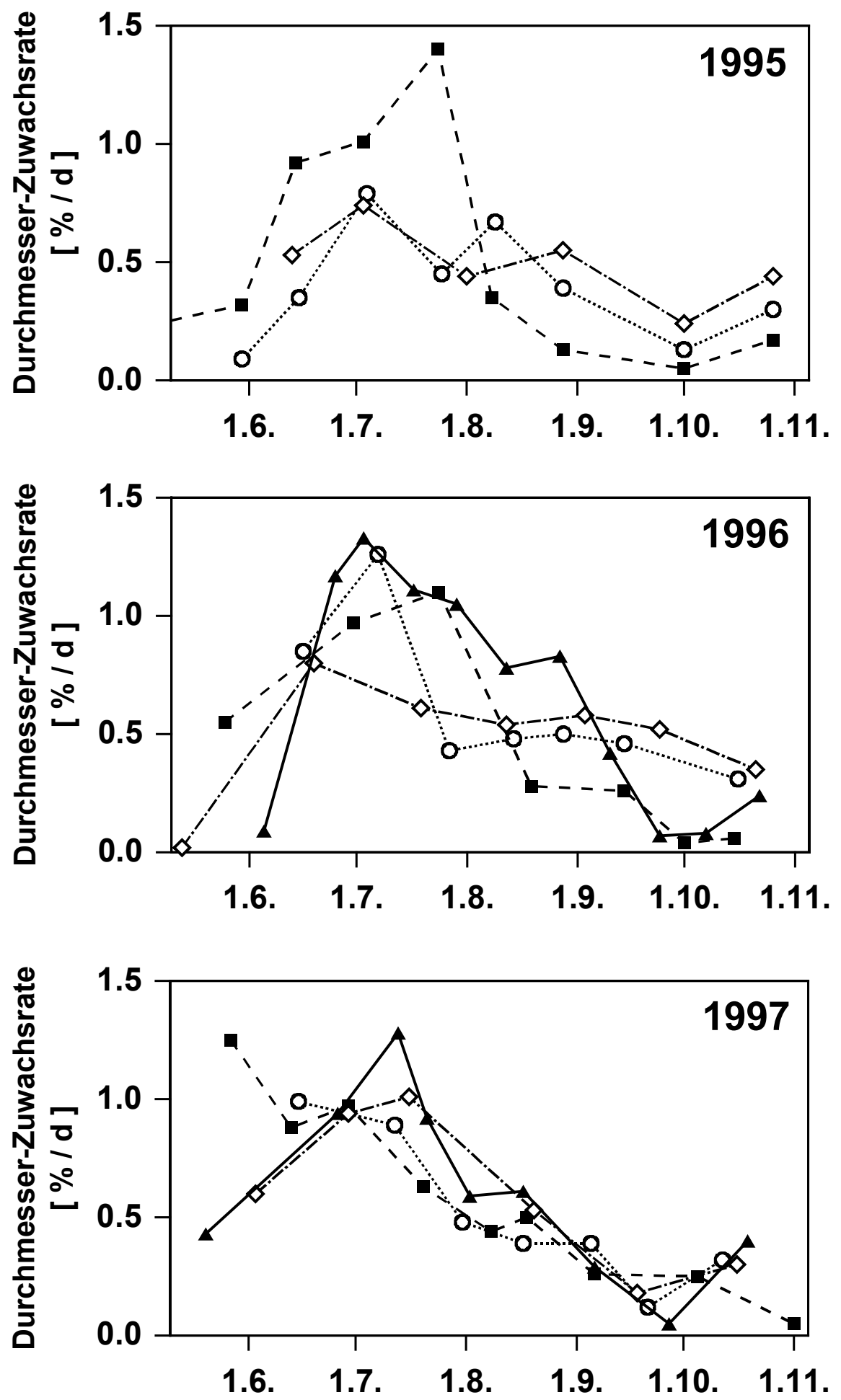

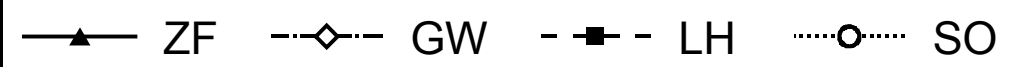

Abb. 4-4: Mittlere relative Durchmesserzuwachsraten in den Untersuchungsbeständen Ziegelrodaer Forst (ZF), Göttinger Wald (GW), Lüneburger Heide (LH) und Solling (SO) im Verlauf der Vegetationsperioden 1995 - 1997. Bezugsgröße des relativen Durchmesserzuwachses ist die bis Anfang November erreichte Durchmesser-Zuwachsleistung. 
Der Bestand Lüneburger Heide besaß dadurch 1995 und 1996 im August und bis Ende September die niedrigsten Zuwachsraten. Nach einer starken Reduktion der relativen Zuwachsraten im Spätsommer war vor allem in den Beständen, in denen das Dickenwachstum bis Ende September nahezu zum Stillstand gekommenen war, jeweils im Oktober noch einmal ein leichter Wiederanstieg der relativen Zuwachsraten zu beobachten.

Demgegenüber zeigten die Bestände Solling und Göttinger Wald in allen drei Untersuchungsjahren mit relativen Zuwachsraten auf mittlerem Niveau eine deutlich geringere saisonale Amplitude der Zuwachsdynamik. Die relativen Zuwachsraten gingen in diesen Beständen von Juli bis September weitgehend kontinuierlich zurück. Eine Ausnahme stellt hier nur der auffällig starke Zuwachsrückgang des Bestandes Solling Mitte Juli 1996 dar. Dieser war so ausgeprägt, daß daraufhin sogar das ungewöhnliche Phänomen eines kontinuierlichen, wenn auch geringen Wiederanstiegs der Zuwachsraten bis Ende August beobachtet werden konnte. Eine so niedrige Zuwachsrate wie Ende Juli trat im Solling dadurch erst wieder Ende September 1996 auf.

\subsection{Blattwasser-Zustandsgrößen}

In der Vegetationsperiode 1995 ab Mitte Juli sowie 1996 über die gesamte Vegetationsperiode hinweg wurden Kennwerte des Blattwasserstatus erfaßt. In Druck-Volumen-Analysen wurden das osmotische Potential bei Wassersättigung $\pi_{0}$, das osmotische Potential bei Grenzplasmolyse $\pi_{\mathrm{p}}$ sowie der relative Wassergehalt bei Grenzplasmolyse $\mathrm{RWC}_{\mathrm{p}}$ ermittelt.

Das osmotische Potential bei Wassersättigung $\pi_{0}$ und das osmotische Potential bei Grenzplasmolyse $\pi_{\mathrm{p}}$ geben als Kennwerte des Blattwasserstatus die physiologisch maximal mögliche Amplitude des osmotischen Wertes im Symplasten an. Dabei definiert $\pi_{\mathrm{p}}$ zugleich das niedrigste Blattwasserpotential, bis zu dem der Turgor aufrechterhalten werden kann. Eine Veränderung des osmotischen Potentials kann zum einen durch eine Änderung des symplastischen Wassergehalts passiv zustande kommen, zum anderen durch eine Synthese von Osmotika im Symplasten oder aktiven Transport dorthin.

Das osmotische Potential bei Wassersättigung wird ausschließlich durch die Konzentration osmotisch wirksamer Teilchen im Symplasten bestimmt. Demgegenüber wird das osmotische Potential bei Grenzplasmolyse zusätzlich durch die elastischen Eigenschaften der Zellwände und die daraus resultierende Gewebeelastizität beeinflußt. Auch der relative Wassergehalt bei Grenzplasmolyse ist sowohl vom osmotischen Wert des Symplasten als auch von der Gewebeelastizität abhängig. Je höher die Gewebeelastizität und die Konzentration osmotisch wirksamer Teilchen im Symplasten sind, desto stärker kann der Wassergehalt reduziert werden, ohne daß ein vollständiger Turgorverlust eintritt.

\subsubsection{Osmotisches Potential bei Wassersättigung und bei Grenzplasmolyse}

Die osmotischen Potentiale bei Wassersättigung und bei Grenzplasmolyse zeigten auf allen Untersuchungsflächen und in beiden betrachteten Jahren zumeist keine ausgeprägte Dynamik oder erkennbar gerichtete Veränderung im saisonalen Verlauf (Abb. 4-5). Auffällig sind nur die bei beiden Parametern zum Teil vergleichsweise hohen Werte im Juni 1996. Nur in den 

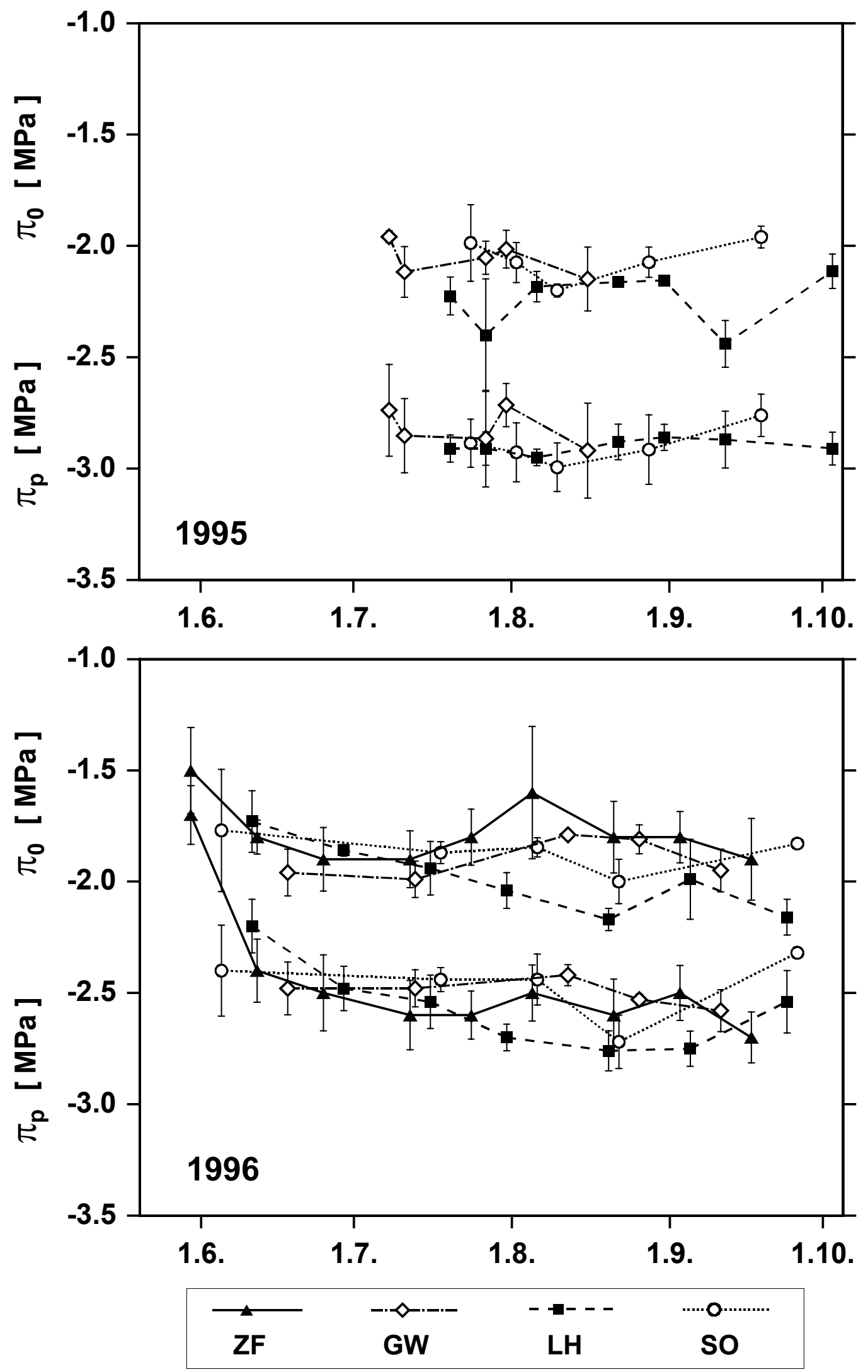

Abb. 4-5: Osmotische Potentiale bei Wassersättigung $\left(\pi_{0}\right)$ und bei Grenzplasmolyse $\left(\pi_{\mathrm{p}}\right)$ in den Untersuchungsbeständen Ziegelrodaer Forst (ZF), Göttinger Wald (GW), Lüneburger Heide (LH) und Solling (SO) im Verlauf der Vegetationsperioden 1995 und 1996. 
Beständen Ziegelrodaer Forst und Lüneburger Heide unterschieden sich diese FrühsommerWerte statistisch signifikant von den ab Mitte Juli 1996 gemessenen Werten. Darüber hinaus waren bei beiden osmotischen Parametern innerhalb eines Bestandes kaum signifikante Unterschiede zwischen den Meßterminen zu beobachten, und diese ließen kein konsistentes Verteilungsmuster erkennen. Bei einer Betrachtung aller Meßwerte der gesamten Vegetationsperiode 1996 über alle Flächen hinweg konnte zwar eine statistisch signifikante Tendenz zu leicht fallenden Werten von $\pi_{0}$ und $\pi_{\mathrm{p}}$ mit fortschreitender Vegetationsperiode festgestellt werden (lineare Regressionen $\pi_{0} /$ Zeit bzw. $\pi_{\mathrm{p}} /$ Zeit mit $\mathrm{p}<0.05$ und $\mathrm{r}=-0.40$ bzw. $\mathrm{p}<0.01$ und $\mathrm{r}=-0.51)$. Für den Beobachtungszeitraum nach abgeschlossener Blattreifung und vor einsetzender Blattseneszenz (1.7. - 15.9.1996) war jedoch keine Veränderung der osmotischen Werte statistisch nachzuweisen.

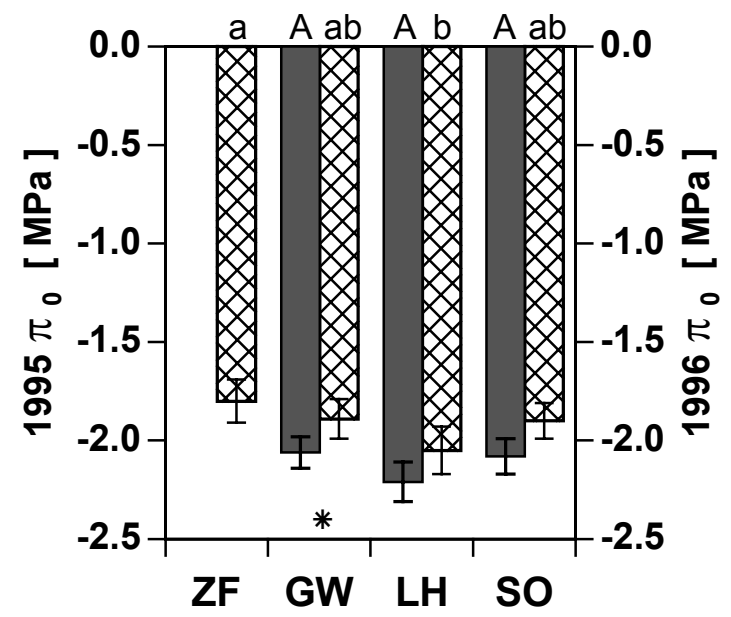

$1995 \times 1996$

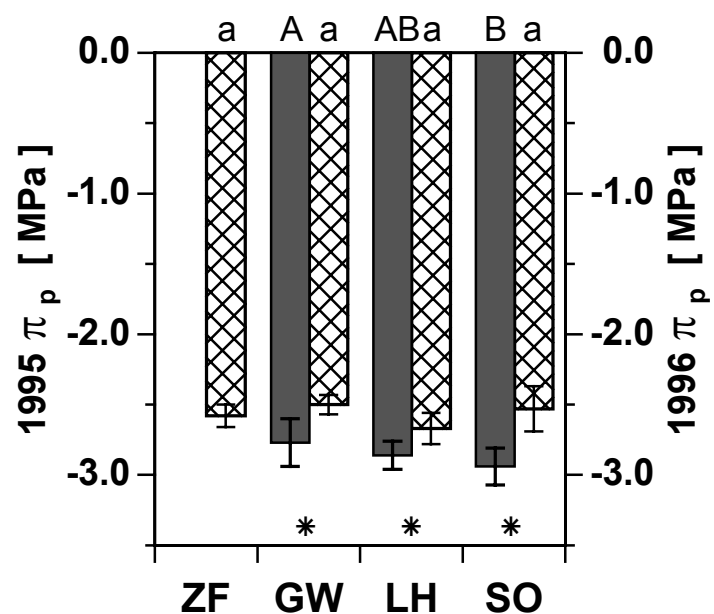

$1995 \times 1996$

Abb. 4-6: Mittlere osmotische Potentiale bei Wassersättigung $\left(\pi_{0}\right)$ und bei Grenzplasmolyse $\left(\pi_{\mathrm{p}}\right)$ in den Untersuchungsbeständen Ziegelrodaer Forst (ZF), Göttinger Wald (GW), Lüneburger Heide (LH) und Solling (SO) im Zeitraum 1. Juli - 15. September 1995 und 1996. Signifikante Unterschiede zwischen Untersuchungsflächen sind durch Buchstaben gekennzeichnet, signifikante Unterschiede zwischen den Untersuchungsjahren mit* (Mittelwertsvergleich nach Scheffé; $\mathrm{p}<0.05$ ).

Abbildung 4-6 zeigt die mittleren osmotischen Potentiale bei Wassersättigung und bei Grenzplasmolyse im Zeitraum zwischen Vollendung der Blattreife und vor Einsetzen der Blattseneszenz (1.7. - 15.9.). Auf den vier Untersuchungsflächen konnten in den Jahren 1995 bzw. 1996 mittlere $\pi_{0}$ von -1.9 bis $-2.2 \mathrm{MPa}$ und mittlere $\pi_{\mathrm{p}}$ von -2.5 bis $-2.9 \mathrm{MPa}$ bestimmt werden. Dabei fällt auf, daß die osmotischen Potentiale im Sommer 1995 auf allen untersuchten Flächen etwas niedriger waren als in der Vegetationsperiode 1996. So lagen 1995 die osmotischen Potentiale bei Wassersättigung durchwegs um etwa $0.2 \mathrm{MPa}$ und die osmotischen Potentiale bei Grenzplasmolyse um etwa 0.2 - 0.4 MPa unter denen des Jahres 1996. Diese Unterschiede zwischen den Untersuchungsjahren konnten für das osmotische Potential bei Grenzplasmolyse in jedem Fall statistisch abgesichert werden, für das osmotische Potential bei Wassersättigung jedoch nur im Bestand Göttinger Wald. Die Unterschiede zwischen den Beständen blieben 1995 wie auch 1996 gering und waren meist nicht signifikant. 


\subsubsection{Relativer Wassergehalt bei Grenzplasmolyse}

Ähnlich wie die osmotischen Potentiale zeigte auch der relative Wassergehalt bei Grenzplasmolyse (RWCp) auf allen Untersuchungsflächen und in beiden betrachteten Jahren keine ausgeprägte Dynamik im saisonalen Verlauf (Abb. 4-7). Er bewegte sich in einem Rahmen von $78 \%-84 \%$ (1995) bzw. $79 \%-88 \%$ (1996).
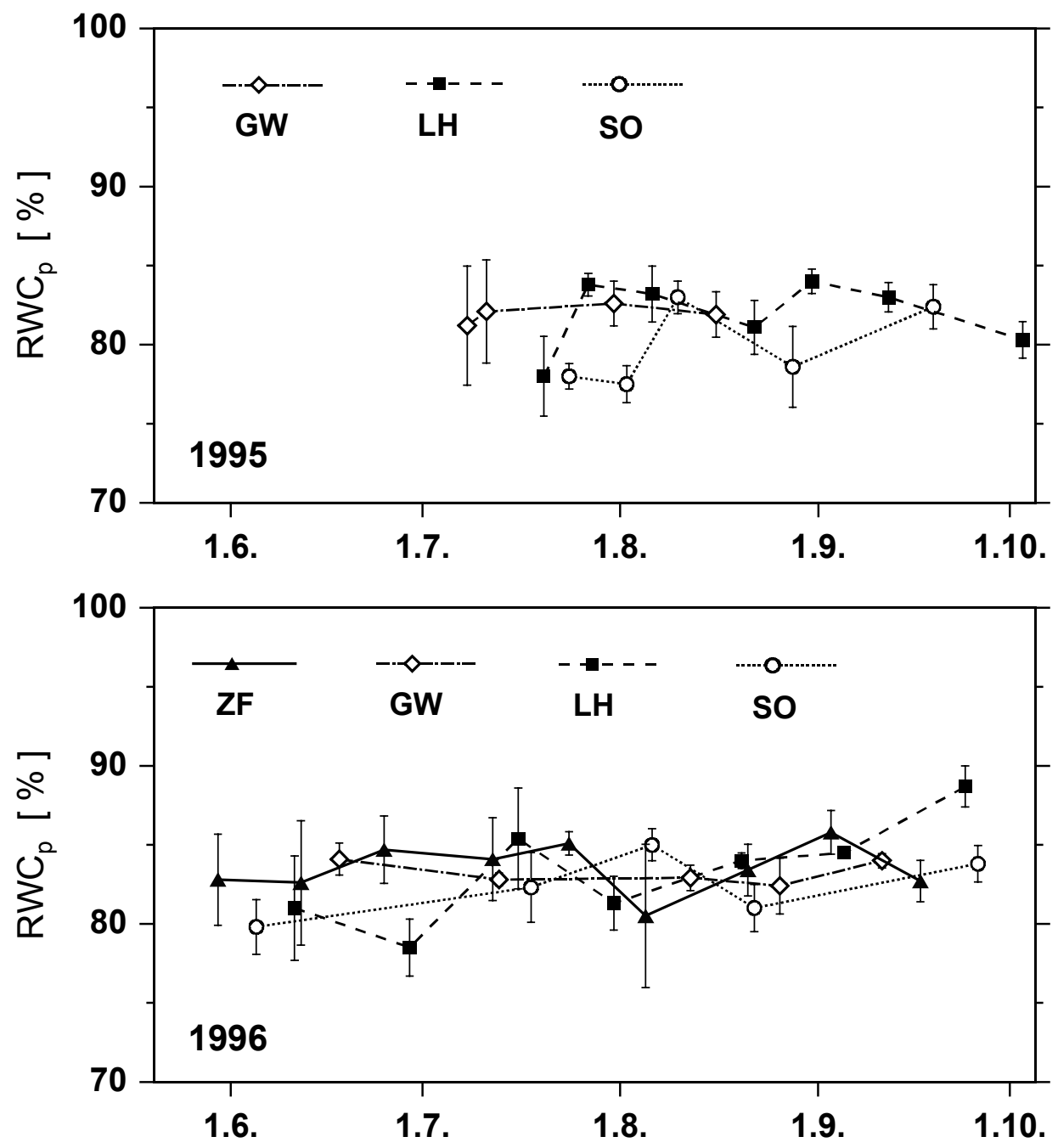

Abb. 4-7: Relativer Wassergehalt bei Grenzplasmolyse $\left(\mathrm{RWC}_{\mathrm{p}}\right)$ in den Untersuchungsbeständen Ziegelrodaer Forst (ZF), Göttinger Wald (GW), Lüneburger Heide (LH) und Solling (SO) in den Vegetationsperioden 1995 und 1996. Angabe des relativen Wassergehalts bezogen auf den Gesamtwassergehalt des Blattes.

Nur über den längeren Beobachtungszeitraum (Juni-September) der Vegetationsperiode 1996 war im Bestand Lüneburger Heide sowie über die Meßwerte aller Flächen hinweg eine statistisch signifikante Tendenz zu leicht steigenden RWCp mit fortschreitender Vegetationsperiode zu erkennen (lineare Regressionen RWCp / Zeit mit $\mathrm{p}<0.05$ und $\mathrm{r}=0.78$ bzw. $\mathrm{r}=0.40$ ). Für den Beobachtungszeitraum nach abgeschlossener Blattreifung und vor einsetzender Blattseneszenz (1.7.-15.9.1996) war jedoch keine Veränderung des RWCp statistisch nachzuweisen. 

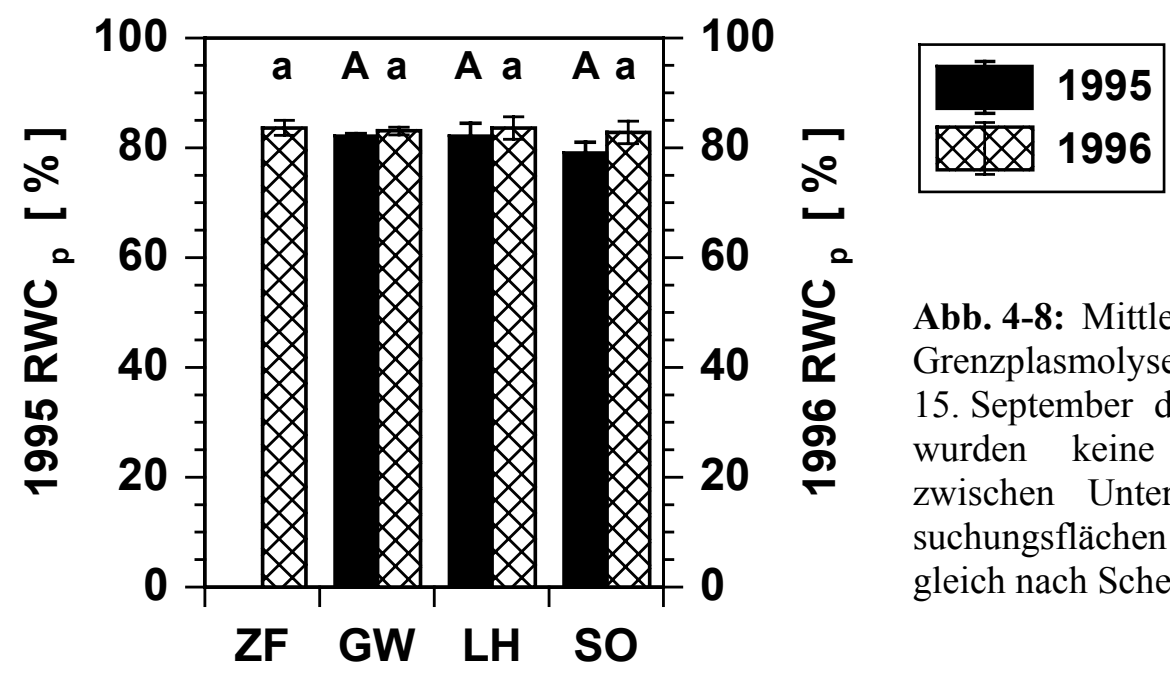

\begin{abstract}
Abb. 4-8: Mittlerer relativer Wassergehalt bei Grenzplasmolyse im Zeitraum 1. Juli 15. September der Jahre 1995 und 1996. Es wurden keine signifikanten Unterschiede zwischen Untersuchungsjahren oder Untersuchungsflächen festgestellt (Mittelwertsvergleich nach Scheffé; $\mathrm{p}<0.05)$.
\end{abstract}

Bei einem Vergleich der mittleren $\mathrm{RWC}_{\mathrm{p}}$-Werte im Zeitraum 1.7. - 15.9. treten keine signifikanten Unterschiede zwischen den Beständen und Untersuchungsjahren auf (Abb.4-8). Der $\mathrm{RWC}_{\mathrm{p}}$ liegt dabei auf allen Untersuchungsflächen und in beiden betrachteten Jahren mit Mittelwerten im Bereich von 79.1 \% - 83.6 \% durchwegs auf einem einheitlichen Niveau.

\title{
4.4 Blattwasserpotentiale
}

Durch Tagesgang-Messungen wurde im Hochsommer 1995 in den Beständen Göttinger Wald, Lüneburger Heide und Solling sowie in den Jahren 1996 und 1997 über die gesamte Vegetationsperiode in allen vier Untersuchungsbeständen die Entwicklung der Blattwasserpotentiale in der Sonnenkrone verfolgt. Die Tagesgänge wurden ausschließlich an Strahlungstagen gemessen. An solchen Tagen tritt in der Mittagszeit bei maximaler Transpiration die stärkste Anspannung des Blattwasserhaushalts mit den minimalen Blattwasserpotentialen $\Psi_{\min }$ auf. Demgegenüber spiegelt das vor Sonnenaufgang (pre-dawn) gemessene Tagesmaximum des Blattwasserpotentials $\Psi_{\max }$ das Maß der nächtlichen Regenerierung des Blattwasserstatus vor Einsetzen der Transpiration wider.

\subsubsection{Tagesgänge des Blattwasserpotentials}

Abb.4-9 gibt Tagesgänge des Blattwasserpotentials an Strahlungstagen bei guter bis stark eingeschränkter Wasserversorgung wider. Kurz vor Sonnenaufgang wird $\Psi_{\max }$ erreicht, dessen Wert vom möglichen Ausmaß der nächtlichen Regenerierung des Blattwasserstatus bestimmt wird. Mit Tagesanbruch setzt ein steiler morgendlicher Abfall des Blattwasserpotentials ein, bis etwa bei Sonnenhöchststand (zumeist im Zeitraum 11.30 - 13.00 Uhr Solarzeit) $\Psi_{\text {min }}$ erreicht wird. Dabei unterschreitet $\Psi_{\min }$ auch an Strahlungstagen in der Regel nicht einen Wert von 2.0 MPa (Abb.4-9a). An Tagen mit besonders hoher Verdunstungsbeanspruchung und/oder stark eingeschränkter Bodenwasserversorgung kann dieser Schwellenwert jedoch bereits einige Stunden vor Mittag (9.00 - 10.00 Uhr) erreicht werden (Abb. 4-9b). Nur an solchen Tagen treten bei extrem angespanntem Blattwasserstatus nach mangelnder nächtlicher Regenerierung zum Teil $\Psi_{\text {min }}$-Werte auf, die den Schwellenwert von $-2.0 \mathrm{MPa}$ mit bis $\mathrm{zu}-2.6 \mathrm{MPa}$ deutlich 
unterschreiten (Abb.4-9c). Auch erfolgt der nachmittägliche Wiederanstieg des Blattwasserpotentials an Tagen mit extrem angespanntem Blattwasserstatus oft deutlich verzögert gegenüber Tagen mit guter Wasserversorgung (Abb.4-9d).

\subsubsection{Tagesmaxima und Tagesminima des Blattwasserpotentials}

1995

1995 wurden nur in den Beständen Göttinger Wald, Lüneburger Heide und Solling und dort vor allem im Hochsommer Messungen des aktuellen Blattwasserstatus durchgeführt (Abb. 4-10). Sie zeigen einheitlich einen starken Abfall der pre-dawn-Werte im Verlauf einer von Mitte Juli bis Mitte August dauernden Trockenperiode. Dabei traten in den Beständen Göttinger Wald und Lüneburger Heide mit Tagesmaxima unter $-1.0 \mathrm{MPa}$ die deutlich niedrigsten in dieser Untersuchung gemessenen pre-dawn-Werte auf. Im Bestand Solling sank $\Psi_{\max }$ erheblich weniger $\mathrm{ab}$, erreichte mit $-0.6 \mathrm{MPa}$ gegen Mitte August dennoch den niedrigsten in den Vegetationsperioden 1995 - 1997 hier gemessenen pre-dawn-Wert. Der Bestand Lüneburger Heide, in dem $\Psi_{\min }$ über die gesamte hochsommerliche Trockenperiode verfolgt wurde, fällt durch ein besonders starkes Absinken der mittäglichen Blattwasserpotentiale bis auf - $2.3 \mathrm{MPa}$ Anfang August auf. Damit wurde in diesem Bestand auch das niedrigste in den Vegetationsperioden 1995 - 1997 dort gemessene Tagesminimum erreicht.

\section{6}

In der Vegetationsperiode 1996 zeigten die pre-dawn-Werte der Bestände Göttinger Wald, Lüneburger Heide und Solling eine sehr geringe Dynamik und sanken so kaum unter - 0.4 MPa ab. Im Bestand Ziegelrodaer Forst waren hingegen schon im Juni pre-dawn-Werte unter - 0.7 MPa zu beobachten (Abb. 4-10). Nach einer Phase deutlicher Erholung Mitte Juli sanken die pre-dawn-Werte dort jedoch schnell wieder stark ab und blieben daraufhin im Zeitraum Anfang August bis Anfang September erneut bei Werten um - 0.7 MPa. Nach einer nochmaligen kurzen Entspannung erreichte $\Psi_{\max }$ im Ziegelrodaer Forst schließlich Ende September einen Extremwert von - 1.3 MPa.

Die Tagesminima des Blattwasserpotentials sanken 1996 in allen Beständen über die Monate Juni und Juli stark ab und erreichten die niedrigsten Werte im Zeitraum Ende Juli bis Ende August, um danach bis Mitte September wieder deutlich anzusteigen. Dabei waren zum Zeitpunkt des angespanntesten Blattwasserstatus im August in den Beständen Göttinger Wald, Lüneburger Heide und Solling Tagesminima um -2.0 MPa zu beobachten. Nur im Bestand Ziegelrodaer Forst konnte im Zeitraum Ende August bis Anfang September ein mittägliches Absinken des Blattwasserpotentials auf bis zu $-2.4 \mathrm{MPa}$ beobachtet werden.

\section{7}

1997 wurden bis Anfang August in allen Untersuchungsbeständen relativ entspannte pre-dawnWerte im Bereich von $0.2-0.4 \mathrm{MPa}$ bestimmt (Abb. 4-11). Daraufhin sank $\Psi_{\max }$ während einer dreiwöchigen Hitzeperiode jedoch deutlich ab und erreichte gegen Ende August die niedrigsten Wert des Sommers. Diese lagen in den Beständen Göttinger Wald, Lüneburger Heide und Solling mit Werten von etwa -0.5 bis $-0.6 \mathrm{MPa}$ durchwegs niedriger als im Sommer 1996. 

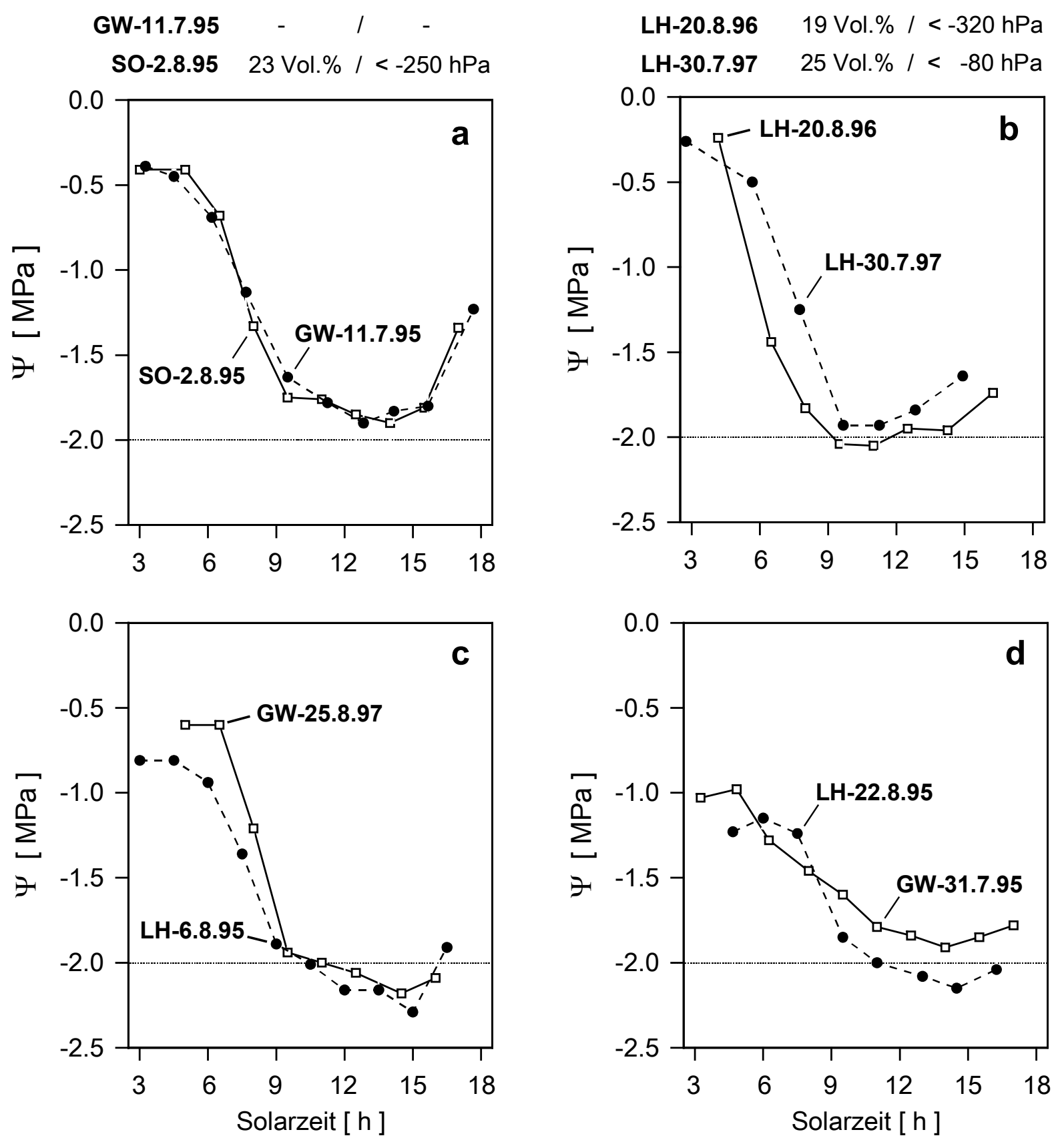

GW-25.8.97 $32 \mathrm{Vol} . \% /<-800 \mathrm{hPa}$

LH-22.8.95 12 Vol. \% / <-800 hPa

LH-6.8.95 $18 \mathrm{Vol} . \% /<-750 \mathrm{hPa}$

GW-31.7.95 $\quad-\quad /<-800 \mathrm{hPa}$

Abb. 4-9: Ausgewählte Tagesgänge des Blattwasserpotentials $(\Psi)$ in den Untersuchungsbeständen Göttinger Wald (GW), Lüneburger Heide (LH) und Solling (SO) bei guter (a) und zunehmend eingeschränkter (b - d) Bodenwasserversorgung in den Vegetationsperioden 1995 - 1997. Volumetrischer Bodenwassergehalt [Vol.\%] und Bodenmatrixpotential $[\mathrm{hPa}]$ in $5 \mathrm{~cm}$ Bodentiefe. 


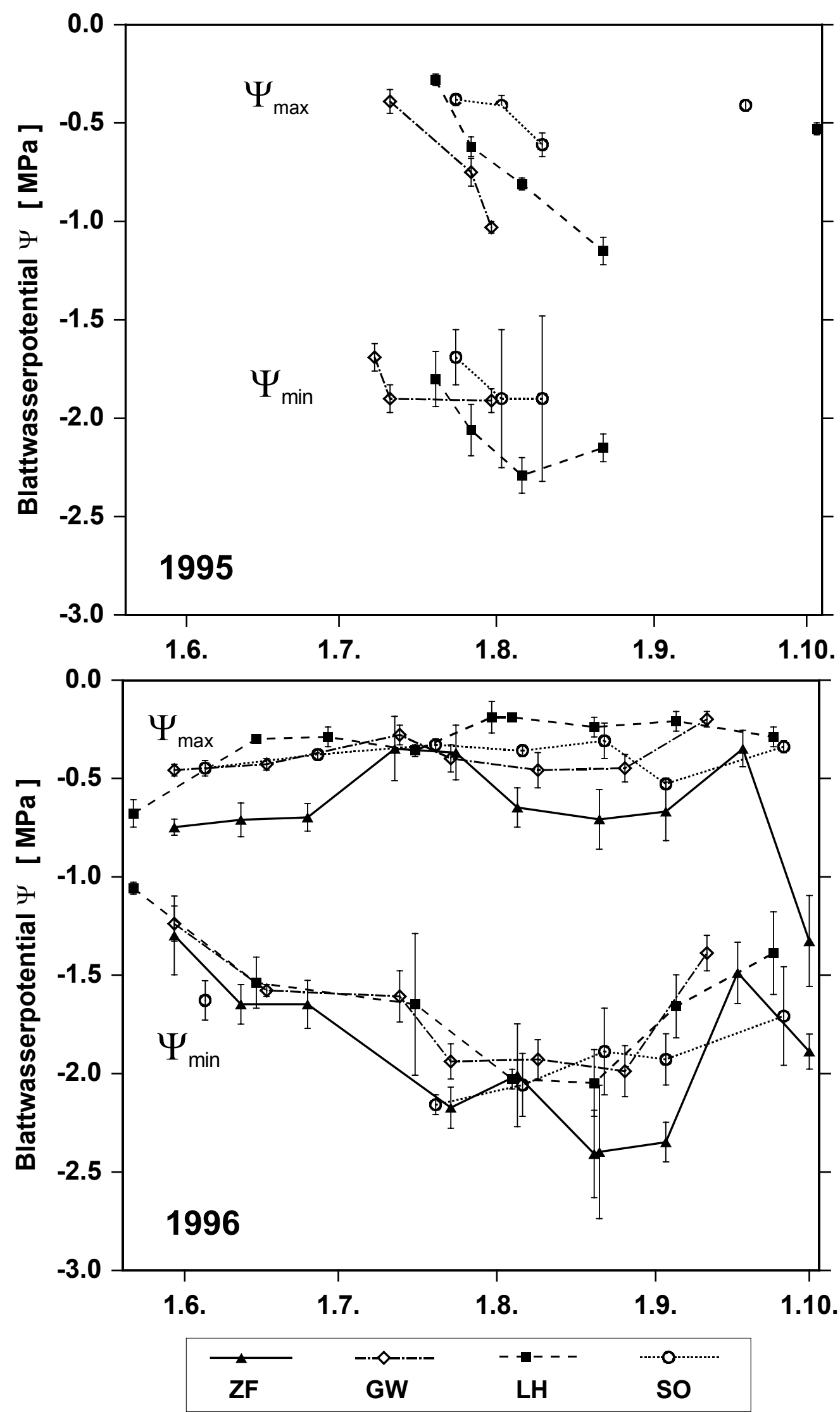

Abb. 4-10: Tagesmaxima ( $\Psi_{\max }$, pre-dawn-Werte) und Tagesminima des Blattwasserpotentials $\left(\Psi_{\min }\right)$ in der Sonnenkrone von Buchen der Untersuchungsbestände Ziegelrodaer Forst (ZF), Göttinger Wald (GW), Lüneburger Heide (LH) und Solling (SO) in den Vegetationsperioden 1995 und 1996. 


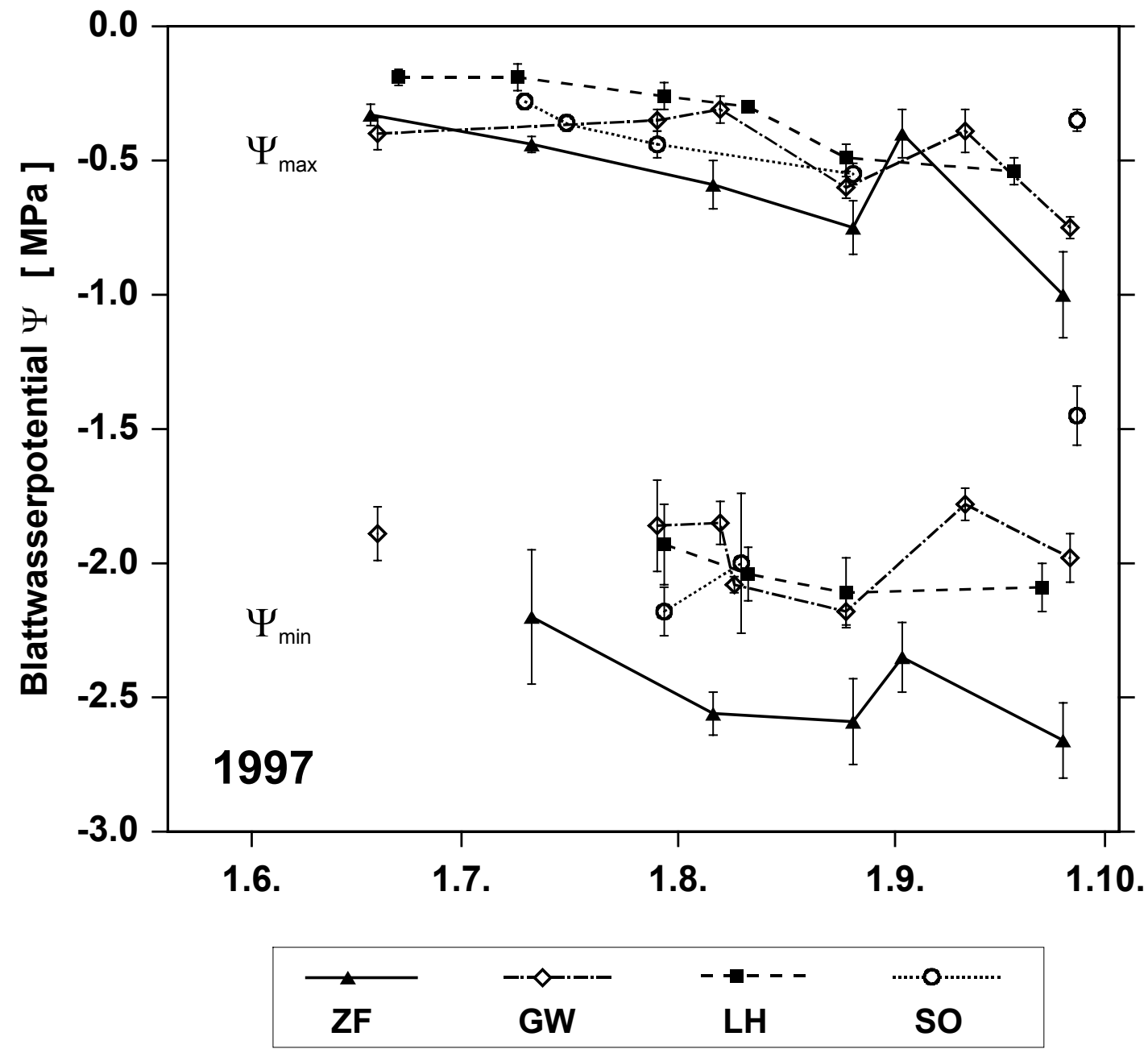

Abb. 4-11: Tagesmaxima ( $\Psi_{\max }$, pre-dawn-Werte) und Tagesminima des Blattwasserpotentials $\left(\Psi_{\min }\right)$ in der Sonnenkrone von Buchen der Untersuchungsbestände Ziegelrodaer Forst (ZF), Göttinger Wald (GW), Lüneburger Heide (LH) und Solling (SO) in der Vegetationsperiode 1997.

Demgegenüber fiel der Bestand Ziegelrodaer Forst Ende August 1997 durch den deutlich niedrigsten $\Psi_{\max }$-Wert von - 0.75 MPa, also in einer Größenordnung wie auch schon 1996 auf. Darüber hinaus wurden im Ziegelrodaer Forst 1997 ebenfalls wie schon im Vorjahr nahezu über die gesamte Vegetationsperiode jeweils die deutlich niedrigsten pre-dawn-Werte der vier Untersuchungsbestände gemessen. Der Bestand Lüneburger Heide zeigte dagegen wiederum tendenziell die entspanntesten pre-dawn-Werte. Gegen Ende der Vegetationsperiode 1997 in der zweiten Septemberhälfte waren schließlich in den Beständen Göttinger Wald, Lüneburger Heide und Ziegelrodaer Forst, nicht jedoch im Bestand Solling noch niedrigere $\Psi_{\text {max }}$-Werte zu beobachten als im August.

Die im Sommer 1997 in den Beständen Göttinger Wald, Lüneburger Heide und Solling bestimmten Tagesminima des Blattwasserpotentials ließen keine große saisonale Dynamik erkennen und bewegten sich durchwegs im Bereich zwischen - 1.8 und - 2.2 MPa. Anders im Bestand Ziegelrodaer Forst, in dem stets die deutlich niedrigsten Tagesminima der vier Untersuchungsbestände bestimmt wurden. Hier sank $\Psi_{\text {min }}$ im August bis auf - 2.6 MPa stark ab und erreichte nach einer leichten Entspannung Ende August erst gegen Ende September mit 

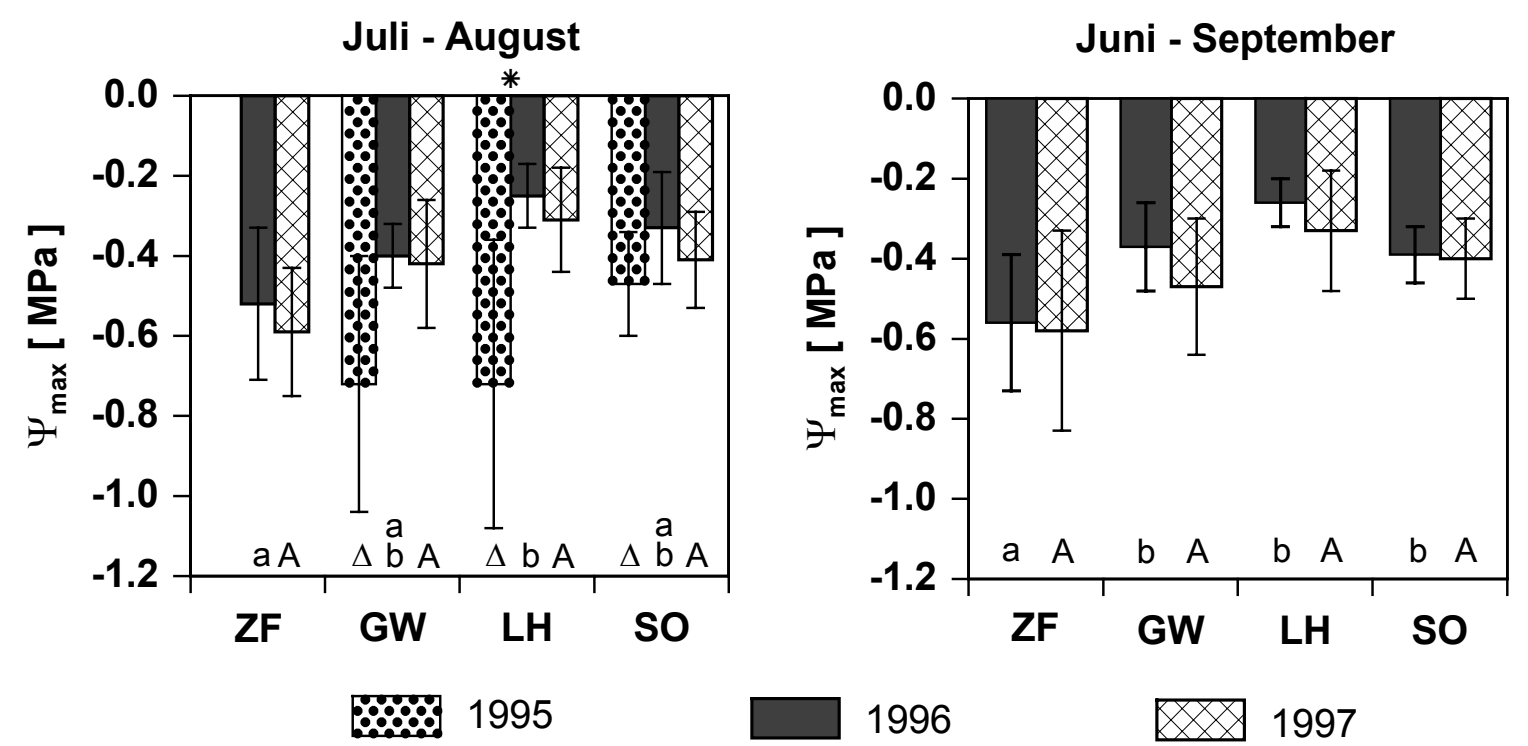

Abb. 4-12: Mittelwerte des maximalen Blattwasserpotentials ( $\left.\Psi_{\max }\right)$ (pre-dawn-Werte) für den Zeitraum Juli - August in den Jahren 1995, 1996 und 1997 sowie für Juni - September 1996 und 1997 in den Untersuchungsbeständen Ziegelrodaer Forst (ZF), Göttinger Wald (GW), Lüneburger Heide (LH) und Solling (SO). Unterschiede zwischen den Untersuchungsflächen sind gekennzeichnet durch griechische Buchstaben für 1995, durch Kleinbuchstaben für 1996 und durch Großbuchstaben für 1997. Signifikante Unterschiede zwischen den Untersuchungsjahren sind gekennzeichnet durch *. (Mittelwertsvergleich nach Scheffé, $\mathrm{p}<0.05$ )
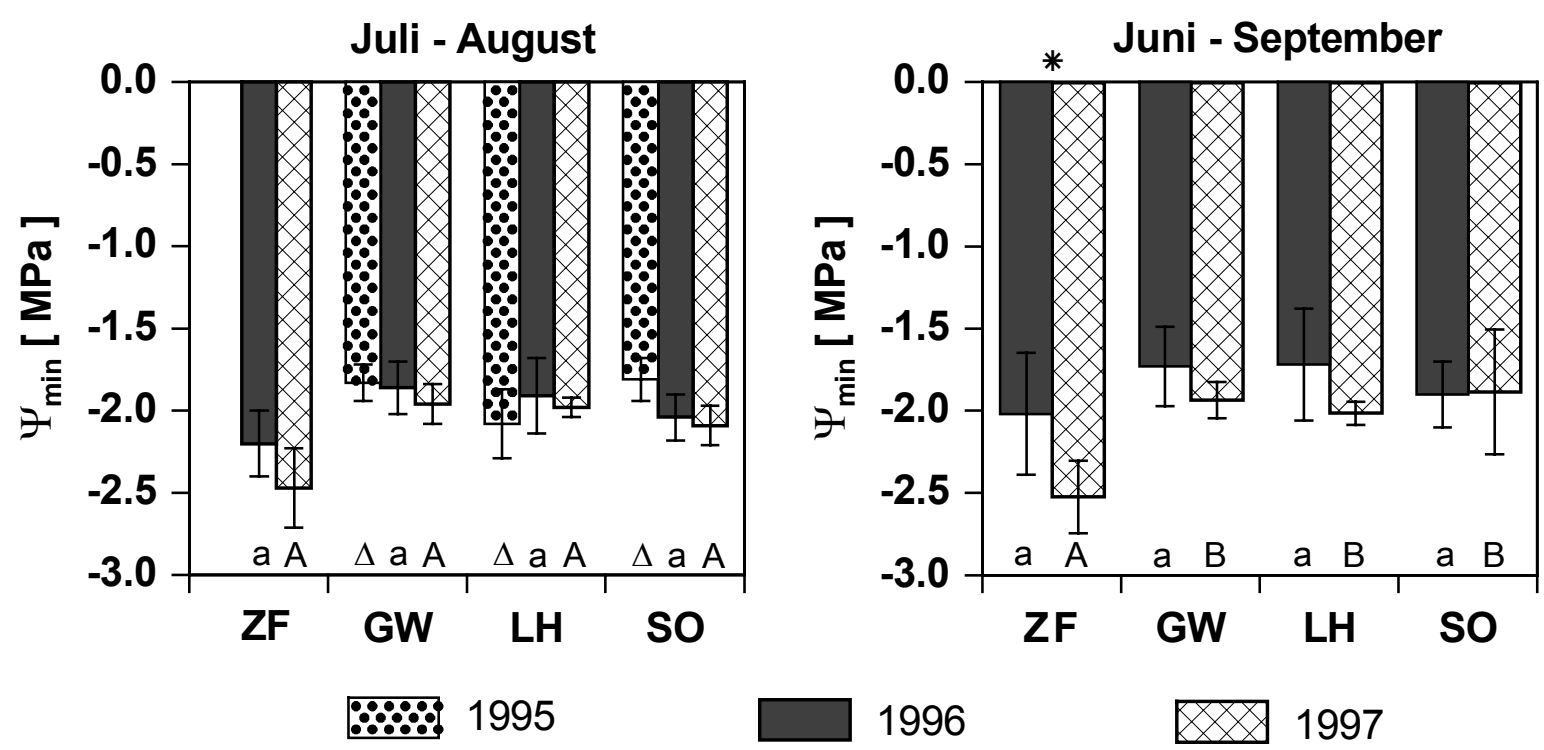

Abb. 4-13: Mittelwerte des minimalen Blattwasserpotentials ( $\left.\Psi_{\min }\right)$ für den Zeitraum Juli - August in den Jahren 1995, 1996 und 1997 sowie für Juni - September 1996 und 1997 in den Untersuchungsbeständen Ziegelrodaer Forst (ZF), Göttinger Wald (GW), Lüneburger Heide (LH) und Solling (SO). Unterschiede zwischen den Untersuchungsflächen sind gekennzeichnet durch griechische Buchstaben für 1995, durch Kleinbuchstaben für 1996 und durch Großbuchstaben für 1997. Signifikante Unterschiede zwischen den Untersuchungsjahren sind gekennzeichnet durch *. (Mittelwertsvergleich nach Scheffé, $p<0.05$ ) 
-2.66 MPa das niedrigste Tagesminimum, das damit zugleich den niedrigsten in dieser Untersuchung gemessenen $\Psi_{\min }$-Wert darstellt.

Abb. 4-12 und 4-13 zeigen für den Zeitraum Juni-September gebildete Mittelwerte der Tagesmaxima und -minima des Blattwasserpotentials. Dabei fiel sowohl 1996 als auch 1997 und jeweils in beiden saisonalen Betrachtungszeiträumen der Bestand Ziegelrodaer Forst durch die deutlich niedrigsten, der Bestand Lüneburger Heide hingegen durch die entspanntesten mittleren Tagesmaxima des Blattwasserpotentials auf. Während für den Ziegelrodaer Forst mittlere Tagesmaxima des Blattwasserpotentials um - 5.5 MPa bestimmt wurden, blieben die pre-dawnWerte im Bestand Lüneburger Heide mit etwa -3.0 MPa stets deutlich entspannter. Die Bestände Göttinger Wald und Solling nahmen mit Werten um - 4.0 MPa eine Mittelstellung ein. Dabei lagen in allen Beständen und beiden saisonalen Betrachtungszeiträumen die mittleren Tagesmaxima des Blattwasserpotentials 1997 etwas niedriger als 1996.

Die niedrigsten saisonalen Mittelwerte der Tagesmaxima des Blattwasserpotentials wurden jedoch im Hochsommer 1995 für die Bestände Göttinger Wald und Lüneburger Heide mit jeweils - 7.2 MPa ermittelt. Auch im Bestand Solling wurde für Juli-August 1995 ein niedrigerer mittlerer pre-dawn-Wert bestimmt als in den Jahren 1996 und 1997.

Die mittleren Tagesminima des Blattwasserpotentials zeigten dagegen nur geringe Unterschiede. Auch hier fiel jedoch der Bestand Ziegelrodaer Forst durch die 1997 deutlich niedrigsten Werte auf. Dabei liegen außer im Solling auf allen Untersuchungsflächen die mittleren Tagesmaxima und - minima des Blattwasserpotentials 1997 unter denen des Jahres 1996.

In Abb. 4-12 und 4-13 werden darüber hinaus die mittleren Tagesmaxima und -minima des Blattwasserpotentials in den Hochsommermonaten Juli und August der Jahre 1995-1997 verglichen. Hier fallen die außergewöhnlich niedrigen mittleren pre-dawn-Werte der Bestände Göttinger Wald und Lüneburger Heide im Hochsommer 1995 auf, die die entsprechenden im Bestand Ziegelrodaer Forst gemessenen Werte der Jahre 1996 und 1997 noch unterschreiten. Dagegen lagen die mittleren Tagesminima des Blattwasserpotentials in den Hochsommermonaten aller drei Untersuchungsjahre weitgehend einheitlich bei Werten um - 2.0 MPa. Davon wichen nur die merklich niedrigeren Hochsommerwerte der Jahre 1996 und 1997 im Bestand Ziegelrodaer Forst ab. 


\subsection{Blattleitfähigkeit}

\subsubsection{Tagesgänge der Blattleitfähigkeit}

Tagesgänge der Blattleitfähigkeit wurden ausschließlich an Strahlungstagen gemessen. Diese weisen relativ einheitliche klimatische Bedingungen auf und erlauben die Beobachtung einer ausgeprägten und typischen Dynamik der Blattleitfähigkeit im Tagesgang ohne Störeinflüsse sich schnell ändernder Witterungsbedingungen. Durch die hohe Verdunstungsbeanspruchung an Strahlungstagen sind deutliche Reaktionen auf unterschiedliche Rahmenbedingungen des Wasserhaushalts wie etwa die aktuelle Bodenwasserversorgung zu beobachten.
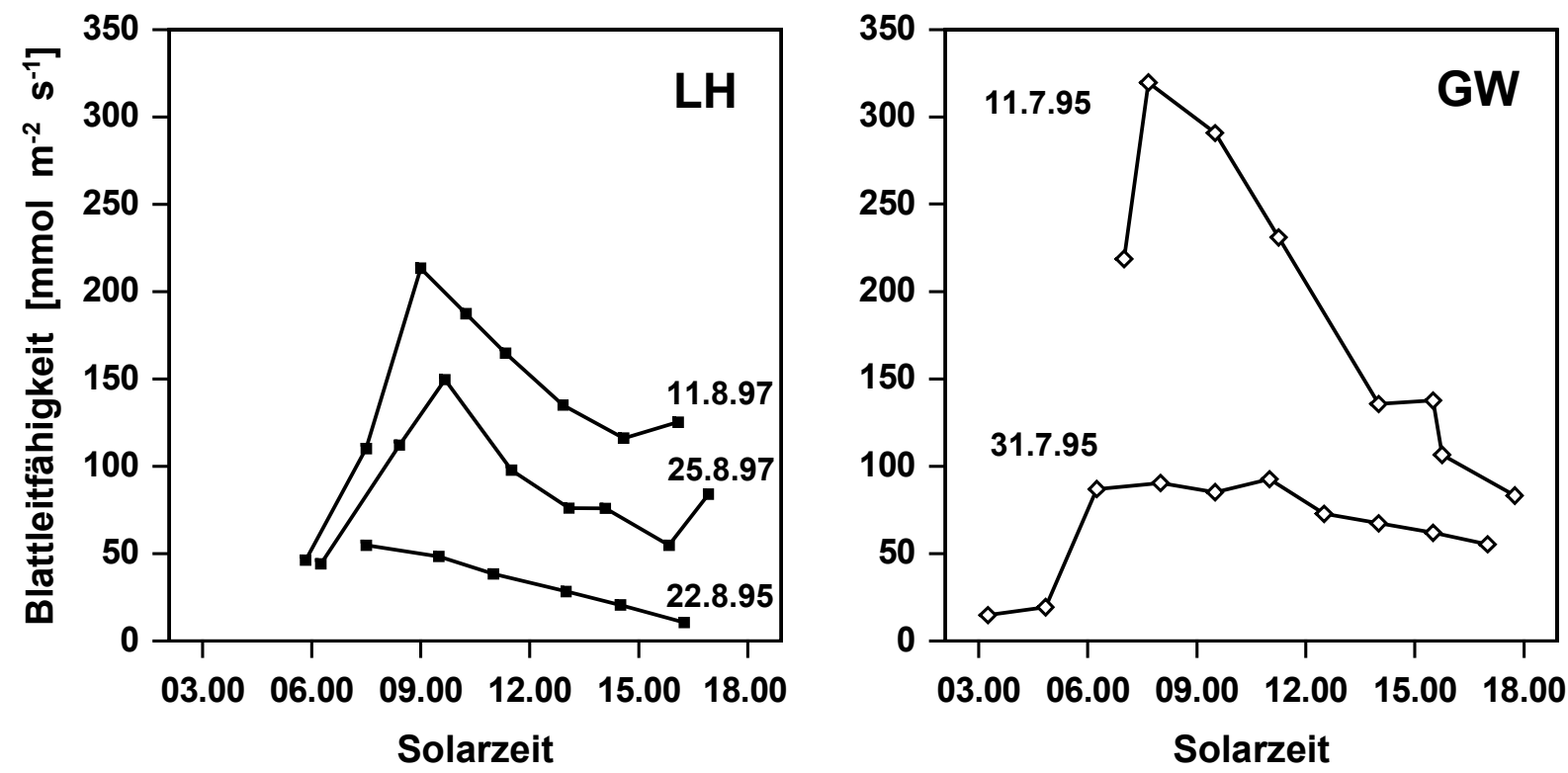

Abb.4-14: Tagesgänge der Blattleitfähigkeit in der Sonnenkrone von Buchen in den Beständen Lüneburger Heide (LH) und Göttinger Wald (GW) zu Beginn und Ende einer Hitze- und Trockenperiode im August 1997 sowie im Verlauf einer extremen Trockenperiode im Hochsommer 1995. (Bodenmatrixpotential und volumetrischer Wassergehalt in $15 \mathrm{~cm}$ Mineralbodentiefe am 11.8.97: $150 \mathrm{hPa} / 16 \mathrm{Vol} . \%$, am 25.8.97: <-700 hPa / $9 \mathrm{Vol} . \%$, am 22.8.95: <<-800 hPa / $6 \mathrm{Vol} . \%$ )

Abb. 4-14 zeigt typische Tagesgänge der Blattleitfähigkeit aus der Sonnenkrone der Buche zu Beginn und Ende einer Hitze- und Trockenperiode im August 1997 sowie im Verlauf einer extremen Trockenperiode im Hochsommer 1995. Die Blattleitfähigkeit steigt bei guter bis ausreichender Bodenwasserversorgung nach Tagesanbruch von nahe Null steil an und erreicht etwa drei bis vier Stunden nach Sonnenaufgang ihren maximalen Wert (LH 11.8.97, LH 25.8.97). Im typischen Tagesgang ist daraufhin im Verlauf des Vormittages ein deutlicher Abfall der Blattleitfähigkeit zu beobachten, die dann ab Mittag auf einem mittleren Niveau verbleibt. Dabei kann es im Verlauf des Nachmittages zu einem leichten Wiederanstieg kommen (LH 11.8.97, LH 25.8.97), bevor am späteren Nachmittag mit abnehmendem Tageslicht der abendliche Abfall der Blattleitfähigkeit gegen Null einsetzt (GW 11.7.95). 
Mit zunehmender Bodenwasserverknappung sinkt das Ausmaß des morgendlichen Leitfähigkeitsanstiegs (LH 11.8.97 und LH 25.8.97). Bei extremem Trockenstreß bricht die typische Tagesgang-Dynamik jedoch zusammen. Dann steigt die Blattleitfähigkeit nach Tagesanbruch nur noch auf sehr geringe Werte $\left(<100 \mathrm{mmol} \mathrm{m}^{-2} \mathrm{~s}^{-1}\right)$ an und verbleibt ab dem frühen Morgen auf diesem niedrigen Niveau oder geht bereits bis zum Nachmittag auf fast Null zurück (GW 31.7.95, LH 22.8.95).

\subsubsection{Mittägliche Blattleitfähigkeit im saisonalen Verlauf}

Im Untersuchungsjahr 1995 wurden mittägliche Blattleitfähigkeiten in der Sonnenkrone nur in den Monaten Juli und August bestimmt. In allen untersuchten Beständen war ein deutlicher Abfall der Leitfähigkeitswerte im Verlauf der ausgeprägten hochsommerlichen Hitze- und Trockenperiode von Mitte Juli bis Mitte August $\mathrm{zu}$ beobachten. Dabei fand die Leitfähigkeitseinschränkung im Solling auf einem deutlich höheren Niveau (300-125 mmol m $\left.\mathrm{m}^{-2} \mathrm{~s}^{-1}\right)$ statt als im Göttinger Wald und in der Lüneburger Heide $\left(140-30 \mathrm{mmol} \mathrm{m}^{-2} \mathrm{~s}^{-1}\right)(\mathrm{Abb} 4-15)$.

Ein Vergleich der mittäglichen Blattleitfähigkeiten zwischen den Untersuchungsbeständen im Verlauf der Vegetationsperiode 1996 zeigt, daß von Juni bis Anfang September stets im Bestand Solling die höchsten Leitfähigkeitswerte gemessen wurden. Es folgte der Bestand Göttinger Wald mit meist deutlich niedrigeren mittäglichen Blattleitfähigkeiten, während im Bestand Lüneburger Heide von Juli bis September die geringsten Leitfähigkeitswerte bestimmt wurden (Abb 4-15). Dabei wichen vor allem die mittäglichen Blattleitfähigkeiten im Solling und in der Lüneburger Heide im Verlauf der Vegetationsperiode zunehmend voneinander ab. Im Solling wurden von Anfang Juni bis Anfang September bis auf $280 \mathrm{mmol} \mathrm{m}^{-2} \mathrm{~s}^{-1}$ steigende mittägliche Blattleitfähigkeiten ermittelt. Der Bestand Lüneburger Heide fiel dagegen ab Mitte Juli durch kontinuierlich niedrige Leitfähigkeitswerte von nur $30-80 \mathrm{mmol} \mathrm{m}^{-2} \mathrm{~s}^{-1}$ auf.

Im Bestandesvergleich der mittäglichen Blattleitfähigkeiten 1997 ist über weite Teile der Vegetationsperiode die Reihung der Bestände aus den Jahren 1995 und 1996 ebenfalls zu erkennen (Abb 4-15). Die 1997 zusätzlich im Bestand Ziegelrodaer Forst durchgeführten Messungen der mittäglichen Blattleitfähigkeit lassen erkennen, daß die Leitfähigkeitswerte sich hier vorwiegend auf einem niedrigen Niveau vergleichbar demjenigen im Bestand Lüneburger Heide bewegten. Auffällig waren die sehr geringen Blattleitfähigkeiten, die bei einem frühen Beginn der Messungen 1997 während und kurz nach der Blattentfaltung im Mai und noch bis Anfang Juni bestimmt wurden. Diese lagen in den verschiedenen Untersuchungsbeständen zunächst auf sehr ähnlichem Niveau um $80 \mathrm{mmol} \mathrm{m}^{-2} \mathrm{~s}^{-1}$ und stiegen daraufhin bis etwa Anfang Juli kontinuierlich an. Anfang August waren in allen Untersuchungsbeständen wiederum sehr ähnliche mittägliche Blattleitfähigkeiten auf einem mittleren Niveau um $150 \mathrm{mmol} \mathrm{m}^{-2} \mathrm{~s}^{-1} \mathrm{zu}$ beobachten. Diese fielen im Laufe der dreiwöchigen Hitze- und Trockenperiode bis Ende August $\mathrm{ab}$; am stärksten in den Beständen Ziegelrodaer Forst und Lüneburger Heide auf deutlich unter $100 \mathrm{mmol} \mathrm{m}^{-2} \mathrm{~s}^{-1}$. Nach einem teilweise $\mathrm{zu}$ beobachtenden deutlichen Wiederanstieg Anfang September wurden am Ende der Vegetationsperiode in allen Beständen erneut vergleichsweise niedrige mittägliche Blattleitfähigkeiten um $100 \mathrm{mmol} \mathrm{m}^{-2} \mathrm{~s}^{-1}$ bestimmt. 

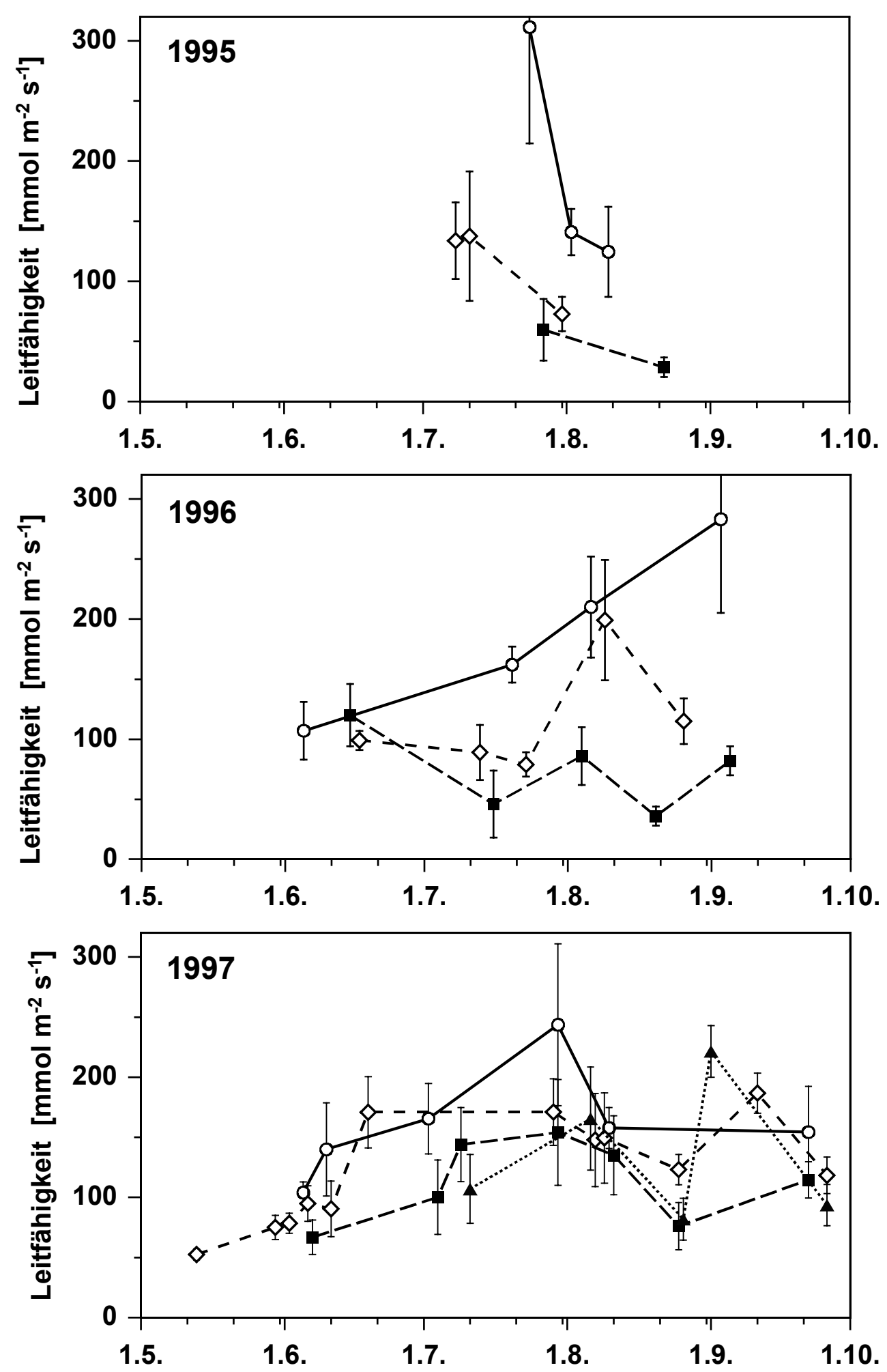

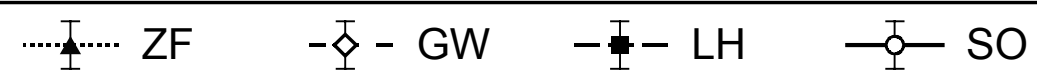

Abb. 4-15: Mittägliche stomatäre Blattleitfähigkeit in der Sonnenkrone von Buchen der Untersuchungsbestände Ziegelrodaer Forst (ZF), Göttinger Wald (GW), Lüneburger Heide (LH) und Solling (SO) in den Vegetationsperioden 1995, 1996 und 1997. 
Tab. 4-3: Mittelwerte der mittäglichen und maximalen stomatären Blattleitfähigkeit in den Sonnenkronen der Untersuchungsbestände Ziegelrodaer Forst (ZF), Göttinger Wald (GW), Lüneburger Heide (LH) und Solling (SO) für die Zeiträume Juni-September und Juli-August der Untersuchungsjahre 1995 - 1997.

Unterschiedliche Kleinbuchstaben kennzeichnen signifikante Unterschiede zwischen Untersuchungsbeständen, unterschiedliche Großbuchstaben kennzeichnen signifikante Unterschiede zwischen Untersuchungsjahren (Mittelwertsvergleich nach Scheffé, $\mathrm{p}<0.05$ ).

\begin{tabular}{|c|c|c|c|c|c|c|}
\hline & & & ZF & GW & LH & so \\
\hline 1995 & Jun-Sep & $\mathbf{g}_{\text {mittag }}$ & - & - & - & - \\
\hline 1995 & Jul-Aug & $\mathbf{g}_{\text {mittag }}$ & - & A $114.6 \pm 37^{a}$ & A $44.0 \pm 22^{a}$ & a $\quad$ A $192.2 \pm 104^{a}$ \\
\hline 1995 & Jun-Sep & $\mathbf{g}_{\max }$ & - & - & $\mathrm{A}_{126.3 \pm 85^{\mathrm{a}}}$ & - \\
\hline 1995 & Jul-Aug & $g_{\max }$ & - & A $195.3 \pm 115^{a}$ & A $79.5 \pm 35^{a}$ & a $\quad$ A $277.0 \pm 72^{a}$ \\
\hline 1996 & Jun-Sep & $\mathbf{g}_{\text {mittag }}$ & - & A $116.2 \pm 48^{a b}$ & A $74.0 \pm 34^{a}$ & a $\quad$ A $190.5 \pm 75$ \\
\hline 1996 & Jul-Aug & $\mathbf{g}_{\text {mittag }}$ & - & A $120.5 \pm 55^{\mathrm{ab}}$ & A $62.5 \pm 25^{\mathrm{a}}$ & 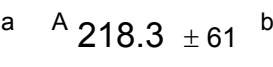 \\
\hline 1996 & Jun-Sep & $\mathbf{g}_{\max }$ & - & - & ${ }^{A} 280.0 \pm 91$ & a $\quad$ A $336.7 \pm 62^{\mathrm{a}}$ \\
\hline 1996 & Jul-Aug & $\mathbf{g}_{\max }$ & - & ${ }^{A} 280.0 \pm 102^{a}$ & ${ }^{\mathrm{B}} 237.3 \pm 40^{\mathrm{a}}$ & a $\quad{ }^{A} 304.0 \pm 34^{a}$ \\
\hline 1997 & Jun-Sep & $\mathbf{g}_{\text {mittag }}$ & $-133.7 \pm 59^{a}$ & A $152.5 \pm 26$ a & $\mathrm{A}_{113.0 \pm 34^{\mathrm{a}}}$ & a $\quad A \quad 177.8 \pm 66^{a}$ \\
\hline 1997 & Jul-Aug & $\mathbf{g}_{\text {mittag }}$ & $-118.1 \pm 62$ & A $147.8 \pm 20^{a}$ & ${ }^{B} 121.8 \pm 33^{a}$ & 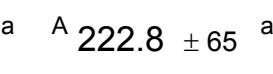 \\
\hline 1997 & Jun-Sep & $\mathbf{g}_{\max }$ & - & ${ }^{A} 246.4 \pm 54$ a & $\mathrm{A}_{193.4 \pm 47^{\mathrm{a}}}$ & - \\
\hline 1997 & Jul-Aug & $g_{\max }$ & - & ${ }^{A} 282.2 \pm 34$ & ${ }^{B} 203.2 \pm 48^{a}$ & a $\quad{ }^{A} 306.6 \pm 174^{a}$ \\
\hline $95-97$ & Jun-Sep & $\mathbf{g}_{\text {mittag }}$ & - & $132.8 \pm 39^{a b}$ & $89.2 \pm 40^{a}$ & $185.0 \pm 71^{b}$ \\
\hline $95-97$ & Jul-Aug & $\mathbf{g}_{\text {mittag }}$ & - & $128.8 \pm 39^{a}$ & $86.1 \pm 42^{a}$ & $211.1 \pm 70^{b}$ \\
\hline $95-97$ & Jun-Sep & $\mathbf{g}_{\max }$ & - & $242.0 \pm 81 a b$ & $205.5 \pm 90^{a}$ & $303.5 \pm 86^{b}$ \\
\hline $95-97$ & Jul-Aug & $g_{\max }$ & - & $252.5 \pm 90^{a}$ & $187.1 \pm 73^{a}$ & $291.2 \pm 83^{a}$ \\
\hline
\end{tabular}

In Tabelle 4-3 sind Mittelwerte der mittäglichen und der maximalen im Tagesgang bestimmten stomatären Blattleitfähigkeit für den Betrachtungszeitraum Juni bis September sowie für die Hochsommerperiode mit den Monaten Juli und August angegeben. Ein Vergleich der saisonalen Mittelwerte der stomatären Blattleitfähigkeiten läßt weitgehend einheitliche Unterschiede zwischen den Beständen erkennen. Hier fiel sowohl bei den mittags bestimmten als auch bei den im Tagesgang maximalen stomatären Blattleitfähigkeiten der Bestand Solling stets durch besonders hohe, der Bestand in der Lüneburger Heide dagegen durch besonders niedrige Mittelwerte auf. Die Mittelwerte der stomatären Blattleitfähigkeit im Bestand Göttinger Wald lagen in allen Meßjahren und beiden Betrachtungszeiträumen zwischen denen der Bestände im Solling und in der Lüneburger Heide. Im Ziegelrodaer Forst wurden für die Vegetationsperiode 1997 Mittelwerte der stomatären Blattleitfähigkeit bestimmt, die auf einem niedrigen Niveau etwa im Bereich der sehr niedrigen Werten im Bestand Lüneburger Heide lagen. 
Unterschiede der saisonalen Mittelwerte zwischen den Meßjahren blieben meist gering. Hier waren nur im Bestand Lüneburger Heide die stomatären Blattleitfähigkeiten 1995 und 1996 erheblich niedriger als 1997. Im Bestand Solling wurden dagegen über die Meßjahre nur sehr wenig veränderte Blattleitfähigkeiten bestimmt.

Aufgrund der geringen Anzahl von Meßterminen (Juni-September: 3 - 7, Juli-August: 2 - 4), die in die saisonalen Mittelwerte eingingen, waren trotz zum Teil stark voneinander abweichender Mittelwerte nur wenige Unterschiede zwischen den Untersuchungsflächen und den Meßjahren statistisch absicherbar.

\subsubsection{Blattleitfähigkeit im Kronen-Höhenprofil}

Im Untersuchungsjahr 1997 wurden an Strahlungstagen in den Untersuchungsbeständen Blattleitfähigkeiten nicht nur in den Sonnenkronen sondern auch in den Licht- und Schattenkronen, wo möglich bis hinab zum Kronenansatz, gemessen. Dies erlaubt die Darstellung von Höhenprofilen der Blattleitfähigkeit über den gesamten Kronenraum der Untersuchungsbestände. Abb. 4-16 zeigt zwei Höhenprofile der Blattleitfähigkeit über den Kronenraum, die in ihrem Verlauf die für alle untersuchten Buchenbestände als charakteristisch ermittelten Merkmale aufweisen.
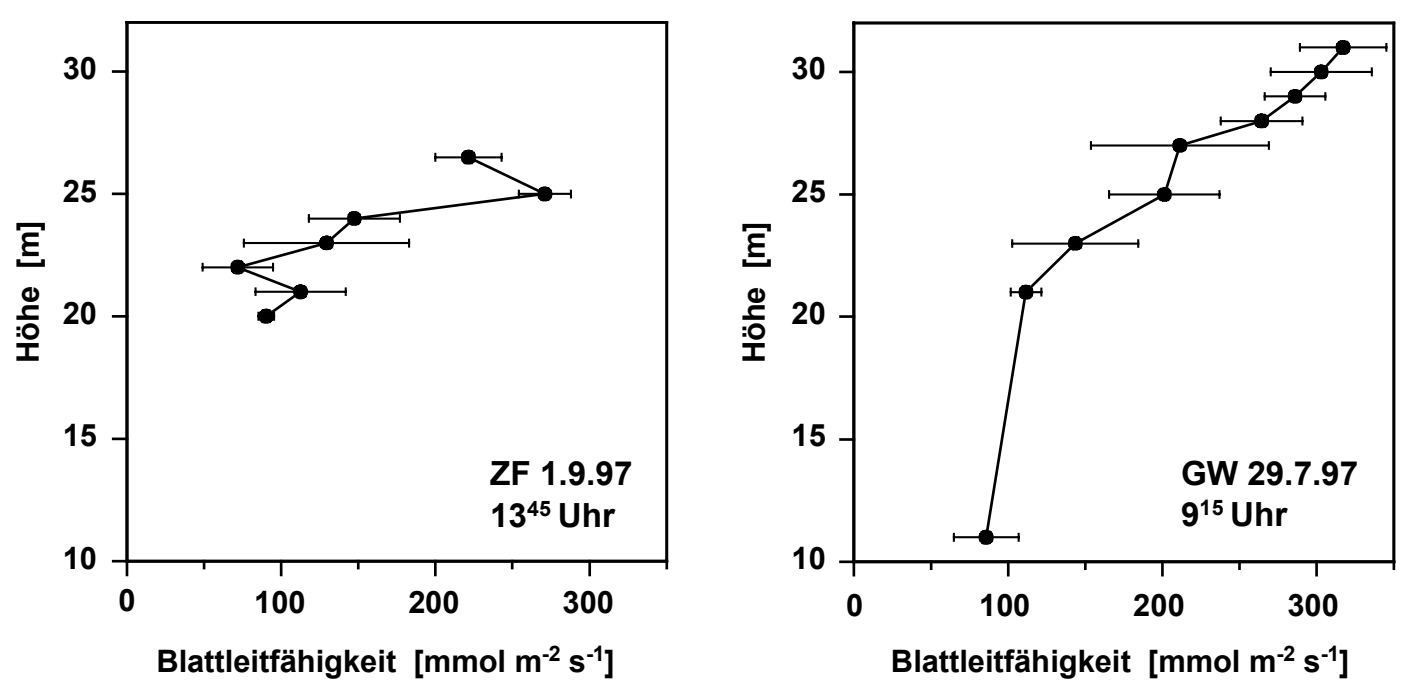

Abb. 4-16: Kronenraum-Höhenprofile der Blattleitfähigkeit in den Beständen Ziegelrodaer Forst (ZF 1.9.1997, Solarzeit 13.45) und Göttinger Wald (GW 29.7.1997, Solarzeit 9.15).

Die deutlich höchsten stomatären Blattleitfähigkeiten wurden jeweils in der Sonnen- und Lichtkrone gemessen, die geringsten in der Schattenkrone. Dabei erstreckte sich unterhalb der Kronenspitze durchwegs ein Bereich, in dem mit abnehmender Höhe im Kronenraum ein besonders starker Rückgang der Blattleitfähigkeit zu beobachten war. Die Mächtigkeit dieser Kronenschicht betrug minimal $3 \mathrm{~m}$ bei einer Messung im Bestand Ziegelrodaer Forst und maximal $10 \mathrm{~m}$ im Bestand Göttinger Wald (im Mittel: $7 \mathrm{~m}$ ). In der Kronenspitze selbst war bisweilen eine etwas niedrigere Blattleitfähigkeit $\mathrm{zu}$ beobachten als im anschließenden Kronenbereich ab etwa 1.5 - 2 m unterhalb der Kronenspitze (Abb. 4-16, Abb. 4-19). 
Auf den 3-10 m mächtigen oberen Kronenbereich mit einem ausgeprägten Leitfähigkeitsrückgang folgte in allen untersuchten Beständen unmittelbar ein deutlich abgrenzbarer unterer Kronenbereich mit einer nur noch geringen Änderung der Blattleitfähigkeit im Höhengradienten. Dieses für alle untersuchten Bestände typische Höhenprofil der Blattleitfähigkeit erwies sich in seiner Grundcharakteristik als nicht nur räumlich sondern auch zeitlich weitgehend stabil. Abb. 4-17 zeigt gemittelte Höhenprofile der Blattleitfähigkeit im Göttinger Wald und in der Lüneburger Heide, erstellt aus den Meßwerten von je vier Strahlungstagen im Zeitraum Juli bis September 1997, an denen jeweils morgens und mittags die Blattleitfähigkeit über den Kronen-Höhengradienten gemessen wurde. In beiden Untersuchungsbeständen war über einen Bereich bis etwa $10 \mathrm{~m}$ unterhalb der Kronenspitze bzw. bis $\mathrm{zu}$ einem kumulativen LAI von etwa 6 ein linearer Rückgang der mittleren Blattleitfähigkeiten mit abnehmender Höhe zu beobachten. In dieser Höhenstufe der Krone belief sich die stomatäre Blattleitfähigkeit nur noch 20-30\% der Werte in der Sonnenkrone. In
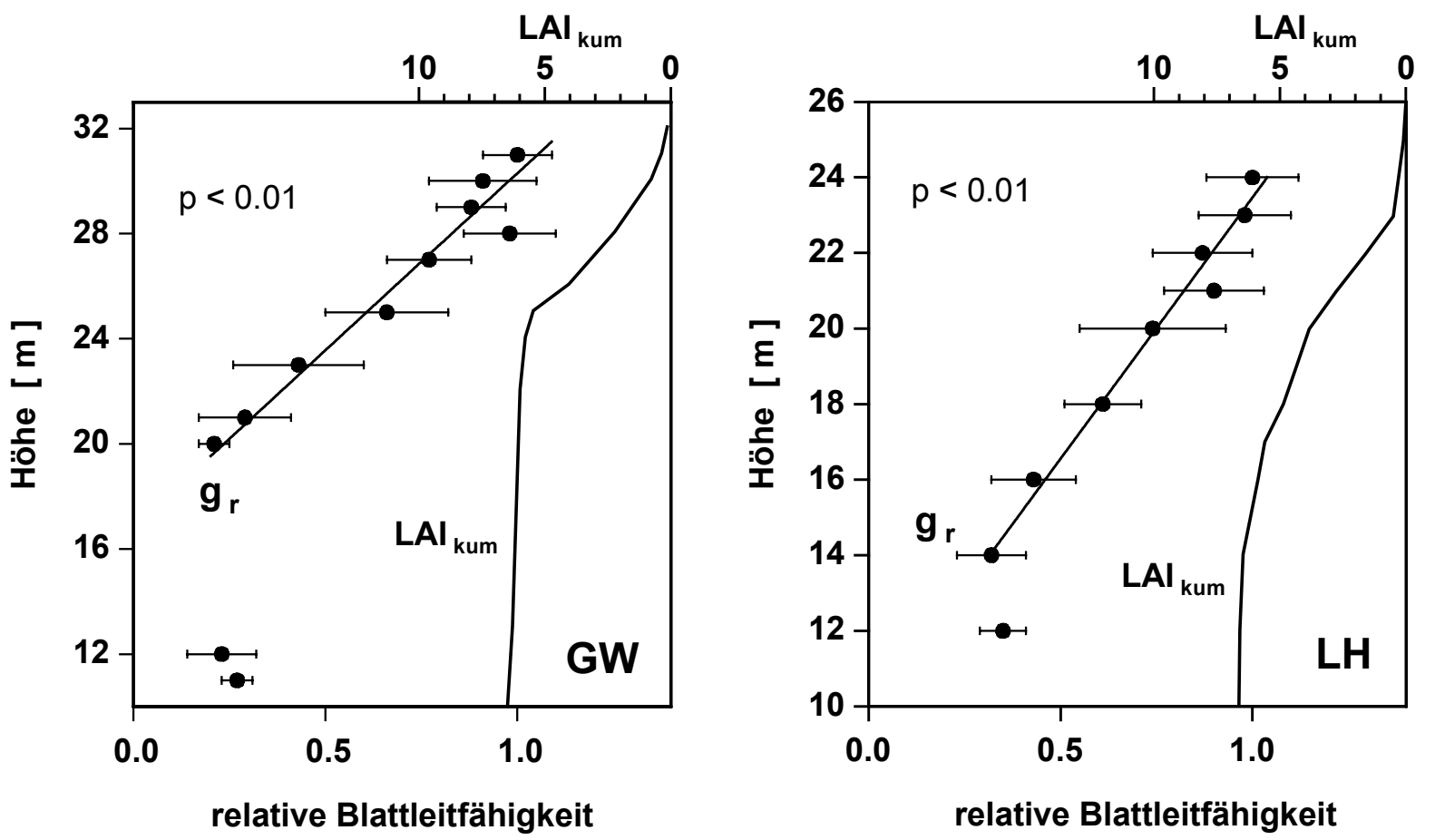

dem Kronenbereich, der sich mehr als $10 \mathrm{~m}$ unterhalb der Kronenspitze befand bzw. bei LAI $>6$ war bis zum Kronenansatz keine wesentliche Änderung der Leitfähigkeit mit der Höhe mehr festzustellen.

Abb. 4-17: Kronen-Höhenprofil der mittleren relativen Blattleitfähigkeit $\left(g_{r}\right)$ und des kumulativen Blattflächenindex $\left(\mathrm{LAI}_{\text {kum }}\right)$ in den Beständen Göttinger Wald $(\mathrm{GW})$ und Lüneburger Heide (LH). Dargestellt sind mittlere Blattleitfähigkeiten aus Messungen morgens und mittags an je vier Meßtagen im Zeitraum Juli bis September 1997 ausgedrückt als Relativwerte gegenüber dem jeweils höchsten Wert der mittleren Blattleitfähigkeit im Kronenraum eines Bestandes. Regressionsgeraden des linearen Rückgangs der mittleren Blattleitfähigkeit mit abnehmender Höhe über die obersten 10 m des Kronenraumes.

Den mittleren Blattleitfähigkeiten in verschiedenen Höhenstufen des Kronenraumes konnten die in den Beständen ebenfalls ermittelten entsprechenden Werte des kumulativen Blattflächenindex 
(LAI kum) zugeordnet werden. Es besteht eine enge Beziehung zwischen der mittleren Blattleitfähigkeit an einem Punkt im Kronenraum und der darüber befindlichen Blattfläche, ausgedrückt durch den Wert des kumulativen LAI in dieser Höhenstufe (Abb. 4-18). Diese Beziehung zeigt in allen daraufhin untersuchten Beständen einen exponentiellen Rückgang der mittleren Blattleitfähigkeit mit zunehmendem LAI.

Die Werte des kumulativen LAI in verschiedenen Höhenstufen des Kronenraumes wurden mit dem optischen Meßgerät LAI 2000 ermittelt. Dieses Gerät mißt neben weiter differenzierenden Parametern vor allem die relative Lichtstärke, die als entscheidende Meßgröße in die Bestimmung der LAI-Werte eingeht. Die Abnahme der Blattleitfähigkeit über den KronenraumHöhengradienten mit ihrer engen Beziehung zum kumlativen LAI ist also im wesentlichen als ein Zusammenhang zu sehen, der auf abnehmenden Lichtstärken bei zunehmendem LAI beruht.

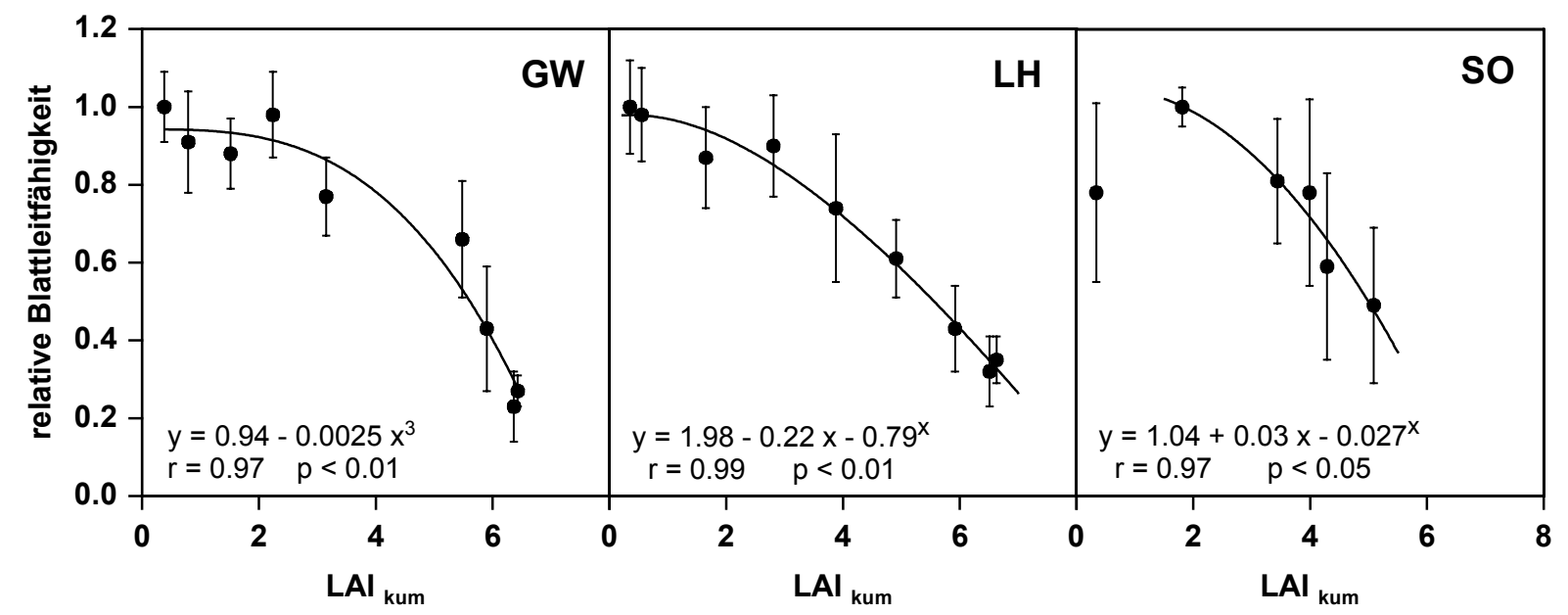

Abb. 4-18: Beziehung der mittleren relativen Blattleitfähigkeit zum kumulativen LAI über verschiedene Höhenstufen des Kronenraums in den Beständen Göttinger Wald (GW), Lüneburger Heide (LH) und Solling (SO). Dargestellt sind mittlere Blattleitfähigkeiten aus Messungen morgens und mittags an je vier Meßtagen im Zeitraum Juli bis September 1997 ausgedrückt als Relativwerte gegenüber dem jeweils höchsten Wert der mittleren Blattleitfähigkeit im Kronenraum eines Bestandes.

Um die tageszeitliche Entwicklung der Blattleitfähigkeit in verschiedenen Höhen des Kronenraums zu erfassen, wurden Höhenprofile der Blattleitfähigkeit während zwei charakteristischer Phasen des typischen Leitfähigkeits-Tagesganges an Strahlungstagen (vgl. Kap. 4.5.1) ermittelt. So wurde die erste Messung etwa zum Zeitpunkt des morgendlichen Leitfähigkeitsmaximums (9.00 Uhr Solarzeit) durchgeführt und eine zweite bei bereits eingeschränkter Leitfähigkeit kurz nach Erreichen des nachmittäglichen Plateauwertes der Blattleitfähigkeit (13.15 Uhr Solarzeit). Der Einfluß unterschiedlicher Bodenwasserversorgung wird deutlich bei einem Vergleich dieser Leitfähigkeits-Höhenprofile zu Beginn und Ende einer Hitze- und Trockenperiode im August 1997 (Abb. 4-19).

Dabei wurde ein für alle untersuchten Bestände charakteristisches Muster der vormittäglichen Leitfähigkeitseinschränkung im Höhenprofil über den Kronenraum erkennbar. In der Regel war über den gesamten Kronenbereich eine Einschränkung der Leitfähigkeit im Laufe des Vormittages zu beobachten. Die absolute Differenz zwischen der morgendlichen und der mittäglichen Blattleitfähigkeit war jedoch im Bereich der Sonnen- und Lichtkrone im Mittel erheblich größer als in der Schattenkrone. Dies beruhte vor allem auf einer besonders starken 
vormittäglichen Einschränkung der Blattleitfähigkeit in einem etwa 6-8 m mächtigen Kronenbereich direkt unterhalb der Kronenspitzen. Demgegenüber war in der Schattenkrone eine weniger ausgeprägte vormittägliche Einschränkung der Blattleitfähigkeit zu beobachten (Abb.4-19, Abb. 4-16). Die beiden bereits im Höhenprofil der Blattleitfähigkeit deutlich unterscheidbaren Kronenbereiche wurden somit auch durch die absoluten Werte der vormittäglichen Leitfähigkeitseinschränkung abgebildet. Aufgrund der stärkeren vormittäglichen Einschränkung der Blattleitfähigkeit in der Sonnen- und Lichtkrone waren mittags flachere Höhenprofile der Blattleitfähigkeit über den Kronenraum zu beobachten als morgens.
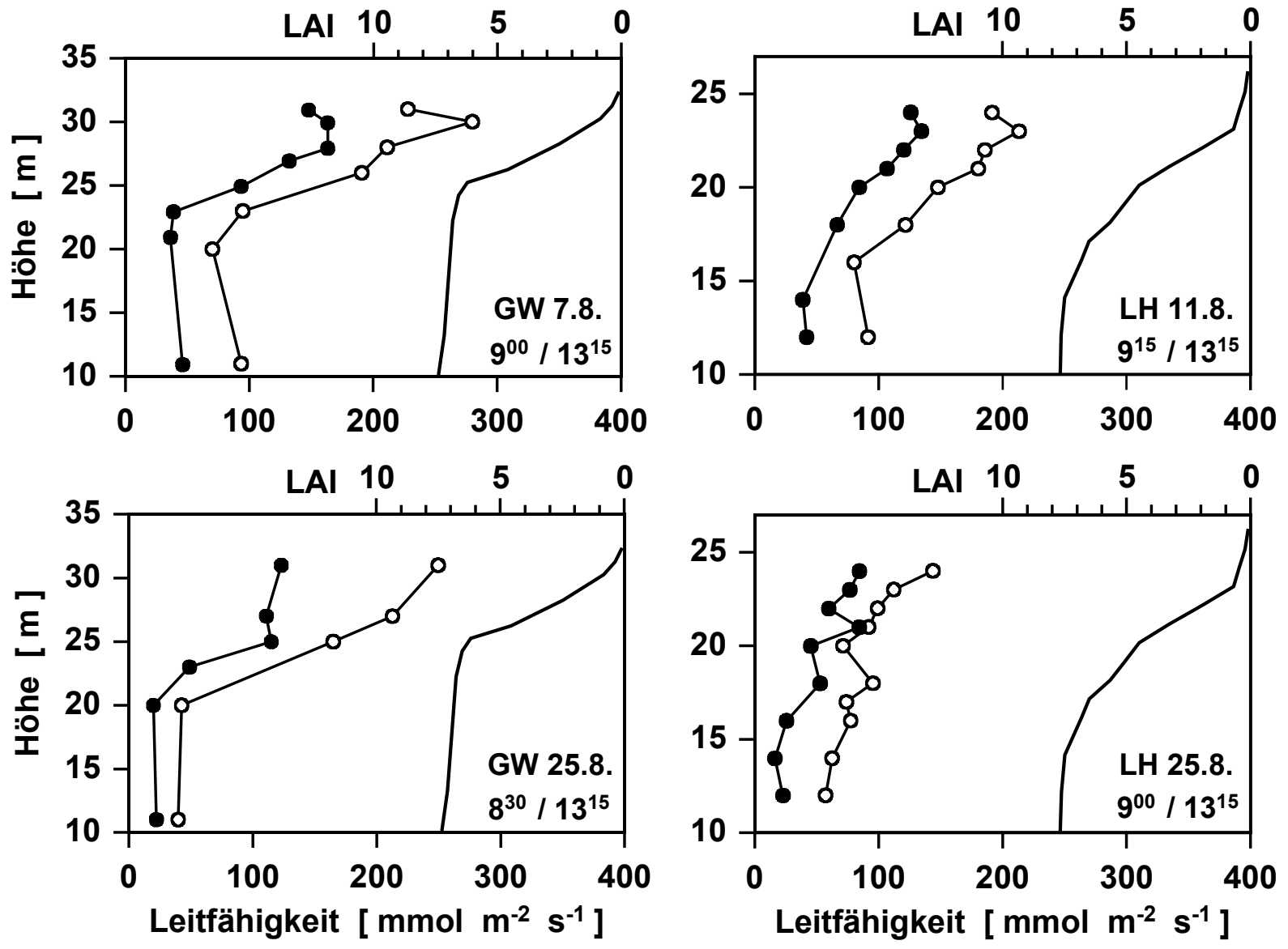

\begin{tabular}{|llc|}
\hline $\begin{array}{l}\text { Blattleitfähigkeit } \\
\text { morgens }-0-\end{array}$ & $\begin{array}{l}\text { Blattleitfähigkeit } \\
\text { mittags }\end{array}$ & LAl kumulativ \\
\hline
\end{tabular}

Abb. 4-19: Höhenprofile der Blattleitfähigkeit im Kronenraum von Buchen in den Beständen Göttinger Wald $(\mathrm{GW})$ und Lüneburger Heide $(\mathrm{LH})$ morgens (bei maximaler Blattleitfähigkeit) und mittags (bei eingeschränkter Blattleitfähigkeit) sowie zu Beginn (oben) und Ende (unten) einer Hitze- und Trockenperiode im August 1997 und Höhenprofile des kumulativen LAI. (Bodenmatrixpotential und volumetrischer Wassergehalt in $15 \mathrm{~cm}$ Mineralbodentiefe:

GW 7.8. / 25.8.: $51 / 34 \mathrm{Vol} . \% ;-150 \mathrm{hPa} /<-750 \mathrm{hPa}$

LH 11.8. / 25.8.: $16 / 8 \mathrm{Vol} . \% ; \quad-150 \mathrm{hPa} /<-700 \mathrm{hPa})$ 
Bei Bodentrockenheit war im Vergleich zu guter Bodenwasserversorgung entweder eine besonders starke vormittägliche Einschränkung der Blattleitfähigkeit $\mathrm{zu}$ beobachten (Abb. 4-19: GW 25.8.) oder eine bereits morgens auch in der Sonnenkrone vergleichsweise geringe Blattleitfähigkeit, die dann bis mittags über das gesamte Profil in etwa gleichem Ausmaß auf sehr niedrige Werte der Blattleitfähigkeit reduziert wurde (Abb. 4-19: LH 25.8.). Zum Zeitpunkt eingeschränkter Bodenwasserversorgung traten somit flachere Höhenprofile der Blattleitfähigkeit über den Kronenraum auf als bei guter Bodenwasserversorgung.

Es konnte also sowohl im typischen Tagesgang eines Strahlungstages bei der Einschränkung der Blattleitfähigkeit im Verlauf des Vormittags als auch bei einer saisonalen Einschränkung der Blattleitfähigkeit infolge Bodenwasserverknappung das gleiche Reaktionsmuster der Leitfähigkeitseinschränkung im Kronenraum-Höhenprofil beobachtet werden.
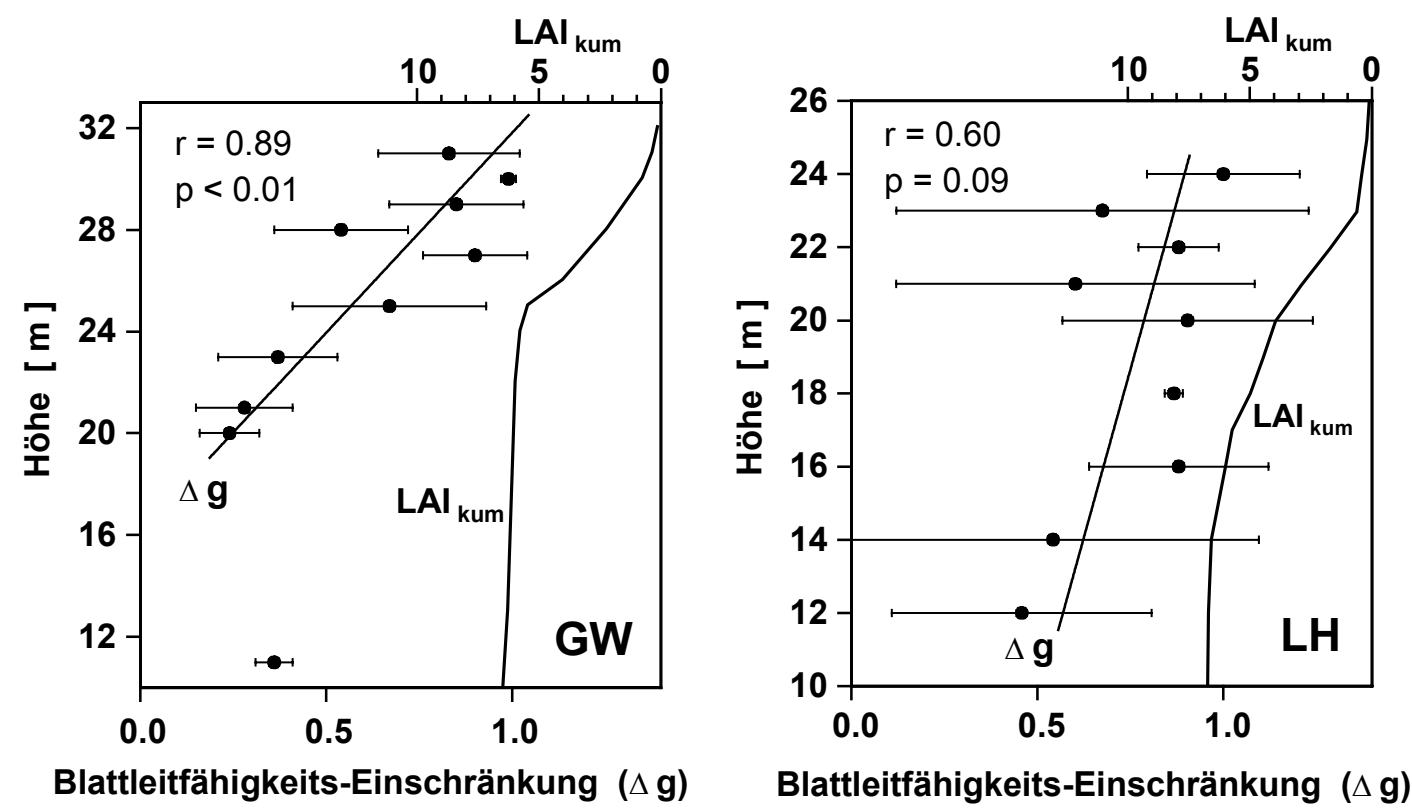

Abb. 4-20: Kronen-Höhenprofil der mittleren Blattleitfähigkeits-Einschränkung $(\Delta \mathrm{g})$ und des kumulativen Blattflächenindex ( $\left.\mathrm{LAI}_{\text {kum}}\right)$ in den Beständen Göttinger Wald $(\mathrm{GW})$ und Lüneburger Heide (LH). Dargestellt sind Mittelwerte der vormittäglichen Blattleitfähigkeits-Einschränkung aus Messungen morgens und mittags an je vier Meßtagen im Zeitraum Juli bis September 1997 ausgedrückt als Relativwerte gegenüber dem jeweils höchsten Wert der mittleren Blattleitfähigkeits-Einschränkung im Kronenraum eines Bestandes. Regressionsgeraden des linearen Rückgangs der vormittäglichen Blattleitfähigkeits-Einschränkung mit abnehmender Höhe im Kronenraum.

Setzt man den absoluten Betrag der vormittägliche Leitfähigkeitseinschränkung in Beziehung zum jeweiligen Ausgangswert der morgendlichen maximalen Blattleitfähigkeit einer Höhenstufe, zeigt sich jedoch ein anderes Kronenraum-Höhenprofil (Abb. 4-21) als bei der Betrachtung der absoluten Leitfähigkeitsänderung (Abb. 4-20). Hier wird deutlich, daß die morgendliche maximale Blattleitfähigkeit bis zum Mittag in der oberen Sonnenkrone im Mittel nur um etwa $20-30 \%$ reduziert wurde, während in der Schattenkrone eine mittlere Leitfähigkeitseinschränkung um etwa 50 \% zu beobachten war. Für die beiden 1997 in dieser Hinsicht näher untersuchten Bestände Göttinger Wald und Lüneburger Heide ergab sich hier ein auffallend übereinstimmendes Bild zunehmender relativer Leitfähigkeitseinschränkung mit 
abnehmender Höhe im Kronenraum. Dabei zeigte auch dieser Leitfähigkeitsparameter wiederum eine weitgehend lineare Änderung über einen etwa 8-10 m mächtigen Bereich unterhalb der Kronenspitze. Auch hier war im darunter liegenden Bereich der Schattenkrone keine wesentliche Änderung mit abnehmender Höhe mehr zu beobachten.
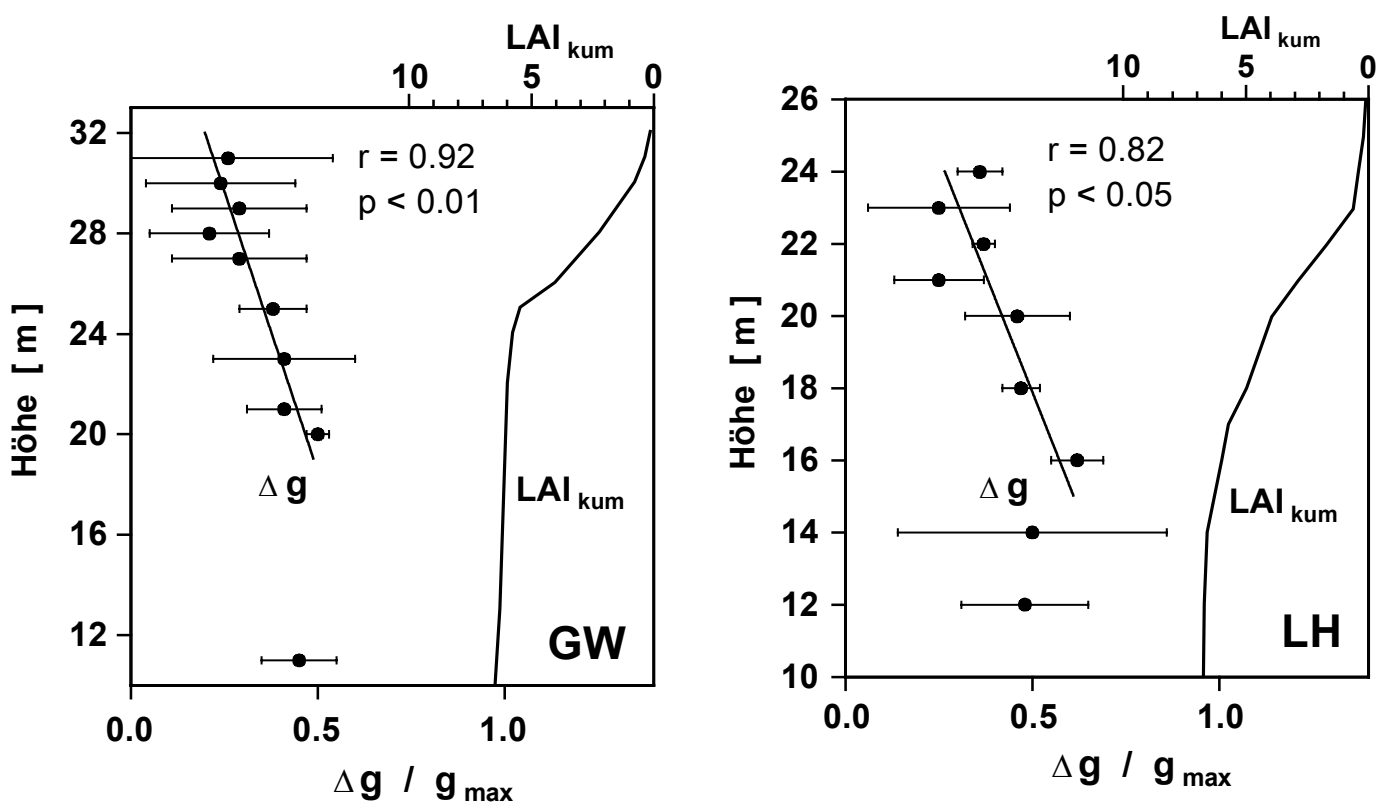

Abb. 4-21: Kronen-Höhenprofil der mittleren relativen Blattleitfähigkeits-Einschränkung ( $\left.\Delta \mathrm{g} / \mathrm{g}_{\max }\right)$ und des kumulativen Blattflächenindex $\left(\mathrm{LAI}_{\text {kum }}\right)$ in den Beständen Göttinger Wald $(\mathrm{GW})$ und Lüneburger Heide (LH). Dargestellt sind Mittelwerte der vormittäglichen Blattleitfähigkeits-Einschränkung aus Messungen morgens und mittags an je vier Meßtagen im Zeitraum Juli bis September 1997 ausgedrückt als Relativwerte gegenüber der maximalen morgendlichen Blattleitfähigkeit in der jeweiligen Höhenstufe $\left(\Delta \mathrm{g} / \mathrm{g}_{\max }\right)$. Regressionsgeraden des linearen Anstiegs der relativen vormittäglichen BlattleitfähigkeitsEinschränkung mit abnehmender Höhe im Kronenraum.

Im Bestand Ziegelrodaer Forst waren ohne Meßturm entsprechende Messungen in allen Kronenbereichen nicht möglich. Im Solling beeinträchtigte ein im Tagesgang sehr unregelmäßiger und starker Störlichteinfluß durch Kronenlücken im Bestand die Erstellung von charakteristischen Höhenprofilen der Blattleitfähigkeit erheblich. 


\subsection{Xylemsaftfluß und Bestandestranspiration}

\subsubsection{Xylemsaftfluß im Tagesgang}

Unter der Annahme, daß der Saftfluß durch das Stammxylem eines Baumes weitgehend der aktuell in der Krone transpirierten Wassermenge entspricht, kann durch eine kontinuierliche Messung des Xylem-Saftflusses der Tagesgang der Transpiration einer Buche erfaßt werden.

Abb. 4-22 zeigt Tagesgänge der Saftflußrate einer $35 \mathrm{~m}$ hohen Buche mit $56 \mathrm{~cm}$ Brusthöhendurchmesser im Bestand Göttinger Wald im Verlauf der Hitze- und Trockenperiode im Hochsommer 1995.

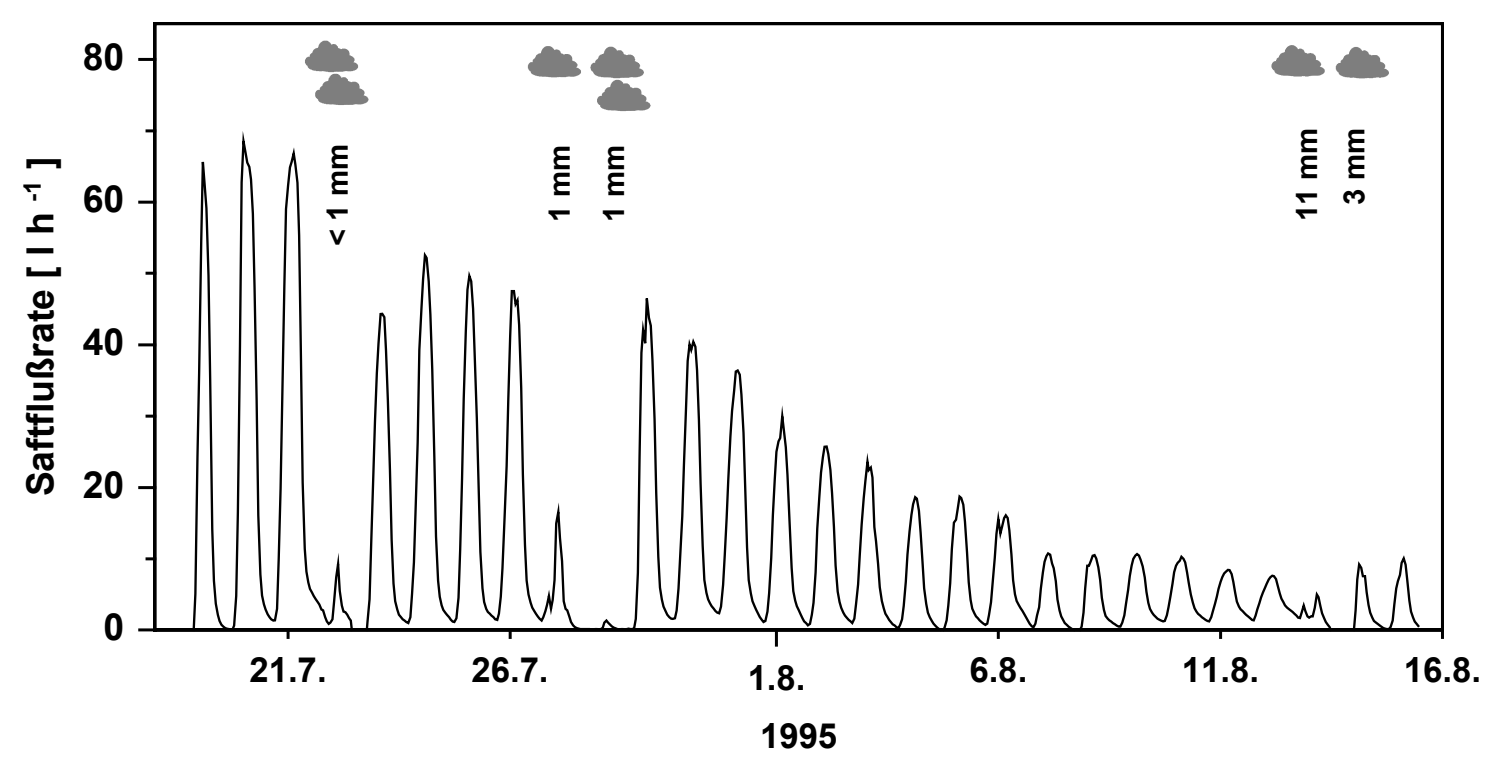

Abb. 4-22: Tagesgänge der Saftflußrate einer Buche (Höhe $35 \mathrm{~m}$, BHD $56 \mathrm{~cm}$ ) im Bestand Göttinger Wald im Verlauf einer Hitze- und Trockenperiode im Hochsommer 1995. Angabe von Tagen mit Bewölkung und Niederschlag.

Nach ergiebigen Niederschlägen Mitte Juli erreichte der Meßbaum an Strahlungstagen nach einem jeweils steilen Anstieg der Saftflußrate mit Tagesbeginn meist zwischen 13.00 und 16.00 Uhr maximale Flußraten von etwa $701 \mathrm{~h}^{-1}$. Die Saftflußrate fiel danach am späteren Nachmittag und abends bis zur Dämmerung wieder steil ab. Dabei kam der Saftfluß nach Strahlungstagen und bei hohen Temperaturen oft auch nachts nicht ganz zum Erliegen, so daß noch Flußraten von $1-21 \mathrm{~h}^{-1} \mathrm{zu}$ beobachten waren, wenn der morgendliche Saftflußanstieg erneut einsetzte. Mit zunehmender Dauer ausbleibender Niederschläge sanken die maximalen Flußraten der Tagesgänge von nahezu $701 \mathrm{~h}^{-1}$ Mitte Juli auf unter $101 \mathrm{~h}^{-1}$ Mitte August ab. Die lange Reihe von Strahlungstagen in der beständigen Schönwetterperiode des Hochsommers 1995 wurde nur durch wenige Tage mit stärkerer Bewölkung und/oder geringem Niederschlag unterbrochen.

Ein charakteristisches Bild des starken Einflusses von Strahlung, Wasserdampf-Sättigungsdefizit der Luft und Niederschlagsereignissen auf die Transpiration und also den Xylemsaftfluß einer 
Buche vermittelt eine nähere Betrachtung der Tagesgänge vom 25. Juli bis zum 28. Juli 1995 (Abb. 4-23). Der 25. Juli stellte einen, ,idealen“ Strahlungstag ohne Bewölkung und mit maximalem Strahlungseinfall dar. Der symmetrische Tagesgang der Globalstrahlung spiegelte sich in einem ebenfalls symmetrischen Tagesgang des Xylemsaftflusses wider. Der Tagesgang des Xylemsaftflusses verlief jedoch über den ganzen Tag um etwa 2 - 3 Stunden verzögert gegenüber dem Tagesgang der Strahlung und folgte damit in typischer Weise weitgehend synchron dem Tagesgang des Sättigungsdefizits der Luft. Schon eine geringe Reduktion der Strahlung infolge durchziehender Wolken am Nachmittag des 26. Juli führte zu leichten Rückgängen der Transpirationsleistung. Die Tagessumme der Transpiration überstieg jedoch mit 4571 aufgrund eines höheren Sättigungsdefizits als am Vortag sogar etwas die Tagessumme von 4311 des vorangegangenen reinen Strahlungstages. An beiden Tagen wurden maximale Transpirationsraten von $501 \mathrm{~h}^{-1}$ gemessen.
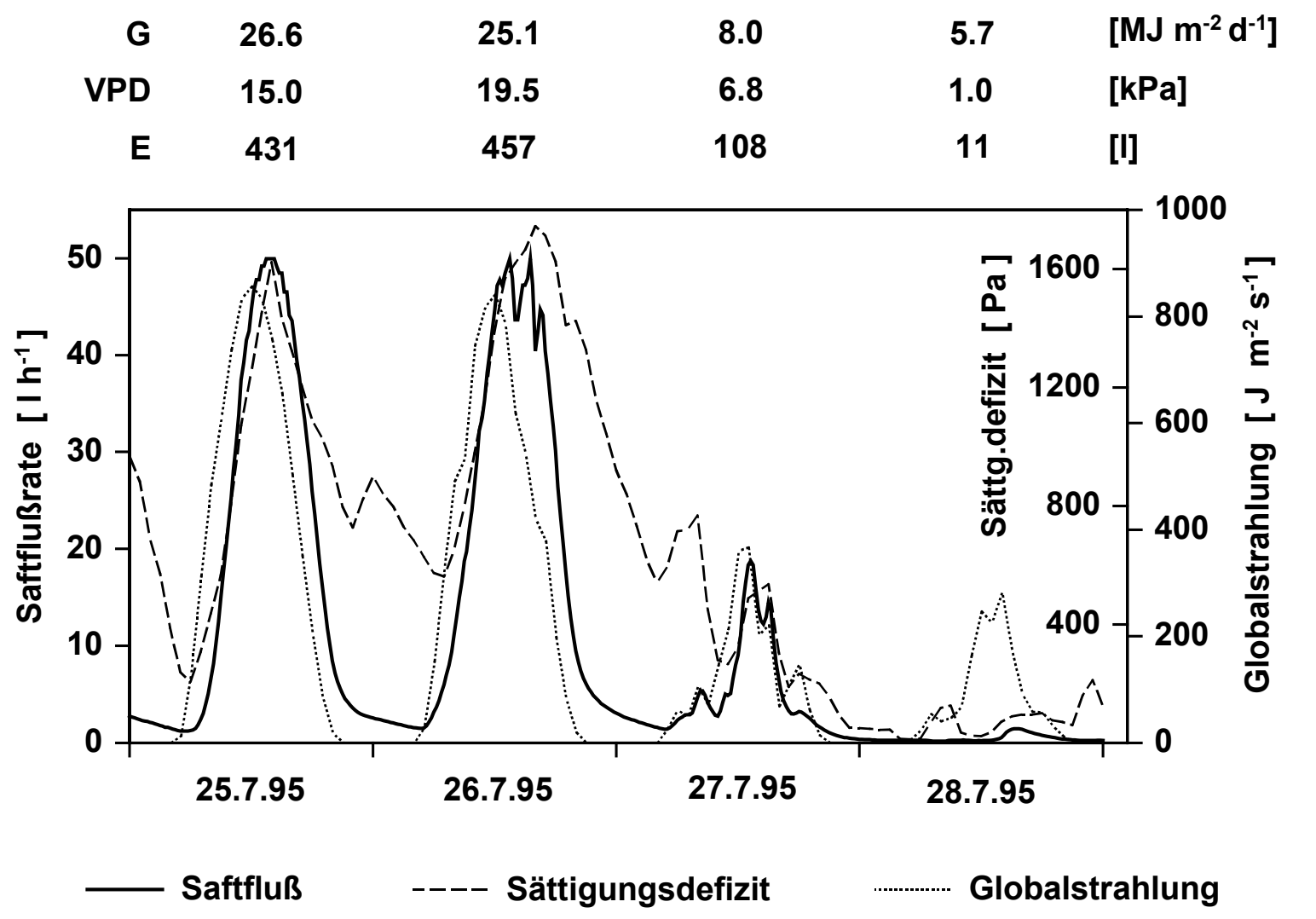

Globalstrahlung

Abb. 4-23: Tagesgänge der Xylem-Saftflußrate einer Buche (Höhe $35 \mathrm{~m}$, BHD $56 \mathrm{~cm}$ ) im Bestand Göttinger Wald und Tagesgänge der Globalstrahlung und des Sättigungsdefizits der Luft an Tagen mit unterschiedlicher Witterung im Hochsommer 1995 sowie Tagessummen der Globalstrahlung (G), TagesHellphasen-Summen $\left(\mathrm{G}>5 \mathrm{~J} \mathrm{~m}^{-2} \mathrm{~s}^{-1}\right)$ aus Stunden-Mittelwerten des Sättigungsdefizits (VPD) und Tagessummen des Saftflusses (E).

Am 27. Juli war bei mehr Bewölkung ein deutlich verringerter Globalstrahlungseinfall zu beobachten. Das Sättigungsdefizit der Luft ebenso wie die Transpiration gingen nach kurzem morgendlichem Anstieg bei vorübergehendem schwachem Niederschlag am Vormittag wieder zurück und stiegen erst nach Mittag wieder etwas an. An diesem Tag wurde eine Transpirationsrate von $201 \mathrm{~h}^{-1}$ nicht überschritten und eine Saftfluß-Tagessumme von 1081 bestimmt. Am 28. Juli blieb bei noch geringerer Globalstrahlung und erneutem Niederschlag das 
Sättigungsdefizit der Luft den ganzen Tag über sehr gering. An diesem Tag war fast keine Transpiration zu beobachten Die maximale Transpirationsrate der Buche betrug nur $1.51 \mathrm{~h}^{-1}$, die Tagessumme der Transpiration 111. Schon am darauffolgenden Tag wurden bei hohen Globalstrahlungs- und Sättigungsdefizitwerten jedoch erneut Transpirationsraten um $501 \mathrm{~h}^{-1}$ erreicht (Abb. 4-23).

\subsubsection{Bestandestranspiration}

Im Jahr 1996 wurde auf allen vier Untersuchungsflächen über die gesamte Vegetationsperiode der saisonale Verlauf der täglichen Bestandestranspiration erfaßt (Abb. 4-24). Die Bestände Ziegelrodaer Forst und Göttinger Wald erreichten mit $216 \mathrm{~mm} \mathrm{bzw.} 225 \mathrm{~mm}$ ähnliche Jahressummen der Bestandestranspiration, von denen sich der Bestand Lüneburger Heide mit $272 \mathrm{~mm}$ sowie der Bestand Solling mit der höchsten jährlichen Bestandestranspiration von $303 \mathrm{~mm}$ deutlich unterschieden.

Im saisonalen Verlauf fällt die weitgehend synchrone Dynamik auf allen vier Untersuchungsflächen bei zugleich sehr unterschiedlichem Niveau der Tageswerte der Bestandestranspiration auf. Auf allen Untersuchungsflächen setzte die Transpiration merklich am 15. / 16. Mai mit einer deutlichen Steigerung der Tagessummen auf Werte über $0.1 \mathrm{~mm}$ ein. Nach einem abrupten Anstieg der täglichen Transpirationsraten Ende Mai traten in allen Untersuchungsbeständen bereits Anfang Juni die höchsten Tageswerte der gesamten Vegetationsperiode auf. Die auf allen Untersuchungsflächen am 7.6.1996 erreichte maximale Tagestranspiration ergab dabei für die Bestände Ziegelrodaer Forst (4.8 mm), Göttinger Wald $(5.3 \mathrm{~mm})$, Lüneburger Heide $(7.2 \mathrm{~mm})$ und Solling $(8.6 \mathrm{~mm})$ die gleiche Reihung zunehmender Bestandestranspiration wie auch bei den Jahressummen. Im Anschluß daran war bis Anfang Juli einheitlich eine abfallende Tendenz der täglichen Transpirationsraten zu beobachten. Während daraufhin in den Beständen Göttinger Wald und Solling im Juli und August noch einmal vergleichbar hohe Tagestranspirationsraten wie Anfang Juni auftraten, blieben diese in den Beständen Ziegelrodaer Forst und Lüneburger Heide auch im weiteren Verlauf des Sommers deutlich unter den hohen Juni-Werten. Ab Mitte September waren in allen Untersuchungsbeständen nur noch sehr niedrige tägliche Transpirationsraten unter $1.5 \mathrm{~mm} \mathrm{zu}$ beobachten, die bis Mitte Oktober auf Werte nahe Null abfielen. 


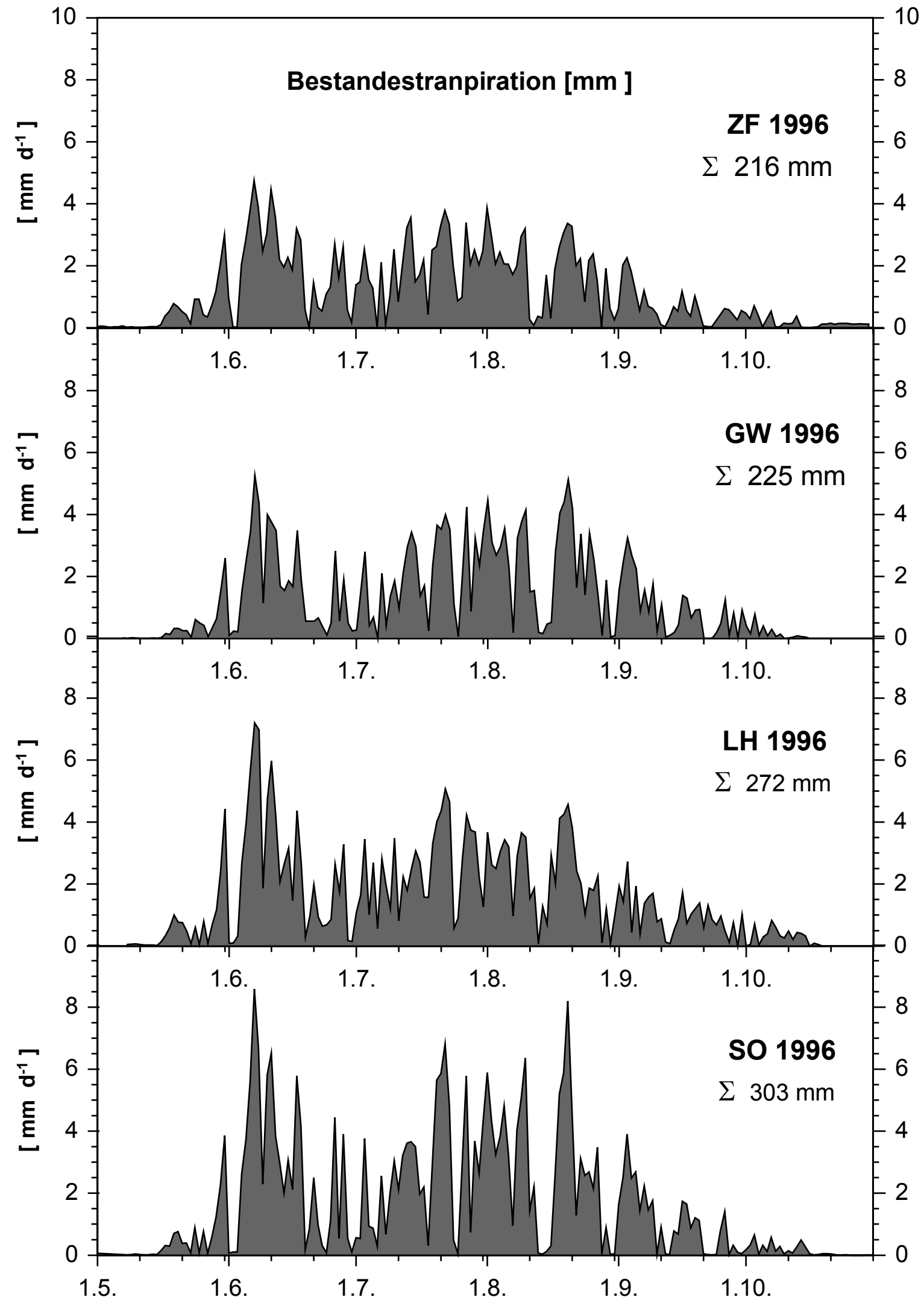

Abb. 4-24: Tagessummen der Bestandestranspiration im Verlauf der Vegetationsperiode 1996 sowie Jahressummen der Bestandestranspiration 1996 in den Beständen Ziegelrodaer Forst (ZF), Göttinger Wald (GW), Lüneburger Heide (LH) und Solling (SO). Angaben für den Bestand Solling nach HEIMANN (pers. Mitt.). 

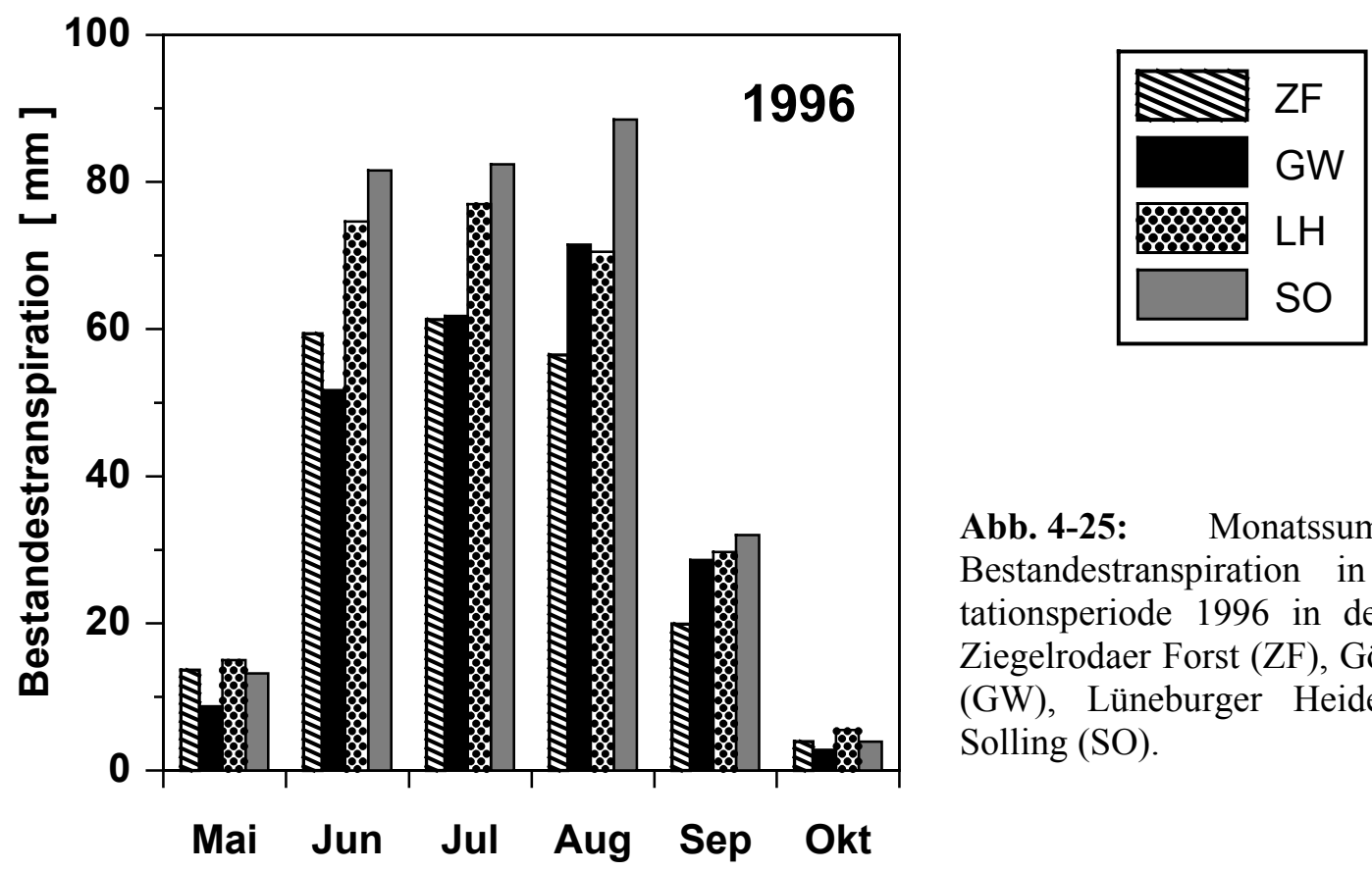

Abb. 4-25: Monatssummen der Bestandestranspiration in der Vegetationsperiode 1996 in den Beständen Ziegelrodaer Forst (ZF), Göttinger Wald (GW), Lüneburger Heide (LH) und Solling (SO).

Abbildung 4-25 zeigt die Monatssummen der Bestandestranspiration 1996 für die vier Untersuchungsflächen. Hier zeichnete sich der Bestand Solling durch die von Juni bis September stets höchsten Monatswerte aus, der Bestand Ziegelrodaer Forst dagegen durch kontinuierlich niedrige Monatssummen. Weiter fällt auf, daß in den Beständen Ziegelrodaer Forst und Lüneburger Heide die höchsten Werte der monatlichen Bestandestranspiration bereits zu Beginn des Sommers zu beobachten waren mit jeweils nahezu gleich hohen Werten im Juni und Juli. Demgegenüber erreichten die Bestände Göttinger Wald und Solling die deutlich höchste monatliche Bestandestranspiration erst im August. Im September war die Monatssumme der Bestandestranspiration auf allen Untersuchungsflächen bereits erheblich geringer. Mai und Oktober trugen nur in sehr geringem Umfang zur Jahressumme der Bestandestranspiration bei.

Die kumulative Auftragung der Tagessummen der Transpiration in Abbildung 4-26 zeigt die unterschiedliche Entwicklung der Bestandestranspiration auf den vier Untersuchungsflächen im Verlauf der Vegetationsperiode. Nach einer Aufspreizung der Kurven im Juni bleiben deren Abstände bis Ende Juli nahezu unverändert. Die Bestände Solling und Lüneburger Heide weisen hier durchweg eine sehr ähnliche sowie die deutlich höchste kumulative Bestandestranspiration auf. Dagegen bleibt die Bestandestranspiration im Ziegelrodaer Forst und noch stärker im Göttinger Wald bereits in diesem Zeitraum deutlich geringer. Im August weichen die Werte der kumulativen Bestandestranspiration schließlich noch stärker auseinander. Ab Anfang August bleibt auch die kumulative Bestandestranspiration des Bestandes Lüneburger Heide merklich hinter derjenigen im Solling zurück. Ab Ende August unterschreitet die kumulative Bestandestranspiration im Ziegelrodaer Forst diejenige im Göttinger Wald und bleibt bis zum Ende der Vegetationsperiode die niedrigste. 


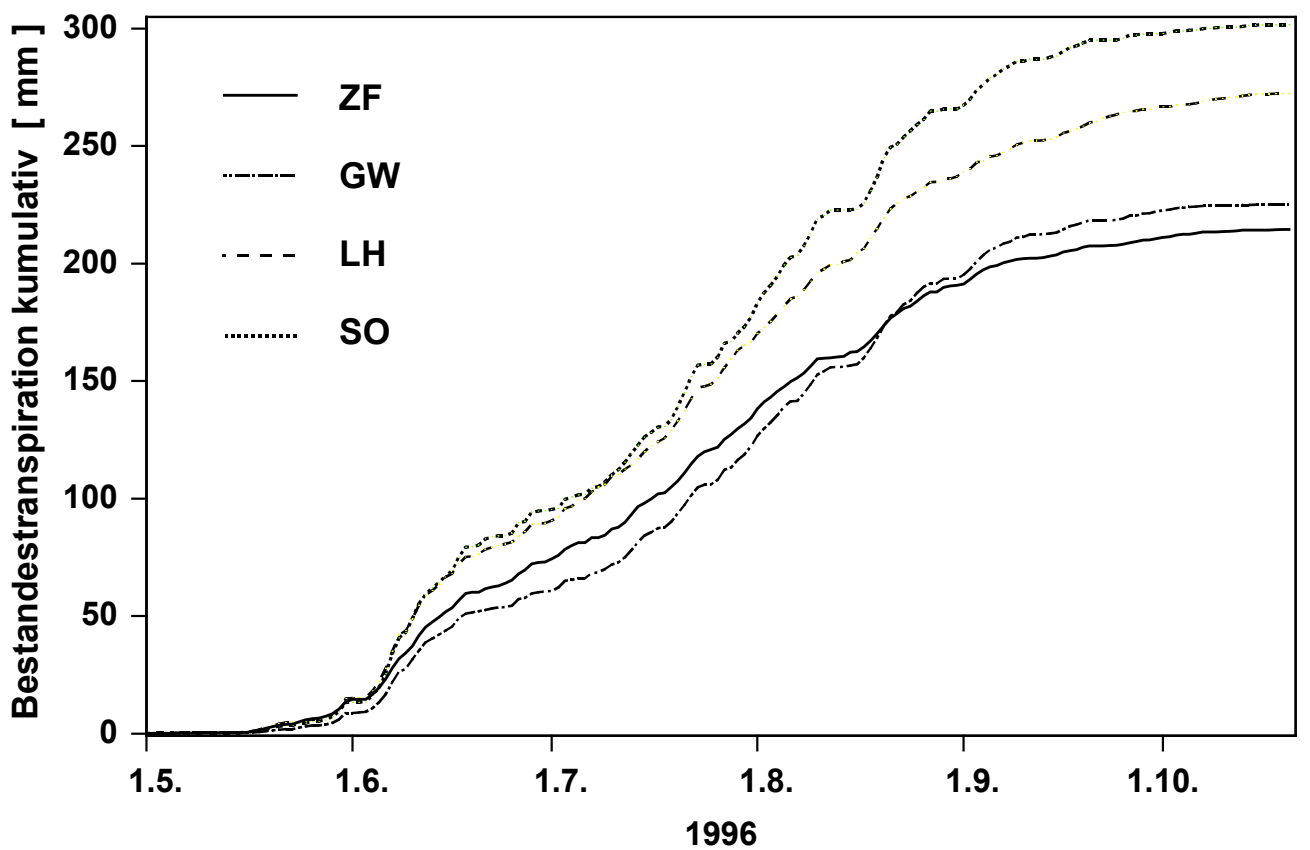

Abb. 4-26: Kumulative Tagessummen der Bestandestranspiration 1996 in den Beständen Ziegelrodaer Forst (ZF), Göttinger Wald (GW), Lüneburger Heide (LH) und Solling (SO).

Die unterschiedliche saisonale Dynamik der kumulativen Transpiration in den Untersuchungsbeständen verdeutlicht ein Vergleich der relativen Anteile an der Jahrestranspiration 1996, die bis zu einem bestimmten Zeitpunkt in der Vegetationsperiode erreicht wurden. Tab. 4-4 gibt für jeden Untersuchungsbestand kumulativ die relativen monatlichen Anteile an der Jahrestranspiration an.

Tab. 4-4: Relative Anteile der Bestandestranspiration an der Jahrestranspiration 1996, kumulativ angegeben für die Monate der Vegetationsperiode 1996 in den Beständen Ziegelrodaer Forst, Göttinger Wald, Lüneburger Heide und Solling.

\begin{tabular}{ccccc}
\hline [ \% ] & $\begin{array}{c}\text { Ziegelrodaer } \\
\text { Forst }\end{array}$ & $\begin{array}{c}\text { Göttinger } \\
\text { Wald }\end{array}$ & $\begin{array}{c}\text { Lüneburger } \\
\text { Heide }\end{array}$ & Solling \\
\hline Mai & 6.3 & 3.9 & 5.5 & 4.4 \\
Juni & 34.0 & 26.8 & 32.9 & 31.5 \\
Juli & 62.6 & 54.3 & 61.2 & 58.8 \\
August & 88.9 & 86.1 & 87.1 & 88.1 \\
September & 98.2 & 98.8 & 98.0 & 98.7 \\
\hline$\sum$ Jun+Jul & $\mathbf{5 5 . 8}$ & $\mathbf{5 0 . 5}$ & $\mathbf{5 5 . 7}$ & $\mathbf{5 4 . 4}$ \\
$\sum_{\text {Aug+Sep }}$ & $\mathbf{3 5 . 3}$ & $\mathbf{4 4 . 5}$ & $\mathbf{3 6 . 8}$ & $\mathbf{4 0 . 0}$ \\
\hline$\sum$ J+J $/ \sum$ A+S & $\mathbf{1 . 5 8}$ & $\mathbf{1 . 1 3}$ & $\mathbf{1 . 5 1}$ & $\mathbf{1 . 3 6}$ \\
\hline
\end{tabular}

Hier wird deutlich, daß der Bestand Lüneburger Heide und noch ausgeprägter der Bestand Ziegelrodaer Forst einen größeren relativen Anteil ihrer Jahrestranspiration bereits im Frühling (Mai) und Frühsommer (Juni und Juli) geleistet haben als die Bestände Göttinger Wald und Solling. Diese erreichten erst durch einen relativ höheren Anteil der Jahrestranspiration im 
Spätsommer (August und September) ein für alle Bestände Ende September etwa gleiches relatives Niveau der Jahrestranspiration.

Für das Untersuchungsjahr 1995 liegt nur für den Bestand Göttinger Wald ein vollständiger Datensatz zur Bestandestranspiration vor. In der Vegetationsperiode 1995 war ein saisonaler Verlauf der täglichen Bestandestranspirationsraten zu beobachten, der stark von demjenigen in der Vegetationsperiode 1996 abwich, ja sogar eine weitgehend zu diesem gegenläufige Entwicklung erkennen ließ (Abb. 4-27).

So setzte die Bestandestranspiration 1995 etwa 15 Tage früher ein als 1996 und erreichte bereits Anfang Mai Tagessummen $>1 \mathrm{~mm}$, die bis Ende Mai und auf Werte $>2 \mathrm{~mm}$ anstiegen. Anders als 1996, als bereits Anfang Juni mit $5.3 \mathrm{~mm}$ der höchste Tageswert der gesamten Vegetationsperiode auftrat, war in der ersten Junihälfte 1995 eine längere Phase auffallend niedriger Transpirationsraten von nur $0.5-1.5 \mathrm{~mm} \mathrm{~d}^{-1} \mathrm{zu}$ beobachten. Diese stiegen daraufhin bis Anfang Juli stark an. Am 9. Juli trat mit einer Tagessumme der Bestandestranspiration von $5.4 \mathrm{~mm}$ das Maximum der Vegetationsperiode 1995 auf und somit ein gleich hoher Maximalwert wie 1996. Im Verlauf der darauf folgenden ausgeprägten sommerlichen Trockenperiode des Jahres 1995 war von Mitte Juli bis Ende August ein starker Rückgang der Bestandestranspiration zu beobachten. Fielen die Transpirationsraten bis Anfang August zunächst rasch auf Werte um $1 \mathrm{~mm} \mathrm{~d}^{-1}$, folgte daraufhin ein langsamerer, aber kontinuierlicher weiterer Rückgang. So wurden zwischen dem 21. und 29. August nur noch Transpirationsraten $<0.5 \mathrm{~mm} \mathrm{~d}^{-1}$ erreicht.

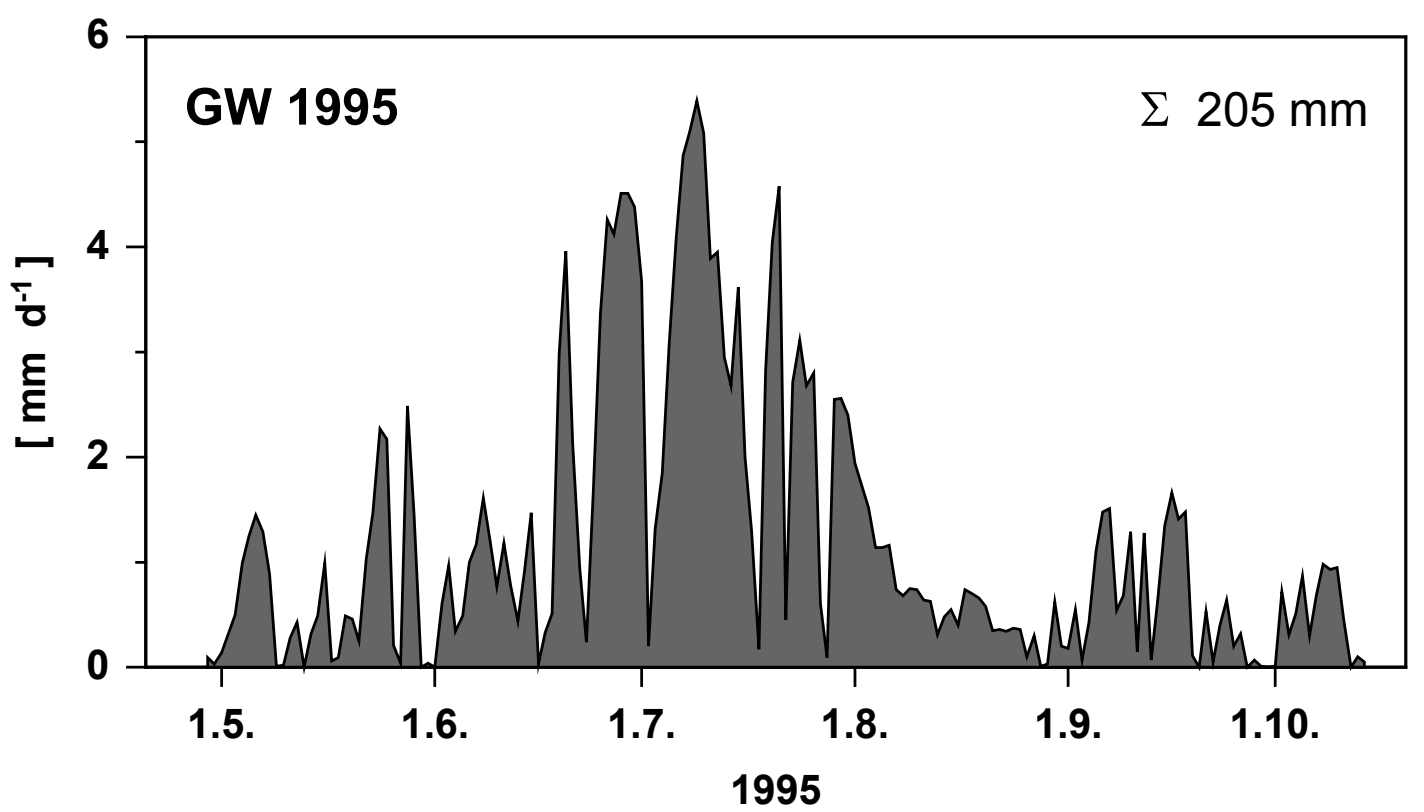

Abb.4-27: Tagessumme der Bestandestranspiration im Verlauf der Vegetationsperiode 1995 und Jahressumme der Bestandestranspiration 1995 im Bestand Göttinger Wald (GW).

Erst am 5. September 1995 war nach einer 30 - tägigen Phase extrem niedriger Transpirationsraten von $<1 \mathrm{~mm} \mathrm{~d}^{-1}$ mit dem Einsetzen ergiebigerer Niederschläge wieder eine Tagessumme der Bestandestranspiration $>1 \mathrm{~mm} \mathrm{zu}$ beobachten. Im September blieben die Tagessummen daraufhin jedoch unter $2 \mathrm{~mm}$ und im Oktober unter $1 \mathrm{~mm}$, obwohl die 
Bestandestranspiration bis kurz vor dem Laubfall Mitte Oktober weniger stark zurückging als 1996.

In der Vegetationsperiode 1997 wurden mit dem in diesem Jahr modifizierten XylemsaftflußMeßsystem (vgl. Kap. 3.5) Jahressummen der Bestandestranspiration von $479 \mathrm{~mm}$ für den Ziegelrodaer Forst, $473 \mathrm{~mm}$ für den Göttinger Wald und $542 \mathrm{~mm}$ für den Bestand Lüneburger Heide ermittelt. Diese zum Teil mehr als doppelt so hohen Jahressummen der Bestandestranspiration gegenüber 1995 und 1996 wurden als unrealistische Fehlmessungen betrachtet, die vermutlich auf eine unzureichende Neuabstimmung der Komponenten des modifizierten Meßsystems zurückzuführen sind (vgl. Kap. 5.3.1). 


\section{Diskussion}

\subsection{Die standörtlichen Wasserhaushaltsbedingungen: Unterschiede in der klimatisch-edaphischen Trockenstreßbelastung}

\subsubsection{Der Klimagradient zwischen den untersuchten Beständen und die klimatische Trockenstreßbelastung in den Untersuchungsjahren}

Auf den Wasserhaushalt eines Buchenbestandes wirkt eine Vielzahl von Klimafaktoren ein. In der vorliegenden Untersuchung wurden Niederschlag, Temperatur, Globalstrahlung und Wasserdampf-Sättigungsdefizit der Luft als wichtige klimatische Parameter des Bestandeswasserhaushalts bestimmt. Die Vielzahl von Klimaparametern erschwert jedoch einen Überblick über unterschiedliche Trockenstreßbelastungen in den verschiedenen Untersuchungsbeständen und Untersuchungsjahren sowie einen Vergleich mit klimatischen Bedingungen an weiteren Standorten, für die nicht zu allen hier untersuchten Klimafaktoren Daten vorliegen.

Komplexe Klimaeigenschaften wie Aridität oder Kontinentalität können jedoch durch Verknüpfung einiger charakteristischer Klimaparameter zu einem Indexwert auch in knapper Form gut beschrieben werden (DE MARTONNE 1925, GAMS 1932, GRIER \& RUNNING 1977, TUHKANEN 1980, ZimMERMANN \& KiENAST 1999).

ELLENBERG (1996) diskutiert als eine entscheidende Ursache für die Verbreitungsgrenze der Buche die Frühjahrs- oder Sommertrockenheit. Er nimmt die kritische Grenze für Buchenstandorte ,bei jährlichen Niederschlägen unter etwa $600 \mathrm{~mm}$ und Mitteltemperaturen des wärmsten Monats über $18-20{ }^{\circ} \mathrm{C}$ “ an. Um das Klimagefälle von buchenreichen zu buchenarmen bis buchenfreien Standorten in Mitteleuropa zu charakterisieren, bildet er aus dem Quotienten der tausendfachen Mitteltemperatur des langjährig wärmsten Monats (i.d.R. Juli) und des langjährigen Jahresniederschlags einen Indexwert der Kontinentalität (Sommertrockenheit) bzw. Humidität des Klimas. Ein hoher Indexwert charakterisiert also ein relativ sommertrockenkontinentales Klima, ein niedriger Indexwert ein humid-ozeanisch geprägtes Klima. Tabelle 5-1 gibt Indexwerte dieses Kontinentalitätsgrades sowie die ihnen von Ellenberg zugeordneten mitteleuropäischen Waldtypen an. Diesen werden die entsprechenden KontinentalitätsIndexwerte aus den langjährigen Klimawerten der Untersuchungsflächen gegenübergestellt. Im Vergleich der Kontinentalitäts-Indexwerte aus langjährigen Klimawerten wird deutlich, daß der Bestand Solling mit einem Indexwert von 13.0 im unteren Bereich der Kontinentalitäts-Skala mitteleuropäischer Buchenwälder rangiert und ein ausgeprägt humides Klima montaner Buchenwälder besitzt. Die Bestände Lüneburger Heide und Göttinger Wald sind mit 20.6 und 22.4 durch mittlere Indexwerte der Kontinentalität gekennzeichnet, die ElLENBERG (1996) submontanen Buchenwäldern als typisch zuordnet. Das Klima dieser Bestände ist immer noch subozeanisch geprägt. Nur der etwas höhere Kontinentalitäts-Index des Göttinger Waldes weist auf einen Übergang zum subkontinentalen Klimatyp mit zunehmender Sommertrockenheit hin. Der Bestand Ziegelrodaer Forst weist mit 32.9 den deutlich höchsten Indexwert der Untersuchungsbestände auf und steht damit am oberen Ende der hier betrachteten 
Kontinentalitätsskala. Er besitzt ein subkontinentales Klima, das bereits von Elementen kontinentaler Sommertrockenheit geprägt ist. ELLENBERG (1996) ordnet dieser Klimaausprägung sogar keine natürlichen Buchenwälder als potentielle natürliche Vegetation mehr zu, sondern sieht hier die Buche typischerweise nur noch als Begleitart der dominierenden trockentoleranteren Eiche an.

Tab. 5-1: Werte des Kontinentalitäts-Index nach ELLENBERG (1996) (1000 • Mitteltemperatur langjährig wärmster Monat / Summe langj. Niederschlag) sowie diesen zugeordnete Waldtypen und entsprechende Indexwerte der Kontinentalität aus langjährigen Mitteln der Klimawerte der Untersuchungsbestände.

\begin{tabular}{cccc}
\hline $\begin{array}{c}\text { Untersuchungs- } \\
\text { bestand }\end{array}$ & $\begin{array}{c}\text { Kont.- } \\
\text { Index }\end{array}$ & $\begin{array}{c}\text { Index-Bereich } \\
\text { nach ELLENBERG (1996) }\end{array}$ & $\begin{array}{c}\text { zugeordneter Waldtyp } \\
\text { nach ELLENBERG (1996) }\end{array}$ \\
\hline- & - & $<10$ & $\begin{array}{c}\text { subalpiner Buchenwald } \\
\text { hochmontaner }\end{array}$ \\
- & - & $\sim 10$ & $\begin{array}{c}\text { Buchen-(Tannen-)Wald } \\
\text { montaner Buchenwald } \\
\text { (mit } \pm \text { Nadelhölzern) }\end{array}$ \\
Solling & 13 & $10-20$ & $\begin{array}{c}\text { submontaner Buchenwald } \\
\text { (mit Eiche u.a.) }\end{array}$ \\
$\begin{array}{c}\text { Lüneburger Heide } \\
\text { Göttinger Wald }\end{array}$ & 20.6 & $20-30$ & $\begin{array}{c}\text { Eiche } \\
\text { ( }\end{array}$ \\
Ziegelrodaer Forst & 32.4 & $>30$ &
\end{tabular}

FELBERMEIER (1993) bestimmte den Kontinentalitäts-Index nach ELLENBERG (1996) für über 1000 Altbuchenbestände in Bayern auf hochmontanen, extrem humiden Standorten bis hin zu ausgeprägt warm-trockenen Standorten, die nach ELLENBERG (1996) bereits als eichendominiert zu betrachten wären. Er ermittelte Kontinentalitäts-Indexwerte von 8-36 mit einem deutlichen Schwerpunkt bei etwa 24. Dabei wiesen nur etwa $4 \%$ der Bestände Indexwerte $<13$ und somit ein humideres Regionalklima als der Bestand im Solling auf. Weniger als $1 \%$ der Buchenstandorte besaß Indexwerte $>33$, die auf ein kontinental-sommertrockeneres Klima als im Bestand Ziegelrodaer Forst hinweisen.

Tab. 5-2: Kennwerte der Kontinentalität des Klimas auf den vier untersuchten Buchenstandorten.

\begin{tabular}{ccccc}
\hline Kontinentalitäts-Kennwerte & $\begin{array}{c}\text { Ziegelrodaer } \\
\text { Forst }\end{array}$ & $\begin{array}{c}\text { Göttinger } \\
\text { Wald }\end{array}$ & $\begin{array}{c}\text { Lüneburger } \\
\text { Heide }\end{array}$ & Solling \\
\hline $\begin{array}{c}\text { Amplitude der langjährigen } \\
\text { Monatsmittel der Temperatur [K] }\end{array}$ & 18.3 & 16.8 & 16.7 & 16.5 \\
$\begin{array}{c}\text { Ausprägung der Niederschlagsverteilung } \\
\text { Sommermaximum / Wintermaximum }\end{array}$ & $\mathrm{SM} /-$ & $\mathrm{SM} /(\mathrm{WM})$ & $\mathrm{SM} / \mathrm{WM}$ & $\mathrm{SM} / \mathrm{WM}$ \\
$\begin{array}{c}\text { Anteil langj. Niederschläge Mai-September } \\
\text { an langj. Jahressumme des Niederschlags [\%] } \\
\begin{array}{c}\text { Variationskoeffizient der langjährigen } \\
\text { Monatsmittel des Niederschlags [\%] }\end{array}\end{array}$ & 53 & 49 & 44 & 44 \\
\hline
\end{tabular}

Die Einordnung der langjährigen mittleren Klimawerte der in der vorliegenden Arbeit untersuchten Buchenbestände zeigt also, daß der klimatische Gradient zwischen diesen einen weiten Bereich des Klimaspektrums abdeckt, das für mitteleuropäische Buchenwälder 
charakteristisch ist. Darüber hinaus unterstreichen weitere Klimakennwerte, die eine ozeanische bzw. kontinentale Klimaausprägung charakterisieren, die zunehmend kontinentalere Tönung des Klimas der Untersuchungsbestände vom Solling über die Lüneburger Heide und den Göttinger Wald bis zum Ziegelrodaer Forst (Tab. 5-2).

Um die in der vorliegenden Untersuchung bestimmten Reaktionsmuster der Wasserhaushaltsregulation vor dem Hintergrund des Niederschlags- und Kontinentalitätsgradienten zwischen den untersuchten Buchenbeständen beurteilen zu können, ist jedoch zu klären, inwieweit der langjährige Klimagradient auch in den Untersuchungsjahren repräsentiert war. Für die Berechnung eines repräsentativen Kontinentalitäts-Indexwertes einzelner Untersuchungsjahre oder Vegetationsperioden ist das Heranziehen des Jahresniederschlags und der Mitteltemperatur des wärmsten Monats nach ELLENBERG (1996) jedoch nur bedingt geeignet. Zumal die Mitteltemperatur eines einzelnen Monats sich stark vom restlichen Witterungsverlauf der betrachteten Vegetationsperiode unterscheidet und so zu einem Indexwert führen kann, der diese Vegetationsperiode insgesamt nur schlecht repräsentiert. Darüber hinaus haben auch die Niederschlagsverteilung über das Jahr und die Wasserspeichereigenschaften des Bodens auf einem Standort wesentlichen Einfluß darauf, in welchem Umfang ein Bestand während der Vegetationsperiode von der Jahresumme der Niederschlags profitieren kann.

MAKOWKA et al. (1991) entwickelte daher aus dem ganzjährigen Kontinentalitäts-Index nach ELLENBERG (1996) einen monatlichen "Kontinentalitätsfaktor" (K), um die Verteilung kalt-feuchter bis warm-trockener Monate über ein einzelnes Untersuchungsjahr zu charakterisieren. Dieser Index errechnet sich nach Gleichung (5-1):

$$
\mathrm{K}=1000 \cdot \frac{\text { Mitteltemperatur betrachteter Monat }}{\text { Niederschlag betr. Monat }+ \text { Niederschlag } 2 \text { Vormonate }}=1000 \cdot \frac{\left(\overline{\mathrm{T}}_{\mathrm{n}}\right)}{\left(\mathrm{Nd}_{\mathrm{n}}+\mathrm{Nd}_{\mathrm{n}-1}+\mathrm{Nd}_{\mathrm{n}-2}\right)}
$$

In einer Untersuchung des Klimaeinflusses auf den jährlichen Holzzuwachs in dem hier ebenfalls untersuchten Bestand Solling stellte MAKOWKA et al. (1991) eine engere Korrelation des Holzzuwachses mit diesem monatlichen Indexwert fest als mit den einzelnen in den Index eingehenden Klimaparametern Temperatur bzw. Niederschlag.

Der Bestand im Solling zeigte in der vorliegenden Untersuchung jedoch bei den höchsten Niederschlägen und einer vergleichsweise hohen Nutzwasserkapazität deutlich langsamere und geringere Änderungen des Bodenwasserzustands als die anderen hier untersuchten Bestände. Für eine vergleichende Betrachtung auch von Beständen mit einem geringeren Wasserspeichervermögen des Bodens und schnelleren Änderungen des Bodenwassergehalts wie etwa im Ziegelrodaer Forst ist daher die Betrachtung eines kürzeren Niederschlagszeitraums sinnvoll. Dementsprechend wird in der vorliegenden Untersuchung für einen Vergleich der Untersuchungsjahre ein nach MAKOWKA et al. (1991) abgewandelter monatlicher Kontinentalitäts- bzw. Trockenheits-Index $\left(\mathrm{K}_{2 \mathrm{n}}\right)$ zu Grunde gelegt, in den nur die Niederschläge eines zweimonatigen Betrachtungszeitraums eingehen (Gl. 5-2).

$$
K_{2 n}=1000 \cdot \frac{\left(\bar{T}_{n}\right)}{\left(\mathrm{Nd}_{n}+\mathrm{Nd}_{\mathrm{n}-1}\right)}
$$


Entsprechende monatliche Indexwerte der Kontinentalität (Sommertrockenheit) im saisonalen Verlauf für die Untersuchungsjahre sowie im langjährigen Mittel zeigt Abbildung 5-1.
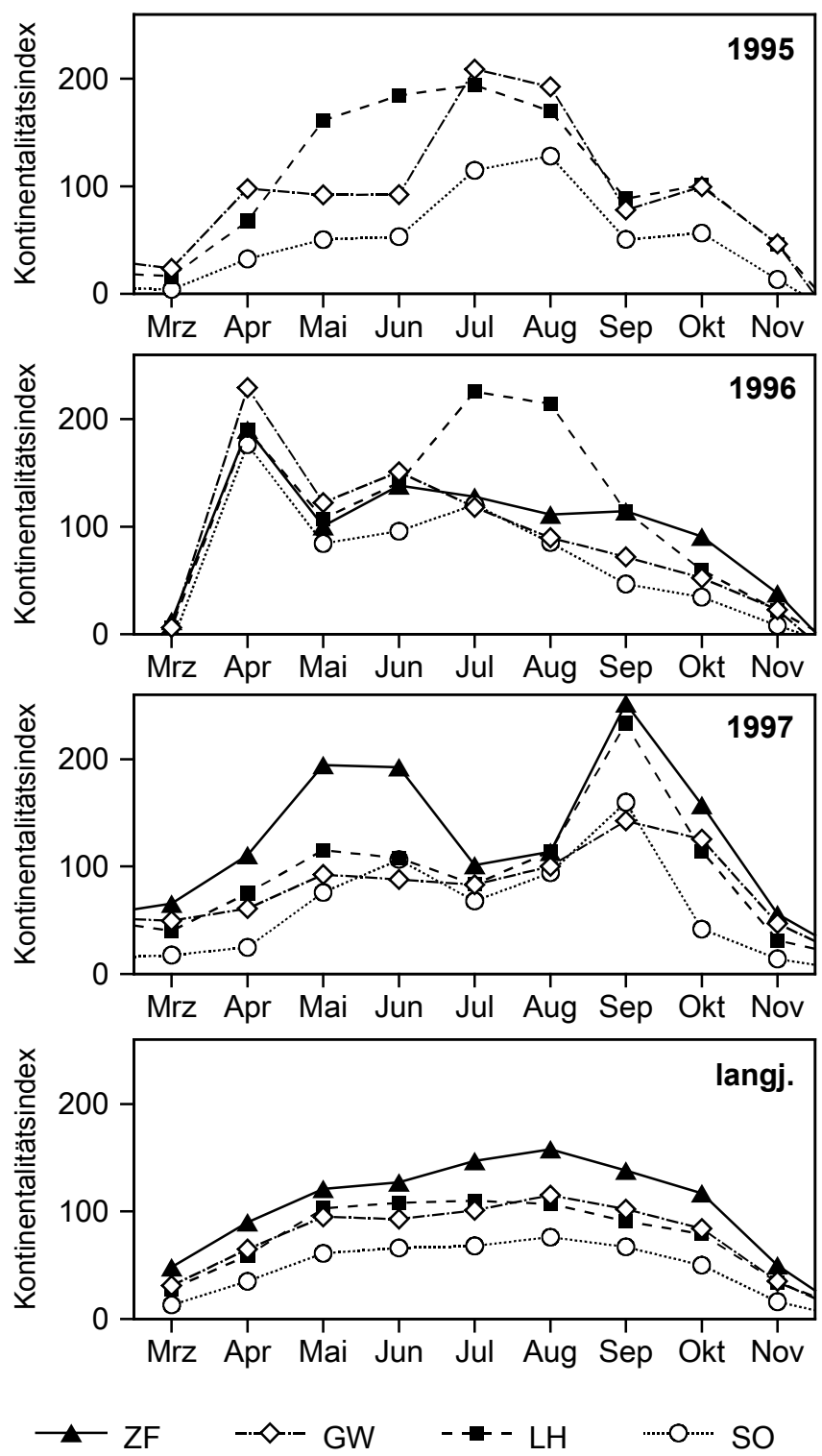

Abb. 5-1: Monatlicher Kontinentalitäts-Index (Trockenheits-Index) abgewandelt nach MAKOwKA et al. (1991) gebildet aus dem Quotienten der tausendfachen Mitteltemperatur des betrachteten Monats und der Summe aus dem Niederschlag des betrachteten Monats und des Vormonats $\left(1000 \cdot\right.$ Mittel-T $\left[{ }^{\circ} \mathrm{C}\right] /$ $\Sigma$ Nd. 2 Monate [mm]) für die Untersuchungsjahre 1995, 1996 und 1997 sowie im langjährigen Mittel in den Untersuchungsbeständen Ziegelrodaer Forst (ZF), Göttinger Wald (GW), Lüneburger Heide (LH) und Solling (SO).

In den monatlichen Indexwerten der Kontinentalität im langjährigen Mittel kommt dabei wie schon beim Index nach ELLENBERG (1996) deutlich zum Ausdruck, daß der Bestand Ziegelrodaer Forst das kontinental-sommertrockenste und der Bestand Solling das humideste Klima der Untersuchungsbestände besitzt. Darüber hinaus fällt im saisonalen Verlauf auf, daß für den Bestand Ziegelrodaer Forst im langjährigen Mittel eine starke Zunahme der klimatischen Trockenstreßbelastung von Mai bis August zu beobachten ist. Im Göttinger Wald und im Solling ist diese weniger ausgeprägt und in der Lüneburger Heide kaum zu erkennen. 
In den Untersuchungsjahren wich die saisonale Entwicklung der Trockenheitsbelastung in den einzelnen Beständen zum Teil erheblich vom langjährigen Mittel ab.

So waren nur im Untersuchungsjahr 1995 ein Trockenstreß-Gradient zwischen den untersuchten Beständen und eine saisonale Entwicklung zu beobachten, die etwa dem langjährigen Mittel entsprachen. Dieses Jahr zeichnete sich jedoch durch eine extreme hochsommerliche Trockenstreßeinwirkung im Göttinger Wald und eine von Mai bis August andauernde starke Trockenheitsbelastung in der Lüneburger Heide aus.

1996 war in allen Beständen außer in der Lüneburger Heide bereits ab Juni / Juli ein Rückgang der klimatischen Trockenheitsbelastung festzustellen. Im Göttinger Wald und im Solling fielen die Monatswerte des Kontinentalitätsindex bis September rasch auf sehr geringe Werte ab. Im Ziegelrodaer Forst war dagegen nur ein geringer Rückgang zu beobachten. Der Bestand Lüneburger Heide zeigte im Hochsommer eine völlig abweichende Entwicklung des Kontinentalitätsindex. Außergewöhnlich geringe Niederschläge seit Juni führten hier im Juli und August zu einer ausgeprägten Sommertrockenheit, obwohl von Juni bis August nur etwa dem langjährigen Mittel entsprechende Temperaturen herrschten.

1997 entsprachen mit Ausnahme des Bestandes im Ziegelrodaer Forst die monatlichen KlimaIndexwerte von Mai bis August etwa dem Durchschnitt. Dort trat nach unterdurchschnittlichen Niederschlägen von April bis Juni eine selbst für diesen Bestand außergewöhnlich hohe klimatische Trockenheitsbelastung im Mai und Juni auf, die somit diejenige der anderen Untersuchungsbestände erheblich übertraf. Im Kontrast dazu wurden im Ziegelrodaer Forst durch extrem hohe Juliniederschläge im Juli und August merklich geringere Monatswerte des Kontinentalitätsindex erreicht als im langjährigen Mittel. Nach allgemein hohen Juliniederschlägen zeigten damit alle Flächen trotz extrem hoher Augusttemperaturen im Hochsommer ein etwa gleiches Niveau mäßiger Trockenheitsbelastung. Die deutlich höchste Trockenstreßeinwirkung trat 1997 in allen Untersuchungsbeständen erst im September auf. Bei durchschnittlichen Temperaturen wurde in allen Beständen für diesen Monat die geringste Niederschlagssumme der gesamten drei untersuchten Vegetationsperioden bestimmt. Dabei wurden im Ziegelrodaer Forst und in der Lüneburger Heide darüber hinaus die höchsten Kontinentalitäts-Indexwerte der gesamten Untersuchung ermittelt.

Sowohl der Ziegelrodaer Forst als auch der Bestand Lüneburger Heide fielen also in jeder der dort untersuchten Vegetationsperioden im Bestandesvergleich durch besonders hohe Indexwerte der Kontinentalität und somit durch besondere Sommertrockenheit auf. Dies kommt auch in saisonalen Mittelwerten des monatlichen Kontinentalitätsindex für die Zeiträume JuniSeptember bzw. Juli - August deutlich zum Ausdruck (Tab. 5-3).

Für beide Betrachtungszeiträume weisen die Bestände Ziegelrodaer Forst und Lüneburger Heide in allen Untersuchungsjahren im Bestandesvergleich jeweils die beiden höchsten Mittelwerte des monatlichen Kontinentalitätsindex auf. Eine Ausnahme stellt hier nur das Untersuchungsjahr 1995 dar, in dem im Ziegelrodaer Forst noch keine Messungen durchgeführt wurden. In diesem Jahr wirkte außer im Bestand Lüneburger Heide auch im Göttinger Wald ein ausgeprägter Trockenstreß. Der Bestand Solling wies dagegen stets die geringsten oder allenfalls gleich hohe Werte des monatlichen Kontinentalitätsindex auf wie der Göttinger Wald (Abb. 5-1, Tab. 5-3). Auf den humidesten Bestand Solling wirkte somit durchwegs kaum eine klimatische Trockenheitsbelastung ein. 
Tab. 5-3: Saisonale Mittelwerte des nach MAKOWKA et al. (1991) veränderten monatlichen Index der Kontinentalität (Sommertrockenheit) $\left(1000 \cdot\left(\overline{\mathrm{T}}_{\mathrm{n}}\right) /\left(\mathrm{Nd}_{\mathrm{n}}+\mathrm{Nd}_{\mathrm{n}-1}\right)\right)$ der untersuchten Bestände in den Untersuchungsjahren sowie im langjährigen Mittel.

\begin{tabular}{lccccc}
\hline \multicolumn{2}{c}{ Betrachtungszeitraum } & $\begin{array}{c}\text { Ziegelrodaer } \\
\text { Forst }\end{array}$ & $\begin{array}{c}\text { Göttinger } \\
\text { Wald }\end{array}$ & $\begin{array}{c}\text { Lüneburger } \\
\text { Heide }\end{array}$ & Solling \\
\hline Jun - Sep & 1995 & - & 143 & 160 & 87 \\
Jun - Sep & 1996 & 123 & 108 & 174 & 87 \\
Jun - Sep & 1997 & 165 & 103 & 134 & 107 \\
Jun - Sep & langj. Mittel & $\mathbf{1 4 3}$ & $\mathbf{1 0 3}$ & $\mathbf{1 0 4}$ & $\mathbf{6 9}$ \\
Jul - Aug & 1995 & - & 201 & 182 & 122 \\
Jul - Aug & 1996 & 120 & 104 & 220 & 103 \\
Jul - Aug & 1997 & 108 & 92 & 99 & 81 \\
Jul - Aug & langj. Mittel & $\mathbf{1 5 2}$ & $\mathbf{1 0 8}$ & $\mathbf{1 0 9}$ & $\mathbf{7 2}$ \\
\hline
\end{tabular}

Betrachtet man den gesamten Untersuchungszeitraum von drei, im Ziegelrodaer Forst zwei Vegetationsperioden ergibt sich aus den monatlichen Indexwerten der Kontinentalität bezüglich der Sommertrockenheit der untersuchten Bestände folgende Reihung:

$$
\text { Lüneburger Heide } \approx \text { Ziegelrodaer Forst }>\text { Göttinger Wald }>\text { Solling }
$$

Dies überrascht insofern als der langjährig subozeanisch geprägte Standort Lüneburger Heide über drei Vegetationsperioden hinweg klimatisch so stark von den langjährigen Mittelwerten abwich, daß er im Untersuchungszeitraum ein etwa gleiches Niveau der Sommertrockenheit erreichte wie der langjährig kontinental-sommertrockenste Standort Ziegelrodaer Forst. Die anderen Bestände zeigten im Untersuchungszeitraum meist eine etwa den langjährigen Mittelwerten entsprechende Belastung durch Sommertrockenheit und wichen somit nicht vom langjährigen Kontinentalitätsgradienten zwischen den Untersuchungsbeständen ab.

Die untersuchten Buchenstandorte zeigten also in den Klimafaktoren Niederschlag und Temperatur und der resultierenden Einwirkung von Trockenstreß sowohl im langjährigen Mittel als auch in den Untersuchungsjahren deutliche Unterschiede. Demgegenüber blieben die Unterschiede von Globalstrahlung und Wasserdampf-Sättigungsdefizit der Luft zwischen den Untersuchungsbeständen stets erstaunlich gering. Die Globalstrahlung ist die bestimmende Input-Größe der Bestandes-Energiebilanz (JONES 1992, LöSCH 1994) und nimmt mit ihrem PARAnteil über die Blaulichtregulation der Stomaöffnung wesentlichen Einfluß auf die Transpiration (SCHUlZE 1970, LöSCH 2001). Das Wasserdampf-Sättigungsdefizit der Luft stellt ein Maß für die auf den Bestand wirkende Verdunstungsbeanspruchung und also die eigentliche treibende Kraft der Transpiration dar (MONTEITH 1981, LARCHER 1994). Diese beiden auf die Transpiration und mithin den Bestandeswasserhaushalt entscheidend einwirkenden Klimaparameter unterschieden sich in den transpirationsintensiven Sommermonaten Juni - September zwischen den Beständen nur um maximal $6 \%$ (Globalstrahlung) bzw. $10 \%$ (Sättigungsdefizit). Ein einheitlicher Gradient zwischen den Untersuchungsflächen war dabei nicht zu erkennen.

Auch die in mehrjährigen Mitteln vorliegenden Monatssummen der Globalstrahlung in den Beständen Solling (EllenberG \& WiLMERS. 1986) und Göttinger Wald (EHRHARDT 1988) 
unterscheiden sich für die Monate der Vegetationsperiode nur sehr geringfügig untereinander sowie von entsprechenden Werten weiterer Stationen im mitteldeutschen Tiefland (GOLCHERT 1981, PALZ 1996) (Tab. 5-4).

Tab. 5-4: Mehrjährige Mittelwerte der Monatssummen der Globalstrahlung für die Bestände Göttinger Wald (Mittelwert über 7 Jahre im Zeitraum 1982 - 1997) und Solling (Mittelwert über 9 Jahre im Zeitraum 1967 - 1997) sowie Mittel der entsprechenden Werte von 10 Stationen im Mitteldeutschen Tiefland (Mittelwert 1966 - 1975) nach PALZ (1996).

\begin{tabular}{cccccccc}
\hline$\left[\mathbf{M J ~ m}^{-2}\right]$ & Mai & Juni & Juli & Aug. & Sept. & Mai-Sep & Jun-Aug \\
\hline Göttinger Wald & 455 & 531 & 568 & 477 & 304 & $2336 \pm 293$ & $1576 \pm 138$ \\
Solling & 496 & 546 & 562 & 491 & 314 & $2408 \pm 196$ & $1598 \pm 120$ \\
Mittel 10 Stationen Tiefland & 506 & 552 & 532 & 471 & 305 & $2366 \pm 84$ & $1555 \pm 60$ \\
\hline
\end{tabular}

Sowohl der langjährige als auch der in den Untersuchungsjahren auftretende Niederschlagsgradient zwischen den Untersuchungsflächen lassen also keine Auswirkung auf die Klimafaktoren Globalstrahlung und Sättigungsdefizit der Luft erkennen. Die Annahme etwa besonders geringer Globalstrahlungssummen (ELLENBERG \& WILMERS 1986) oder Sättigungsdefizitwerte für den montanen und sehr niederschlagsreichen Standort Solling gegenüber tiefer gelegenen und niederschlagsärmeren Standorten trifft so offenbar nicht zu.

Zusammenfassend kann festgehalten werden, daß zwischen den Regionalklimaten der Untersuchungsbestände ein Niederschlags- und Kontinentalitätsgradient besteht, der das Spektrum mitteleuropäischer Buchenklimate weitgehend abdeckt. Dieser Klimagradient war auch in den Untersuchungsjahren repräsentiert. Dem gegenüber steht ein auf allen Untersuchungsflächen auffällig einheitliches Luftfeuchte- und Strahlungsregime.

\subsubsection{Unterschiede und Gemeinsamkeiten in der Bodenwasserversorgung der untersuchten Bestände}

Allgemein stimmte die Entwicklung des Bodenwasserzustands und damit das Ausmaß der edaphischen Trockenheitsbelastung in den untersuchten Beständen weitgehend mit der klimatischen Trockenheitsbelastung überein, wie sie die monatlichen KontinentalitätsIndexwerte ausdrücken. Im Bodenwasserzustand kam jedoch zu Beginn der Vegetationsperiode der noch von der Aufsättigung im Winterhalbjahr stammende hohe Bodenwasservorrat trockenstreß-mildernd zum Tragen. Im Spätsommer wurde dagegen aufgrund einer deutlich fortgeschrittenen Erschöpfung des Bodenwasservorrats die klimatische Trockenheitsbelastung meist noch durch die angewachsene Bodentrockenheit verstärkt. Dadurch war in allen Beständen und Untersuchungsjahren im Verlauf der Vegetationsperiode die Tendenz einer Zunahme der Trockenstreßeinwirkung bis August, in den Jahren 1996 und besonders 1997 sogar bis in den September zu beobachten.

Dabei unterschied sich abhängig von Bodenart und Niederschlagsregime die Dynamik der Änderung des Bodenwasserzustandes zwischen den Beständen in charakteristischer Weise: 
- Im Solling waren stets die entspanntesten Bodenmatrixpotentiale und die geringsten und langsamsten Schwankungen des Bodenwassergehalts zu beobachten. Die ausgeprägteste Bodentrockenheit trat hier meist im Hochsommer auf.

- Im Göttinger Wald erfolgte häufig eine schnelle Änderung des Bodenwasserzustandes über den gesamten flachgründigen Feinbodenbereich. Dabei trat jedoch mit Ausnahme des Hochsommers 1995 keine ausgeprägte und langandauernde Bodenwasserverknappung auf.

- Im Bestand Lüneburger Heide wie auch im Ziegelrodaer Forst waren ebenfalls vergleichsweise schnelle und starke Änderungen des Bodenwasserzustandes zu beobachten mit 1995 im Hochsommer, 1996 und 1997 besonders im Spätsommer langanhaltender und ausgeprägter Bodentrockenheit. Diese war wiederum im Unterboden besonders ausgeprägt.

Allgemein war die beobachtete Tendenz einer zunehmenden Erschöpfung des Bodenwasservorrats mit dem Fortschreiten der Vegetationsperiode verbunden mit einem stärkeren Rückgang des Bodenwasservorrats im Unterboden (10 - $40 \mathrm{~cm}$ Bodentiefe) als in den obersten $10 \mathrm{~cm}$ des Mineralbodens. Die Bodentiefe von 0 bis $40 \mathrm{~cm}$ umfaßt in allen Untersuchungsbeständen den intensiv von Feinwurzeln erschlossenen Bereich des Mineralbodens (Tab. 5-5) mit einer wiederum besonders hohen Feinwurzeldichte in $0-10 \mathrm{~cm}$ Bodentiefe (SCHLICHTER et al. 1983, HERTEL 1999).

Tab.5-5: Trockenmasse lebender Feinwurzeln $(\mathrm{d}<2 \mathrm{~mm})$ in unterschiedlichen Bodentiefen der Bestände Ziegelrodaer Forst (ZF), Göttinger Wald (GW), Lüneburger Heide (LH) und Solling (SO) nach HERTEL (1999). Angegeben sind Mittelwerte von 4 - 5 Probenahmeterminen in den Jahren 1996 und 1997.

\begin{tabular}{|c|c|c|c|c|c|c|c|}
\hline $\begin{array}{l}\text { Tiefe } \\
\text { [cm] }\end{array}$ & $\begin{array}{c}\mathbf{Z F} \\
{\left[\mathrm{g} \mathrm{TM} \mathrm{m}^{-2}\right]}\end{array}$ & $\begin{array}{l}\text { Tiefe } \\
\text { [cm] }\end{array}$ & $\begin{array}{c}\mathbf{G W} \\
{\left[\mathrm{g} \mathbf{T M ~ m}^{-2}\right]}\end{array}$ & $\begin{array}{l}\text { Tiefe } \\
\text { [cm] }\end{array}$ & $\begin{array}{c}\text { LH } \\
{\left[\mathrm{g} \mathrm{TM} \mathrm{m}^{-2}\right]}\end{array}$ & $\begin{array}{l}\text { Tiefe } \\
\text { [cm] }\end{array}$ & $\begin{array}{c}\text { SO } \\
{\left[\mathrm{g} \mathrm{TM} \mathrm{m}^{-2}\right]}\end{array}$ \\
\hline$O_{f}-40:$ & 170.8 & & 328.5 & $O_{f}-40:$ & 447.6 & $O_{f}-40:$ & 308.5 \\
\hline $40-200:$ & 86.9 & $40-100:$ & 63.8 & $40-350:$ & 79.2 & $40-120$ & 40.1 \\
\hline
\end{tabular}

Trotz der höchsten Feinwurzeldichten und damit einhergehenden hohen Wasseraufnahmeraten (CONERS 2001) war in $0-10 \mathrm{~cm}$ Bodentiefe dennoch fast durchwegs eine höhere Bodenfeuchte $\mathrm{zu}$ beobachten als in $10-40 \mathrm{~cm}$ Bodentiefe (Tab. 5-6). Ursache dafür waren bei hohen sommerlichen Transpirationsraten häufig nicht ausreichende Niederschläge, um die Wasseraufnahme durch die Wurzeln zu kompensieren. Dadurch konnte bei geringen oder mäßigen Niederschlägen das Wasser oft nur wenige Zentimeter in den Boden eindringen und so nur den Oberboden wiederbefeuchten. Auch bei ergiebigeren Niederschlägen blieb die Wiederbefeuchtung des Unterbodens meist deutlich geringer als im Oberboden. Infolge dieser geringeren Wiederbefeuchtungsraten und bei zugleich fortschreitender Aufzehrung der aus der Winteraufsättigung stammenden Bodenwasservorräte sanken der Nutzwassergehalt bzw. die Matrixpotentiale im Unterboden (10 - $40 \mathrm{~cm}$ Bodentiefe) im Lauf der Vegetationsperiode meist stärker ab als oberflächennah (vgl. BENECKE 1984, GERKE 1987, LEUSCHNER 1993. STROBEL 1997) (Tab. 5-6). 
Tab. 5-6: Monatliche Mittelwerte der Nutzwassergehalte $(\Theta)$ in $0-10 \mathrm{~cm}$ und $10-40 \mathrm{~cm}$ Bodentiefe der Bestände Ziegelrodaer Forst (ZF), Göttinger Wald (GW) und Lüneburger Heide (LH) sowie monatliche Mittelwerte der Bodenmatrixpotentiale $(\Psi)$ in $10 \mathrm{~cm}$ und $40 \mathrm{~cm}$ Bodentiefe im Bestand Solling (für diesen Bestand liegen keine entsprechend nach Bodentiefen differenzierten Nutzwassergehalte vor) in der Vegetationsperiode 1996.

\begin{tabular}{ccccccc}
\hline $\begin{array}{c}\boldsymbol{\Theta}[\mathbf{V o l . \%} \text { ] } \\
\boldsymbol{\Psi}[\mathbf{h P a}]\end{array}$ & Bodentiefe & Juni & Juli & August & Sept. & Juni-Sept. \\
\hline \multirow{2}{*}{ ZF $\boldsymbol{\Theta}[$ Vol. \%] } & $0-10 \mathrm{~cm}$ & 11.3 & 10.9 & 7.6 & 5.5 & $\mathbf{8 . 8}$ \\
& $10-40 \mathrm{~cm}$ & 12.2 & 10.9 & 6.5 & 3.9 & $\mathbf{8 . 4}$ \\
GW $\boldsymbol{\Theta}[$ Vol. \%] & $0-10 \mathrm{~cm}$ & 19.0 & 17.8 & 14.7 & 17.8 & $\mathbf{1 7 . 3}$ \\
& $10-40 \mathrm{~cm}$ & 10.6 & 11.5 & 10.0 & 10.1 & $\mathbf{1 0 . 5}$ \\
LH $\boldsymbol{\Theta}[$ Vol. \%] & $0-10 \mathrm{~cm}$ & 12.6 & 14.3 & 10.7 & 12.4 & $\mathbf{1 2 . 5}$ \\
& $10-40 \mathrm{~cm}$ & 5.2 & 4.8 & 3.1 & 4.1 & $\mathbf{4 . 3}$ \\
SO $\boldsymbol{\Psi}[\mathbf{h P a}]$ & $10 \mathrm{~cm}$ & -58 & -43 & -70 & -35 & $\mathbf{- 5 1}$ \\
& $40 \mathrm{~cm}$ & -292 & -255 & -375 & -94 & $\mathbf{- 2 5 5}$ \\
\hline
\end{tabular}

Der Oberboden $(0-10 \mathrm{~cm})$ mit seiner besonders hohen Feinwurzeldichte war also zugleich der am besten wasserversorgte Bereich innerhalb des von Feinwurzeln intensiv erschlossenen Mineralbodenraums (0-40) (Tab. 5-5, Tab. 5-6). Man kann somit annehmen, daß der oberflächennahe Mineralboden eine, wenn nicht die entscheidende Rolle bei der Erschließung der Ressource Wasser durch den Bestand spielt. Dabei konnten die Bestände Lüneburger Heide und Solling mit einer stark ausgebildeten Streuauflage sicher auch von den phasenweise durchaus beachtenswerten Mengen darin gespeicherten pflanzenverfügbaren Wassers profitieren (Walsh \& Voight 1977, SchaAp 1996, Leuschner 1998) (Tab. 5-7), insbesondere da die organische Auflage auf beiden Untersuchungsflächen noch dichter durchwurzelt ist als der angrenzende Mineralboden (HERTEL 1999). Dies unterstreicht weiter die schon im Mineralboden erkennbare Tendenz zu einer offenbar stark auf oberflächenahe Bodenschichten hin orientierten Wasserversorgung der Bestände.

Die sehr schwach entwickelte Streuauflage im Ziegelrodaer Forst konnte mit einem nur $1 \mathrm{~cm}$ mächtigen Of-Horizont sicher nur minimale Nutzwasservorräte speichern. Dennoch war auch dieser Auflagehorizont wenn auch nur vergleichsweise schwach durchwurzelt (HERTEL 1999),

Tab. 5-7: Mittelwerte, Maxima und Minima der Nutzwasservorräte in $0-40 \mathrm{~cm}$ Mineralbodentiefe und in der organischen Auflage in den Beständen Ziegelrodaer Forst (ZF), Göttinger Wald (GW), Lüneburger Heide (LH) und Solling (SO) im Zeitraum Juni - September 1996.

\begin{tabular}{|c|ccc|ccc|ccc|}
\hline \multirow{2}{*}{ [mm] } & \multicolumn{3}{|c|}{ organische Auflage } & \multicolumn{3}{c|}{ Mineralboden (0-40 cm) } & \multicolumn{3}{c|}{ Auflage + Mineralboden } \\
& Mittel & Max. & Min. & Mittel & Max. & Min. & Mittel & Max. & Min. \\
\hline ZF & - & - & - & 25 & 49 & 9 & 25 & 49 & 9 \\
GW & - & - & - & 49 & 68 & 29 & 49 & 68 & 29 \\
LH & 3 & 9 & 0 & 25 & 45 & 13 & 28 & 54 & 13 \\
SO & 7 & 12 & 2 & 31 & 46 & 10 & 38 & 58 & 12 \\
\hline
\end{tabular}

und konnte so wohl zumindest eine kurzfristige Wasseraufnahme gewährleisten (CONERS 2001). Generell blieben die Nutzwasservorräte bis $40 \mathrm{~cm}$ Mineralbodentiefe in den Beständen Ziegelrodaer Forst und Lüneburger Heide, die auf Sandboden stocken und zusätzlich die 
geringsten Niederschläge erhielten, merklich geringer als im Göttinger Wald und im Solling (Tab. 5-7). Der Bestand Lüneburger Heide konnte hier gegenüber dem ebenfalls bodentrockenen Ziegelrodaer Forst nur zu Zeiten guter Wasserversorgung deutlich vom Nutzwasservorrat der mächtigen Streuauflage profitieren (LEUSCHNER 1998). In Trockenperioden konnte auch die organische Auflage im Bestand Lüneburger Heide nicht mehr zur Wasserversorgung des Bestandes beitragen. Demgegenüber stellte die organische Auflage im bodenfeuchten Bestand Solling stets noch zusätzlich 20 - 25\% des Nutzwasservorrats von 0 - $40 \mathrm{~cm}$ Mineralbodentiefe zur Verfügung. Im Göttinger Wald wurden trotz geringerer Niederschläge als im Solling die höchsten Nutzwasservorräte bis $40 \mathrm{~cm}$ Bodentiefe ermittelt. Der Boden im Göttinger Wald ist zwar flachgründig und sehr skelettreich, besitzt im vorhandenen Feinbodenraum jedoch durch intensive Gefügebildung ein extrem hohes Porenvolumen und eine hohe Nutzwasserkapazität (GERKE 1987).

Matrixpotentialmessungen in größeren Bodentiefen zeigten, daß im Bestand Solling etwa bis $70 \mathrm{~cm}$ Bodentiefe noch deutliche Schwankungen des Matrixpotentials auftreten und bis $130 \mathrm{~cm}$ Bodentiefe solche, die noch als von der Transpirationsleistung abhängig erkennbar sind und also durch Wurzelwasseraufnahme hervorgerufen sein müssen (BENECKE 1984). In diesen großen Bodentiefen bleiben die Schwankungen des Matrixpotentials jedoch gering, und es treten selten Werte $<-50 \mathrm{hPa}$ auf. Dies läßt auf eine zwar durchwegs gute Bodenwasserverfügbarkeit, aber nur geringe Wasseraufnahme unterhalb $70 \mathrm{~cm}$ Bodentiefe im Bestand Solling schließen.

Im Göttinger Wald konnte GERKE (1987) durch Matrixpotentialmessungen eine Wasseraufnahme durch den Bestand bis in $1 \mathrm{~m}$ Tiefe des klüftigen $\mathrm{Cv}$-Horizonts und in einzelnen Fällen bis weit darunter $(4 \mathrm{~m})$ feststellen. Der extrem hohe und kleinräumig stark schwankende Skelettgehalt im $\mathrm{C}_{\mathrm{v}}$-Horizont der flachgründigen Rendzina erlaubt jedoch kaum ein Abschätzen des Beitrags, den der tiefreichende Verwitterungshorizont zur Wasserversorgung dieses Bestandes leisten kann.

Messungen des volumetrischen Wassergehalts in 50-60 cm Tiefe ergaben auch im Bestand Ziegelrodaer Forst in größerer Bodentiefe deutlich langsamere und beständigere Bodenfeuchteänderungen als im Oberboden (vgl. STROBEL 1997). Anders als im Oberboden führten in 50-60 cm Tiefe in beiden Meßjahren jeweils nur einmal in der Vegetationsperiode sehr ergiebige Niederschläge zu einer kurzzeitigen Erholung des dort ansonsten kontinuierlich abnehmenden Nutzwasservorrats. In Trockenperioden sowie im Spätsommer bei weitgehend erschöpften Bodenwasservorräten war dagegen eine nur noch sehr geringe Änderung des stark abgesunkenen Nutzwasservorrats in $50-60 \mathrm{~cm}$ Tiefe zu beobachten. Der Anteil tieferer Mineralbodenbereiche an der Wasserversorgung war demzufolge vergleichsweise niedrig und verringerte sich zudem mit Fortschreiten der Vegetationsperiode.

LEUSCHNER (1993) beschrieb für den Bestand Lüneburger Heide eine deutliche Abnahme der Bodenmatrixpotentiale während der Vegetationsperiode bis etwa $100 \mathrm{~cm}$ Bodentiefe und konnte eine sommerliche Abnahme der Bodenmatrixpotentiale noch bis $>170 \mathrm{~cm}$ Bodentiefe nachweisen. Damit reichte in diesem Bestand die Zone, in der mit Einsetzen der Bestandestranspiration die Matrixpotentiale absanken, vergleichsweise tief. Dies stimmt auffallend überein mit der in diesem Bestand bis in $>300 \mathrm{~cm}$ Tiefe nachgewiesenen Erschließung des Bodens durch Feinwurzeln, wobei jedoch unterhalb $100 \mathrm{~cm}$ Bodentiefe nur noch sehr geringe Feinwurzeldichten erreicht werden (HERTEL 1999). Wie in der hier vorliegenden Untersuchung fand LEUSCHNER (1993) in unterschiedlich feuchten 
Vegetationsperioden minimale Bodenmatrixpotentiale nicht im Oberboden sondern stets in etwa $30-50 \mathrm{~cm}$ Mineralbodentiefe. In der vorliegenden Untersuchung waren in dieser Tiefe deutlich geringere Bodenfeuchteänderungen zu beobachten als im Oberboden. In Trockenperioden stand darüber hinaus in $10-40 \mathrm{~cm}$ Bodentiefe nur weniger als ein Drittel des Nutzwasservorrats von 0 - $10 \mathrm{~cm}$ Bodentiefe einschließlich organischer Auflage zur Verfügung.

In allen untersuchten Beständen erreichen die Wurzeln keinen Anschluß an grundwasserführende Bodenschichten (BENECKE 1984, GERKE 1987, LEUSCHNER 1993).

Tabelle 5-8 gibt eine schematische Übersicht über die Verteilungsmuster von Bodenwasserverfügbarkeit und Feinwurzeldichte, wie sie unabhängig von Unterschieden in Bodenausbildung und Niederschlagsregime in allen Untersuchungsbeständen ähnlich beobachtet wurden.

Tab. 5-8: Schema der Verteilungsmuster von Bodenwasserverfügbarkeit und Feinwurzeldichte während der Vegetationsperiode in den Untersuchungsbeständen. Die Angaben für die organische Auflage beziehen sich nur auf die Bestände Lüneburger Heide und Solling. Die sehr geringmächtige organische Auflage im Bestand Ziegelrodaer Forst wurde nicht berücksichtigt.

\begin{tabular}{|c|c|c|c|c|}
\hline \multicolumn{2}{|c|}{ Bodenbereich / Tiefe } & \multicolumn{2}{|c|}{$\begin{array}{c}\begin{array}{c}\text { Bodenwasserverfügbarkeit } \\
\text { saisonale } \\
\text { Niveau } \\
\text { Schwankung }\end{array} \\
\end{array}$} & Feinwurzeldichte \\
\hline org. Auflage & $(+4)-(+10) \mathrm{cm}$ & gering - hoch & hoch & sehr hoch \\
\hline Oberboden & $0-10 \mathrm{~cm}$ & mäßig - hoch & hoch & (sehr) hoch \\
\hline \multirow{2}{*}{ Unterboden } & $\begin{array}{c}10-40 \mathrm{~cm} \\
(-50) \mathrm{cm}\end{array}$ & $\begin{array}{c}\text { mäßig - } \\
\text { (sehr) gering }\end{array}$ & mäßig & $\begin{array}{c}\text { hoch }- \text { mäßig } \\
\text { (mit Tiefe abnehmend) }\end{array}$ \\
\hline & $>50 \mathrm{~cm}$ & mäßig - hoch & gering & $\begin{array}{l}\text { gering - sehr gering } \\
\text { (mit Tiefe abnehmend) }\end{array}$ \\
\hline
\end{tabular}

Man kann demnach für alle Untersuchungsbestände von einer entscheidenden Bedeutung der am dichtesten durchwurzelten und über die Vegetationsperiode hinweg vergleichsweise feuchten oberflächennahen Bodenschichten für die Bestandeswasserversorgung ausgehen.

Bei geringen Niederschlägen und in Beständen mit einer geringen Nutzwasserkapazität des Bodens (Ziegelrodaer Forst, Lüneburger Heide) gewinnt der Beitrag oberflächennaher Bodenschichten zur Wasserversorgung zusätzlich an Bedeutung. Darüber hinaus kann eine mächtig ausgebildete Streuauflage die Tendenz zum Erschließen von vor allem oberflächennahen Wasserressourcen noch verstärken. 


\subsection{Blattwasserzustand und Blattleitfähigkeit der untersuchten Buchen- bestände}

\subsubsection{Gibt es ,osmotic adjustment' bei Fagus sylvatica?}

Die Trockenstreßresistenz von Bäumen hängt entscheidend von der Fähigkeit zur Wasseraufnahme durch die Wurzeln und der Aufrecherhaltung des Turgors in den Blattzellen ab. Eine mögliche Reaktionsebene, um Trockenstreß entgegenzuwirken, besteht in der Anreicherung osmotisch wirksamer Substanzen im Zellsaft (osmotic adjustment). Eine Erhöhung des osmotischen Potentials im Zellsaft kann den Potentialgradienten zwischen Blatt und Boden vergrößern und dadurch die Wasseraufnahme bei Bodentrockenheit erleichtern (LÖSCH 2001, AugÉ \& MoORE 2002). Dabei können Osmotika wie Saccharide (z.B. Fructose, Glucose, Saccharose), Zuckeralkohole (z.B. Mannit) und Aminosäuren (z.B. Prolin) den osmotischen Druck erhöhen, aber auch bei Wasserverlust der Zelle die Funktionsfähigkeit von Membranen aufrechterhalten und Proteine stabilisieren (HARE et al. 1998, LÖSCH 2001). Vorteile einer aktiven Osmoregulation bestehen in einer Aufrechterhaltung des Turgors und turgorabhängiger Stoffwechselprozesse und einem Offenhalten der Stomata bis $\mathrm{zu}$ niedrigeren Blattwasserpotentialen (LÖSCH 2001). Letzteres hat wiederum höhere Transpirationsraten und ein dadurch noch verschärftes Wasserdefizit zur Folge, ermöglicht andererseits aber $\mathrm{CO}_{2}-$ Assimilation noch unter Bedingungen, unter denen ohne Osmoregulation eine $\mathrm{CO}_{2}$-Aufnahme schon nicht mehr möglich ist.

Ein deutliches und schnelles osmotic adjustment als Antwort auf Trockenstreß stellten etwa NiINemets et al. (1999) bei Populus tremula und Tilia cordata fest. Peltier \& MARIGO (1998) beobachteten osmotic adjustment an Fraxinus excelsior. TSCHAPLINSKI et al. (1998) wiesen osmotic adjustment auch an der nordamerikanischen Buchenart Fagus grandifolia nach, UEMURA et al. (2000) an den ostasiatischen Buchenarten Fagus crenata und Fagus japonica.

In der vorliegenden Untersuchung an Fagus sylvatica war in keinem Fall eine gerichtete Veränderung des osmotischen Potentials bei einer gleichzeitigen Zunahme der Trockenstreßbelastung nachweisbar. Nur im Bestand in der Lüneburger Heide war 1996 eine beständig fallende Tendenz des osmotischen Potentials bei einer zugleich kontinuierlich und stark zunehmenden Bodenwasserverknappung zu beobachten. Diese fallende Tendenz war jedoch nach der bis etwa Anfang Juli erfolgten Blattreifung, bei der generell ein Absinken des osmotischen Potentials zu beobachten ist (vgl. ARANDA et al. 1996, BACKES 1996), statistisch nicht signifikant. In allen anderen Fällen, auch in den im Hochsommer 1995 starkem Trockenstreß ausgesetzten Beständen Göttinger Wald und Lüneburger Heide, zeigte das osmotische Potential nur uneinheitliche und meist geringe saisonale Veränderungen. BACKES (1996) beobachtete an Buchenblättern des Untersuchungsbestandes in der Lüneburger Heide eine tageszeitliche Veränderung des osmotischen Wertes, die jedoch ausschließlich auf tageszeitliche Wasserverluste zurückzuführen war, nicht auf eine aktive Anreicherung von Osmotika im Tagesverlauf. Ein klarer Hinweis auf osmotic adjustment in den untersuchten Buchenbeständen liegt somit nicht vor. 
Schraml \& RENNEnBerg (2000) sowie PeUKe et al. (2002) konnten an Buchen verschiedener deutscher Herkünfte unter Trockenstreßeinwirkung kein osmotic adjustment durch eine signifikante Anreicherung von Sacchariden nachweisen. Sie beschrieben jedoch für einige Herkünfte eine deutliche Steigerung der Prolinkonzentration, was auf die prinzipielle Fähigkeit zur aktiven Anreicherung osmotisch wirksamer Substanzen auch bei der Buche hinweist. BACKES (1996) fand in dem auch in der vorliegenden Arbeit untersuchten Mischbestand in der Lüneburger Heide einen Hinweis auf osmotic adjustment bei Quercus petraea, während Fagus sylvatica wie in der vorliegenden Untersuchung keine Reaktion des osmotischen Werts auf Trockenstreß erkennen ließ. Ebenso konnten ARANDA et al. (1996) in einem extrem sommertrockenen mediterranen Mischbestand an Quercus pyrenaica osmotic adjustment beobachten, nicht jedoch an Fagus sylvatica. Auch THOMAs (2000) fand in einem TrockenstreßExperiment an 1-jährigen Buchen selbst bei massiver Trockenheitsbelastung keinen Hinweis auf osmotic adjustment bei Fagus sylvatica.

Für Fagus sylvatica scheint osmotic adjustment demzufolge nicht oder nur in sehr begrenztem Umfang als Reaktionsebene bei Trockenstreßbelastung zur Verfügung zu stehen.

Tab. 5-9: Mittlere osmotische Potentiale bei Wassersättigung $\left(\pi_{0}\right)$ und bei Grenzplasmolyse $\left(\pi_{\mathrm{p}}\right)$ ohne Trockenstreßbelastung (- Streß) und mit Trockenstreßbelastung (+ Streß) in den Untersuchungsbeständen Ziegelrodaer Forst (ZF), Göttinger Wald (GW), Lüneburger Heide (LH) und Solling (SO) sowie nach Literaturangaben.

\begin{tabular}{|c|c|c|c|c|c|}
\hline \multicolumn{2}{|c|}{$\Pi_{0}[\mathrm{MPa}]$} & \multicolumn{2}{|c|}{$\Pi_{\mathrm{p}}[\mathrm{MPa}]$} & \multirow{2}{*}{\multicolumn{2}{|c|}{ Autoren }} \\
\hline- Streß & + Streß & - Streß & + Streß & & \\
\hline-1.85 & -1.83 & -2.57 & -2.60 & vorl. Unters. ZF (1996) & \multirow{4}{*}{$\frac{\mathscr{e}}{0}$} \\
\hline-1.97 & -2.07 & -2.61 & -2.84 & vorl. Unters. GW $(1995,1996)$ & \\
\hline-2.20 & -2.16 & -2.77 & -2.79 & vorl. Unters. LH $(1995,1996)$ & \\
\hline- & -1.95 & - & -2.61 & vorl. Unters. SO $(1995,1996)$ & \\
\hline-2.05 & -2.20 & -2.45 & -2.70 & ARANDA et al. (1996) & \multirow{5}{*}{$\frac{\mathscr{D}}{0}$} \\
\hline-2.15 & -2.26 & -2.48 & -2.94 & BACKES (1996) & \\
\hline-1.74 & & & & ROBERTS \& ROSIER (1994) & \\
\hline-1.74 & - & -2.12 & - & TAYLOR \& DOBSON (1989) & \\
\hline-1.96 & -1.99 & -2.54 & -2.64 & THOMAS (2000) & \\
\hline \multirow{2}{*}{\multicolumn{4}{|c|}{$\begin{array}{l}-2.7 \text { Bäume gemäßigter Laubwälder } \\
-5.1 \text { mediterrane Gehölze }\end{array}$}} & LARCHER (1994), LÖSCH (2001) & \multirow{2}{*}{ 竞 } \\
\hline & & & & LARCHER (1994), LÖSCH (2001) & \\
\hline
\end{tabular}

In Tabelle 5-9 werden die osmotischen Potentiale bei Wassersättigung und bei Grenzplasmolyse bei herrschender Trockenstreßbelastung und ohne Trockenstreßbelastung aufgeführt und entsprechenden Angaben für Buchen aus der Literatur gegenübergestellt. Hier wie schon im Vergleich saisonaler Mittelwerte (vgl. Kap. 4.3.1) unterscheiden sich die osmotischen Potentiale in den Untersuchungsbeständen kaum. Unterschiede zwischen den Untersuchungsflächen waren nur in zwei Fällen statistisch signifikant (vgl. Abb. 4-6), die jedoch keinen plausiblen Schluß auf systematische Flächenunterschiede oder eine Absenkung des osmotischen Potentials als Reaktion auf Trockenstreßbelastung zuließen. So war am 1995 weitaus niederschlagsreichsten Standort im Solling ein signifikant niedrigeres osmotisches Potential bei Grenzplasmolyse zu beobachten als in dem Bestand im Göttinger Wald, der in dieser Vegetationsperiode erheblichem 
Trockenstreß ausgesetzt war. 1996 unterschieden sich nur die osmotischen Potentiale bei Wassersättigung der Bestände Lüneburger Heide und Ziegelrodaer Forst signifikant. Obwohl beide Bestände in der Vegetationsperiode 1996 einem etwa vergleichbaren deutlichen Trockenstreß ausgesetzt waren, wurde im Ziegelrodaer Forst das positivste, in der Lüneburger Heide dagegen das negativste osmotische Potential bei Wassersättigung aller untersuchten Bestände bestimmt. Darüber hinaus weichen die in der vorliegenden Untersuchung ermittelten osmotischen Potentiale kaum von den in der Literatur für Buchen angegebenen Werten ab, auch wenn diese unter noch erheblich extremerer Trockenstreßbelastung als in der vorliegenden Untersuchung ermittelt wurden (ARANDA et al. 1996, THOMAS 2000).

Das osmotische Potential von Buchen stellt demzufolge über einen weiten Gradienten von Wasserhaushaltsbedingungen eine wenig plastische Größe dar.

\subsubsection{Blattleitfähigkeiten und Blattwasserpotentiale bei unterschiedlicher Wasserversorgung}

\subsubsection{Blattleitfähigkeit}

Die stomatäre Blattleitfähigkeit besitzt eine große Dynamik im Tagesgang, zeigt über unterschiedliche Kronenbereiche teilweise sehr starke räumliche Gradienten und wird darüber hinaus intensiv und unmittelbar von aktuell im Bestand herrschenden mikroklimatischen Bedingungen beeinflußt. Daher ist für eine vergleichende Einordnung von porometrisch bestimmten Werten der stomatären Blattleitfähigkeit entscheidend, wann, wo und unter welchen Witterungsbedingungen sie gemessen wurden.

In verschiedenen Untersuchungen der stomatären Leitfähigkeit von Buchenblättern wurden die entsprechenden Meßbedingungen sehr unterschiedlich eingegrenzt und nicht immer klar angegeben. Literaturwerte zur stomatären Blattleitfähigkeit von Buchen sind deshalb oft nur bedingt vergleichbar mit den in der vorliegenden Untersuchung erhobenen. Eine geeignete und repräsentative Vergleichsebene stellen mittägliche Blattleitfähigkeiten an Strahlungstagen dar, da an Strahlungstagen im typischen Tagesgang von mittags bis nachmittags in der Regel ein vergleichsweise stabiles Niveau der Blattleitfähigkeit zu beobachten ist (BACKES 1996, KUTSCH et al. 2001, ARANDA et al. 2000) (vgl. Abb. 4-14). Häufig werden auch die meist schon morgens, aber nur für kurze Zeit erreichten Maximalwerte der stomatären Blattleitfähigkeit als Kenngröße angegeben. In Tabelle 5-10 werden entsprechende Angaben aus der Literatur den Ergebnissen der vorliegenden Untersuchung gegenübergestellt.

Die Mittelwerte der mittäglichen Blattleitfähigkeit in den vier Untersuchungsbeständen bewegten sich mit Werten von $89 \mathrm{mmol} \mathrm{m}^{-2} \mathrm{~s}^{-1}$ im Bestand Lüneburger Heide bis $185 \mathrm{mmol} \mathrm{m}$ ${ }^{2} \mathrm{~s}^{-1}$ im Bestand Solling im mittleren Bereich der in der Literatur angegebenen Werte. Zugleich deckten die Extremwerte der mittäglichen Blattleitfähigkeit aus der vorliegenden Untersuchung $\left(28 \mathrm{mmol} \mathrm{m}^{-2} \mathrm{~s}^{-1}-311 \mathrm{mmol} \mathrm{m}^{-2} \mathrm{~s}^{-1}\right)$ die in der Literatur angegebene Wertespanne ab. THOMAS (2000) und RAFTOYANNIS \& RADOGLOU (2002) bestimmten an Buchen bei guter Wasserversorgung mittägliche Blattleitfähigkeiten von $230 \mathrm{mmol} \mathrm{m}^{-2} \mathrm{~s}^{-1}$ bzw. $240 \mathrm{mmol} \mathrm{m}^{-2} \mathrm{~s}^{-1}$, bei extremem Trockenstreß ( $\Psi_{\min }$ von $-3.0 \mathrm{MPa}$ bzw. $-4.2 \mathrm{MPa}$, vgl. Tab. 5-10) jedoch nur Werte um $30 \mathrm{mmol} \mathrm{m}^{-2} \mathrm{~s}^{-1}$. 
Tab. 5-10: Mittägliche und maximale stomatäre Blattleitfähigkeiten $\left(\mathrm{g}_{\mathrm{s}}\right)$ in den Untersuchungsbeständen Ziegelrodaer Forst (ZF), Göttinger Wald (GW), Lüneburger Heide (LH) und Solling (SO) sowie nach Literaturangaben. Der Mittelwert der mittäglichen $\mathrm{g}_{\mathrm{s}}$ im Bestand Ziegelrodaer Forst bezieht sich nur auf die Vegetationsperiode 1997, die Mittelwerte der anderen Untersuchungsbestände der vorliegenden Arbeit auf die Untersuchungsjahre 1995 - 1997. Saisonale Mittelwerte sind durch $\varnothing$ gekennzeichnet, Messungen bei guter Wasserversorgung durch (- Streß), Messungen bei Trockenstreßbelastung durch (+ Streß).

\begin{tabular}{|c|c|c|c|}
\hline$\underset{\left[\mathrm{mmol} \mathrm{m}^{-2} \mathbf{s}^{-1}\right]}{\mathrm{g}_{\mathrm{s}} \text { mittags }}$ & $\underset{\left[\mathrm{mmol} \mathrm{m}^{-2} \mathrm{~s}^{-1}\right]}{\mathbf{g}_{\mathrm{s}} \max }$ & Autoren & Arten \\
\hline Ø $134(94-183)$ & - & vorl. Unters. (ZF 1997) & \\
\hline Ø 133 (73-199) & $\varnothing 242$ & vorl. Unters. (GW 1995-1997) & \\
\hline$\varnothing 89(28-154)$ & $\varnothing 206$ & vorl. Unters. (LH 1995-1997) & \\
\hline$\varnothing 185(124-311)$ & $\varnothing 304$ & vorl. Unters. (SO 1995-1997) & \\
\hline $\begin{array}{l}\varnothing 160(- \text { Stre } \beta) \\
\varnothing \quad 80(+ \text { Stre } \beta)\end{array}$ & Ø $175(\max .330)$ & ARANDA et al. (2000) & \\
\hline$\varnothing 231$ & $\varnothing 446$ & BACKES (1996) & 뇌 \\
\hline $120-140$ & 230 & KUTSCH et al. (2001) & u \\
\hline $\begin{array}{r}240(- \text { Stre } \beta) \\
30(+ \text { Stre } \beta)\end{array}$ & - & RAFTOYANNIS \& RADOGLOU(2002) & $\stackrel{p}{\infty}$ \\
\hline$\varnothing 175$ & Ø $250(\max .300)$ & ROBERTS \& ROSIER (1994) & \\
\hline- & 350 & SCHULZE \& HALL (1982) & \\
\hline- & $\begin{array}{r}750(- \text { Stre } \beta) \\
80(+ \text { Stre } \beta)\end{array}$ & TOGNETTI et al. (1995) & \\
\hline $\begin{array}{l}\varnothing 230 \text { (- Streß) } \\
\varnothing \quad 30(+ \text { Streß })\end{array}$ & - & THOMAs (2000) & \\
\hline \multicolumn{4}{|c|}{ 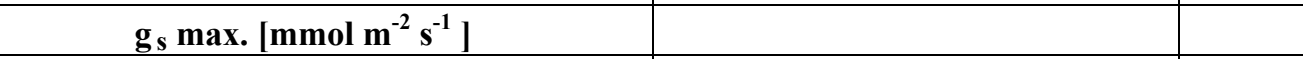 } \\
\hline \multirow{3}{*}{\multicolumn{2}{|c|}{$\begin{array}{r}\text { Laubwälder gemäßigter Breiten } 190( \pm 71) \\
\text { (boreale) Nadelwälder } 234( \pm 99) \\
\text { mediterrane Hartlaubgehölze } 203( \pm 108)\end{array}$}} & KÖRNER (1994) & \multirow{3}{*}{ 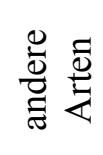 } \\
\hline & & KÖRNER (1994) & \\
\hline & & KÖRNER (1994) & \\
\hline
\end{tabular}

Der Untersuchungsbestand im Solling wies im Vergleich mit Literaturwerten für Buchen relativ hohe stomatäre Blattleitfähigkeiten auf, der Bestand im Göttinger Wald mittlere Werte, während im untersuchten Bestand in der Lüneburger Heide vergleichsweise niedrige Leitfähigkeitswerte gemessen wurden. Die stomatären Blattleitfähigkeiten spiegeln somit gut die Wasserhaushaltsbedingungen wider, denen diese Bestände in den drei Untersuchungsjahren ausgesetzt waren. Der Bestand im Solling besaß bei den stets höchsten Niederschlägen eine ausgeglichene Bodenwasserversorgung und ließ auch auf Ebene der Blattwasserpotentiale zu keinem Zeitpunkt Anzeichen von Trockenstreß erkennen. Dementsprechend war in diesem Bestand weder im Tagesgang noch im saisonalen Verlauf eine stärkere Beschränkung der stomatären Blattleitfähigkeit $\mathrm{zu}$ beobachten. Im Gegensatz dazu war der Bestand in der Lüneburger Heide in jedem der drei Untersuchungsjahre einer klimatisch-edaphischen Trockenstreßbelastung ausgesetzt. In verschiedenen Phasen der Vegetationsperiode trat dort mäßiger bis extremer Trockenstreß auf und führte $\mathrm{zu}$ einer häufigen, mitunter gravierenden Einschränkung der stomatären Blattleitfähigkeit. Der Bestand im Göttinger Wald nahm hier wie bei der Niederschlags- und Bodenwasserversorgung eine Mittelstellung ein. Dort war nur selten 
eine starke Einschränkung der stomatären Blattleitfähigkeit bei zugleich deutlich absinkenden Blattwasserpotentialen als Folge von Trockenstreßeinwirkung zu beobachten.

In dem Buchenbestand im Ziegelrodaer Forst wurde die stomatäre Blattleitfähigkeit 1997 an fünf Meßtagen punktuell mittags bestimmt. Für einen Vergleichszeitraum Juli bis September 1997 wiesen die Bestände im Ziegelrodaer Forst und in der Lüneburger Heide mit $133 \mathrm{mmol} \mathrm{m}^{-2} \mathrm{~s}^{-1}$ bzw. $121 \mathrm{mmol} \mathrm{m}^{-2} \mathrm{~s}^{-1}$ ähnlich niedrige mittägliche Blattleitfähigkeiten auf, obwohl im Ziegelrodaer Forst die deutlich niedrigsten Blattwasserpotentiale auftraten und auf eine dort besonders starke Trockenstreßbelastung hinwiesen. Die Bestände im Göttinger Wald und im Solling zeigten auch in diesem Vergleichszeitraum mit $149 \mathrm{mmol} \mathrm{m}^{-2} \mathrm{~s}^{-1}$ bzw. $180 \mathrm{mmol} \mathrm{m}^{-2} \mathrm{~s}^{-1}$ wiederum entsprechend höhere mittägliche Blattleitfähigkeiten (vgl. Kap. 4.5.2).

Trotz einer geringeren Anzahl an Meßtagen und der hohen Variabilität der stomatären Blattleitfähigkeit zeichnet sich hier ab, daß die stomatäre Blattleitfähigkeit im Ziegelrodaer Forst nicht in dem Maße eingeschränkt wurde, wie die an diesem Standort geringsten Niederschläge, niedrigsten Nutzwasservorräte und weitaus negativsten Blattwasserpotentiale vermuten lassen könnten.

\subsubsection{Schwellenwerte des Blattwasserpotentials}

Unter normalen Bedingungen wird im pflanzlichen Wasserhaushalt durch Regulation der stomatären Leitfähigkeit und damit auch der Transpiration gewährleistet, daß ein für die Art charakteristischer Blattwasserpotential-Grenzwert nicht unterschritten wird (WULLSCHLEGER et al. 1998). Die Notwendigkeit einer sensiblen und effektiven Regulation der stomatären Blattleitfähigkeit geht hervor aus einem drohenden Verlust der hydraulischen Leitfähigkeit des Xylems durch Emboliebildung (Kavitation) in den Gefäßen bei Unterschreiten eines kritischen Wertes des Blatt- bzw. Xylemwasserpotentials (TyreE \& Ewers 1991, Bond \& Kavanagh 1999). Die genauen Abläufe und die Lokalisation der komplexen Regulationsvorgänge sind trotz zahlreicher Untersuchungen in weiten Teilen noch immer unbekannt (WULLSCHLEGER et al. 1998, Comstock 2002, Peuke et al. 2002). Eine wichtige Rolle spielt offenbar Abszisinsäure, die bei Trockenstreß vermehrt in den Wurzeln gebildet wird, mit dem Transpirationsstrom zu den Schließzellen gelangt und dort regulierend auf den Öffnungszustand der Stomata wirkt (STURM et al. 1996, NiINEMETS et al. 1999, KUTSCH et al. 2001). Eine Reihe von Untersuchungen ergab jedoch auch Hinweise darauf, daß die Schließzellen direkt auf Änderungen des Blattwasserpotentials reagieren (SALIENDRA et al. 1995, COMSTOCK \& MENCUCCINI 1998, SPERRY et al. 2002) oder daß die beiden Regulationsfaktoren erst im Zusammenspiel differenziert wirken (LÖSCH 2001, COMSTOCK 2002).

Bis zu einem gewissen Grad ist Emboliebildung ein normaler Vorgang in Pflanzen (LösCH 1999). Viele Pflanzen, auch die Buche, senken schon unter normalen Wasserhaushaltsbedingungen das Blattwasserpotential auf Werte ab, die nur noch einen geringen Spielraum bieten bis zu einem drastisch ansteigenden Verlust an hydraulischer Leitfähigkeit (TYREE \& Sperry 1988, Magnani \& Borghetti 1995, SPerry et al. 2002). Unter diesen Bedingungen kommt es auch ohne extreme Trockenstreßeinwirkung und ein Absinken des Blattwasserpotentials unter den kritischen Wert im Verlauf einer Vegetationsperiode zu einem gewissen Ausmaß an Kavitation und Xylemdisfunktion (HACKE \& SAUTER 1995, MAGnani \& BorghetTi 1995, TOGNETTI et al. 1995, LANG 1999). Prinzipiell können Embolien im Xylem offenbar durch ein aktives Wiederbefüllen der Gefäße auch aufgelöst werden (TYREE et al. 1999, HOLBROOK \& 
ZWIENIECKI 1999). Eine solche Regeneration konnten BORGHETTI et al. (1993) nach winterlicher Emboliebildung an Buchen allerdings nicht nachweisen. Eine wichtige Möglichkeit, den Verlust an hydraulischer Leitfähigkeit $\mathrm{zu}$ kompensieren, bleibt aber in jedem Fall die jährliche Neubildung von Gefäßen.

Der kritische Grenzwert des Blattwasserpotentials, bei dessen Überschreitung ein verstärkter Verlust an hydraulischer Leitfähigkeit eintritt, ist artspezifisch und vor allem abhängig von der Porenweite der Tüpfel, weniger von der Gefäßweite (LÖSCH 2001). TYREE et al. (1999) beschreibt in einer Übersichtsstudie für zahlreiche Arten mit Werten von -0.6 MPa bis - $11 \mathrm{MPa}$ eine weite Amplitude von Xylemwasserpotentialen, bei denen ein 50-prozentiger Verlust der hydraulischen Leitfähigkeit zu beobachten war.

In der vorliegenden Untersuchung wiesen die Tagesminima des Blattwasserpotentials deutlich geringere Unterschiede zwischen den Untersuchungsbeständen auf als die Tagesmaxima. Zwischen den Beständen im Göttinger Wald, in der Lüneburger Heide und im Solling blieben die Unterschiede der Tagesminima des Blattwasserpotentials sehr gering. Nur der Bestand im Ziegelrodaer Forst fiel durch besonders niedrige Tagesminima des Blattwasserpotentials auf. Dies war sowohl im Mittel über die Vegetationsperiode der Fall als auch im saisonalen Verlauf und in Trockenperioden. Diese einheitlichen Tagesminima zeigen, daß die Buchen in den genannten Beständen über ein relativ weites Spektrum von Wasserhaushaltsbedingungen in der Lage sind, den Blattwasserstatus effektiv zu regulieren. Dabei wurden mit Ausnahme des Bestandes im Ziegelrodaer Forst in der Regel im Tagesgang Blattwasserpotentiale von etwa -2.0 bis -2.2 MPa nicht unterschritten (Abb. 5-2, vgl. Kap. 4.4).

Dieser untere Grenzbereich der Blattwasserpotentiale stimmt gut mit dem Schwellenwert des Xylemwasserpotentials von -1.9 MPa überein, ab dem HACKE \& SAUTER (1995) bei der Buche einen beginnenden Verlust der hydraulischen Leitfähigkeit des Xylems beobachteten. $\mathrm{Zu}$ berücksichtigen ist hierbei, daß infolge des Potentialgradienten zwischen Blatt- und Sproßxylem im Sproß stets positivere Xylemwasserpotentiale herrschen als die bei der Bestimmung des Wasserpotentials am Blatt gemessenen (TYREE \& CHEUNG 1977, COCHARD et al. 1999). Unter Trockenstreßbedingungen bei geringen Transpirationsraten und hohem Nachleitwiderstand des Bodens nähern sich die beiden Größen jedoch an und man kann von ähnlichen bis identischen Xylemwasserpotentialen in Blatt und Sproß ausgehen (COCHARD et al. 1996, LU et al. 1996, LEMOINE et al. 2002).

COCHARD et al. (1999) und LEMOINE et al. (2002) stellten einen starken ansteigenden Verlust der Leitfähigkeit durch Emboliebildung bei Wasserpotentialen unterhalb von etwa $-1.6 \mathrm{MPa}$ im Xylem von Schattenzweigen bzw. $-2.5 \mathrm{MPa}$ bei Sonnenzweigen der Buche fest. Dabei war ein deutlicher Einfluß eines höheren Strahlungsgenusses sowie niedrigerer mittäglicher Blattwasserpotentiale infolge einer höheren Verdunstungsbeanspruchung in der Sonnenkrone zu beobachten. Durch beide Faktoren kann offensichtlich die Ausbildung eines weniger kavitationsempfindlichen Xylems in Sonnenzweigen induziert werden. AldER et al. (1996) sowie LEMOINE et al. (2001) konnten für Acer grandidentatum bzw. Fraxinus excelsior entlang Bodenfeuchtegradienten zeigen, daß bei der gleichen Baumart an trockeneren Standorten ein Verlust der hydraulischen Leitfähigkeit erst bei niedrigeren Xylemwasserpotentialen einsetzte als auf feuchteren Standorten. Die Kavitationsempfindlichkeit des Xylems ist demnach eine plastische Größe, die sowohl innerhalb der Krone als auch auf verschiedenen Standorten eine Anpassung an unterschiedliche Wasserhaushaltsbedingungen erlaubt. 

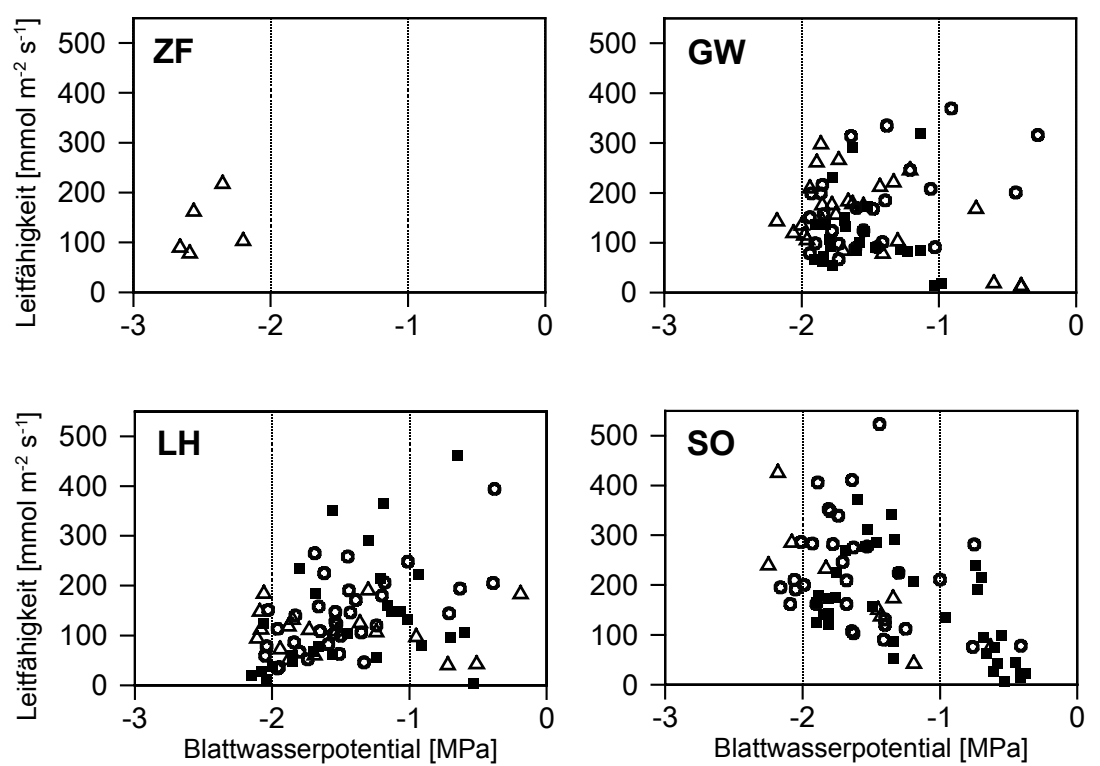

- 1995

○ 1996

$\Delta 1997$

Abb. 5-2: Blattleitfähigkeits- und Blattwasserpotentialwerte aus Tagesgangmessungen in der Sonnenkrone von Buchen der Untersuchungsbestände Ziegelrodaer Forst (ZF), Göttinger Wald (GW), Lüneburger Heide (LH) und Solling (SO) in den Vegetationsperioden 1995-1997. Die einander zugeordneten Werte sind jeweils Mittelwerte aus vier Einzelmessungen, in denen kurz hintereinander am selben Blatt die Blattleitfähigkeit und das Blattwasserpotential bestimmt wurden. Für den Bestand im Ziegelrodaer Forst sind nur mittags gemessene Werte von Blattleitfähigkeit und Blattwasserpotential aus der Vegetationsperiode 1997 angegeben.

Ohne Trockenstreßeinwirkung wurde auf allen vier untersuchten Buchenstandorten ein typischer unterer Grenzbereich des Blattwasserpotentials von etwa -2.0 MPa bis -2.2 MPa eingehalten. Dieser Wert wird durch zahlreiche andere Untersuchungen bestätigt (ROBERTS \& ROSIER 1994, Hacke \& Sauter 1995, Magnani \& Borghetti 1995, Backes 1996, KowaliK et al. 1997, ARANDA et al. 2000). Von den genannten Autoren wie auch in der vorliegenden Untersuchung wurden niedrigere Blattwasserpotentiale nur bei hoher Verdunstungsbeanspruchung und zugleich stark eingeschränkter Bodenwasserversorgung beobachtet (Lüneburger Heide: August 1995, Ziegelrodaer Forst: August 1996 und August 1997). Am trockensten Standort Ziegelrodaer Forst wurden in zwei klimatisch sehr unterschiedlichen Untersuchungsjahren die niedrigsten Blattwasserpotentiale der vier Untersuchungsflächen bestimmt. Nur dort wurde der Schwellenwert von etwa $-2.0 \mathrm{MPa}$ bei Trockenstreß wiederholt und deutlich unterschritten mit Tagesminima des Blattwasserpotentials bis -2.7 MPa. Eine unter diesen Umständen eigentlich zu erwartende wesentliche Beeinträchtigung der Vitalität des Bestandes durch Xylemkavitation war jedoch nicht erkennbar. Eine Regeneration von durch Emboliebildung entstandenen Verlusten der hydraulischen Leitfähigkeit noch während der Vegetationsperiode konnten LEMOINE et al. (2002) an Buchen nicht feststellen. Zudem war im Bestand Ziegelrodaer Forst noch bei Blattwasserpotentialen von $-2.6 \mathrm{MPa}$ eine nur mäßige Einschränkung der stomatären Blattleitfähigkeit in der Sonnenkrone zu beobachten. Anders als etwa im Bestand in der Lüneburger Heide, wo bei ebenfalls starkem Trockenstreß bereits bei Blattwasserpotentialen um - 2.0 MPa eine extreme Einschränkung der Blattleitfähigkeit einsetzte (Abb. 5-2). 
Es liegt somit eine Reihe von Hinweisen auf eine besonders geringe Kavitationsempfindlichkeit des Xylems der Buchen im Ziegelrodaer Forst vor, die ein tieferes Absinken der Blattwasserpotentiale sowie eine geringere Einschränkung der stomatären Leitfähigkeit bei Trockenheit erlaubt. Eine damit verbundene erhöhte Trockenstreßtoleranz kann als Anpassung an eine häufige Trockenstreßbelastung dieses Untersuchungsbestandes am niederschlagsärmsten Standort verstanden werden. Weitere Untersuchungen zu dieser Thematik erscheinen hier wünschenswert und vielversprechend.

Tab. 5-11: Mittlere minimale und maximale Blattwasserpotentiale (pre-dawn-Werte) in den Untersuchungsbeständen Ziegelrodaer Forst (ZF), Göttinger Wald (GW), Lüneburger Heide (LH) und Solling (SO) sowie nach Literaturangaben bei guter Wasserversorgung (- Streß) und bei Trockenstreßbelastung (+ Streß).

\begin{tabular}{|c|c|c|c|c|c|}
\hline \multicolumn{2}{|c|}{$\Psi_{\max }[\mathrm{MPa}]$} & \multicolumn{2}{|c|}{$\boldsymbol{\Psi}_{\min }[\mathrm{MPa}]$} & \multirow{2}{*}{\multicolumn{2}{|c|}{ Autoren }} \\
\hline- Streß & + Streß & - Streß & + Streß & & \\
\hline$-0.43 \pm 0.14$ & $-0.67 \pm 0.18$ & $-2.10 \pm 0.31$ & $-2.29 \pm 0.35$ & vorl. Unters. ZF $(1996,1997)$ & \\
\hline$-0.34 \pm 0.08$ & $-0.63 \pm 0.23$ & $-1.82 \pm 0.16$ & $-1.93 \pm 0.09$ & vorl. Unters. GW (1995-1997) & $\approx$ \\
\hline$-0.29 \pm 0.10$ & $-0.50 \pm 0.32$ & $-1.72 \pm 0.24$ & $-2.10 \pm 0.09$ & vorl. Unters. LH (1995-1997) & $\equiv$ \\
\hline$-0.4 \pm 0.09$ & - & $-1.90 \pm 0.23$ & - & vorl. Unters. SO (1995-1997) & \\
\hline-0.23 & -0.48 & -1.93 & -2.23 & ARANDA et al. (2000) & \\
\hline-0.36 & -0.71 & -1.82 & -2.19 & BACKES (1996) & \\
\hline-0.23 & - & -1.4 & - & DREYER (1994) & \\
\hline-.025 & -0.6 & -2.0 & - & MAGNANI \& BORGHETTI (1995) & \\
\hline$-0.3--0.8$ & - & $-1.4--2.1$ & - & NIEDERSTADT (1987) & $\frac{\pi}{0}$ \\
\hline-0.25 & -0.6 & - & - & PeuKe et al. (2002) & 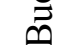 \\
\hline - & - & -1.9 & -4.2 & RAFTOYANNIS \& RADOGLOU(2002) & \\
\hline$-0.4--0.8$ & $-0.5--1.0$ & -2.1 & -3.0 & THOMAS (2000) & \\
\hline-0.6 & -2.3 & - & - & TOGNETTI et al. (1995) & \\
\hline $\begin{array}{l}-1.1- \\
-0.9\end{array}-$ & $\begin{array}{ll}-2.7 & \text { Bäun } \\
-5.1 & \text { medit }\end{array}$ & $\begin{array}{l}\text { e gemäßigter } \\
\text { errane Gehölz }\end{array}$ & aubwälder & $\begin{array}{l}\text { LARCHER (1994), LÖSCH (2001) } \\
\text { LARCHER (1994), LÖSCH (2001) }\end{array}$ & $\begin{array}{l}\text { 离 } \\
\text { 离 }\end{array}$ \\
\hline
\end{tabular}

\subsubsection{Pre-dawn-Werte des Blattwasserpotentials}

Das kurz vor Sonnenaufgang (pre-dawn) gemessene Tagesmaximum des Blattwasserpotentials ist durch den nächtlichen Stomaschluß vom direkten Einfluß der Transpiration auf den Blattwasserstatus abgekoppelt. Der pre-dawn-Wert erlaubt daher eine von aktuellen mikroklimatischen Bedingungen weitgehend unabhängige, gut vergleichbare Aussage über die Fähigkeit der Pflanze, das tägliche Absinken des Blattwasserpotentials durch nächtliche Wasseraufnahme aus dem Boden auszugleichen. In der Nacht steht das Wasserpotential der Pflanze weitgehend im Gleichgewicht mit demjenigen im Boden. Es besteht dann also außer durch das bei Bäumen durch ihre große Höhe relevante Gravitationspotential so gut wie kein Potentialgradient zwischen Pflanze und Boden. Das Maß der nächtlichen Regenerierung des Blattwasserstatus gibt also Auskunft über die generelle Wasserversorgungssituation bzw. Trockenstreßbelastung eines Standortes in Abhängigkeit von der Wasserverfügbarkeit für die Pflanze im Boden (LÖSCH 2001). 
Die weitaus niedrigsten pre-dawn-Werte der vorliegenden Untersuchung wurden mit - 1.0 MPa bzw. - 1.15 MPa in den Beständen Göttinger Wald und Lüneburge Heide im Hochsommer 1995 gemessenen. $\mathrm{Zu}$ diesem Zeitpunkt herrschte dort eine extreme Trockenstreßbelastung, wie ein Vergleich mit bei Trockenstreß an Buchen gemessenen pre-dawn-Werten anderer Untersuchungen zeigt (vgl. Tab.5-11). Ein Absinken des pre-dawn-Wertes noch unter - 1.0 MPa verfolgten TOGNETTI et al. (1995) in einem Austrocknungsexperiment an 1-jährigen Buchen. Bereits ab pre-dawn-Werten <- 1.0 MPa war ein drastischer Anstieg der Xylemkavitation zu beobachten, der bei einem Absinken des pre-dawn-Wertes auf einen Extremwert von - 2.3 MPa zu einem fast 90-prozentigen Verlust der hydraulischen Leitfähigkeit führte. In der vorliegenden Untersuchung war ein Unterschreiten des Kavitations-Schwellenwerts der Tagesminima des Blattwasserpotentials von etwa - 2.2 MPa nur dann zu beobachten, wenn auch das pre-dawn gemessene Tagesmaximum des Blattwasserpotentials zuvor auf Werte $<-0.5 \mathrm{MPa}$ abgesunken war.

Ähnlich niedrige Tagesmaxima des Blattwasserpotentials wie in den Beständen Göttinger Wald und Lüneburger Heide 1995 wurden in keinem anderen Untersuchungsjahr oder Untersuchungsbestand bestimmt. Nur selten wurde ein pre-dawn-Wert von - $0.5 \mathrm{MPa}$ unterschritten. In den Vegetationsperioden 1996 und 1997, in denen auch im Ziegelrodaer Forst der Blattwasserstatus untersucht wurde, fiel dieser Bestand durch die niedrigsten pre-dawn-Wert auf. Saisonale Mittel des pre-dawn-Wertes von $<-0.5 \mathrm{MPa}$ mit einem zeitweisen Absinken bis auf $<-0.7 \mathrm{MPa}$ unterstrichen deutlich die schlechte Bodenwasserversorgung und hohe Trockenstreßbelastung des Buchenbestandes am niederschlagsärmsten Standort. Die besser wasserversorgten Bestände im Göttinger Wald und im Solling konnten durch eine bessere nächtliche Regenerierung einen deutlich entspannteren Blattwasserstatus mit saisonalen Mitteln des pre-dawn-Wertes von - 0.3 MPa bis - 0.4 MPa aufrecherhalten.

Überraschend war, daß der Bestand in der Lüneburger Heide trotz zum Teil ausgeprägter Bodentrockenheit in den Vegetationsperioden 1996 und 1997 die entspanntesten pre-dawnWerte aufwies. Dieser Bestand erhielt in der Vegetationsperiode 1996 die deutlich geringsten Niederschläge aller Untersuchungsbestände und wies dennoch die entspanntesten Saisonmittel des pre-dawn-Wertes auf. Wenngleich ein Unterschied nur gegenüber dem niedrigsten Vegetationsperiodenmittel des pre-dawn-Wertes im Ziegelrodaer Forst statistisch signifikant war. Für diese erstaunlich effektive nächtliche Regenerierung des Blattwasserstatus trotz teilweise ausgeprägter Bodentrockenheit könnte neben einer guten Nachleitfähigkeit des Sandbodens vor allem die deutlich höchste Feinwurzel-Biomasse aller Untersuchungsbestände (HERTEL 1999) am Standort Lüneburger Heide von Bedeutung sein. Eine wichtige Rolle für die effektive Wasserversorgung dieses Bestandes spielt außerdem die stark entwickelte organische Auflage (LEUSCHNER 1994 und 1998) (vgl. Kap. 5.4.2). Für einen entscheidenden Einfluß dieser Faktoren auf die Effektivität der nächtlichen Regenerierung des Blattwasserstatus spricht auch ein Vergleich mit dem Bestand im Ziegelrodaer Forst. Bei einer vergleichbaren Bodentrockenheit wie in der Lüneburger Heide, aber der weitaus geringsten FeinwurzelBiomasse aller Untersuchungsbestände (HERTEL 1999) und ohne eine stark entwickelte organische Auflage waren dort die deutlich angespanntesten pre-dawn-Werte zu beobachten. 


\subsection{Der Wasserumsatz der untersuchten Buchenbestände}

\subsubsection{Bestimmung der Bestandestranspiration: Methoden und Kritik}

In zahlreichen Untersuchungen wurde die Transpiration von Bäumen und Waldbeständen sowie deren Abhängigkeit vom Einfluß verschiedener klimatischer, edaphischer, physiologischer und morphologisch-bestandesstruktureller Faktoren bestimmt. Einen Überblick über Methoden und Ergebnisse der letzten 30 Jahre geben WuLLSCHLEGER et al. (1998).

Eine klassische Methode besteht im Aufstellen von Wasserbilanzen für Bestände bzw. GeländeAusschnitte. Über eine Wasserbilanzgleichung kann die Transpiration und die Evaporation eines Bestandes per Differenzbildung aus den Wasserhaushaltsgrößen Niederschlag, Interzeption, Oberflächenabfluß, Sickerung und Änderung der Wasserspeicherung im Boden berechnet werden (BENECKE 1984, LuXMOORE \& HufF 1989, HeIL 1996). Diese Methode erlaubt jedoch nur eine indirekte und durch die zum Teil nur schwer korrekt zu erfassenden Bilanzgrößen oft fehlerbehaftete Bestimmung der Bestandestranspiration mit geringer zeitlicher Auflösung. Bei der Anwendung mikrometereologischer Methoden (Eddy-Korrelation, Bowen ratio) werden Wasserdampf- und Energieflüsse zwischen der Bestandesoberfläche und der Atmosphäre bestimmt (Leuschner 1994, OGINK-HENDriks 1995, BALdOCCHI et al. 1996, BERBIGIER et al. 1996). Dies erschwert jedoch ein Untergliedern der Evapotranspiration eines Bestandes in die Elemente Transpiration und Interzeptions- bzw. Boden-Evaporation. Darüber hinaus erfordern diese Methoden Messungen, die über einen vergleichsweise großen zeitlichen bzw. räumlichen Maßstab integrieren (WILSON et al.2001). Der Einsatz von Xylemsaftfluß-Meßsystemen (SWANSON 1994, SMith \& ALLEN 1996) erlaubt dagegen eine zeitlich hoch aufgelöste und räumlich differenzierte Bestimmung der Transpiration von einzelnen Bäumen, Arten oder Kronendach-Schichten in einem Bestand bis hin zur Extrapolation auf Bestandesebene (GrANIER et al. 1996b, KÖSTNER et al. 1998a, PATAKI et al. 1998). Ein kombinierter und vergleichender Einsatz der geschilderten Methoden zeigte in einigen Untersuchungen weitgehend übereinstimmende Resultate (DIAWARA et al. 1991, KELLIHER et al. 1992, GRANIER et al. 1996a), führte aber auch zu zum Teil deutlich voneinander abweichenden Ergebnissen (WILSON et al. 2001, LunDBLAD \& LINDROTH 2002). Eine Reihe methodischer Probleme bei der Bestimmung des Parameters Transpiration im komplexen System des Bestandeswasserhaushalts sind also noch nicht ausgeräumt.

In der vorliegenden Untersuchung wurde zur Bestimmung der Bestandestranspiration die Xylemsaftfluß-Messung mit der Tissue Heat Balance (THB) Methode nach CERMAK et al. (1973 und 1976) angewandt. Diese beruht auf einer kontinuierlichen Massenfluß-Messung des Xylemsaftes in einem Stammsektor auf Grundlage rein physikalischer Zusammenhänge. Ein empirisches Kalibrieren am spezifischen Meßobjekt wie im System nach GRANIER (1985 und 1987) ist damit nicht erforderlich, aber auch kaum möglich (KöSTNER 2001, STROBEL 1997).

Korrekte Meßergebnisse setzen daher ein räumlich vollständiges und exaktes Erfassen der zugrundeliegenden physikalischen Parameter im leitenden Splintholz voraus.

In der Vegetationsperiode 1997 wurde mit einer am Saftfluß-Meßpunkt am Baum veränderten Meßeinrichtung gearbeitet. Dadurch sollte ein eventuell zu hohe Saftflußwerte vorspiegelnder 
Fehler behoben werden, auf den bis dahin nicht beobachtete sehr hohe Tagessummen der Transpiration (>10 mm) speziell in Buchenbeständen aufmerksam gemacht haben (pers. Mitt. HEIMANN, KuCERA).

Die Fehlerursache wurde vom Hersteller in einem nicht erfaßten Wärmeverlust durch die Erwärmung des Phloems vermutet. Das bei den untersuchten Buchen etwa 5-15 mm starke Phloem (Bast) befindet sich zwischen Borke und dem Xylem (Splintholz) und wird demnach von den Heizelektroden ebenfalls durchdrungen und erwärmt. Gegenüber dem Xylem hohe Elektrolytgehalte im Phloem können dort vergleichsweise hohe Stromflüsse und damit eine überproportionale Erwärmung des Phloems bewirken, mit folgenden Auswirkungen auf das Meßergebnis (pers. Mitt. KUCERA):

Diese saftflußunabhängige Wärmeausbreitung im Phloem wurde von der ThermoelementAnordnung nur unzureichend als nicht in die Splintholzerwärmung gegangener Wärmeverlust erfaßt. Zudem weist die Buche als zerstreutporige Art relativ hohe Flußdichten auf, wie sie sonst vor allem für ringporige Arten typisch sind (PHILliPs et al. 1996). Die Buche besitzt gleichzeitig aber ein wesentlich tiefer reichendes leitendes Splintholzes als ringporige Arten, in denen meist nur die äußersten Jahresringe noch leitende Funktion haben (PHILLIPS et al. 1996, LANG 1999). Diese Faktoren-Kombination kann bewirken, daß die durch eine konstante Heizenergie erzeugte immer gleiche Wärmemenge sich nicht auch in größere Tiefen des leitenden Splints gleichmäßig ausbreiten kann, sondern vor allem im Phloem und phloemnahen Xylem abgeführt wird. Eine solche geringere Erwärmung des Xylemsaftes spiegelt aber aufgrund des Meßprinzips eine erhöhte Saftflußgeschwindigkeit vor und also im Meßergebnis einen höheren Xylem-Saftfluß als er wirklich stattfindet.

Um diesen Effekt zu verhindern, wurden vom Hersteller zum einen Heizelektroden entwickelt, die in dem Bereich, in dem sie das Phloem durchdringen, mit einer Isolierschicht versehen waren. Zum anderen wurde im Meßfeld die Position der Thermoelemente, die die Wärmeausbreitung erfassen sollen, verändert. Vermutlich durch eine unzureichende Anpassung der Position der Thermoelemente bzw. der Berechnung der lateralen Ausbreitung von Wärme, die nicht durch den Fluß des erwärmten Xylemsafts abgeführt wird, entstand jedoch ein offenbar erheblicher neuer Fehler.

Dieser führte zu Saftflußraten der Einzelbäume auf Tages- wie Jahresebene, die etwa doppelt so hoch waren wie in den vorangegangenen beiden Meßjahren mit alter Meßeinrichtung. Entsprechend erreichte auch die Extrapolation auf die Bestandestranspiration der Untersuchungsbestände Tagessummen bis $16 \mathrm{~mm}$ und Jahressummen um $500 \mathrm{~mm}$ für die Vegetationsperiode 1997. Diese Werte erscheinen erheblich zu hoch. Zumal gerade in Untersuchungen der letzten Jahre mit verschiedenen Methoden für Buchenbestände deutlich niedrigere Jahres- und Tagessummen der Transpiration bestimmt wurden, die etwa im Bereich der in den Jahren 1995 und 1996 ermittelten Werte liegen (KÖSTNER 2001) (vgl. Tab. 5-12). Darüber hinaus wurden in mehrjährigen Untersuchungen desselben Buchenbestandes Schwankungen der jährlichen Bestandestranspiration um den Faktor 2 bisher noch nicht beobachtet (BENECKE 1984, BÜCKING \& KreBs 1986, Gerke 1987, LeusChNER 1994, HeIL 1996, Herbst et al. 1999) (vgl. Tab. 5-12). Die für die Bestandestranspiration der Vegetationsperiode 1997 ermittelten extrem hohen Werte waren zudem in keinem Untersuchungsbestand mit einer möglichen Änderung der Bodenwasservorräte und den 
Niederschlagssummen der Vegetationsperiode in Übereinstimmung zu bringen. Sie wurden deshalb als Artefakt betrachtet und verworfen.

Prinzipiell ist eine gewisse Überschätzung des Xylemsaftflusses durch den ursprünglich vermuteten „Phloemeffekt-Fehler“ denkbar. Ein noch während der Vegetationsperiode 1996 an einigen Meßpunkten durchgeführtes Ausschälen des Phloems rund um die Heizelektroden, um den Kontakt zum Phloem zu unterbrechen, ergab jedoch keinen Hinweis auf geringere gemessene Flußraten nach dieser Maßnahme.

Dem steht andererseits eine zu vermutende Unterschätzung des wirklichen Xylemsaftflusses durch ein in der Regel offenbar nicht vollständiges Erfassen des leitenden Splintbereichs entgegen. Eigene Untersuchungen in Zusammenarbeit mit HEIMANN (pers. Mitt.) sowie von LANG (1999), GRANIER et al. (zit. in LANG 1999) und KocH (2002) an Buchen durchgeführte Messungen der Profiltiefe des leitenden Splintholzbereiches zeigten, daß sich dieser offenbar bis deutlich über $80 \mathrm{~mm}$ Entfernung vom Kambium nach innen erstrecken kann. LANG (1999) bestimmte eine im Mittel hyperbolische Abnahme der Saftflußdichten mit zunehmender Entfernung vom Kambium, ein Trend, wie er auch von PHILLIPS et al. (1996) in einer Übersicht der radialen Änderung der Saftflußgeschwindigkeit bei verschiedenen Arten beobachtet und von GRANIER et al. (2000) sowie KOCH (2002) bestätigt wurde. Darüber hinaus gibt LANG (1999) von GRANIER (pers. Mitt.) ermittelte Meßergebnisse an, die im Splintholz eine in etwa hyperbolische Abnahme der Saftflußdichten von außen nach innen auf ein Niveau von immerhin noch etwa $10 \%$ in 90 mm Entfernung vom Kambium zeigten. GRANIER et al. (2000) fanden eine Abnahme auf etwa $20 \%$ in $60 \mathrm{~mm}$ Entfernung vom Kambium. In der vorliegenden Untersuchung durchdrangen die Heizelektroden das Splintholz nur auf einer Länge von maximal $56 \mathrm{~mm}$. Es ist also davon auszugehen, daß tiefere leitende Splintholzbereiche nicht in gleichem Maße erwärmt wurden wie flachere Splintholzbereiche. Eine zu flache Position der Thermoelemente ließ in diesem Fall auch keine ausreichende Berücksichtigung von Temperaturgradienten fließenden Xylemsaftes in tieferen Splintholzbereichen zu. Durch die niedrigen Flußdichten, die in tieferen Splintholzbereichen gemessen wurden, blieb der daher rührende Fehler allerdings vermutlich relativ gering (JIMÉNEZ et al. 2000). Eine zum Teil sehr unregelmäßige Verteilung der Flußdichten über das Splintholzprofil bei verschiedenen Baumindividuen (LANG 1999) macht ihn jedoch schwer abschätzbar.

Die Variation des Xylemsaftflusses zwischen den Individuen eines Bestandes ist meist gut durch Korrelation mit einer Bezugsgröße wie der Grund- bzw. Splintholzfläche oder Blattfläche des einzelnen Baumes erklärbar (HATTON \& WU 1995, VERTESSY et al. 1995, ALSHEIMER et al. 1998). Diese Bezugsgröße, in der vorliegenden Untersuchung die Baumgrundfläche (KÖSTNER et al. 1992, TESKEY \& SHERIFF 1996), kann dadurch als Skaliergröße zur Hochrechnung des Xylemsaftflusses von wenigen Meßbäumen auf Bestandesebene herangezogen werden. GRANIER et al. (2000) konnten mit diesem Vorgehen die Bestandestranspiration von Buchenbeständen zuverlässig extrapolieren.

In homogenen Beständen ist bei der Bestimmung des mittleren Xylemsaftflusses und damit der Transpiration eines Bestandes der Variationskoeffizient mit hoher Wahrscheinlichkeit recht gering $(<15 \%$ ), wenn an etwa 10 Probebäumen gemessen wird (KöSTNER et al. 1998b, KÖSTNER 2001). Einen deutlichen Anstieg des Variationskoeffizienten beobachteten KÖSTNER et al. (1996b) jedoch erst bei < 5 zufällig ausgewählten Probebäumen. 
Die Zuverlässigkeit skalierter Saftflußmessungen konnte im Vergleich mit Messungen des Wasserdampfflusses über dem Bestand bestätigt werden (GRANIER et al. 1996b, KÖSTNER et al. 1998a). Auch führte die vergleichende Anwendung verschiedener Saftfluß-Meßmethoden zu ähnlichen Ergebnissen (KÖSTNER et al. 1996b, KÖSTNER et al. 1998a).

In der vorliegenden Untersuchung standen nur Meßsysteme für je 12 Meßpunkte in jedem Bestand zur Verfügung. Die Ergebnisse der vorliegenden Untersuchungen sowie von LANG (1999) zeigten, daß die Saftlußdichten im Xylem auf verschiedenen Seiten desselben Stammes sich deutlich (bis um den Faktor 2.7) unterscheiden und auch im Verlauf der Vegetationsperiode relativ zueinander erheblich variieren können. Daher erschien es geraten, an jedem Meßbaum dauerhaft zwei Meßpunkte zu installieren und so mit einer repräsentativen Auswahl von nur 6 Meßbäumen bei dennoch ausreichender bis guter Korrelation mit der Skaliergröße für die Bestandesextrapolation den Fehler minimal zu halten.

Insgesamt sind die in den Jahren 1995 und 1996 bestimmten Werte der Bestandestranspiration demnach als weitgehend zuverlässige und realistische Ergebnisse einzuordnen.

\subsubsection{Die Jahressummen der Bestandestranspiration unter dem Einfluß von Niederschlagsregime und morphologisch-strukturellen Bestandesmerkmalen}

In einer Literaturübersicht verglichen PECK \& MAYER (1996) die Jahressummen der Bestandestranspiration von 68 Beständen aus 7 mitteleuropäischen Waldbaumarten (Tab. 5-12). Die Wertespanne reichte dabei von nur $88 \mathrm{~mm}$ für einen Birkenbestand bis $765 \mathrm{~mm}$, die für einen Kiefernbestand ermittelt wurden. Eine beträchtliche Variabilität um bis zu $300 \%$ stellte auch KÖSTNER (2001) bei in den letzten Jahren ermittelten Werten der jährlichen Bestandestranspiration von Wäldern fest. Damit widerlegten PECK \& MAYER (1996) sowie KÖSTNER (2001) die Annahme von LYR et al. (1967), die auch ROBERTs (1983) noch vertrat, daß sich die Bestandestranspirationswerte verschiedener Waldbestände selbst bei unterschiedlichen Baumarten nur wenig unterscheiden.

Die in Tabelle 5-12 aufgeführten, von diversen Autoren bestimmten Jahressummen der Bestandestranspiration von Buchenwäldern bewegen sich bei einer Wertspanne von $164 \mathrm{~mm}-601 \mathrm{~mm}$ überwiegend im Bereich $250 \mathrm{~mm}-350 \mathrm{~mm}$ und ergeben einen Mittelwert von $300 \mathrm{~mm}$. Im Vergleich dazu bleiben die in der vorliegenden Arbeit ermittelten Jahressummen der Bestandestranspiration mit einer Wertespanne von 205 - $303 \mathrm{~mm}$ und einem Mittel von $244 \mathrm{~mm}$ auf einem relativ niedrigen Niveau, jedoch klar im Rahmen der aus der Literatur bekannten Werte.

KÖSTNER (2001) weist darauf hin, daß die von Autoren der letzten Jahrzehnte vor allem mit der Wasserbilanzmethode ermittelten Werte der jährlichen Bestandestranspiration von Buchenwäldern (vgl. Brechtel \& LeHNHARDT 1982, PECK \& MAYER 1996) zum Teil deutlich höher liegen als die in den letzten Jahren mit Saftfluß-Methoden bestimmten Werte, die meist um 250 mm (GRANIER et al. 2000) liegen. 
Tab. 5-12: Maximalwerte der täglichen Bestandestranspiration und Jahressummen der Bestandestranspiration in den Untersuchungsbeständen Ziegelrodaer Forst (ZF), Göttinger Wald (GW), Lüneburger Heide (LH) und Solling (SO) sowie nach Literaturangaben für Buche und andere Baumarten. $\varnothing$ kennzeichnet Mittelwerte aus mehreren einzelnen Werten, deren Wertespanne in Klammer angegeben ist.

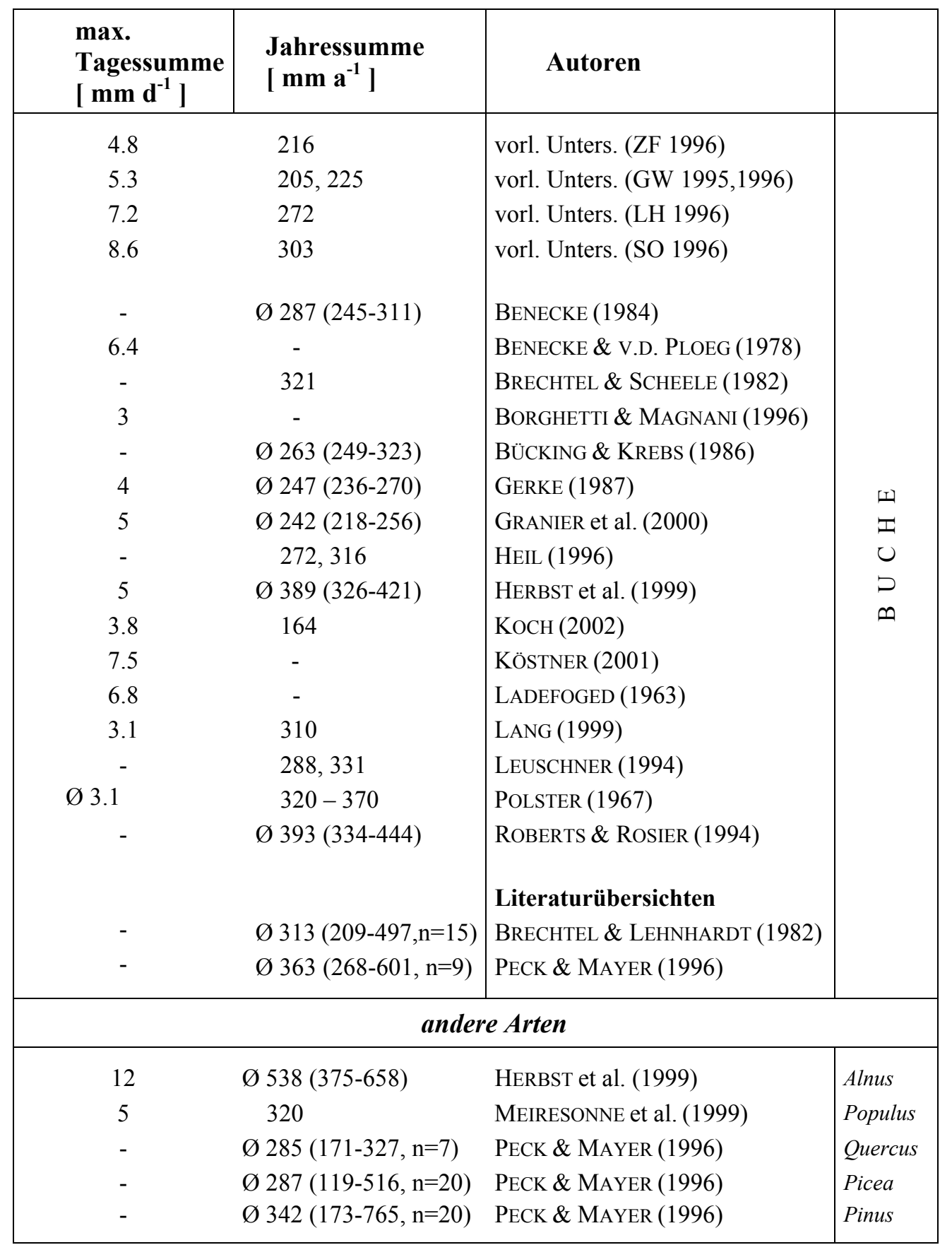

Die im Bestand Lüneburger Heide bestimmten hohen Werte der Bestandestranspiration (und Bestandesleitfähigkeit) stehen im Widerspruch $\mathrm{zu}$ den dort vergleichsweise sehr niedrigen mittleren mittäglichen Blattleitfähigkeiten (vgl. Kap. 5.2.2). Eine für den Bestand Lüneburger Heide spezifische potentielle Fehlerquelle bei der Bestimmung der Bestandestranspiration liegt in der Tatsache, daß es sich um den einzigen Mischbestand der vorliegenden Untersuchung handelt. Für eine Extrapolation der Xylemsaftfluß-Messungen auf die Transpiration eines 
großflächigen Buchen-Reinbestands mußte deshalb auf einen vergleichsweise kleinen Ausschnitt dieser Untersuchungsfläche zurückgegriffen werden, auf dem sich ausschließlich Buchen befinden (0.16 ha gegenüber $0.3-1$ ha in den anderen Beständen). Dieser kleine Ausschnitt war möglicherweise nicht ausreichend repräsentativ für eine Hochrechnung auf einen großflächigen Bestand.

KÖSTNER (2001) betonte die Bedeutung der Bestandesstruktur für die Höhe der Bestandestranspiration. Sie beobachtete in einem von Fichten umgebenen exponierten Bestandesausschnitt aus Buchen stark erhöhte Transpirationsraten gegenüber geschlossenen Buchenbeständen. Da mit den Transpirationsraten dieses exponierten Bestandesausschnitts teilweise sogar die für die Verdunstung von Wasser zur Verfügung stehende Energiemenge überschritten wurden, spricht sie von einen „Oaseneffekt“", also einer erhöhten Verdunstung durch advektiv zugeführte Energie. Darüber hinaus macht KÖSTNER (2001) auch auf die große Auswirkung eines mehrschichtigen Bestandesaufbaus aufmerksam, der eine beträchtliche Erhöhung der Bestandestranspiration gegenüber einem Bestand mit einschichtigem Kronendach zur Folge haben kann.

Der Bestand in der Lüneburger Heide besitzt in der herrschenden Baumschicht zwar eine den anderen Untersuchungsbeständen vergleichbare Stammzahl. Betrachtet man jedoch die Anzahl aller Stämme eines Bestandes, fällt der Bestand in der Lüneburger Heide durch eine etwa doppelt so hohe Gesamtstammzahl und gleichzeitig die deutlich geringsten mittleren BHD gegenüber den anderen Untersuchungsbeständen auf. Hierin kommt zum Ausdruck, daß

der Bestand in der Lüneburger Heide als einziger Untersuchungsbestand einen erkennbar mehrschichtigen Aufbau mit einem ausgeprägten Buchenunterstand besitzt. Dieser ist vornehmlich unter den aufgelichteten Kronen der eingestreuten Eichen $\mathrm{zu}$ finden. Eine vergleichsweise hohe Transpirationsleistung des Bestandes in der Lüneburger Heide infolge seiner spezifischen Bestandesstruktur ist also denkbar.

In der vorliegenden Untersuchung wurden neben der Bestandestranspiration auch klimatische, bodenhydrologische und morphologisch-bestandesstrukturelle Parameter bestimmt, die als Rahmenbedingungen den Bestandeswasserhaushalt entscheidend prägen

- Mit der Witterung schnell veränderliche Klimafaktoren (Globalstrahlung, Sättigungsdefizit der Luft) nehmen kurzfristig und unmittelbar Einfluß auf das aktuelle Ausmaß der Transpiration.

- Der Bodenwasserzustand steht als puffernde Speichergröße des Bestandeswasserhaushalts einerseits unter dem Einfluß des Niederschlagsregimes sowie andererseits in Wechselwirkung mit dem wasserverbrauchenden Bestand und ist dabei mittelfristig mitunter starken Veränderungen unterworfen.

- Strukturelle Parameter des Bestandeswasserhaushalts wie der Bestandesaufbau, der Blattflächenindex (LAI), die Blattmorphologie oder die Wurzelbiomasse eines Bestandes verändern sich nur in vergleichsweise geringem Umfang und allenfalls langsam oder in Jahreszyklen. 
Eine morphologische und strukturelle Anpassung von Einzelpflanzen, Arten oder Pflanzenbeständen an unterschiedliche Trockenstreßbelastung ist für zahlreiche Arten und Klimaregionen beschrieben worden (WALTER \& BRECKLE 1991, LARCHER 1994, FREY \& LÖSCH 1998). Eine Anpassung an Trockenstreß-Standorte kann dabei etwa in Form einer Verringerung der transpirierenden Oberfläche durch eine niedrigere Bestandesblattfläche bzw. geringe Bestandesdichte auftreten (WALTER 1960, HARRINGTON et al. 1995, BRÉDA 1999) oder durch Ausbildung kleinerer, skleromorpher Blätter mit vor Wasserverlust schützenden Oberflächen (SHIELDS 1950, LÖSCH 2001, RIEDERER \& SCHREIBER 2001).

Beispiele hierfür beziehen sich jedoch in der Regel auf Transekte entlang großer Humiditätsgradienten, die meist nicht nur eine starke Veränderung des Niederschlagsregimes und der potentiellen Evapotranspiration umfassen (HARRINGTON et al. 1995), sondern auch eine sich ändernde Artenzusammensetzung (ABRAMS 1994, BUSSOTTI et al. 2000) oder gar gänzlich unterschiedliche Vegetationsformen (GRIER \& RUNNING 1977, GHOLZ 1982).

Über entsprechende morphologisch-strukturelle Veränderungen von Beständen derselben Art entlang eines Gradienten der Wasserversorgung liegen bisher nur sehr wenig Erkenntnisse vor (GHOlZ et al. 1976, MAHERALI \& DeLuCIA 2001), insbesondere für Arten der gemäßigten Klimazonen (REICH \& HincKley 1989, MENCuCCINI \& GRACE 1995, BussotTI et al. 1997 und 2000).

Entlang des Humiditätsgradienten zwischen den untersuchten Buchenbeständen war eine solche Anpassung nach „klassischen“ Reaktionsmustern nicht zu beobachten. Im Gegenteil besaß der langjährig niederschlagsärmste Bestand im Ziegelrodaer Forst mit der am stärksten ausgeprägten Trockenstreßbelastung im Vergleich der Untersuchungsbestände den höchsten Blattflächenindex, die im Mittel größten Blätter und ein geringes spezifisches Blattgewicht. Der Bestand Solling mit dem deutlich humidesten Klima ohne Sommertrockenheit wies dagegen stets eine relativ niedrige Bestandesblattfläche und die kleinsten Blätter mit einem hohen spezifischen Blattgewicht auf. Einen ähnlichen Trend, der der Annahme einer Ausbildung größerer transpirierender Oberflächen mit steigender Humidität entgegenläuft, beobachteten auch FOETZKI (1998) bzw. VOß (1998) in ihrer Untersuchung von Buchenwäldern in Mitteldeutschland. Eine deutliche Abhängigkeit des Blattflächenindex von der Bestandeswasserversorgung war jedoch nicht erkennbar.

Andere Faktoren wie Temperatur- oder Strahlungssummen im Frühjahr oder Sommer (RolOFF 1985, Wetlander \& OTtosson 1997), die Nährstoffversorgung (Vose \& Allen 1988, SchenK et al. 1989, Voß 1998), das Bestandesalter (HeInsdorf \& CHROzON 1997, Voß 1998) oder die genetische Disposition scheinen die Blattflächenausbildung der untersuchten Buchenbestände stärker zu beeinflussen als Wasserdefizite (LANDSBERG 1986, HEINSDORF \& CHROZON 1997).

Auch die Tendenz zu einem Anstieg der Bestandestranspiration mit steigendem Blattflächenindex, wie sie etwa von BRÉDA \& GRANIER (1996) und BRÉDA (1999) an Traubeneichen beobachtet und von KÖSTNER (2001) auch für Buchen beschrieben wurde, konnte bei den untersuchten Buchenbeständen nicht festgestellt werden (Abb. 5-3a). Ein indirekter Einfluß der Bestandesblattfläche auf die Bestandestranspiration besteht jedoch über die Niederschlags-Interzeption als Verlustgröße der Wasserbilanz, die den Bestandesniederschlag gegenüber dem Freilandniederschlag verringert. Die Interzeption steigt in der Regel mit steigender Bestandesblattfläche, da eine größere Oberfläche auch eine größere 
Benetzungskapazität besitzt (Delfs 1955, Crandell \& LuXMOORE 1982, Grote \& SuCKOW 1998). Auch mit der Menge des Jahres- bzw. Vegetationsperioden-Niederschlags wächst der absolute Betrag der Interzeption, der relative Anteil am Freilandniederschlag nimmt jedoch ab (HIEGE 1985). Des weiteren spielt auch die zeitliche Verteilung des Niederschlags eine bedeutende Rolle, da häufige geringe Niederschläge die Interzeption gegenüber seltenen Starkregenereignissen erhöhen (BENECKE 1984, HIEGE 1985). Durch die Vielfalt variabler Einflußfaktoren können Unterschiede der Interzeption im selben Bestand zwischen einzelnen Jahren größer sein als die Unterschiede zwischen verschiedenen Beständen oder Arten (PECK \& MAYER 1996).

Für Buchenbestände wurden jedoch in zahlreichen Untersuchungen meist recht ähnliche Anteile der Interzeption am Freilandniederschlag von im Mittel etwa $25 \%$ bzw. $20 \%$ für die Vegetationsperiode bzw. das gesamte Jahr bestimmt (EIDMANN 1959, AUSSENAC \& Boulangeat 1980, ForgeArd et al. 1980, Mitscherlich 1981, BAlAzS 1983, BÜCKING \& Krebs 1986, Brechtel \& Balazs 1988, Heil 1996, PeCK \& Mayer 1996, Granier et al. 2000). Für die in der vorliegenden Arbeit untersuchten Bestände ermittelten BENECKE (1984) im Solling $23 \%$ bzw. $18 \%$, GERKE (1987) im Göttinger Wald $25 \%$ bzw. $16 \%$ und LeUSCHNER (1994) in der Lüneburger Heide $30 \%$ bzw. $27 \%$ als mittleren Anteil der Interzeption am Freilandniederschlag jeweils für die Vegetationsperiode bzw. das gesamte Jahr. In dem Bestand im Ziegelrodaer Forst wurde zwar 1996 wie auch 1997 ein Anteil der Kronentraufe am Freilandniederschlag von etwa 63 \% ermittelt, der Stammablauf jedoch nicht erfaßt. Dies erlaubt nur ein Abschätzen der Interzeption anhand von Stammablaufwerten aus der oben angeführten Literatur. Je nach zugrundegelegter Stammablaufmenge ergeben sich daraus $23-32 \%$ Interzeption in der Vegetationsperiode für den Bestand im Ziegelrodaer Forst. Der mittlere Anteil der Interzeption am Freilandniederschlag ist also in allen Untersuchungsbeständen offenbar ähnlich. Vergleichsweise hohe Interzeptionsraten in der Lüneburger Heide gegenüber niedrigeren im Solling verstärkten jedoch auf Ebene des Bestandesniederschlags vermutlich noch zusätzlich den in den Untersuchungsjahren beobachteten Gradienten des Freilandniederschlags. Eine vergleichsweise starke Verringerung des Bestandesniederschlags durch Interzeption kann auch für den schon bezüglich des Freilandniederschlags trockensten Standort im Ziegelrodaer Forst angenommen werden. Weist dieser doch mit besonders geringen Niederschlägen bei einer besonders hohen Bestandesblattfläche potentiell die Interzeption erhöhende Bedingungen auf.

Die mittlere Xylem-Saftfußrate der einzelnen untersuchten Buchen zeigte in allen Untersuchungsjahren eine gute bis sehr gute Beziehung zur jeweiligen Grundfläche des Baumes (vgl. Abb. 3-2). Auf der Ebene der untersuchten Bestände war diese enge Beziehung zwischen Transpirationsleistung und Grundfläche jedoch nicht mehr gegeben (Abb. 5-3b). Auch zwischen der Stammzahl der herrschenden Baumschicht und der Bestandestranspiration der Untersuchungsbestände trat kein erkennbarer Zusammenhang auf (Abb. 5-3c), ebenso bei Bezug der Bestandestranspiration auf die Zahl aller Stämme im Bestand (nicht dargest.). Auch PECK \& MAYER (1996) konnten anhand in ihrer Literaturübersicht bei keiner der untersuchten Baumarten eine systematische Abhängigkeit der Bestandestranspiration von der Bestandesdichte erkennen. AlsheimnER et al. (1998), KÖSTNER et al. (2001) und LunDBLAD \& LindROTH (2002) stellten dagegen bei Fichten- bzw Kiefernbeständen einen Anstieg der Bestandestranspiration mit steigender Stammdichte fest. 

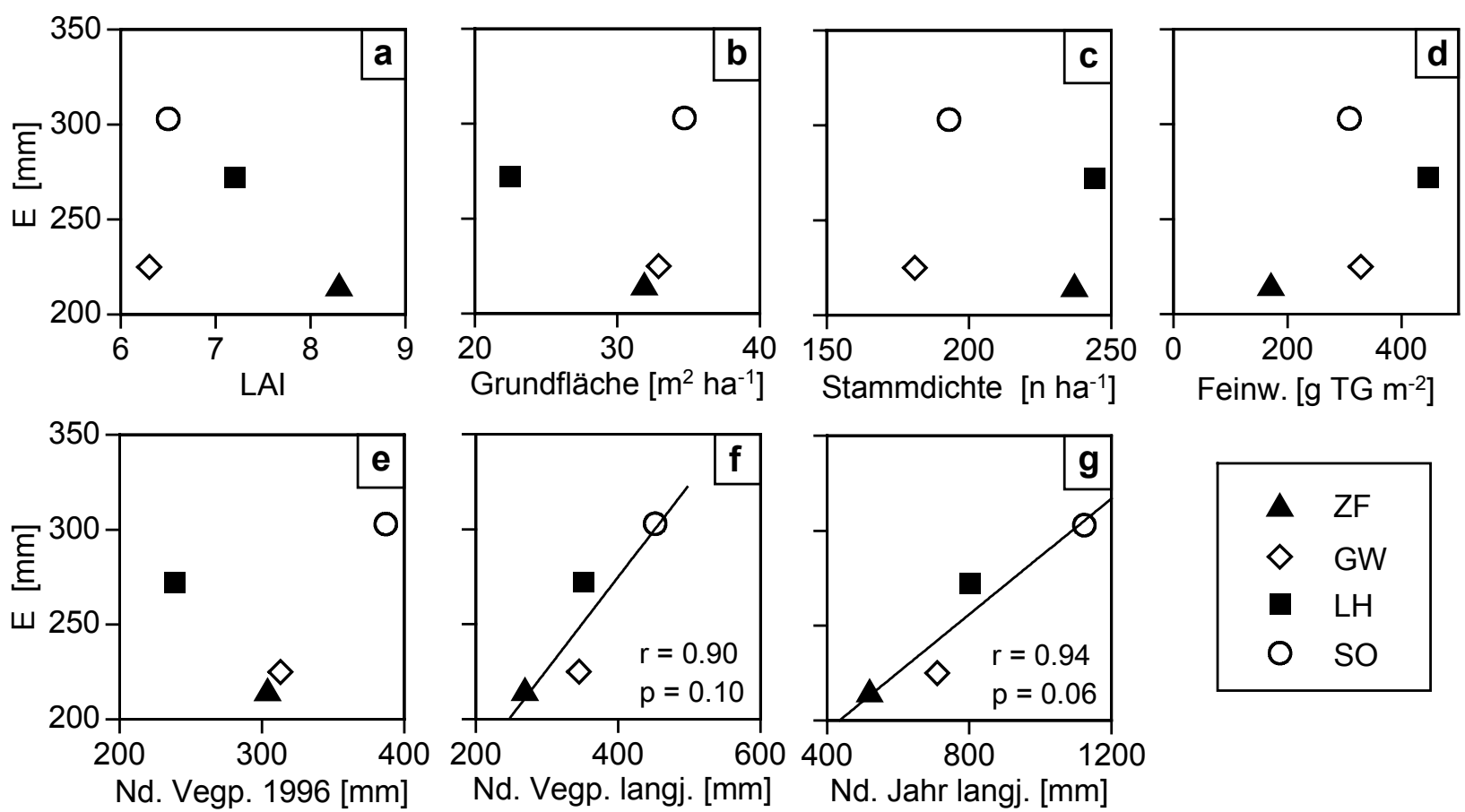

Abb. 5-3: Beziehung der Bestandestranspiration der Vegetationsperiode 1996 in den Untersuchungsbeständen Ziegelrodaer Forst (ZF), Göttinger Wald (GW), Lüneburger Heide (LH) und Solling (SO) zum Blattflächenindex (LAI) (a), zur Bestandesgrundfläche (b), zur Stammdichte (c), zur Feinwurzelbiomasse in Auflage und 0-40 cm Mineralbodentiefe (d), zum Niederschlag in der Vegetationsperiode 1996 (e), zum langjährigen Mittel des Niederschlags in der Vegetationsperiode (f) und zum langjährigen Mittel des Jahresniederschlags $(\mathrm{g})$.

Die Unterschiede der Bestandestranspiration der untersuchten Buchenbestände in der Vegetationsperiode 1996 ließen sich nicht auf unterschiedliche Feinwurzel-Biomassen zurückführen, die HERTEL (1999) im gleichen Jahr dort ermittelte. Zwar zeigte der Bestand in der Lüneburger Heide mit der deutlich höchsten Feinwurzel-Biomasse auch eine vergleichsweise hohe Transpirationsleistung und der Bestand im Ziegelrodaer Forst mit der deutlich geringsten Feinwurzel-Biomasse die niedrigste Bestandestranspiration. Die Bestände im Solling und im Göttinger Wald mit sehr ähnlichen Feinwurzel-Biomassen deckten jedoch nahezu die gesamte Spanne der in den vier Untersuchungsbeständen beobachteten Bestandestranspirationswerte ab. Der Bestand im Ziegelrodaer Forst hingegen konnte mit der Hälfte der Feinwurzel-Biomasse des Bestandes im Göttinger Wald eine nahezu gleich Menge Wasser wie dieser umsetzen. Dabei ergab der Bezug der Bestandestranspiration auf die Feinwurzel-Biomasse bis $40 \mathrm{~cm}$ Bodentiefe (Abb. 5-3d) ein sehr ähnliches Bild wie der Bezug auf die Feinwurzel-Biomasse der gesamten Profiltiefe (nicht dargest.).

Neben einem möglichen Einfluß bestandesstruktureller Parameter auf den Wasserhaushalt von Buchenwäldern ist eine entscheidende Bedeutung der Niederschlagsmenge als einziger positiver Bilanzgröße des Bestandeswasserhaushalts zu vermuten. Die in den Untersuchungsbeständen ermittelten Jahressummen der Bestandestranspiration lassen jedoch keine Beziehung zu den Niederschlägen in der Vegetationsperiode 1996 erkennen (Abb. 5-3e). Der in der Vegetationsperiode 1996 herrschende Niederschlagsgradient zwischen den Untersuchungsflächen spiegelte sich also in dieser Form nicht in der Bestandestranspiration der untersuchten Buchenbestände wider. Erstaunlich ist jedoch die gute Übereinstimmung, die die Transpiration 
der Bestände in der Vegetationsperiode 1996 mit den langjährigen Mittelwerten des Niederschlags auf den Untersuchungsflächen zeigte. Sowohl zum langjährigen Mittel des Niederschlags in der Vegetationsperiode (Abb. 5-3f) als auch zum langjährigen mittleren Jahresniederschlag (Abb. 5-3g) zeichneten sich hier enge lineare Beziehungen ab. Diese waren aufgrund der geringen Zahl der betrachteten Bestände allerdings mit Irrtumswahrscheinlichkeiten $(p=0.10$ bzw. $p=0.06)$ behaftet, die geringfügig über dem üblichen Signifikanzniveau von $\mathrm{p}<0.05$ lagen. Es bleibt somit fragwürdig, ob hierin ein Hinweis auf eine strukturelle oder physiologische Anpassungen der Bestände an die langjährige Niederschlagsversorgung gesehen werden kann, die auch bei abweichenden Klimabedingungen einzelner Jahre oder Vegetationsperioden zum Ausdruck kommt. KÖSTNER (2001) konnte in ihrer Literaturstudie eine relativ hohe Variabilität der Bestandestranspiration von 16 Buchenwäldern nicht durch einen Bezug auf den Jahresniederschlag verringern.

Keiner der oben betrachteten Faktoren allein, weder die Bestandesblattfläche noch die Stammdichte oder die Grundfläche, die Feinwurzelbiomasse oder die Niederschlagsmenge des Untersuchungsjahres hatte demnach einen so deutlichen Einfluß auf die Höhe der Bestandestranspiration, daß dieser im Vergleich der vier untersuchten Buchenbestände erkennbar würde.

\subsection{Bestandestranspiration und Bestandesleitfähigkeit in ihrer Reaktion auf das aktuelle Wasserhaushaltsregime}

\subsubsection{Die Bestandestranspiration in Abhängigkeit von abiotischen Einflußgrößen des Wasserhaushalts}

In einer Vielzahl von Untersuchungen zum Wasserhaushalt von Waldökosystemen erwiesen sich durchwegs die auf den Bestand treffende Strahlung (Globalstrahlung bzw. PAR) und das Sättigungsdefizit der Luft als die Klimafaktoren, welche die Höhe der Bestandestranspiration entscheidend bestimmen (LOUSTAU \& GRANIER 1993, BACKES 1996, HERBST et al. 1999, Wullschleger et al. 2000, KöStner 2001, Oren \& PAtaki 2001, Wilson et al. 2001). Dies gilt sowohl im Tagesgang als auch auf Ebene von Tageswerten im Verlauf der Vegetationsperiode (HEIMANN 1995, KÖSTNER et al. 1996b, ALSHEIMER et al. 1998, LANG 1999). Die Betrachtung von Tagesmitteln oder Tagessummen hat dabei gegenüber einer Analyse von Wasserhaushaltsparametern im Tagesgang den Vorteil, daß Effekte einer zeitverzögerten Reaktion der Bestandestranspiration auf Klimafaktoren (HINCKLEY et al. 1994, STROBEL 1997, Loustau et al. 1998), wie sie durch die Pufferwirkung des Wasserspeichers im Stamm- und Blattgewebe entstehen (JARVIS 1976, KOWALIK et al. 1997, LANG 1999), weitgehend vermieden werden.

Die Tagessumme der Bestandestranspiration war auch in der vorliegenden Untersuchung in allen untersuchten Beständen und in allen Phasen der Vegetationsperiode mit der Globalstrahlung und dem Sättigungsdefizit der Luft jeweils eng und hochsignifikant korreliert. Dabei wies eine sigmoidale Kurvenanpassung beim Sättigungsdefizit der Luft stets und bei der Globalstrahlung in den meisten Fällen ein etwas besseres adjustiertes Bestimmtheitsmaß ( $r^{2}$ adj.) auf als eine lineare Regression (Overdieck \& Forstreuter 1994, LANG 1999, KÖSTNER 2001, OREN \& PATAKI 2001) (Abb. 5-4, Tab.5-13). 

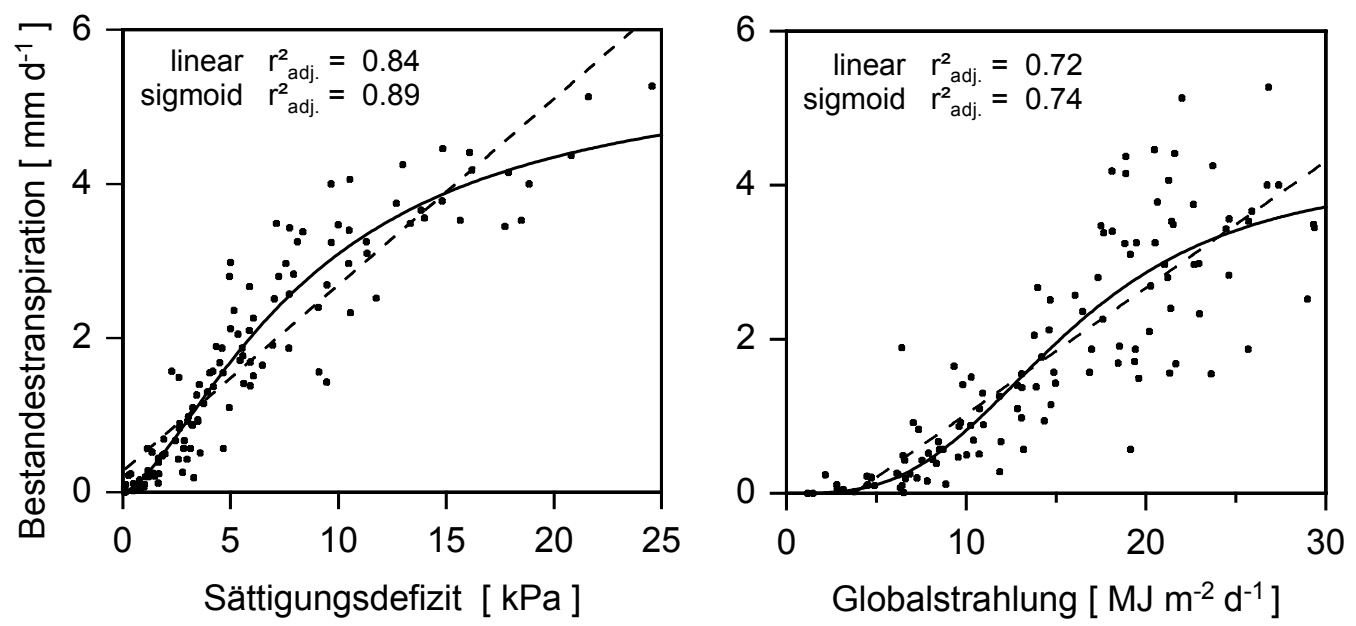

Abb.5-4: Lineare Beziehungen $E=a+b \cdot x$ und sigmoidale Beziehungen $E=a /\left(1+(b / x)^{c}\right)$ zwischen der Tagssumme der Bestandestranspiration und der Hellphasen-Tagessumme des WasserdampfSättigungsdefizits der Luft sowie zwischen der Tagssumme der Bestandestranspiration und der Tagessumme der Globalstrahlung für den Zeitraum Juni bis September 1996 im Untersuchungsbestand Göttinger Wald $(\mathrm{p}<0.01)$.

Tab.5-13: Adjustierte Bestimmtheitsmaße $\left(\mathrm{r}^{2}{ }_{\text {adj. }}\right)$ der linearen Beziehungen $E=a+b \cdot x$ und der sigmoidalen Beziehungen $\mathrm{E}=\mathrm{a} /\left(1+(\mathrm{b} / \mathrm{x})^{\mathrm{c}}\right)$ zwischen der Tagssumme der Bestandestranspiration $\left[\mathrm{mm} \mathrm{d}^{-1}\right]$ und der Hellphasen-Tagessumme des Wasserdampf-Sättigungsdefizits der Luft (VPD) [kPa] sowie den zwischen der Tagssumme der Bestandestranspiration $\left[\mathrm{mm} \mathrm{d}^{-1}\right]$ und der Tagessumme der Globalstrahlung $(\mathrm{G})\left[\mathrm{MJ} \mathrm{m}^{-2} \mathrm{~d}^{-1}\right]$ für die vier untersuchten Bestände in verschiedenen Phasen der Vegetationsperiode 1996 (alle Beziehungen: $\mathrm{p}<0.01$ ).

\begin{tabular}{|c|c|c|c|c|c|c|c|c|}
\hline $\mathbf{r}_{\text {adj. }}^{2}$ & $\begin{array}{l}\text { VPD } \\
\text { linear }\end{array}$ & $\begin{array}{c}\text { VPD } \\
\text { sigmoid }\end{array}$ & $\begin{array}{l}\text { G } \\
\text { lin }\end{array}$ & $\begin{array}{c}G \\
\text { sig }\end{array}$ & $\begin{array}{c}\text { VPD } \\
\text { lin }\end{array}$ & $\begin{array}{c}\text { VPD } \\
\text { sig }\end{array}$ & $\begin{array}{c}\text { G } \\
\text { lin }\end{array}$ & $\begin{array}{c}\text { G } \\
\text { sig }\end{array}$ \\
\hline & \multicolumn{4}{|c|}{ Ziegelrodaer Forst } & \multicolumn{4}{|c|}{ Göttinger Wald } \\
\hline Juni & - & - & - & - & 0.83 & 0.87 & 0.64 & 0.65 \\
\hline Juli & - & - & - & - & 0.74 & 0.87 & 0.84 & 0.83 \\
\hline August & 0.87 & 0.94 & 0.80 & 0.83 & 0.87 & 0.88 & 0.78 & 0.79 \\
\hline September & 0.94 & 0.94 & 0.85 & 0.88 & 0.93 & 0.93 & 0.82 & 0.83 \\
\hline \multirow[t]{2}{*}{ Jun - Sep } & - & - & - & - & 0.84 & 0.89 & 0.72 & 0.74 \\
\hline & \multicolumn{4}{|c|}{ Lüneburger Heide } & \multicolumn{4}{|c|}{ Solling } \\
\hline Juni & 0.93 & 0.94 & 0.71 & 0.72 & 0.85 & 0.90 & 0.69 & 0.68 \\
\hline Juli & 0.77 & 0.88 & 0.54 & 0.53 & 0.87 & 0.94 & 0.84 & 0.85 \\
\hline August & 0.80 & 0.89 & 0.86 & 0.87 & 0.92 & 0.93 & 0.81 & 0.83 \\
\hline September & 0.88 & 0.88 & 0.82 & 0.81 & 0.95 & 0.95 & 0.88 & 0.90 \\
\hline Jun - Sep & 0.72 & 0.80 & 0.75 & 0.70 & 0.89 & 0.93 & 0.77 & 0.79 \\
\hline
\end{tabular}


Die Bestimmtheitsmaße $\left(\mathrm{r}^{2}{ }_{\text {adj. }}\right)$ der sigmoidalen und der linearen Regressionen zeigen jedoch sowohl innerhalb eines Bestandes im saisonalen Verlauf als auch im Vergleich zwischen den untersuchten Beständen jeweils ein sehr ähnliches Verhalten. Dabei zeigte die Bestandestranspiration in der Regel eine stärkere Abhängigkeit vom Sättigungsdefizit der Luft als von der Globalstrahlung (vgl. WULLSCHLEGER et al. 2000, CONERS 2001, KÖSTNER 2001).

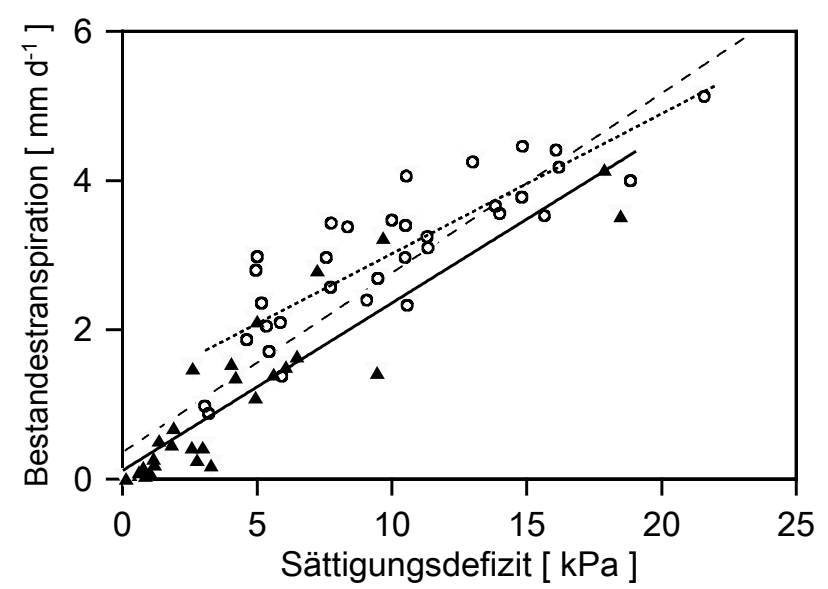

Trockentage $\quad \cdots \cdot \cdots$
$r=0.86 \quad p<0.001$

Niederschlagstage

$r=0.91 p<0.001$

alle Tage $\quad---$

$r=0.91 p<0.001$

Abb. 5-5: Vergleich der linearen Beziehungen $E=f(V P D)=a+b \cdot x$ zwischen der Tagessumme der Bestandestranspiration (E) und der Hellphasen-Tagessumme des Sättigungsdefizits der Luft (VPD) an 25 Tagen mit und 37 Tagen ohne Niederschlag im Zeitraum Juli - August 1996 für den Bestand Göttinger Wald.

Tab.5-14: Mittelwerte der Tagessummen von Bestandestranspiration (E) und Globalstrahlung (G), Tageshellphasenmittel des Sättigungsdefizits der Luft (VPD) und mittlerer volumetrischer Wassergehalt in $15 \mathrm{~cm}$ Bodentiefe $(\Theta)$, sowie Achsenabschnitte (a) und Steigungskoeffizienten (b) der linearen Beziehungen $E=f(x)=a+b \cdot x$ zwischen (E) und (G) bzw. (E) und (VPD) jeweils für 25 Tage mit bzw. 37 Tage ohne Niederschlag im Zeitraum Juli - August 1996 im Bestand Göttinger Wald. Unterschiedliche Buchstaben kennzeichnen signifikante Unterschiede zwischen Tagen mit Niederschlag $(>1 \mathrm{~mm})$ und ohne Niederschlag (Mittelwertsvergleiche mit dem U-Test nach Wilcoxon, $\mathrm{p}<0.001$ ), * kennzeichnet Regressionsparameter mit signifikant unterschiedlichen Konfidenz-intervallen.

\begin{tabular}{|c|c|c|}
\hline $\begin{array}{c}\text { GW } \\
07-081996\end{array}$ & $\begin{array}{c}\text { Tage mit } \\
\text { Niederschlag }\end{array}$ & $\begin{array}{c}\text { Tage ohne } \\
\text { Niederschlag }\end{array}$ \\
\hline \multirow[t]{2}{*}{$\mathbf{E}[\mathbf{m m}]$} & $1.22 \pm 1.2^{\mathrm{a}}$ & $2.78 \pm 1.2^{\mathrm{b}}$ \\
\hline & $11.31 \pm 5.5^{\mathrm{a}}$ & $18.54 \pm 5.6^{\mathrm{b}}$ \\
\hline VPD [kPa] & $4.64 \pm 4.9^{\mathrm{a}}$ & $9.33 \pm 4.9^{\mathrm{b}}$ \\
\hline$\Theta[$ Vol.\%] & $42.7 \pm 5.3^{\mathrm{a}}$ & $40.7 \pm 3.7^{\mathrm{a}}$ \\
\hline $\mathbf{a}_{\mathbf{E}}=\mathbf{f}($ & $-0.91 *$ & $-0.31 *$ \\
\hline $\mathbf{b}_{\mathbf{E}}=\mathbf{f}($ & 0.188 * & $0.168 *$ \\
\hline $\mathbf{a}_{\mathrm{E}=\mathrm{f}(\mathrm{VPD})}$ & $0.11 *$ & $1.15 *$ \\
\hline$b_{E}=f(V P D)$ & $0.225 *$ & $0.188 *$ \\
\hline
\end{tabular}

Es fällt auf, daß speziell an Tagen mit niedrigen Sättigungsdefizit- und Globalstrahlungswerten die Bestandestranspirationsantwort durchwegs Werte annahm, die beim Aufstellen einer linearen Regression unter der Regressionsgeraden für die Gesamtheit der beobachteten Tage liegen. Niedrige Werte von Globalstrahlung und Sättigungsdefizit der Luft treten vor allem bei stark bewölktem Himmel auf, besonders aber während und nach Regenereignissen (vgl. LeUSCHNER 1994). Ein Vergleich von Tagen mit und ohne Niederschlag im Zeitraum JuliAugust 1996 im Bestand Göttinger Wald zeigt deutlich, daß an den Regentagen im Mittel nicht 
nur ein geringeres Sättigungsdefizit und eine niedrigere Globalstrahlung herrschten, sondern auch eine deutlich schwächere Transpirationsantwort pro Sättigungsdefizit- und Globalstrahlungseinheit zu beobachten war als an niederschlagsfreien Tagen (Tab. 5-14). Dementsprechend weichen die Regressionsgeraden für Tage mit und ohne Niederschlag in ihrem Verlauf voneinander und von der Regressionsgeraden für die Gesamtheit der beobachteten Tage ab (vgl. GRANIER et al. 2000a) (Abb. 5-5). Dies kann zum einen beruhen auf einem Effekt verminderter Nettostrahlung bei Regen und einem Verbrauch der Verdunstungsenergie durch die Interzeptionsverdunstung. GRANIER et al. (2000) konnten in einem Buchenbestand zeigen, daß nach Regenphasen die Bestandestranspiration durch eine stark ansteigende Interzeptionsevaporation erheblich reduziert wurde. Eine schwächere Transpirationsantwort des Bestandes auf Sättigungsdefizit und Globalstrahlung an Regentagen weist jedoch auch auf einen physiologischen Effekt verminderter Leitfähigkeit infolge der Benetzung der Blätter durch Regen hin. ISHIBASHI \& TERASHIMA (1995) wiesen an Bohnenpflanzen bei Blattbenetzung durch Regen einen schnellen Stomaschluß und einen nur langsamen Wiederanstieg der stark eingeschränkten stomatären Blattleitfähigkeit nach. Längere Blattbenetzung führte sogar zu einer lang anhaltenden Beeinträchtigung der photosynthetischen Leistungsfähigkeit. LANDWEHR (1997) beobachtete in der Vegetationsperiode 1996 an Blättern des Buchenbestandes im Ziegelrodaer Forst nach einem starken Regenereignis selbst an bereits wieder abgetrockneten Blättern ebenfalls eine deutliche Einschränkung von Blattleitfähigkeit und Photosynthesevermögen.

Eine verringerte Transpirationsantwort an Regentagen, aber auch eine Reduktion der Transpirationsantwort durch starke Leitfähigkeitseinschränkung an besonders strahlungsreichen Tagen mit einem sehr hohen Sättigungsdefizit (MARTIN et al. 1997, WULLSCHLEGER et al. 2000, OREN \& PATAKI 2001) kann durch eine sigmoidale Kurvenanpassung besser widergegeben werden als durch eine Ausgleichsgerade.

Um den Einfluß aller untersuchten Umweltfaktoren des Wasserhaushalts auf die Bestandestranspiration in ihrem Zusammenwirken bestimmen zu können, wurden im Rahmen einer multiplen Regression das Sättigungsdefizit der Luft, die Globalstrahlung und der volumetrische Bodenwassergehalt in verschiedenen Bodentiefen als Parameter eines mehrfach linearen Modells getestet (Tab. 5-15) (Frisse 1977, CONERS 2001, LANG 1999). Dabei wurde für jeden Parameter ermittelt, ob er über eine lineare Beziehung signifikant $(\mathrm{p}<0.05)$ mit der Bestandestranspiration korreliert ist und damit zur Erklärung der Varianz der Bestandestranspiration beitragen kann. Parameter, die so im Zusammenwirken mit weiteren signifikant mit der Bestandestranspiration korrelierten Einflußfaktoren den erklärbaren Anteil der Varianz der Bestandestranspiration erhöhen konnten, wurden jeweils in das Modell übernommen, andernfalls verworfen. Die in der multiplen Regression mit den sukzessive aufgenommenen Einflußfaktoren jeweils erklärbaren Anteile der Varianz der Bestandestranspiration ( $=\mathrm{r}^{2}$ adj.) (WEBER 1980) sind in Tabelle 5-15 angegeben. Außer dem Sättigungsdefizit wurde fast immer auch die Globalstrahlung in das Modell aufgenommen. Die beiden Klimaparameter gemeinsam konnten jeweils einen bereits sehr hohen Varianzanteil (81 $95 \%$ ) erklären und stellen also die wesentlich bestimmenden Umweltfaktoren der Bestandestranspiration dar. 
Tab. 5-15: Adjustierte Bestimmtheitsmaße $\left(\mathrm{r}^{2}\right.$ adj. $)$ der multiplen linearen Regressionen $\mathrm{E}=\mathrm{f}\left(\mathrm{x}_{1}, \mathrm{x}_{2}, \ldots\right)$ $=\mathrm{a}+\mathrm{b} \cdot \mathrm{x}_{1}+\mathrm{c} \cdot \mathrm{x}_{2}+\ldots$ für die Beziehung der Bestandestranspiration (E) zu den Einflußfaktoren Sättigungsdefizit der Luft (VPD), Globalstrahlung (G) und volumetrischer Wassergehalt des Bodens in verschiedenen Tiefenstufen $(\Theta)$ auf der Ebene von Tageswerten in verschiedenen Phasen der Vegetationsperiode 1996.

Die Einflußfaktoren wurden entsprechend dem Anteil der durch sie erklärbaren Varianz $\left(=\mathrm{r}^{2}{ }_{\text {adj. }}\right)$ der Bestandestranspiration sukzessive in die multiple Regression aufgenommenen. Einflußfaktoren, die $\mathrm{r}^{2}$ adj. nicht erhöhen konnten, wurden nicht in das Modell aufgenommen.(alle Beziehungen: $p<0.05$ )

\begin{tabular}{|c|c|c|c|c|c|c|c|c|c|c|c|c|}
\hline \multirow{2}{*}{$\begin{array}{l}1996 \\
r^{2} \text { adj. }\end{array}$} & \multicolumn{3}{|c|}{ Ziegelrodaer Forst } & \multicolumn{3}{|c|}{ Göttinger Wald } & \multicolumn{3}{|c|}{ Lüneburger Heide } & \multicolumn{3}{|c|}{ Solling } \\
\hline & VPD & $\begin{array}{c}\text { VPD } \\
\text { G }\end{array}$ & $\begin{array}{l}\text { VPD, } \\
\text { G, }\end{array}$ & VPD & $\begin{array}{c}\text { VPD } \\
\text { G }\end{array}$ & $\begin{array}{l}\text { VPD, } \\
\text { G, } \Theta\end{array}$ & VPD & $\begin{array}{c}\text { VPD } \\
\text { G }\end{array}$ & $\begin{array}{l}\text { VPD, } \\
\text { G, },\end{array}$ & VPD & $\begin{array}{c}\text { VPD } \\
\text { G }\end{array}$ & $\begin{array}{l}\text { VPD, } \\
\text { G, }\end{array}$ \\
\hline Juni & $-\cdot$ & $-*$ & $-*$ & 0.8 & 0.87 & - & 0.93 & - & - & 86 & 0.88 & - \\
\hline Juli & $-*$ & $-*$ & -* & 0.75 & 0.90 & 0.93 & 0.77 & - & - & 0.88 & 0.92 & - \\
\hline August & 0.87 & 0.93 & - & 0.87 & 0.90 & 0.91 & .88 & 0.93 & 0.94 & 0.91 & 0.94 & 0.96 \\
\hline September & 0. & 0.95 & 0.9 & 0.9 & 0.94 & - & 0.88 & 0.91 & - & 0.95 & 0.95 & - \\
\hline Jun - Jul & $-*$ & $-*$ & $-*$ & 0.7 & 0.00 & 0.87 & & - & - & & 0.88 & 0.89 \\
\hline Jul - Aug & $-*$ & $-*$ & -* & 0.82 & 0.88 & - & 0.72 & 0.81 & 0.82 & 0.89 & 0.94 & - \\
\hline Aug - Sep & 0.91 & 0.95 & - & 0.89 & 0.93 & 0.93 & 0.85 & 0.92 & - & 0.93 & 0.95 & 0.96 \\
\hline Jun - Sep & $-*$ & $-^{*}$ & $-*$ & 0.84 & 0.88 & - & 0.83 & 0.87 & 0.87 & 0.88 & 0.91 & 0.91 \\
\hline
\end{tabular}

* aufgrund fehlender Meßwerte des Sättigungsdefizits keine entsprechende Berechnung möglich

Zwischen der Globalstrahlung und dem am engsten mit der Bestandestranspiration korrelierten Sättigungsdefizit besteht jedoch wiederum eine enge, weitgehend lineare Beziehung. Durch diese Kollinearität kann die Globalstrahlung neben dem Sättigungsdefizit im multiplen Modell nur relativ wenig zusätzlich zur Erklärung der Varianz der Bestandestranspiration beitragen (LANG 1999). Die zusätzliche Aufnahme des volumetrischen Bodenwassergehalts in einer oder mehreren Tiefenstufen als Einflußparameter des Bestandeswasserhaushalts konnte das Modell nur in einigen Fällen signifikant verbessern und dann durchwegs nur in sehr geringem Maße (Tab. 5-15).

Ein ähnliches Bild ergab sich auch für die Beziehung der Bodenwassergehalte zur Bestandestranspiration in Einfachregressionen ohne Einbeziehen weiterer Einflußparameter. Hier war nur im Bestand Ziegelrodaer Forst eine relativ deutliche und häufige positive Beziehung zwischen Bodenwassergehalt und Bestandestranspiration zu beobachten (CERMaK et al. 1993, Granier \& Loustau 1994, Oren et al. 1998a). In den anderen Untersuchungsbeständen trat vergleichsweise selten und wenn dann meist nur eine sehr lockere oder sogar negative Korrelation zwischen Bodenwassergehalt und Bestandestranspiration auf (LUNDBLAD \& LINDROTH 2002). Eine negative Korrelation scheint zunächst überraschend. Sie wird aber verständlich, wenn man berücksichtigt, daß außer bei massivem Trockenstreß der Einfluß des Bodenwassergehalts auf die Bestandestranspiration generell durch den starken Einfluß der Klimaparameter weitgehend überlagert wird. Hinzu kommen die Sonderbedingungen an Regentagen mit typischerweise sehr niedrigen Transpirationsraten bei gleichzeitig sehr hohen Bodenwassergehalten, also einer negativen Korrelation der beiden Größen. Ein deutlicher Einfluß von Bodenwasserverknappung als begrenzendem Faktor der Bestandestranspiration, wie 
er von GRANIER et al. (2000) auch an Buchen beobachtet wurde, war demnach nur für den Bestand Ziegelrodaer Forst nachweisbar.

\subsubsection{Reaktionsmuster der Bestandesleitfähigkeit bei unterschiedlicher Trockenstreßbelastung}

Die stärkste Abhängigkeit von einem Umweltfaktor zeigte die Bestandestranspiration der Untersuchungsbestände gegenüber dem Sättigungsdefizit der Luft als direkt treibender Kraft der Transpiration. Indirekt wirkt das Sättigungsdefizit der Luft auf die Transpiration auch durch eine sättigungsdefizitabhängige Regulation der Stomata (LÖSCH 2001). Mit der durch Saftflußmessung bestimmten Bestandestranspiration und dem im Bestand herrschenden Sättigungsdefizit der Luft kann über die Beziehung (Gl. 5-3) die Bestandesleitfähigkeit abgeschätzt werden (THOM 1972, KÖSTNER et al. 1992, KÖSTNER 2001). Aus Saftflußmessungen hergeleitete Bestandesleitfähigkeiten ergeben dabei vergleichbare Werte wie solche, die aus Porometerdaten oder über Eddy-Korrelations-Messungen gewonnen werden (KELLIHER et al. 1995, OREN et al. 1998a, KÖSTNER 2001).

$$
\begin{aligned}
& (\text { Gl. 5-3 }) \quad g_{t}=\frac{E}{V P D} \cdot \varsigma_{w} \cdot G_{v} \cdot T_{K} \\
& \mathrm{~g}_{\mathrm{t}}=\text { Bestandesleitfähigkeit }\left[\mathrm{mm} \mathrm{s}^{-1}\right] \\
& \mathrm{E}=\text { Bestandestranspiration }\left[\mathrm{mm} \mathrm{s}^{-1}\right] \\
& \mathrm{D}=\text { Wasserdampf-Sättigungsdefizit der Luft }[\mathrm{kPa}] \\
& \left.\zeta_{\mathrm{w}}=\text { Dichte von Wasser [998 } \mathrm{kg} \mathrm{m}^{-3}\right] \\
& \mathrm{G}_{\mathrm{v}}=\text { Gaskonstante für Wasserdampf }\left[0.462 \mathrm{~m}^{3} \mathrm{kPa} \mathrm{kg}^{-1} \mathrm{~K}^{-1}\right] \\
& \mathrm{T}_{\mathrm{K}}=\text { Lufttemperatur }[\mathrm{K}]
\end{aligned}
$$

In die so beschriebene Bestandesleitfähigkeit $\left(g_{t}\right)$ geht nach Gleichung (5-4) sowohl die stomatäre Leitfähigkeit $\left(g_{c}\right)$ als auch die aerodynamische Leitfähigkeit $\left(g_{a}\right)$ des Kronendaches ein.

$$
\text { (G1. 5-4) } \quad \frac{1}{g_{\mathrm{t}}}=\frac{1}{\mathrm{~g}_{\mathrm{c}}}+\frac{1}{\mathrm{~g}_{\mathrm{a}}} \quad \text { (LARCHER 1994) }
$$

Die Oberfläche des Kronendachs ist durch aerodynamische Wasserdampf-Diffusionswiderstände an den Blattgrenzschichten (JARVIS \& MCNAUGHTON 1986) sowie bei eingeschränktem turbulentem Austausch über der Krone (SwINBANK 1951) teilweise von der Atmosphäre entkoppelt (AusSENAC \& DuCrey 1977, MCNAUghton \& JARVis 1983, VAN EIMERN \& RIEDINGER 1986). In Laubwäldern übersteigt jedoch im allgemeinen der stomatäre Diffusionswiderstand $\left(1 / \mathrm{g}_{\mathrm{c}}\right)$ den aerodynamischen Transportwiderstand $\left(1 / \mathrm{g}_{\mathrm{a}}\right)$ um mehr als eine Größenordnung (GRANIER et al. 2000a, KÖSTNER 2001). Insbesondere für Buchenwälder wurde ein sehr geringer aerodynamischer Transportwiderstand und damit eine enge Kopplung der Transpiration an die Atmosphäre ermittelt (HERBST 1995, BORGHETTI \& MAGNANI 1996, GRANIER et al. 2000). Diese kommt in einer starken Abhängigkeit der Bestandestranspiration vom Sättigungsdefizit der Luft zum Ausdruck, wie sie auch in der vorliegenden Untersuchung für alle Bestände festgestellt wurde. Daher entspricht nach Gleichung (5-4) die Bestandesleitfähigkeit $\left(g_{t}\right)$ in guter Näherung der stomatären Leitfähigkeit $\left(\mathrm{g}_{\mathrm{c}}\right)$ der untersuchten Buchenbestände. Vernachlässigt man also den 
vergleichsweise sehr geringen aerodynamischen Transportwiderstand, so kann nach Gleichung (5-3) mit hinreichender Genauigkeit die aus der mittleren Stoma-Öffnungsweite der Blätter im Kronendach resultierende Bestandesleitfähigkeit bestimmt werden (KÖSTNER et al. 1992 und KÖSTNER 2001).

Dementsprechend wurden aus der Tagessumme der Bestandestranspiration und dem Mittelwert des Wasserdampf-Sättigungsdefizits der Luft bzw. der Lufttemperatur in der Tageshellphase (Globalstrahlung $>5 \mathrm{~J} \mathrm{~m}^{-2} \mathrm{~s}^{-1}$ ) Tageshellphasenmittel der Bestandesleitfähigkeit berechnet.

Die Tageshellphasenmittel der Bestandesleitfähigkeit in den Untersuchungsbeständen wiesen im Verlauf der Vegetationsperiode 1996 kurzfristig erhebliche Schwankungen auf. Für eine Darstellung des saisonalen Verlaufs der Bestandesleitfähigkeit wurde daher die Form gleitender 5-Tage-Mittelwerte gewählt (Abb. 5-6). Dadurch werden mittel- und längerfristige Veränderungen besser erkennbar.

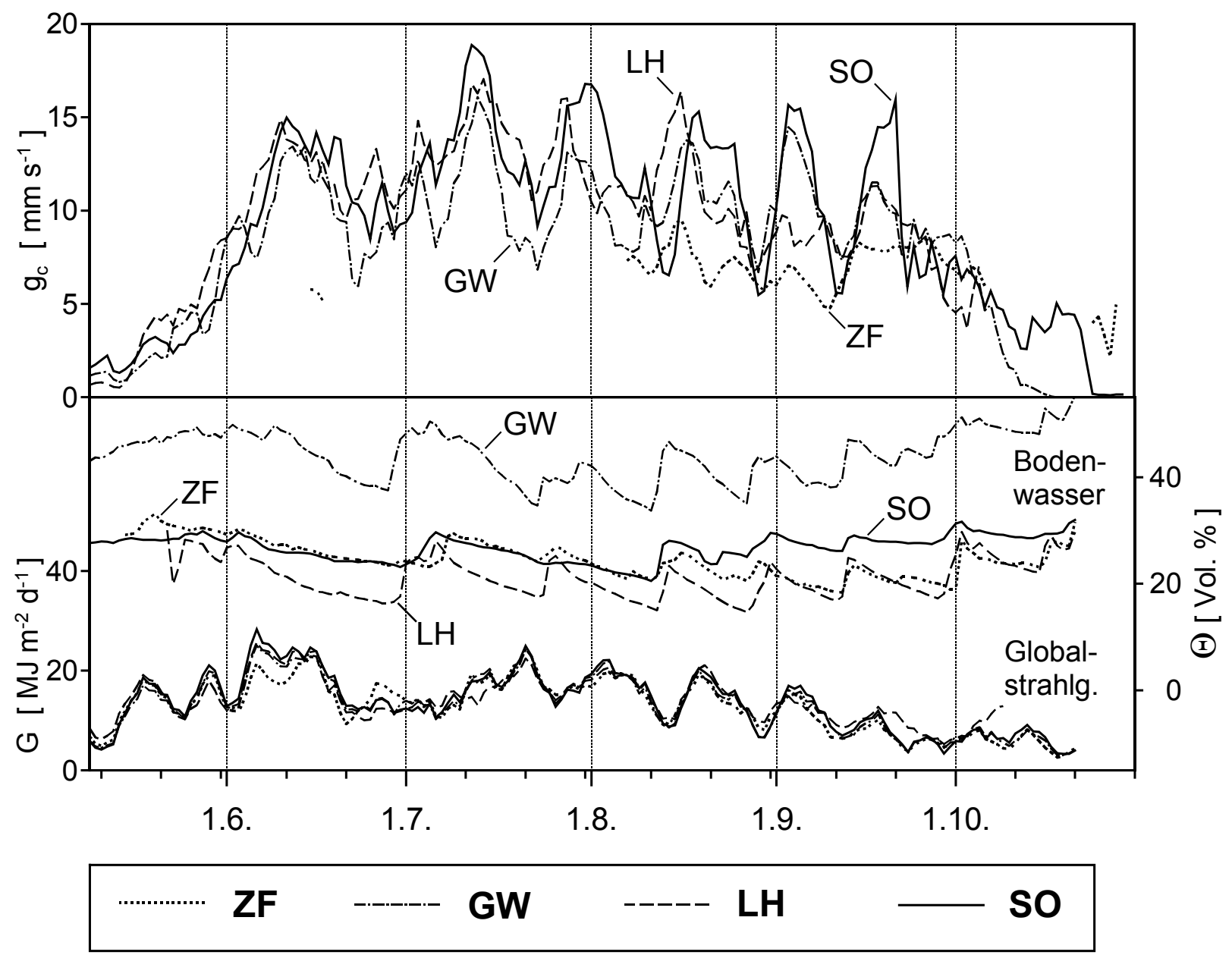

Abb. 5-6: Saisonaler Verlauf der Bestandesleitfähigkeit ( $g_{c}$, Darstellung in Form gleitender 5-TageMittelwerte, gebildet aus Tagesmittelwerten der Tageshellphase) sowie Tagessummen der Globalstrahlung $(\mathrm{G})$ und Tagesmittelwerte des volumetrischen Wassergehalts im Oberboden $(\Theta)$ in den Untersuchungsbeständen Ziegelrodaer Forst (ZF), Göttinger Wald (GW), Lüneburger Heide (LH) und Solling (SO) in der Vegetationsperiode 1996. 
Während zu Beginn der Vegetationsperiode die untersuchten Bestände weitgehend übereinstimmende Bestandesleitfähigkeiten zeigten, übertrafen ab Mitte Juni die Werte der Bestände Solling und Lüneburger Heide diejenigen des Bestandes im Göttinger Wald. Ab Mitte August fiel die Bestandesleitfähigkeit im Bestand Lüneburger Heide gegenüber den anderen Beständen jedoch deutlich ab und lag damit nur noch wenig über den Werten des Bestandes im Ziegelrodaer Forst. Dieser fiel bis Ende September durch die niedrigste Bestandesleitfähigkeit auf, während im Spätsommer im Göttinger Wald vergleichsweise hohe, im Solling die höchsten Werte zu beobachten waren.

Trotz zum Teil starker mittelfristiger Schwankungen der Bestandesleitfähigkeit fällt ein den Beständen gemeinsamer deutlicher Anstieg von Beginn der Vegetationsperiode bis zu maximalen Werten etwa Mitte Juli auf. Danach wird die Tendenz zu einem langsamen Absinken der Werte bis Mitte September erkennbar, gefolgt von einem starken Abfall bis Mitte Oktober. Diese Entwicklung der Bestandesleitfähigkeit entspricht weitgehend dem charakteristischen saisonalen Verlauf des Photosynthesevermögens von Buchenblättern, wie es von ScHULZE (1970) und Stickan et al. (1991) im Bestand Solling sowie Terborg (1998) im Bestand Lüneburger Heide beobachtet wurde. Diese Autoren stellten über mehrere Untersuchungsjahre eine einheitliche, relativ starre saisonale Dynamik des Photosynthesevermögens mit einem Maximum im Juli fest, die weitgehend unabhängig von unterschiedlichen Witterungsverläufen blieb. Dabei ließ das Photosynthesevermögen jedoch eine auffällige saisonale Parallelentwicklung mit dem Chlorophyllgehalt der Blätter und dem spezifischen Blattgewicht erkennen. REICH et al. (1991) und WILSON et al. (2000a) wiesen an nordamerikanischen Laubbaumarten eine saisonale Abhängigkeit des photosynthetischen Leistungsvermögens vom Stickstoffgehalt der Blätter nach. In dem Untersuchungsbestand im Solling konnte SCHULTE (1992) allerdings keine Beziehung zwischen der saisonalen Änderung des Photosynthesevermögens der Buche und den Stickstoffgehalten der Blätter feststellen. SCHULTE (1992) wies im Bestand Solling jedoch eine enge Korrelation des Photosynthesevermögens der Buche mit der maximalen Blattleitfähigkeit nach, eine Beziehung, die auch SCHULzE \& HALL (1982) belegten. Das Photosynthesevermögen und mit diesem die Blatt- bzw. Bestandesleitfähigkeit werden in den Grundzügen ihrer saisonalen Entwicklung also entscheidend von den charakteristischen saisonalen Phasen der Blattreifung bzw. Blattseneszenz geprägt (WILSON et al. 2000). Buchenblätter befinden sich demnach bis Anfang Juli im Zustand fortschreitender Ausdifferenzierung, in dem die photosynthetische Leistungsfähigkeit und die maximale Blattleitfähigkeit dementsprechend noch ansteigen. Einen Hinweis auf diese Saisonalität geben auch die in der vorliegenden Untersuchung porometrisch bestimmten mittäglichen stomatären Blattleitfähigkeiten. Diese wurden 1997 schon ab Mai gemessen und ließen durchwegs noch bis Ende Juni einen kontinuierlicher Anstieg erkennen. (vgl. Abb. 4-15).

Auch der Vergleich von Monatsmitteln der Bestandesleitfähigkeit läßt einheitlich ein Maximum im Juli erkennen, was aufgrund der hohen Schwankung der Tageswerte jedoch nur zum Teil auch statistisch signifikant ist (Tab. 5-16).

Für den Bestand Ziegelrodaer Forst war durch fehlende Werte des Sättigungsdefizits keine Berechnung der Bestandesleitfähigkeit für die Monate Juni und Juli möglich. Dieser Bestand wies ansonsten durchweg ähnliche Monatswerte des Sättigungsdefizits und der Globalstrahlung 
Tab. 5-16: Mittelwerte der Bestandesleitfähigkeit $\left[\mathrm{mm} \mathrm{s}^{-1}\right]$ während der Tageshellphase auf den Untersuchungsflächen Ziegelrodaer Forst (ZF), Göttinger Wald (GW), Lüneburger Heide (LH) und Solling (SO) in verschiedenen Phasen der Vegetationsperiode 1996.

Unterschiedliche Kleinbuchstaben kennzeichnen signifikante Unterschiede zwischen Untersuchungsbeständen, unterschiedliche Großbuchstaben signifikante Unterschiede zwischen einzelnen Monaten, unterschiedliche griechische Buchstaben einen signifikanten Unterschied zwischen Frühsommer (JuniJuli) und Spätsommer (August-September). (Mittelwertsvergleich zwischen Untersuchungsflächen mit dem U-Test nach Wilcoxon, Mittelwertsvergleich zwischen Betrachtungszeiträumen nach van der Waerden; jeweils $\mathrm{p}<0.05$ Bonferoni-korrigiert.)

\begin{tabular}{|c|c|c|c|c|}
\hline$\left[\mathrm{mm} \mathrm{s}^{-1}\right]$ & $\mathbf{Z F}$ & GW & LH & SO \\
\hline Juni & - & A $9.87 \pm 3.7^{\mathrm{a}}$ & $\mathrm{A} 11.27 \pm 3.8^{\mathrm{a}}$ & ${ }^{\mathrm{AB}} 10.96 \pm 4.8^{\mathrm{a}}$ \\
\hline Juli & - & $\mathrm{A} 11.21 \pm 4.8^{\mathrm{a}}$ & В $13.93 \pm 3.8^{\mathrm{b}}$ & A $13.69 \pm 4.6^{\mathrm{b}}$ \\
\hline August & ${ }^{\mathrm{A}} 7.11 \pm 2.0^{\mathrm{a}}$ & A $9.86 \pm 4.0^{\mathrm{b}}$ & $\mathrm{AC}_{10.66 \pm 3.7^{\mathrm{bc}}}$ & $\mathrm{AB} 11.06 \pm 5.2^{\mathrm{c}}$ \\
\hline September & 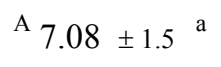 & ${ }^{\mathrm{A}} 10.23 \pm 3.7^{\mathrm{bc}}$ & C $8.94 \pm 2.9^{b}$ & B $10.54 \pm 5.2^{\mathrm{c}}$ \\
\hline Juni - Juli & - & ${ }^{\alpha} 10.55 \pm 4.3^{\mathrm{a}}$ & ${ }^{\alpha} 12.62 \pm 4.0^{b}$ & ${ }^{\alpha} 12.35 \pm 4.9^{b}$ \\
\hline Aug. - Sept. & $7.10 \pm 1.7^{\mathrm{a}}$ & ${ }^{\alpha} 10.04 \pm 3.8^{b}$ & ${ }^{\beta} 9.82 \pm 3.5^{\mathrm{b}}$ & ${ }^{\alpha} 10.82 \pm 5.1^{c}$ \\
\hline Juni - Sept. & - & $10.30 \pm 4.1^{\mathrm{a}}$ & $11.22 \pm 4.0^{\mathrm{ab}}$ & $11.60 \pm 5.0^{\mathrm{b}}$ \\
\hline
\end{tabular}

sowie eine nahezu gleiche Jahressumme der Bestandestranspiration 1996 wie der Bestand im Göttinger Wald auf. Im saisonalen Verlauf jedoch überstieg im Frühsommer die Bestandestranspiration im Ziegelrodaer Forst diejenige im Göttinger Wald, während sie im Spätsommer dahinter zurückblieb. Da der Bestand Ziegelrodaer Forst zudem die deutlich geringsten Spätsommerwerte der Bestandesleitfähigkeit aufwies, muß der auch in den anderen Beständen beobachtete Abfall der Bestandesleitfähigkeit vom Früh- zum Spätsommer im Bestand Ziegelrodaer Forst besonders ausgeprägt gewesen sein. Ein solcher besonders starker Abfall der Bestandesleitfähigkeit steht einerseits in Übereinstimmung mit der starken spätsommerlichen Bodenwasserverknappung im Ziegelrodaer Forst und entspricht andererseits gut dem von LANDWEHR (1997) in diesem Bestand beobachteten besonders starken Abfall des Photosynthesevermögens vom Früh- zum Spätsommer (vgl. Kap. 5.5). Im Untersuchungsbestand Lüneburger Heide, dem zweiten Bestand mit ausgeprägter spätsommerlicher Bodentrockenheit, war der Rückgang der Bestandesleitfähigkeit von hohen Werten im Juni und Juli auf deutlich niedrigere Werte im August und September statistisch signifikant. Anders in den vor allem im August und September besser wasserversorgten Beständen Göttinger Wald und Solling, wo die Unterschiede der Bestandesleitfähigkeit zwischen Früh- und Spätsommer geringer und damit statistisch nicht nachweisbar blieben.

Der bodentrockene Bestand Ziegelrodaer Forst wies im August und September zum Zeitpunkt maximaler Bodenwasserverknappung mit $7.1 \mathrm{~mm} \mathrm{~s}^{-1}$ die signifikant niedrigsten Monatsmittel der Bestandesleitfähigkeit aller Untersuchungsbestände in der gesamten Vegetationsperiode 1996 auf. Die höchsten Monatsmittel der Bestandesleitfähigkeit von fast $14 \mathrm{~mm} \mathrm{~s}^{-1}$ erreichten dagegen die Bestände Lüneburger Heide und Solling im Juli zum Zeitpunkt des höchsten Photosynthesevermögens und guter Bodenwasserversorgung. Der niederschlagsreichste, stets gut wasserversorgte Bestand Solling zeigte als einziger kontinuierlich hohe Monatswerte und besaß 
dadurch auch im Mittel über die Vegetationsperiode mit $11.6 \mathrm{~mm} \mathrm{~s}^{-1}$ die höchste Bestandesleitfähigkeit. Die Bestände im Göttinger Wald und der Lüneburger Heide wiesen mit $10.3 \mathrm{~mm} \mathrm{~s}^{-1}$ bzw. $11.2 \mathrm{~mm} \mathrm{~s}^{-1}$ jedoch nur wenig niedrigere Mittel der Vegetationsperiode auf.

Die beobachteten Werte stimmen gut mit den von SHUTTLEWORTH (1989) ermittelten überein, der die Bestandesleitfähigkeit von 8 Laub- und Nadelwaldbeständen der gemäßigten bis tropischen Klimazone verglich. Die verschiedenen Arten zeigten dabei weitgehend ähnliche Bestandesleitfähigkeiten und erreichten ein durchschnittliches Tageshellphasenmittel von $10 \mathrm{~mm} \mathrm{~s}^{-1}$. DoLMAN et al. (1998) fanden über eine Vegetationsperiode Tageshellphasenmittel der Bestandesleitfähigkeit von $18 \mathrm{~mm} \mathrm{~s}^{-1}$ für Populus, $10 \mathrm{~mm} \mathrm{~s}^{-1}$ für Larix und $7 \mathrm{~mm} \mathrm{~s}^{-1}$ für Pinus, PHILIPS \& OREN (1998) in einem Bestand von Pinus taeda ein Vegetationsperiodenmittel von etwa $4 \mathrm{~mm} \mathrm{~s}^{-1}$. Die untersuchten Buchenbestände wiesen also im Juli bei maximaler physiologischer Aktivität der Blätter und guter Bodenwasserversorgung vergleichsweise hohe Bestandesleitfähigkeiten auf. Diese wurden jedoch in den beiden Beständen mit Trockenstreßeinwirkung im Verlauf der Vegetationsperiode auf eher niedrige, für Koniferenbestände bekannte Bestandesleitfähigkeiten eingeschränkt.

Im Verlauf der Vegetationsperiode waren in einem etwa 15- bis 20-tägigen Rhythmus zum Teil erhebliche Schwankungen der Bestandesleitfähigkeit $\mathrm{zu}$ beobachten, die in den untersuchten Beständen weitgehend synchron verliefen. Diese zeigten wiederum auffällige Übereinstimmungen mit der saisonalen Entwicklung von Bodenfeuchte- und Globalstrahlungsregime.

In wie weit die Bodenwasserversorgung die Bestandesleitfähigkeit der Untersuchungsbestände beeinflußte, läßt sich durch eine multiple Regression mit den volumetrischen Wassergehalten in verschiedenen Bodentiefen untersuchen. Dabei konnte in allen Untersuchungsbeständen eine deutlich engere Beziehung zwischen der Bestandesleitfähigkeit und der Bodenfeuchte festgestellt werden, wenn nicht Tageswerte sondern gleitende 5-Tage-Mittelwerte der Bestandesleitfähigkeit betrachtet wurden. Dies betont mittelfristige Niveauänderungen der Bestandesleitfähigkeit, wie sie auch beim Bodenwassergehalt auftreten, gegenüber starken täglichen Schwankungen, wie sie etwa durch sich schnell ändernde Witterungsbedingungen zustande kommen.

Auf allen Untersuchungsflächen konnte in mindestens zwei Monaten der Vegetationsperiode 1996 eine statistisch signifikante positive Beziehung zwischen der Bestandesleitfähigkeit und dem volumetrischen Wassergehalt des Bodens in den untersuchten Tiefenstufen festgestellt werden (vgl. Granier \& Loustau 1994, Oren et al. 1998, Oren \& PataKi 2001). Die engsten Korrelationen traten in den bodentrockenen Beständen Ziegelrodaer Forst und Lüneburger Heide auf und dort wiederum besonders im August und September, als in diesen Beständen mit Monatsmitteln von nur noch $21-45 \%$ des maximalen Nutzwasservorrats die ausgeprägteste Bodenwasserverknappung zu beobachten war (Tab. 5-17). In diesem Zeitraum konnten im Bestand Lüneburger Heide 35-61\%, im Bestand Ziegelrodaer Forst sogar 59-83\% der Varianz der Bestandesleitfähigkeit auf die Veränderung der Bodenwasserversorgung zurückgeführt werden. Demgegenüber blieb im Bestand Göttinger Wald die Beziehung zwischen der Bestandesleitfähigkeit und der Bodenfeuchte meist weniger eng. Im niederschlagsreichsten und kontinuierlich gut wasserversorgten Bestand Solling konnte durchwegs nur eine schwache oder keine Korrelation beobachtet werden. Dies stimmt überein mit den Beobachtungen von DOLMAN et al. (1998), GRANIER et al. (1999 und 2000a) sowie LUNDBLAD \& LINDROTH (2002), 
die für sehr unterschiedliche Waldbestände (5 verschiedene Laub-und Nadelbaumarten) einheitlich eine verstärkte Einschränkung der Bestandesleitfähigkeit bei relativen Nutzwasservorräten des Bodens von weniger als ca. 40\% (30-50\%) des Maximalwertes feststellten. Die Abhängigkeit der Bestandesleitfähigkeit von der Bodenwasserversorgung war auch in den Buchenbeständen der vorliegenden Untersuchung dort besonders ausgeprägt, wo der Faktor Bodenwasser jenseits dieses offenbar typischen Grenzbereiches am stärksten ins Minimum geriet. Man kann also für die bodentrockenen Bestände Ziegelrodaer Forst und Lüneburger Heide von einer deutlichen trockenstreßbedingten Einschränkung der Bestandesleitfähigkeit im Verlauf der Vegetationsperiode 1996 sprechen.

Tab. 5-17: Adjustiertes Bestimmtheitsmaß $\left(\mathrm{r}^{2}{ }_{\text {adj. }}\right)$ der multiplen linearen Regressionen $\mathrm{g}_{\mathrm{c}}=\mathrm{f}\left(\mathrm{x}_{1}, \mathrm{x}_{2}, \ldots\right)$ $=\mathrm{a}+\mathrm{b} \cdot \mathrm{x}_{1}+\mathrm{c} \cdot \mathrm{x}_{2}+\ldots$ für die Beziehung der Bestandesleitfähigkeit $\left(\mathrm{g}_{\mathrm{c}}\right)$ zum volumetrischen Wassergehalt des Bodens $(\Theta)$ in verschiedenen Tiefenstufen auf der Ebene von Tageswerten und mittlerer relativer Nutzwasservorrat (als Anteil des maximalen Nutzwasservorrats) in Streuauflage und $0-40 \mathrm{~cm}$ Bodentiefe für verschiedene Phasen der Vegetationsperiode 1996 auf den Untersuchungsflächen Ziegelrodaer Forst (ZF), Göttinger Wald (GW), Lüneburger Heide (LH) und Solling (SO). Die volumetrischen Wassergehalte des Bodens in verschiedenen Tiefenstufen wurden entsprechend dem Anteil der durch sie erklärbaren Varianz $\left(=\mathrm{r}^{2}{ }_{\text {adj. }}\right)$ der Bestandestranspiration sukzessive in die multiple Regression aufgenommenen. Konnte der volumetrische Wassergehalt einer bestimmten Bodentiefe $\mathrm{r}^{2}$ adj. nicht erhöhen, wurde er nicht in das Modell aufgenommen.

(alle Beziehungen: $\mathrm{p}<* 0.05$, n.s.: nicht signifikant).

\begin{tabular}{|c|c|c|c|c|c|c|c|c|}
\hline & \multicolumn{4}{|c|}{$\mathbf{r}_{\text {adj. }}^{2} \quad g_{c .}=f\left(\Theta_{1}, \Theta_{2}, \Theta_{3}\right)$} & \multicolumn{4}{|c|}{ relativer Nutzwasservorrat $[\%]$} \\
\hline & $\mathbf{Z F}$ & GW & $\mathbf{L H}$ & SO & $\mathbf{Z F}$ & GW & $\mathbf{L H}$ & SO \\
\hline Juni & - & 0.52 & n.s. & 0.14 & $65 \pm 13$ & $63 \pm 12$ & $57 \pm 16$ & $59 \pm 10$ \\
\hline Juli & - & 0.16 & n.s. & n.s. & $58 \pm 9$ & $65 \pm 11$ & $50 \pm 10$ & $57 \pm 13$ \\
\hline August & 0.59 & 0.31 & 0.35 & 0.15 & $35 \pm 6$ & $56 \pm 13$ & $33 \pm 8$ & $47 \pm 18$ \\
\hline September & 0.83 & 0.54 & 0.61 & n.s. & $21 \pm 2$ & $60 \pm 9$ & $45 \pm 6$ & $73 \pm 5$ \\
\hline Juni - Juli & - & 0.27 & 0.22 & 0.26 & $61 \pm 11$ & $64 \pm 12$ & $54 \pm 14$ & $58 \pm 11$ \\
\hline Juli - Aug. & - & 0.20 & 0.41 & 0.12 & $46 \pm 14$ & $61 \pm 13$ & $42 \pm 13$ & $52 \pm 16$ \\
\hline Aug. - Sept. & 0.29 & 0.12 & 0.39 & 0.06 & $28 \pm 8$ & $58 \pm 11$ & $39 \pm 9$ & $60 \pm 19$ \\
\hline Juni - Sept. & - & 0.10 & 0.26 & 0.03 & $45 \pm 13$ & $61 \pm 12$ & $46 \pm 14$ & $59 \pm 15$ \\
\hline
\end{tabular}

Die Bestandesleitfähigkeit war mit der Bodenfeuchte in den Untersuchungsbeständen in fast allen Betrachtungszeiträumen signifikant korreliert, aber nur relativ selten eng korreliert. Dies läßt erkennen, daß ein Einfluß der Bodenfeuchte auf die Bestandesleitfähigkeit zwar vermutlich durchgängig besteht; er wird jedoch vor allem bei ausreichender bis guter Bodenwasserversorgung in zum Teil erheblichen Ausmaß durch andere Einflußfaktoren überlagert ( vgl. HERBST 1995, OREN \& PATAKI 2001) .

GRANIER \& BRÉDA (1996) und GRANIER et al. (2000a) stellten sowohl für Laub- als auch für Nadelbaumbestände in tropischen bis borealen Klimaten einen Anstieg der Bestandesleitfähigkeit mit steigender Bestandesblattfläche fest, jedoch nur bis zu einem Blattflächenindex von etwa 6 . Sie sehen die Ursache dafür, daß bei LAI $>6$ kein Einfluß der Bestandesblattfläche auf die Bestandesleitfähigkeit mehr nachzuweisen war, in einer verstärkten 
Beschattung der unteren Kronenbereiche. Dies stimmt überein mit den Ergebnissen der in der vorliegenden Untersuchung porometrisch bestimmten Vertikalgradienten der Blattleitfähigkeit im Kronenraum. Diese zeigten im Kronenhöhengradienten mit zunehmendem kumulativen LAI eine exponentielle Abnahme der Blattleitfähigkeit, die bei LAI $>6$ im unteren Kronenraum schließlich auf sehr geringem Niveau stagnierte (vgl. Abb. 4-18, Kap. 4.5.3). Dementsprechend war bei den untersuchten Buchenbeständen mit LAI-Werten von 6.3 bis 8.3 in der Vegetationsperiode 1996 kein Zusammenhang zwischen der Bestandesleitfähigkeit und dem Blattflächenindex zu erkennen.

Einen kurzfristig wirkenden und starken Einfluß auf die Stomaöffnungsweite und dadurch auf die Blatt- und Bestandesleitfähigkeit übt das herrschende Strahlungsangebot aus (SCHULTE 1992, LÖSCH 2001).
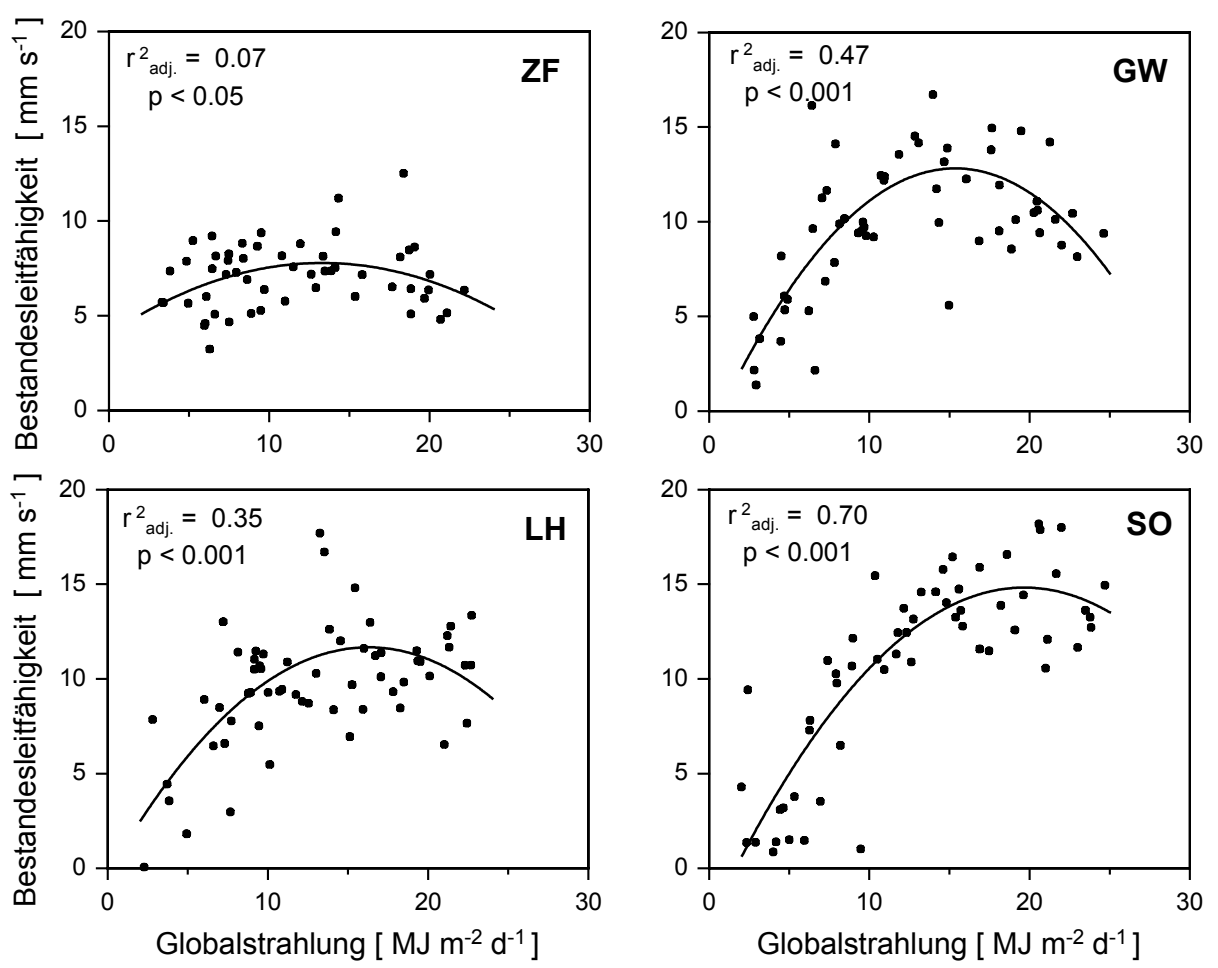

Abb. 5-7: Beziehung der Tagesmittelwerte der Bestandesleitfähigkeit $\left(\mathrm{g}_{\mathrm{c}}\right)$ in der Tageshellphase (Globalstrahlung $>5 \mathrm{~J} \mathrm{~m}^{-2} \mathrm{~s}^{-1}$ ) zur Tagessumme der Globalstrahlung $(\mathrm{G})$ nach der Optimumfunktion $\left(\mathrm{g}_{\mathrm{c}}\right)=\mathrm{f}(\mathrm{G})=\mathrm{a}+\mathrm{bx}+\mathrm{c} \mathrm{x}^{2}$ für den Zeitraum August-September 1996 in den Untersuchungsbeständen Ziegelrodaer Forst (ZF), Göttinger Wald (GW), Lüneburger Heide (LH) und Solling (SO).

Zur Beschreibung der Beziehung zwischen den Tageswerten der Bestandesleitfähigkeit und der Globalstrahlung erwies sich für alle Untersuchungsbestände und Phasen der Vegetationsperiode eine quadratische Optimumkurve als geeignet (Abb. 5-7) (vgl. KÖSTNER et al. 1992, DOLMAN et al. 1998). Während im Bestand Solling eine durchgehend enge Korrelation zwischen der Bestandesleitfähigkeit und der Globalstrahlung beobachtet werden konnte, blieb diese in den anderen Beständen deutlich lockerer (Tab. 5-18). Dabei war im Bestand Göttinger Wald die Abhängigkeit der Bestandesleitfähigkeit von der Globalstrahlung meist noch etwas stärker als im Bestand Lüneburger Heide. Im Bestand Ziegelrodaer Forst war diese Beziehung im Spätsommer besonders schwach ausgeprägt. 
Tab. 5-18: Adjustiertes Bestimmtheitsmaß $\left(\mathrm{r}^{2}\right.$ adj. $)$ der Optimumfunktion $\left(\mathrm{g}_{\mathrm{c}}\right)=\mathrm{f}(\mathrm{G})=\mathrm{a}+\mathrm{b} \cdot \mathrm{x}+\mathrm{c} \cdot \mathrm{x}^{2}$ zwischen den Tageswerten der Bestandesleitfähigkeit $\left(\mathrm{g}_{\mathrm{c}}\right)$ und den Tagessummen der Globalstrahlung $(\mathrm{G})$ sowie Globalstrahlungs-Tagessumme ( $\left.\mathrm{G}_{\text {gmax }}\right)$, für die am Scheitelpunkt der Optimumkurve das Maximum der Bestandesleitfähigkeit ermittelt wurde, in verschiedenen Phasen der Vegetationsperiode 1996. Angabe von $\mathrm{G}$ gmax in Klammern: maximaler Wert der Bestandesleitfähigkeit wurde ermittelt, ohne daß der Scheitelpunkt der Optimumkurve erreicht wurde.(Signifikanzniveau: $p<0.01$ bzw. nicht signifikant: n.s.).

\begin{tabular}{|c|c|c|c|c|c|c|c|c|}
\hline \multirow[b]{2}{*}{$\mathbf{r}^{2}{ }_{\text {adj. }}$} & \multicolumn{2}{|c|}{ Ziegelrodaer Forst } & \multicolumn{2}{|c|}{ Göttinger Wald } & \multicolumn{2}{|c|}{ Lüneburger Heide } & \multicolumn{2}{|c|}{ Solling } \\
\hline & $\mathbf{r}_{\mathrm{g}=\mathbf{f}(\mathbf{G})}$ & $\begin{array}{c}\mathbf{G}_{\text {gmax }} \\
{\left[\mathbf{M J} \mathbf{~ m}^{-2} \mathbf{d}^{-1}\right]} \\
\end{array}$ & $\mathbf{r}_{\mathrm{g}=\mathbf{f}(\mathbf{G})}^{2}$ & $\begin{array}{c}\mathbf{G}_{\text {gmax }} \\
{\left[\mathbf{M J ~ m}_{\mathbf{~}}^{-2} \mathbf{d}^{-1}\right]} \\
\end{array}$ & $\mathbf{r}_{\mathrm{g}=\mathrm{f}(\mathrm{G})}^{2}$ & $\begin{array}{c}\mathbf{G}_{\text {gmax }} \\
{\left[\mathbf{M J ~ m}_{\mathbf{~}}^{-2} \mathbf{d}^{-1}\right]} \\
\end{array}$ & $\mathbf{r}_{\mathrm{g}=\mathbf{f}(\mathbf{G})}^{2}$ & $\begin{array}{c}\mathbf{G}_{\text {gmax }} \\
{\left[\mathbf{M J} \mathbf{~ m}^{-2} \mathbf{d}^{-1}\right]} \\
\end{array}$ \\
\hline Juni & - & - & n.s. & n.s. & 0.44 & 21.8 & 0.52 & 22.5 \\
\hline Juli & - & - & 0.53 & 18.7 & n.s. & n.s. & 0.49 & 20.3 \\
\hline August & 0.26 & 14.0 & 0.28 & 15.7 & 0.21 & 15.4 & 0.71 & 20.2 \\
\hline September & n.s. & n.s. & 0.71 & 15.7 & 0.47 & 15.2 & 0.73 & $(20.7)$ \\
\hline Jun - Jul & - & - & 0.12 & 20.3 & 0.18 & 19.8 & 0.53 & 20.6 \\
\hline Jul - Aug & - & - & 0.35 & 17.9 & 0.06 & 16.9 & 0.61 & 20.4 \\
\hline Aug - Sep & 0.07 & 13.3 & 0.47 & 15.4 & 0.35 & 16.3 & 0.70 & 19.7 \\
\hline Jun - Sep & - & - & 0.24 & 18.5 & 0.25 & 20.3 & 0.63 & 20.8 \\
\hline
\end{tabular}

Der Einfluß der Globalstrahlung auf die Bestandesleitfähigkeit verhielt sich also komplementär zum Einfluß der Bodenwasserversorgung. In den Beständen Ziegelrodaer Forst und Lüneburger Heide blieb bei einem hohen Einfluß des Minimumfaktors Bodenwasserversorgung durch Trockenstreß der Einfluß des Strahlungsangebots auf die Höhe der Bestandesleitfähigkeit relativ gering. In den Beständen Göttinger Wald und Solling dagegen blieb der Einfluß der ausreichenden bis guten Bodenwasserversorgung gering, wodurch dort vor allem das Strahlungsangebot als begrenzender Faktor hervortrat und einen entsprechend höheren Einfluß auf die Bestandesleitfähigkeit ausübte.

In den bodentrockeneren Beständen, insbesondere im Ziegelrodaer Forst wurden zudem bereits bei deutlich geringeren Tagessummen der Globalstrahlung Maximalwerte der Bestandesleitfähigkeit erreicht als im niederschlagsreichen und bodenfeuchten Solling (Tab. 5-18). Die bei höheren Tagessummen der Globalstrahlung wieder absinkenden Werte der Bestandesleitfähigkeit sind eine Folge der an Strahlungstagen in der Regel auch besonders starken Verdunstungsbeanspruchung durch ein hohes Sättigungsdefizit der Luft (SHUTTLEWORTH 1989, KÖSTNER et al. 1992, GRANIER et al. 2000a) (vgl. Abb. 5-8). Bei einer eingeschränkten Wassernachlieferung aus dem Boden wird daher schon bei einer geringeren Einstrahlung und Verdunstungsbeanspruchung eine Einschränkung der Bestandesleitfähigkeit zur Begrenzung der Transpiration erforderlich als bei guter Bodenwasserversorgung. Das Strahlungsoptimum der Bestandesleitfähigkeit stieg dementsprechend mit der Wasserversorgung der Untersuchungsbestände an.

Der Einfluß der Temperatur auf die Bestandesleitfähigkeit bleibt nach GRANIER et al. (2000a) gering. Sie konnten für mehrere Waldbestände unterschiedlicher Arten keine signifikante Beziehung zwischen der Temperatur und der Bestandesleitfähigkeit nachweisen, wenn diese um den Einfluß der jeweils stark kovariaten Parameter Strahlung und Sättigungsdefizit bereinigt wurde. Dementsprechend beobachteten GRANIER et al. (2000) an Buchen nur in der ersten Hälfte 
der Vegetationsperiode und nur bei $<17^{\circ} \mathrm{C}$ und einen Rückgang der Bestandesleitfähigkeit mit der Temperatur.
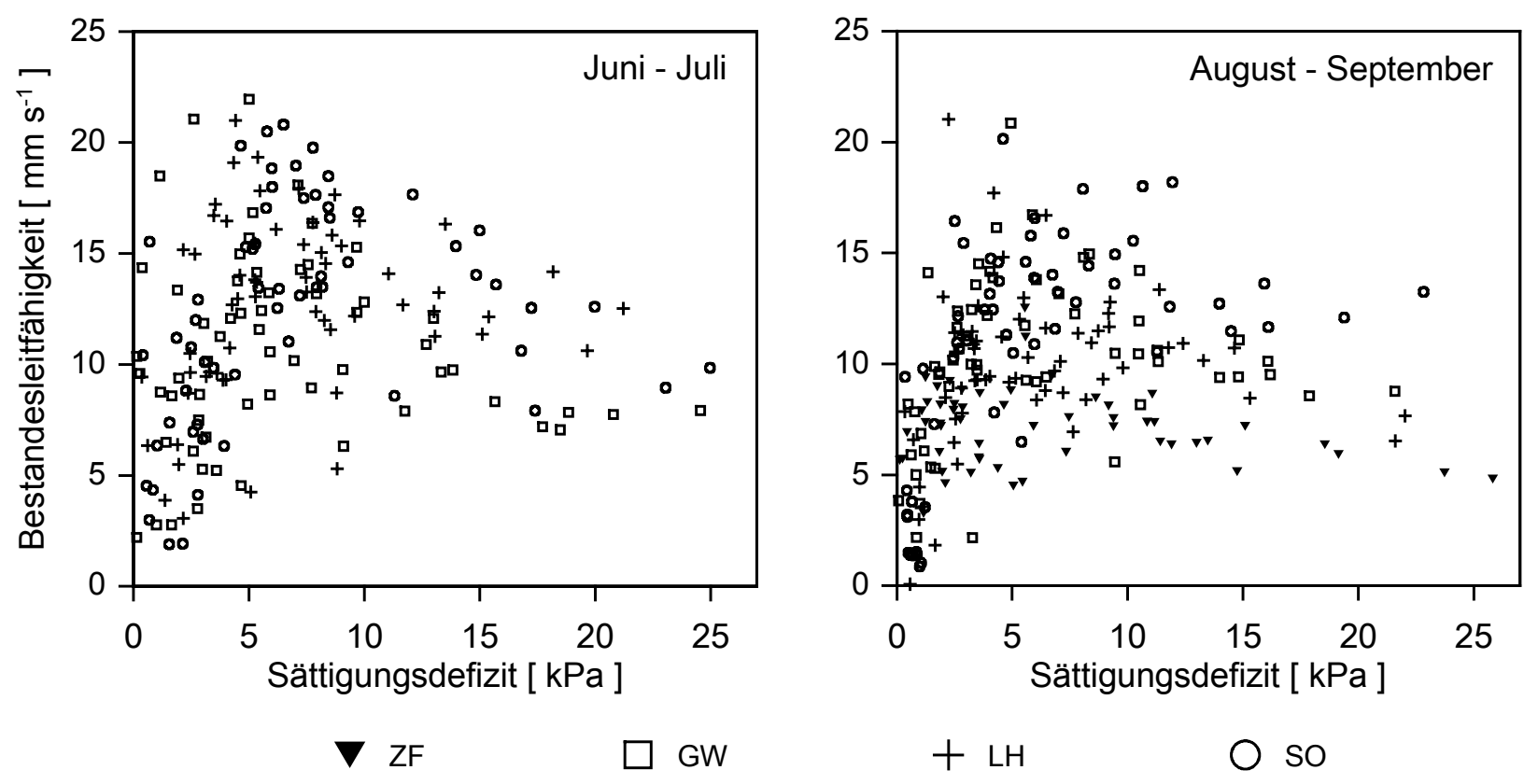

Abb. 5-8: Beziehung der Tageshellphasenmittel der Bestandesleitfähigkeit zur Tageshellphasensumme des Sättigungsdefizits der Luft für die Zeiträume Juni-Juli und August-September 1996 in den Untersuchungsbeständen Ziegelrodaer Forst (ZF), Göttinger Wald (GW), Lüneburger Heide (LH) und Solling (SO).

Bei einer Auftragung der Tageshellphasenwerte von Bestandesleitfähigkeit und Sättigungsdefizit wird einheitlich ein deutlicher Abfall der Maximalwerte der Bestandesleitfähigkeit mit steigenden Sättigungsdefizitwerten erkennbar (BORGHETTI \& MAGNANi 1996, Dolman et al. 1998, GRANIER et al. 2000a). Bei zunehmender Verdunstungsbeanspruchung schränkten die Bestände die Leitfähigkeit also verstärkt ein. Nur der Bestand im Ziegelrodaer Forst im Zeitraum August und September zeigte kaum einen Rückgang der Bestandesleitfähigkeit bei steigender Verdunstungsbeanspruchung, dies allerdings auf durchweg sehr niedrigem Niveau (Abb. 5-8).

Im Zeitraum Juni und Juli fällt auf, daß bei höheren Tageswerten des Sättigungsdefizits die Tageswerte der Bestandesleitfähigkeit im Solling und in der Lüneburger Heide höhere Maximalwerte erreichten als im Göttinger Wald, während dies bei niedrigen Tageswerten des Sättigungsdefizits nicht der Fall war. Darüber hinaus waren im Solling und in der Lüneburger Heide im Juni und Juli sowohl auf Tages- als auch auf Monatsebene die höchsten Bestandestranspirationsraten zu beobachten (vgl. Abb. 4-24, Abb. 4-25).

Dabei fielen die Bestände im Solling und in der Lüneburger Heide jedoch keineswegs etwa durch besonders hohe Mittelwerte des absoluten oder relativen Nutzwassergehalts im Zeitraum Juni und Juli auf. Auch die Feinwurzelmassen allein können nicht eine besonders effektive Wasseraufnahme in diesen Beständen erklären, die dort besonders hohe Tageswerte der Bestandesleitfähigkeit und Bestandestranspiration erlaubt hätte. Die in Solling und Göttinger Wald bestimmten Feinwurzelmassen waren nahezu gleich, nur in der Lüneburger Heide höher und im Ziegelrodaer Forst sehr gering (vgl. Tab. 5-5). 
Auffällig ist jedoch, daß die Bestände Solling und Lüneburger Heide, die im Frühsommer durch besonders hohe Tageswerte der Bestandesleitfähigkeit und Bestandestranspiration auffielen, beide sowohl hohe Feinwurzelmassen als auch eine stark entwickelte organische Auflage besitzen. In den Untersuchungsbeständen im Solling und in der Lüneburger Heide besitzt die organische Auflage gegenüber dem Mineralboden eine überproportional hohe Nutzwasserkapazität und weist deshalb bei hoher Bodenfeuchte auch einen vergleichsweise hohen Nutzwasservorrat auf (LEUSCHNER 1994). Darüber hinaus hat die Streuauflage durch einen hohen Grobporenanteil speziell bei höheren Wassergehalten besonders günstige Wassernachleiteigenschaften (GöRLITZ 1992, LEUSCHNER 1994, FIEDLER 2001). Angesichts zudem besonders hoher Feinwurzeldichten in den organischen Auflagehorizonten der Bestände Lüneburger Heide und Solling (HERTEL 1999) wird damit die herausgehobene Bedeutung der Streuauflage für die Wasserversorgung dieser beiden Bestände deutlich. So stellte LEUSCHNER (1998) für die Auflage des Bestandes in der Lüneburger Heide einen zwei bis dreimal höheren Wasserumsatz durch Wurzelaufnahme fest als für den Mineralboden. Die Bestände im Solling und in der Lüneburger Heide profitieren somit vor allem bei ausreichender bis guter Wasserversorgung deutlich von der großen und gut verfügbaren Wassermenge in den Auflagehorizonten. Sie können unter diesen Umständen offenbar bei einer relativ hohen Verdunstungsbeanspruchung eine bessere Wassernachlieferung gewährleisten als die Bestände ohne stark entwickelte Streuauflage.

Im Solling waren dementsprechend bei durchgängig hoher Bodenfeuchte auch im August und September 1996 noch sehr hohe Tageswerte der Bestandesleitfähigkeit und Bestandestranspiration zu beobachten. In der Lüneburger Heide gingen diese jedoch bei sehr geringen, insbesondere aber in der Streuauflage zumeist völlig erschöpften Nutzwasservorräten im Spätsommer auffällig zurück. So zeigten die Bestände Solling, Lüneburger Heide und Göttinger Wald im August und September bei geringer Verdunstungsbeanspruchung zwar weiterhin ähnliche Bestandesleitfähigkeiten, bei höherer Verdunstungsbeanspruchung fiel hingegen nur noch der Bestand im Solling durch besonders hohe Tageswerte der Bestandesleitfähigkeit auf (Abb. 5-6). Die stärkste Abweichung von den anderen Untersuchungsbeständen zeigte jedoch der Bestand im Ziegelrodaer Forst. Dieser wies bei den geringsten Feinwurzelbiomassen (HERTEL 1999) und ohne nennenswert entwickelte Streuauflage zudem den niedrigsten Nutzwasservorrat auf. Dadurch wurde die Wasseraufnahme in diesem Bestand offenbar erheblich erschwert, so daß dort auch an Tagen mit geringer Verdunstungsbeanspruchung durchweg besonders niedrige Tageswerte der Bestandesleitfähigkeit und Bestandestranspiration zu beobachten waren. 


\subsection{Zuwachsverhalten: Die Bedeutung von Trockenstreß und Phänomene der Trockenstreß-Anpassung}

Eine Reihe der untersuchten Wasserhaushaltsparameter geben deutliche Hinweise auf ein Einwirken von zum Teil intensivem Trockenstreß in einigen der untersuchten Buchenbestände bzw. Vegetationsperioden:

- Bodenwasserversorgung

- Blattwasserpotentiale

- stomatäre Leitfähigkeit der Blätter

- Bestandesleitfähigkeit

- Bestandestranspiration

Dabei traten besonders die Bestände Ziegelrodaer Forst $(1996,1997)$ und Lüneburger Heide (1995, 1996) durch häufige, langandauernde und starke Trockenstreßerscheinungen hervor. Der Bestand im Göttinger Wald wies nur 1995, im Jahr mit der ausgeprägtesten hochsommerlichen Trocken- und Hitzeperiode, Anzeichen eines massiven Wasserdefizits auf. Es steht zu vermuten (Niederschlagsdaten der Station Artern weisen darauf hin), daß dies 1995 auch in dem Bestand im Ziegelrodaer Forst der Fall war, wenngleich dieser langjährig trockenste Standort erst ab dem darauffolgenden Jahr untersucht wurde. Der einzige Buchenbestand, für den in keinem der drei Untersuchungsjahre und bei keinem der untersuchten Parameter ein Hinweis auf Trockenstreßeinwirkung vorlag, war derjenige mit den humidesten Standortbedingungen im Solling.

Die Kohlenstoffbilanz und das Wachstum von Pflanzen sind über die ökophysiologischen Rahmenbedingungen der Photosynthese eng mit dem pflanzlichen Wasserhaushalt verbunden. In den untersuchten Buchenbeständen war im Fall einer ausgeprägten Bodenwasserverknappung jeweils auf Blatt- bzw. Bestandesebene eine deutliche Einschränkung der stomatären Leitfähigkeit zu beobachten. Dies läßt als Folge von Trockenstreß einen Rückgang der Assimilationsleistung und damit eine Verschlechterung der Kohlenstoff-Bilanz (STICKAN et al. 1991, ARANDA et al. 2000) und der Zuwachsleistung erwarten (Mitscherlich 1981a, GRANIER et al. 1999).

Betrachtet man den Zuwachs mithin als Ausdruck der Vitalität eines Bestandes, überrascht auf den ersten Blick, daß in der vorliegenden Untersuchung der Bestand Ziegelrodaer Forst mit sowohl 1996 als auch 1997 deutlichen Trockenstreßsymptomen in beiden Jahren dennoch den höchsten Holzvolumenzuwachs der Untersuchungsbestände aufwies. Auf dem weitaus humidesten Standort Solling dagegen wurde stets die geringste Zuwachsleistung bestimmt, während die Bestände im Göttinger Wald und der Lüneburger Heide jeweils mittlere Zuwächse zeigten.

In zahlreichen Analysen des Holzzuwachses von Buchen in Abhängigkeit von Klimafaktoren konnte ein verminderter Zuwachs in Jahren mit ausgeprägter Trockenheit nachgewiesen werden (ECKSTEIn et al. 1984, Abetz 1988, GÄrtner \& Stoll 1990, Creus Novau et al. 1992, WENK \& VOGEL 1992, LEUSCHNER et al. 2001). Dies war jedoch vor allem auf Trockenstandorten und im Tiefland der Fall (Mitscherlich et al. 1966, ANDERs 1988). An humiden, 
häufig montanen Buchenstandorten war dagegen zumeist nur geringe Abhängigkeit des Zuwachses vom Niederschlag bzw. der Bodenfeuchte erkennbar, statt dessen aber eine positive Korrelation des Zuwachses mit dem Strahlungsgenuß und der Temperatur in der Vegetationsperiode (Rosenberg 1995, DitTMAR \& Elling 1999, KirChNER et al. 2000), wie dies auch für den Untersuchungsbestand Solling beschrieben wurde (SEIBT 1981, KRAMER 1982, MAKOWKA et al. 1991). Im Unterschied zu Extremstandorten oder -jahren mit existierendem Minimumfaktor (Asthaler \& LeHMANN 1979, KIENAST 1987, DitTMAR 1999) ist auf Übergangsstandorten der Einfluß einzelner Klimafaktoren auf den Holzzuwachs durch ihr komplexes Zusammenspiel meist schwer zu bestimmen (MAMMEN 1952, FrISSE 1977).

Bei den weitaus meisten in der Literatur beschriebenen dendroökologischen Zuwachsstudien an Buchen handelt es sich um Jahrringanalysen. Diese erlauben zwar eine bisweilen viele Jahrzehnte bis Jahrhunderte zurückreichende Analyse des Zusammenhangs zwischen Witterung und jährlicher Zuwachsantwort (HUBER et al. 1949, VON JAZEWITSCH 1953), nicht aber eine dahingehende Betrachtung des saisonalen Verlaufs der Zuwachsleistung in der einzelnen Vegetationsperiode (Wilhelmi 1959, SEIBT 1981, KrAMER 1982). Untersuchungen, die den saisonalen Verlauf der Zuwachsdynamik von Buchenbeständen im Zusammenhang mit der Bodenwasserversorgung und physiologischen Wasserhaushaltsparametern betrachten, liegen kaum vor (vgl. LEBAUBE et al. 2000, LEUSCHNER et al. 2001).

Die Kombination von maximalem Photosynthesevermögen der Blätter und einem zugleich hohen Strahlungsangebot bei großen Tageslängen ermöglicht im Juni und Juli eine besonders hohe Assimilationsleistung (STICKAN et al. 1991, SCHULTE 1992). Zudem können Waldbestände in der ersten Hälfte der Vegetationsperiode auch bei geringen Niederschlägen in der Regel noch vom Nutzwasservorrat aus der Winteraufsättigung des Bodens profitieren (BENECKE 1984, GERKE 1987, LEUSCHNER 1994). Diese günstigen Rahmenbedingungen spiegelten sich in allen Buchenbeständen und Vegetationsperioden der vorliegenden Untersuchung in einer besonders hohen Zuwachsleistung im Frühsommer wider, die auch LADEFOGED (1952) und LEBAUBE et al. (2000) an Buchen beobachteten. Ein spätsommerlicher Zuwachsrückgang findet bei fortschreitender Blattseneszenz und abnehmender Tageslänge typischerweise auch unabhängig vom Witterungsverlauf und der Bodenwasserversorgung statt (MiTsCHERLICH 1981a, LEBAUBE et al. 2000). Er kann aber bei Trockenstreß durch eine Einschränkung der stomatären Leitfähigkeit verfrüht einsetzen und wesentlich verstärkt werden (PIgOTT \& PIGOTT 1993, KOZLOWSKI \& PALLARDY 1997a und 1997b).

Dies kommt deutlich zum Ausdruck in der Zuwachsdynamik der am stärksten trockenstreßbelasteten Bestände Ziegelrodaer Forst (1996, 1997) und Lüneburger Heide (1995, 1996). So war im Verlauf der extremen hochsommerlichen Hitze- und Trockenperiode 1995 im Bestand Lüneburger Heide ein massiver Zuwachseinbruch zu beobachten. Der Holzzuwachs kam dort nach einer noch im Juli sehr hohen Wachstumsrate innerhalb eines Monats bis Ende August fast vollständig zum Erliegen. Auffällig ist der zu dieser Zeit vergleichsweise geringe Zuwachsrückgang im Bestand Göttinger Wald, der ebenfalls, wenn auch weniger stark und lange, unter Trockenstreß litt. 1996 ging im in dieser Vegetationsperiode weitaus niederschlagsärmsten Bestand Lüneburger Heide der Zuwachs wiederum bereits Anfang August auffallend stark zurück, im Bestand Ziegelrodaer Forst bei ausgeprägter spätsommerlicher Bodentrockenheit ab Anfang September. Die besser wasserversorgten Bestände Göttinger Wald und Solling, in denen keine wesentliche saisonale Einschränkung der stomatären Leitfähigkeit zu 
beobachten war, zeigten dagegen jeweils bis in den Oktober hinein ein weitgehend gleichmäßiges Zuwachsverhalten. In der Vegetationsperiode 1997, die bis Ende August relativ feucht war, zeigten alle Untersuchungsbestände von Mitte Juli bis Ende September beständig abnehmende Zuwachsraten. Dabei wies jedoch der Bestand Ziegelrodaer Forst mit der 1997 kontinental-sommertrockensten Witterung und den niedrigsten Blattwasserpotentialen wie schon im Vorjahr den stärksten Rückgang der Zuwachsraten von Juli bis September auf. Dort kam bei maximaler Bodentrockenheit Ende September der Zuwachs sogar praktisch zum Stillstand und setzte erst Mitte Oktober nach kräftigen Niederschlägen wieder ein.

Ein Zuwachseinbruch unter der Einwirkung von Trockenstreß war also vor allem in den Untersuchungsbeständen Ziegelrodaer Forst und Lüneburger Heide deutlich erkennbar, trat aber ebenso wie eine massive Trockenstreßeinwirkung meist erst im August oder September auf. $\mathrm{Zu}$ diesem Zeitpunkt war jedoch auch in den ausreichend bis gut wasserversorgten Beständen jeweils ein Großteil (60 - 90 \%) des Gesamtzuwachses der Vegetationsperiode bereits erfolgt. Darüber hinaus war nach Beendigung einer spätsommerlichen Trockenperiode in der Regel im Oktober ein Wiederanstieg der zuvor stark zurückgegangenen Zuwachsraten zu beobachten. Die beobachtete Zuwachsdynamik weist also darauf hin, daß der relative Verlust an Kohlenstoffgewinn durch den meist erst spät in der Vegetationsperiode einsetzenden Trockenstreß (vgl. GERKE 1987, LEUSCHNER 1994) geringer blieb, als allein das Ausmaß der zum Teil starken physiologischen Trockenstreßsymptome vermuten lassen könnte (SCHRAML \& RENNENBERG 2000).

Auch wenn die Wirkung von Trockenstreß auf den Zuwachs im Jahr des Auftretens selbst also relativ gering bleiben kann, so wurde doch in Jahrringanalysen immer wieder nach einem extrem trockenen Sommer im Folgejahr oder sogar mehreren darauffolgenden Jahren eine Zuwachsverringerung aufgrund der vorausgegangenen Erschöpfung des Kohlenstoffspeichers festgestellt (ECKSTEIN et al. 1984, DiTTMAR 1999, RoZAS 2001).

Wie sind vor diesem Hintergrund die besonders hohen Zuwachsraten im Ziegelrodaer Forst zu erklären?

Der Bestand im Ziegelrodaer Forst besaß im Untersuchungszeitraum gegenüber den anderen Buchenbeständen die deutlich höchste Bestandesblattfläche und die größten Blätter mit einem auffallend geringen spezifischen Blattgewicht. Zudem wurde in diesem Bestand die am schnellsten fortschreitende Blattalterung beobachtet. Das Vergilben der Blätter begann im Ziegelrodaer Forst in der Kronenspitze bereits Anfang August, drei bis vier Wochen früher als in den anderen Untersuchungsbeständen, und reichte im Spätsommer besonders tief in die Kronen herab.

Dies steht in Übereinstimmung mit Ergebnissen von LANDWEHR (1997), die in den auch in der vorliegenden Arbeit untersuchten Buchenbeständen weitere Blatteigenschaften bestimmte und Photosyntheseparameter der Bestände im Ziegelrodaer Forst und in der Lüneburger Heide verglich: Im Ziegelrodaer Forst lagen in der Vegetationsperiode 1996 Photosynthesevermögen sowie Carboxylierungseffizienz und Quantenausbeute der Photosynthese im Juni und Juli auf hohem Niveau, fielen dann aber bis September stark ab. Das Photosynthesevermögen zeigte in diesem Bestand einen von Juni bis September kontinuierlichen, ab Juli deutlich beschleunigten Rückgang. Demgegenüber wiesen die gleichen Photosyntheseparameter in der Lüneburger Heide 
von Juni bis August 1996 hohe Werte auf, bevor erst im September ein Rückgang zu beobachten war (vgl. Terborg 1998). Das Photosynthesevermögen erreichte dort sogar erst im August den Maximalwert. Dabei lagen die auf das Trockengewicht bezogenen Werte von Photosynthesevermögen und Quantenausbeute in den Monaten Juni und Juli im Ziegelrodaer Forst deutlich höher als in der Lüneburger Heide, fielen dann aber bis September auf in beiden Beständen ähnliche hohe Werte ab.

Auch die Chlorophyllgehalte von Sonnen- und Schattenblättern waren im Ziegelrodaer Forst gegenüber den anderen Untersuchungsbeständen zunächst auffallend hoch, fielen dann jedoch im Spätsommer stark ab und erreichten so im September etwa das Niveau der anderen drei Bestände. Darüber hinaus besaßen Sonnen- wie Schattenblätter im Bestand Ziegelrodaer Forst das deutlich engste $\mathrm{C} / \mathrm{N}-$ Verhältnis der vier Untersuchungsbestände und eine hohe Stomadichte (LANDWEHR 1997).

Gegenüber den anderen Untersuchungsbeständen zeichnet sich der Bestand im Ziegelrodaer Forst also dadurch aus, daß dort mit einem relativ geringen Kohlenstoffaufwand eine besonders große Bestandesblattfläche aus vergleichsweise „dünnen“ Blättern erzeugt wird. Diese „kostengünstige“ große Blattfläche besitzt zudem im Frühsommer eine besonders hohe photosynthetische Leistungsfähigkeit und gewährleistet dadurch zum Zeitpunkt hoher Strahlung und meist noch guter Wasserversorgung einen besonders effektiven und hohen Kohlenstoffgewinn. Im Hoch- und Spätsommer, dem Zeitraum mit zunehmend höherer Trockenstreßwahrscheinlichkeit, kann bzw. muß dafür im Ziegelrodaer Forst ein besonders starker Abfall der photosynthetischen Leistungsfähigkeit in Kauf genommen werden.

Hier zeichnet sich eine nur im Bestand Ziegelrodaer Forst beobachtete strukturelle wie auch physiologische Anpassung an die dort herrschenden subkontinental geprägten Klimabedingungen ab. Diese ermöglicht durch Konzentration der Assimilationsleistung auf den dafür günstigeren Frühsommer auch bei häufig auftretender und bis zum Spätsommer zunehmender Sommertrockenheit einen ausreichenden Kohlenstoffgewinn.

In Anbetracht der durch diese "Anpassungs-Strategie" vorgegebenen spezifischen Rahmenbedingungen der Assimilation erscheinen die hohen Zuwachsleistungen des Bestandes im Ziegelrodaer Forst plausibel. Zumal in den beiden Untersuchungsjahren ein dafür günstiger Witterungsverlauf zu beobachten war:

1996, vor allem aber 1997 erhielt der Bestand im Ziegelrodaer Forst im Zeitraum Juni-Juli deutlich höhere Niederschläge als im langjährigen Mittel. 1996 waren die Juni-JuliNiederschläge im Ziegelrodaer Forst sogar die höchsten aller untersuchten Buchenbestände. Mit der erst im Spätsommer einsetzenden Trockenheit und auch in der Summe von Mai bis September etwas überdurchschnittlichen Niederschlägen waren die untersuchten Vegetationsperioden 1996 und 1997 also sicher nicht ungewöhnlich kritisch für den Bestandeswasserhaushalt, sondern stellten an diesem Standort eher noch günstige Vegetationsperioden dar. Die geringen langjährigen Niederschlagsmittel im Ziegelrodaer Forst lassen demnach Vegetationsperioden mit noch früher einsetzender, länger andauernder und extremerer Trockenheit gerade an diesem Standort also durchaus häufiger erwarten. In solchen Vegetationsperioden ist auch mit einem noch deutlich früheren und stärkeren Verlust der photosynthetischen Leistungsfähigkeit der Buchenblätter im Ziegelrodaer Forst zu rechnen, wie ihn RAFTOYANNIS \& RAdOGlOU (2002) während eines extrem trockenen Sommers in einem mediterranen Buchenbestand bei Blattwasserpotentialen bis -4.2 MPa feststellten. Der 1996 im 
Ziegelrodaer Forst von LANDWEHR (1997) beobachtete starke Rückgang des Photosynthesevermögens zeigte ebenfalls eine parallele Entwicklung zu den stark absinkenden Blattwasserpotentialen in diesem Bestand, während bei deutlich entspannteren Blattwasserpotentialen in der Lüneburger Heide kein vergleichbarer Abfall des Photosynthesevermögens auftrat. Ein weitgehend konstantes Niveau des Photosynthesevermögens mit einem leichten Maximum im Juli beschrieben auch SchUlte (1992) für den Bestand im Solling und TerborG (1998) für den Bestand in der Lüneburger Heide in Jahren ohne Trockenstreß. Unter der Einwirkung von starkem Trockenstreß beobachtete TERBORG (1998) jedoch auch im Bestand Lüneburger Heide einen massiven Einbruch des Photosynthesevermögens.

Das Erreichen einer möglichst hohen Assimilationsleistung noch vor einem Einsetzen extremer Sommertrockenheit hat also für den am stärksten trockenstreßgefährdeten Bestand Ziegelrodaer Forst eine besondere Bedeutung. Eine entsprechende Anpassung auf bestandesstruktureller, blattmorphologischer und physiologischer Ebene scheint dabei entscheidend zur Aufrechterhaltung einer positiven Kohlenstoffbilanz dieses Bestandes beizutragen.

Auffällig war auch das Zuwachsverhalten des Untersuchungsbestandes im Solling, der den humidesten Standort im betrachteten Kontinentalitätsgradienten zwischen den untersuchten Buchenbeständen repräsentiert. Der Bestand im Solling wies trotz der höchsten Niederschläge und gänzlich fehlender Anzeichen von Wassermangel in allen drei klimatisch sehr unterschiedlichen Untersuchungsjahren jeweils die geringste Zuwachsrate auf. SCHULTE (1992) ermittelte für diesen Bestand in ebenfalls drei klimatisch unterschiedlichen Jahren den Verlust an Kohlenstoffgewinn durch suboptimale Temperatur- und Strahlungsbedingungen gegenüber der bei optimalen Umweltbedingungen theoretisch möglichen Kohlenstoff-Bilanz. Er bestimmte unter der Annahme einer kontinuierlich guten Wasserversorgung einen mittleren Verlust von $10 \%$ durch Temperatur- und 34\% durch Strahlungslimitierung. TERBORG (1998) ermittelte im Untersuchungsbestand in der Lüneburger Heide im Mittel über vier unterschiedlich feuchte Jahre entsprechend $7 \%$ Temperatur- und $25 \%$ Strahlungslimitierung.

Das Strahlungsregime aller untersuchten Standorte war im Untersuchungszeitraum sehr ähnlich.

Die Temperatur in den Vegetationsperioden lag jedoch in den (sub-)montanen Beständen Göttinger Wald und Solling um etwa $1.5^{\circ} \mathrm{C}$ bzw. $2.5^{\circ} \mathrm{C}$ niedriger als in den tiefer gelegenen Beständen Ziegelrodaer Forst und Lüneburger Heide. Auch wenn die Temperaturlimitierung des Zuwachses auf den kühleren Standorten vermutlich größer war als im wärmeren Tiefland (vgl. KrAMER 1982, EllenBerg et al. 1986, RosenberG 1995), so kann diese allein die vor allem im Solling sehr niedrigen Zuwächse doch nicht hinreichend erklären. Zumal mit stärkerem Trockenstreßeinfluß auf den beiden Tieflandstandorten an die Stelle der Temperaturlimitierung sicher ein wenn auch schwer zu quantifizierendes höheres Maß an Zuwachslimitierung durch Wassermangel trat.

Als Ursache für den auffallend geringen Zuwachs am Standort Solling zu beachten ist sicherlich das höhere Alter dieses etwa 150-jährigen Bestandes gegenüber den anderen Untersuchungsbeständen, die etwa 30 - 40 Jahre jünger sind. Ertragstafeln geben für 150-jährige Buchenbestände einen um 15 - 40 \% niedrigeren jährlichen Holzzuwachses an als für Bestände im Alter von 110 Jahren (HAMILTON \& CHRISTIE 1971, SCHOBER 1995). Ein entsprechender Trend zu abnehmendem Wachstum im Bestand Solling wurde bereits von ELLENBERG et al. (1986) beschrieben. 
Im Vergleich zwischen den Untersuchungsjahren fällt auf, daß in allen untersuchten Buchenbeständen 1996 ein besonders niedriger, 1995 ein mäßiger und 1997 der höchste Zuwachs auftrat.

Die Vegetationsperiode 1995 war durch eine extreme Hitze- und Trockenperiode im Hochsommer geprägt. Diese hatte offenbar nur auf dem 1995 deutlich niederschlagsreichsten Standort Solling keine trockenstreßbedingten Zuwachseinbußen zur Folge (DITTMAR \& ELLING 1999) und führte dadurch dort zu einem nur in diesem Jahr den anderen Beständen vergleichbaren Holzzuwachs. Demgegenüber beobachtete HERTEL (1999) in dem Untersuchungsbestand in der Lüneburger Heide im Verlauf der 1995 dort extrem ausgeprägten hochsommerlichen Trockenperiode einen stark erhöhten Anteil toter Feinwurzeln sowie eine entsprechend erhöhte Feinwurzel-Neubildungsrate. Trockenstreß brachte dort also zusätzlich zur Assimilationseinbuße durch Leitfähigkeitseinschränkung noch eine Belastung der Kohlenstoffbilanz durch eine erhöhte Kohlenstoff-Investition zur Aufrechterhaltung eines funktionsfähigen Wurzelsystems mit sich. Für den 1995 wurzelanalytisch nicht bearbeiteten Bestand im Göttinger Wald steht eine ähnliche Auswirkung zu vermuten. HERTEL \& LEUSCHNER (2002) ermittelten für den Bestand in der Lüneburger Heide einen Anteil von etwa $25 \%$ der Kohlenstoffallokation, der für Feinwurzelwachstum zu Verfügung steht und ebenso wie LEBAUBE et al. (2000) in einem anderen Buchenbestand Anteile von etwa $50 \%$ für das oberirdische Holzwachstum und $25 \%$ für die Ausbildung der Blätter. Darüber hinaus war 1995 in allen untersuchten Buchenbeständen ein ausgeprägtes Mastjahr. Die hohe Biomasseinvestition in Blüten und Früchte bedingt in Mastjahren einen meist nur mäßigen bis geringen Holzzuwachs (Holmsgandd \& Jensen 1962, Pellinen 1986, Kirchner et al. 2000), wie er 1995 einheitlich zu beobachten war.

Die 1996 durchweg besonders geringen Zuwächse beruhen sicher wesentlich auf der allgemein kühlen, strahlungsarmen und außer im Ziegelrodaer Forst vergleichsweise trockenen Vegetationsperiode. Des weiteren ist eine Auswirkung der extremen hochsommerlichen Trockenperiode im Vorjahr wahrscheinlich (ROZAS 2001), aber auch Zuwachseinbußen im Folgejahr einer Buchenmast sind bekannt (ABETZ 1988). Darüber hinaus liegen Hinweise vor, daß im kalten Winter 1995/1996 bei sehr niedrigen Temperaturen und fehlender Schneedecke ein Kahlfrostereignis auftrat, das offenbar vor allem im kältesten Bestand Solling eine starke Schädigung oberflächennaher Feinwurzeln zur Folge hatte (GRIES in Vorb.). Dieser Bestand wies im Frühjahr 1996 einen besonders hohen Anteil toter Feinwurzeln auf und leistete in der Vegetationsperiode 1996 entsprechend die höchste Biomasseinvestition in FeinwurzelNeubildung (Hertel 1999, vgl. Hertel \& Leuschner 2002). Die hohe unterirdische Biomasseinvestition ist vermutlich mit Ursache dafür, daß 1996 im Bestand Solling der weitaus niedrigste oberirdische Jahreszuwachs der vorliegenden Untersuchung bestimmt wurde.

In der Vegetationsperiode 1997 erlaubten günstige Bedingungen mit einem hohen Strahlungsangebot, hohen Temperaturen und einer bis in den August weitgehend ausgeglichenen Wasserversorgung in allen untersuchten Buchenbeständen vergleichsweise hohe Zuwachsraten.

Für die untersuchten Buchenbestände wurden jährliche Holzzuwächse zwischen $2.4 \mathrm{~m}^{3} \mathrm{ha}^{-1} \mathrm{a}^{-1}$ (Solling 1996) und $12.5 \mathrm{~m}^{3} \mathrm{ha}^{-1} \mathrm{a}^{-1}$ (Ziegelrodaer Forst 1997) bestimmt. In der Literatur werden für Buchenbestände in Mittel-, West- und Südwest-Europa mit einer etwa vergleichbaren Bestandesstruktur mittlere jährliche Holzzuwächse von $1.3 \mathrm{~m}^{3} \mathrm{ha}^{-1} \mathrm{a}^{-1}$ bis $13.5 \mathrm{~m}^{3} \mathrm{ha}^{-1} \mathrm{a}^{-1}$ (HAmilton \& Christie 1971, Schober 1972, PELlinen 1986, Anders 1988, 
Hofmann et al. 1991, MAdrigal 1992, Pretzsch 1996), in einzelnen Jahren bis über $20 \mathrm{~m}^{3} \mathrm{ha}^{-1} \mathrm{a}^{-1}$ (Ellenberg et al. 1986, Kotar 1996) angegeben. Die in der vorliegenden Untersuchung ermittelten jährlichen Holzzuwächse umfassen demnach nahezu die gesamte Amplitude in Europa häufig beobachteter mittlerer Zuwachsraten strukturell vergleichbarer Bestände. Sie bleiben jedoch deutlich unter sehr hohen Werten einzelner besonders wüchsiger Bestände bzw. günstiger Zuwachsjahre.

Die Vielfalt von Umweltfaktoren und Sonderereignissen, die jeweils in Wechselwirkung und mit unterschiedlicher Intensität den Holzzuwachs eines Bestandes beeinflussen, erschwert die Interpretation der Bedeutung von Trockenstreß für das Wachstum und die Vitalität der untersuchten Buchenbestände. Ein zuwachsreduzierender Einfluß von Trockenstre $ß$ ist sicher vorhanden, jedoch schwer zu quantifizieren. Die zum Teil trotz deutlicher Trockenstreßbelastung sehr hohen Zuwächse weisen darauf hin, daß nicht nur das Ausmaß sondern auch der Zeitpunkt der Trockenstreßeinwirkung eine entscheidende Bedeutung für die Auswirkung auf die Kohlenstoffbilanz eines Bestandes hat. Darüber hinaus kann offenbar selbst an Trockenstandorten durch strukturelle, morphologische und physiologische Anpassungsmechanismen eine nachhaltige trockenstreßbedingte Beeinträchtigung der Kohlenstoffbilanz und der Vitalität von Buchenbeständen weitgehend vermieden werden. 


\section{Zusammenfassung}

In einer vergleichenden Studie wurden in den Vegetationsperioden 1995-1997 in vier Altbuchenbeständen entlang eines Niederschlagsgradienten in Mitteldeutschland Parameter des Bestandeswasserhaushalts untersucht. Ziel der Studie war eine Analyse der Plastizität der Rotbuche in Wasserumsatz und Wasserhaushaltsregulation bei Anpassung an Standorte mit stark unterschiedlichem Niederschlagsregime.

Die Standortbedingungen der untersuchten Bestände umfaßten einen weiten Bereich des Klimaspektrums mitteleuropäischer Buchenstandorte. Dieser reichte von einem der trockensten mitteleuropäischen Buchenstandorte im Ziegelrodaer Forst mit einem subkontinental getönten Klima bei $520 \mathrm{~mm}$ Jahresniederschlag im mitteldeutschen Trockengebiet über Standorte im Göttinger Wald $(710 \mathrm{~mm})$ und in der südlichen Lüneburger Heide $(801 \mathrm{~mm})$ bis zu einem Buchenbestand mit subozeanisch-montaner Klimaausprägung im Solling mit einem Jahresniederschlag von $1040 \mathrm{~mm}$.

Das Niederschlagsregime sowie mikroklimatische Parameter (Globalstrahlung, Temperatur, Wasserdampfsättigungsdefizit) wurden mit Messungen auf oder nahe den Untersuchungsflächen erfaßt. Die saisonale Entwicklung des Bodenwasserzustands wurde mit kontinuierlichen Messungen des volumetrischen Bodenwassergehalts (TDR-Methode) und des Bodenmatrixpotentials in verschiedenen Bodentiefen verfolgt. Anhand von MatrixpotentialWassergehalts-Beziehungen (Feld-pF-Kurven) konnten aktuelle Nutzwasservorräte im Boden ermittelt werden. Zur Bestimmung der Bestandestranspiration der untersuchten Buchenwälder kamen Xylemsaftfluß-Meßsysteme nach der Tissue Heat Balance Methode (System nach CERMAK) zum Einsatz. Aus Bestandestranspirationsraten und mikroklimatischen Parametern konnte die Bestandesleitfähigkeit abgeleitet werden. Tagesgänge der stomatären Leitfähigkeit von Blättern in verschiedenen Kronenbereichen wurden porometrisch bestimmt. Parallel dazu sowie ,pre-dawn' erfolgten Messungen der Blattwasserpotentiale mit der Druckkammermethode. In Druck-Volumen-Analysen wurden Kennwerte des Blattwasserstatus ermittelt (osmotische Potentiale, relativer Wassergehalt bei Grenzplasmolyse). Zuwachsmaßbänder, Streufänger und Blattflächen-Meßgeräte dienten der Bestimmung von Holzzuwachs, Blattflächenindex (LAI) und morphologischen Blattmerkmalen.

Globalstrahlungsregime und Sättigungsdefizit der Luft unterschieden sich zwischen den untersuchten Buchenstandorten nur wenig. Die Temperaturen in den (sub-)montanen Beständen im Göttinger Wald und im Solling lagen jedoch im Mittel um 1.5 K bzw. $2.5 \mathrm{~K}$ niedriger als in den beiden Tieflandbeständen. Die Niederschläge auf den Untersuchungsflächen wichen in den Untersuchungsjahren zum Teil erheblich von den langjährigen Mittelwerten ab und unterschieden sich zwischen den Untersuchungsflächen deutlich. In allen Untersuchungsbeständen außer am niederschlagsreichsten montanen Standort im Solling war saisonale Trockenstreßeinwirkung zu beobachten. Am ausgeprägtesten war die Trockenstreßbelastung am langjährig niederschlagsärmsten Standort im mitteldeutschen Trockengebiet und in dem im Untersuchungszeitraum ungewöhnlich niederschlagsarmen Bestand in der Lüneburger Heide. Diese beiden Bestände stocken auf Sandböden und besaßen durchweg die geringsten Nutzwasservorräte. 
Die pre-dawn-Werte des Blattwasserpotentials sanken während einer extremen Trockenperiode im Hochsommer 1995 in den Beständen im Göttinger Wald und in der Lüneburger Heide bis auf - 1.0 MPa bzw. - 1.15 MPa ab und wiesen damit auf gravierende Nutzwasserdefizite hin. In dem Bestand im mitteldeutschen Trockengebiet sanken die pre-dawn-Werte in den Vegetationsperioden 1996 und 1997 bis auf - 0.7 MPa ab, während in den anderen Untersuchungsbeständen 1996 und 1997 Werte von - 0.5 MPa nicht unterschritten wurden. Nur in dem Bestand im mitteldeutschen Trockengebiet erreichte das mittägliche Blattwasserpotential bei Trockenstreß Werte bis - 2.6 MPa. In den anderen Buchenbeständen unterschritten die Tagesminima des Blattwasserpotentials nur selten und nur geringfügig einen Schwellenwert von etwa - 2.0 MPa.

Unterschiede in der Bestandeswasserversorgung spiegelten sich deutlich im Niveau der stomatären Blattleitfähigkeit wider. Der niederschlagsreichste Buchenbestand im Solling wies die höchsten mittäglichen Blattleitfähigkeiten auf (124-311 mmol m $\mathrm{ms}^{-1}$ ), während die bodentrockenen Bestände im mitteldeutschen Trockengebiet und in der Lüneburger Heide durch besonders niedrige Blattleitfähigkeiten auffielen (28 - $\left.183 \mathrm{mmol} \mathrm{m}^{-2} \mathrm{~s}^{-1}\right)$.

Die Bestandestranspiration der Vegetationsperiode 1996 blieb im Ziegelrodaer Forst (216 mm) und im Göttinger Wald $(225 \mathrm{~mm})$ niedriger als in den Beständen in der Lüneburger Heide (272 mm) und im Solling $(303 \mathrm{~mm})$. Die Werte ließen keine Abhängigkeit von bestandesstrukturellen Merkmalen wie Stammdichte, Bestandesgrundfläche, Feinwurzel-Biomasse oder LAI erkennen. Die Höhe der täglichen Bestandestranspiration wurde im wesentlichen vom Sättigungsdefizit der Luft und der Globalstrahlung bestimmt und wies nur eine schwache Korrelation mit der Bodenfeuchte auf. Die Bestandesleitfähigkeit der untersuchten Buchenbestände zeigte einheitlich eine starke Saisonalität mit einem Maximum im Juli und wurde in den bodentrockenen Beständen bei zunehmender Bodenwasserverknappung besonders stark eingeschränkt.

Die osmotischen Potentiale des Zellsaftes unterschieden sich zwischen den untersuchten Buchenbeständen nur wenig und zeigten keine gerichtete Veränderung bei saisonaler Trockenstreßbelastung. Eine Anpassung an Trockenstreß in Form von aktivem ,osmotic adjustment' war nicht erkennbar. Die weitaus bedeutendste Reaktionsebene der Wasserhaushaltsregulation der untersuchten Buchenbestände stellte die Einschränkung der Blatt- bzw. Bestandesleitfähigkeit bei Bodenwasserverknappung und absinkenden Blattwasserpotentialen dar. Hinweise auf eine darüber hinausgehende Anpassung an Trockenstreß lagen nur für den langjährig niederschlagsärmsten Bestand mit häufiger Sommertrockenheit vor. Der Bestand im mitteldeutschen Trockengebiet fiel durch eine besonders große Bestandesblattfläche mit einem niedrigen spezifischen Blattgewicht auf, die vor allem im Frühsommer eine hohe photosynthetische Leistungsfähigkeit besaß. Hier zeichnete sich eine Trockenstreßanpassung durch die Konzentration der Assimilationsleistung auf die erste Hälfte der Vegetationsperiode vor einer früh einsetzenden Blattseneszenz infolge Sommertrockenheit ab.

Der Bestand im mitteldeutschen Trockengebiet zeigte die niedrigsten Blattwasserpotentiale und zugleich eine nur mäßige Einschränkung der stomatären Blattleitfähigkeit. Dies weist auf eine erhöhte Trockenstreßtoleranz durch eine geringere Empfindlichkeit gegenüber Verlust an hydraulischer Leitfähigkeit in dem Bestand am langjährig niederschlagsärmsten Standort hin.

Bei spätsommerlicher Trockenstreßbelastung war an den beiden bodentrockenen Standorten ein saisonaler Rückgang des Holzzuwachses zu beobachten. Die Höhe des jährlichen Holz- 
zuwachses ließ jedoch keinen Schluß auf eine wesentliche trockenstreßbedingte Beeinträchtigung der Kohlenstoffbilanz und der Vitalität der untersuchten Buchenbestände zu. Diese kann offenbar selbst an einem der niederschlagsärmsten mitteleuropäischen Buchenstandorte durch physiologische und morphologisch-strukturelle Anpassungsmechanismen weitgehend vermieden werden. 


\section{Literaturverzeichnis}

ABEtz, P. (1988): Untersuchungen zum Wachstum der Buche auf der schwäbischen Alb. Allg. F. u. J. Ztg. 159: 215-223.

ABRAMS, M.D. (1994): Genotypic and phenotypic variations as stress adaptions in temperate tree species: A review of several case studies. Tree Physiol. 14: 833-842.

ALDER, N.N., SPERRY, J.S. \& PoCKMAN, W.T. (1996): Root and stem xylem embolism, stomatal conductance and leaf turgor in Acer grandidentatum populations along a soil moisture gradient. Oecologia 105: 293-301.

Alsheimer, M., Köstner, B., Falge, E. \& Tenhunen, J.D. (1998): Temporal and spatial variation in transpiration of Norway spruce stands within a forested catchment of the Fichtelgebirge, Germany. Ann. Sci. For. 55: 103-124.

ANDERS, S. (1988): Modelle der ökofaktorenabhängigen Stoffproduktion gleichaltriger Baumholzreinbestände von Kiefer und Buche. Diss. TU Dresden, $180 \mathrm{~S}$.

ARANDA, I., GIL, L. \& PARdos, J. (1996): Seasonal water relations of three broadleaved species (Fagus sylvatica L., Quercus petraea (Mattuschka) Liebl. and Quercus pyrenaica Willd.) in a mixed stand in the centre of the Iberian Peninsula. Forest Ecol. Manag. 84: 219-221.

ArAnda, I., GiL, L. \& PARdos, J. (2000): Water relations and gas exchange in Fagus sylvatica L. and Quercus petraea (Mattuschka) Liebl. in a mixed stand at their southern limit of distribution in Europe. Trees 14: 344-352.

ARYA, L.M. \& PARIS, J.F. (1981): A physico-empirical model to predict the soil moisture characteristic from particle-size distribution and bulk density data. Soil Sci. Soc. Am. J. 51: $1218-1227$.

Asthaler, K. \& LehmanN, L. (1979): Ergebnisse einer ökologischen Untersuchung von Trocknisschäden 1976 an Buche in Hessen. AFZ 34: 1029-1033.

Augé, R.M., Green, C.D., Stodolo, J.W., Saxton, A.M., Olinick, J.B. \& Evans, R.M. (2000): Correlations of stomatal conductance with hydraulic and chemical factors in several deciduous tree species in a natural habitat. New Phytol. 145: 483-500.

Aussenac, G. \& Boulangeat, C. (1980): Intercéption des précipitations et évapotranspiration réelle dans des peuplements de feuillu (Fagus sylvatica L.) et de résineux (Pseudotsuga menziesii (Mirb.) Franco). Ann. Sci. For. 37: 91-107.

AussenAC, G. \& DuCREY, M. (1977): Etude bioclimatique d'une futaie feuillue (Fagus sylvatica L. et Quercus sessiliflora Salisb.) de 1'Est de la France. I. Analyse des profils microclimatiques et des caracteristiques anatomiques et morphologiques de l'appareil foliaire. Ann. Sci. For. 36: 265-280.

BACKES, K. (1996): Der Wasserhaushalt vier verschiedener Baumarten der Heide-WaldSukzession. Diss. Univ. Göttingen, Cuvilllier Verlag, Göttingen, 134 S. 
BALAZS, A. (1983): Ein Kausalanalytischer Beitrag zur Quantifizierung des Bestandes- und Nettoniederschlags von Waldbeständen. Verlag Beiträge zur Hydrologie, Kirchzarten, $180 \mathrm{~S}$.

Baldocchi, D.D., Valentini, R., Running, S., Oechel, W. \& Dahlmann, R. (1996): Strategies for measuring and modelling carbon dioxide and water vapor fluxes over terrestrial ecosystems. Global Change Biol. 2: 159-168.

BeneCKE, P. (1984): Der Wasserhaushalt eines Buchen- und eines Fichtenwaldökosystems im Hochsolling. Schriften der forstl. Fak. Univ. Göttingen 77: 1-158.

Benecke, P. \& VAn DeR Ploeg, R.R. (1978): Quantifizierung des Wasserumsatzes am Beispiel eines Buchen- und Fichtenaltbestandes im Solling. Forstarchiv 2: 26-32.

Berbigier, P., Bonnefond, J.M., Lousteau, D., Ferreira, M., David, J.S. \& Pereira, J.S. (1996): Transpiration of a 64-year old maritime pine stand in Portugal: 2. Evapotranspiration and canopy stomatal conductance measured by an eddy covariance technique. Oecologia 107: 43-52.

BMELF (Bundesministerium für Ernährung, Landwirtschaft und Forsten) (1993): Unser Wald. Natur und Wirtschaftsfaktoren zugleich. Bonn, $52 \mathrm{~S}$.

Borghetti, M., LeOnARdi, S., RAschi, A. \& Snyderman, D. (1993): Ecotopic variation of xylem embolism, phenological traits, growth parameters and allozyme characteritics in Fagus sylvatica. Functional Ecology 7: 713-720.

Borghetti, M. \& Magnani, F. (1996): Controllo microclimatico della traspirazione in una faggeta appenninica. Monti e Boschi 6: 49-53.

BRECHTEL, M. \& LEHNHARDT, F. (1982): Einfluss der Grundwasserabsenkung auf Waldstandorten : 4. Fortbildungslehrgang Grundwasser, Nutzbares Grundwasserdargebot, 11. bis 14. Oktober 1982 in Darmstadt, 49 S.

BRechtel, M. \& Scheele, G. (1982): Erwirtschaftung von Grundwasser durch Land- und Forstwirtschaftliche Maßnahmen.

Brechtel, M. \& BALAzS, A. (1988): Wieviel Wasser kommt aus dem Bramwald? AFZ 15: 397-400.

BREDA, N. (1999): L'indice foliaire des couverts forestiers: mesure, variabilité et rôle fonctionnel. Rev For. Fr. 50: 135-150.

BRÉDA, N. \& GRANIER, A. (1996): Intra- and interannual variations of transpiration, leaf area index and radial growth of a sessile oak stand (Quercus petreae). Ann. Sci. For. 53: 521536.

BREDEMEIER M. \& WIEDEY G.A. (1990): Exkursionsführer Solling. Ber. Forsch.zentr. Waldökosysteme Göttingen B 17: 119 S.

BÜCKING, W. \& KREBS, A. (1986): Interzeption und Bestandesniederschläge von Buche und Fichte im Schönbuch. In: EINSELE, G. (Hrsg.): Das landschaftsökologische Forschungsprojekt Naturpark Schönbuch. VCH, Göttingen, 113-131. 
Burger, H. (1939): Holz, Blattmenge und Zuwachs. Mitt. Schweiz. Anst. f. d. Forstl. Vers.wesen 21: 307-348.

Bussotti, F., Borghini, F., Celesti, C., Leonzio, C. \& Bruschi, P. (2000): Leaf morphology and macronutrients in broadleaved trees in central Italy. Trees 14: 361-368.

Bussotti, F., Grossoni, P. \& BotTacci, A. (1997): Sclerophylly in beech (Fagus sylvatica L.) trees: its relationship with crown transparency, nutritional status and summer drought. Forestry 70: 267-271.

Cermak, J., Ciencela, E., Kucera, J., Lindroth, A. \& Bednarova, E. (1995): Individual variation in sap flow rate in large pine and spruce trees and stand transpiration: a pilot study at the central NOPEX site. J. Hydr. 168: 17-27.

Cermak, J., Deml, M. \& Penka, M. (1973): A new method of sapflow rate determination in trees. Biol. Plant. 15: 171-178.

Cermak, J., Deml, M. \& Penka, M. (1976): Improvement of the method of sap flow rate determination in full-grown trees based on heat balance with direct electric heating of xylem. Biol. Plant. 18: 105-110.

CERMAK, J. \& KUCERA J. (1981): The compensation of natural temperature gradient at the measuring point during the sap flow rate determination in trees. Biol. Plant. 23: 469-471.

Cermak, J. \& Kucera J. (1986): Transpiration of mature stands of spruce (Picea abies L. [Kars.]) as estimated by the tree-trunk heat balance method. Forest and water shed management (Proceedings of the Vancouver Symposium, Aug. 1987). IAHS-AISH Publ. Nr. 167: 311-317.

Chason, J.W., Baldocchi, D.D. \& Huston, M.M. (1991): A comparison of direct and indirect methods for estimating forest canopy leaf area. Agr. For. Met. 57: 107-128.

Cochard, H., BrÉDA, N. \& Granier, A. (1996): Whole tree hydraulic conductance and water loss regulation in Quercus during drought: evidence for stomatal control of embolism? Ann. Sci. For. 53: 197-206.

Cochard, H., Lemoine, D. \& DREYeR, E. (1999): The effects of acclimation to sunlight on the xylem vulnerability to embolism in Fagus sylvatica L.. Plant, Cell and Env. 22: 101-108.

Comstock, J.P. (2002): Hydraulic and chemical signalling in the control of stomatal conductance and transpiration. J. Exp. Bot. 53: 195-200.

Comstock, J.P. \& Mencuccini, M. (1998): Control of stomatal conductance by leaf water potential in Hymenoclea salsola (T. and G.), a desert subshrub. Plant, Cell and Env. 21: 1029-1038.

CONERS H. (2001): Wasseraufnahme und artspezifische hydraulische Eigenschaften der Feinwurzeln von Buche, Eiche und Fichte: In situ-Messungen an Altbäumen. Diss. Univ. Göttingen, $118 \mathrm{~S}$.

Crandell, D.A. \& LuXMoORE, R.J. (1982): Simulated water budgets for an irrigated Sycamore Phytomass Farm. For. Sci. 28: 17-30. 
Creus Novau, J., Fernandezz Cancio, A. \& Munarriz Guezala, D. (1992): Dendroecologia de los hayos surorientalis de Navarra. Sierra de Alaiz y Leyre. Investition agraria, Sistema y recursos forestales, fuera de serie $\mathrm{N}^{\circ} 1$ : Actas del congreso internacional del haya. actas Vol I: 161-166.

DANNER, E. (1990): Untersuchung und Kartierung der räumlichen Variabilität der Böden einer Calluna-Heide, eines Kiefern-Bestandes und eines Eichen-Buchenwaldes auf Sanden der Lüneburger Heide. Unveröff. Dipl.Arb. Univ. Göttingen, 127 S.

DELFS, J. (1955): Die Wasserzurückhaltung im Walde (Interception). Mitt. Arb.Kreis "Wald und Wasser" 2: 54.

DeUtSCHER WeTterdiEnst: Monatlicher Witterungsbericht. Amtsblatt des Deutschen Wetterdienstes.

Diawara, A., Lousteau, D. \& Berbugier, P. (1991): Comparison of two methods for estimating the evaporation of a Pinus pinaster (Ait.) stand: sap flow and energy balance with sensible heat flux measurements by an eddy covariance method. Agr. For. Met. 54: 49-66.

DIERSCHKE H. \& SONG Y. (1982): Vegetationsgliederung und kleinräumige Horizontalstruktur eines submontanen Kalkbuchenwaldes. In: DiERSCHKE, H. (Hrsg.): Struktur und Dynamik von Wäldern. Ber. Internat. Symp. IVV, (Rinteln 1981). Cramer, Vaduz: 513539.

DitTMAR, C. (1999): Radialzuwachs der Rotbuche (Fagus sylvatica L.) auf unterschiedlich immissionsbelasteten Standorten in Europa. Bayreuther Bodenkundl. Ber. 67

DitTMAR, C. \& Elling, W. (1999): Jahrringbreite von Fichte und Buche in Abhängigkeit von Witterung und Höhenlage. Forstw. Cbl. 118: 251-270.

Dolman, A.J., Moors, E.J., Elbers, J.A. \& Snijders, W. (1998): Evaporation and surface conductance of three temperate forests in the Netherlands. Ann. Sci. For. 55: 255-270.

DREYER, E. (1994): Compared sensivity of seedlings from three woody species (Quercus robur L., Quercus rubra L. and Fagus sylvatica L.) to water logging and associated root hypoxia: effects on water relations and photosynthesis. Ann. Sci. For. 51: 417-429.

DufrÊNE, E. \& BRÉDA, N. (1995): Estimation of decidious forest leaf area index using direct and indirect methods. Oecologia 104: 156-162.

Eckstein, D., Richter, K., ANiOL, W. \& QuieHL, F. (1984): Dendroklimatologische Untersuchungen zum Buchensterben im südwestlichen Vogelsberg. Forstw. Cbl. 103: 274-289.

EHRHARDT, O. (1988): Der Strahlungshaushalt eines Buchenwaldes und dessen Abwandlung während der verschiedenen phänologischen Entwicklungsphasen. Ber. Forsch.zentr. Waldökosysteme Göttingen A 45, 170 S.

EIDMANN, F. E. (1959): Die Interception von Buchen- und Fichtenbeständen. Ergebnis mehrjähriger Untersuchungen im Rothaargebirge (Sauaerland). Publ. Nr. 48, Ass. Int. Hydr. Sci. (Gentbrugge): 5-25. 
EIMERN, J. VAN \& RIEDINGER, F.P. (1986): Zur vertikalen Verteilung der Luft- und Pflanzentemperatur in einem Buchenhochwald, besonders im Kronenraum. Agr. For. Met. $38: 27-45$.

EllenberG, H. (1996): Vegetation Mitteleuropas mit den Alpen. Ulmer Verlag, Stuttgart, $1095 \mathrm{~S}$.

Ellenberg, H., MaYer, R. \& Schauermann, J. (Hrsg.) (1986): Ökosystemforschung. Ergebnisse des Sollingprojektes 1966-1986. Ulmer Verlag, Stuttgart, 507 S.

EllenberG, H. \& Wilmers, F. (1986): Das Allgemeinklima des Sollings im Rahmen Mitteleuropas. In: EllenberG, H., MAYer, R. \& Schauermann, J. (Hrsg.) (1986): Ökosystemforschung. Ergebnisse des Sollingprojektes 1966-1986: 61-75.

FELBERMEIER, B. (1993): Der Einfluß von Klimaänderungen auf die Baumarten: Methodenstudie und regionale Abschätzung für die Rotbuche (Fagus sylvatica L.) in Bayern. Forstl. Forschungsber. München 134: 228 S.

FIEDLER, H.J. (2001): Böden und Bodenfunktionen. In: Forum EIPOS 7. Expert Verlag, Stuttgart: $598 \mathrm{~S}$.

FoETZKI A. (1998): Beziehungen zwischen Kronenverlichtung, Licht-Transmission und Blattfläche in verschiedenen Buchenwäldern Nordhessens. Unveröff. Diplomarbeit Univ.,Gh. Kassel.

Forgeard, F., GloAguen, J.C. \& Touffet, J. (1980): Interception of precipitations and mineral supply to the soil by rainfall and leaching in an atlantic beech forest. Ann. Sci. For. 37: 53-71.

FREY, W. \& LÖSCH, R. (1998): Lehrbuch der Geobotanik. G. Fischer Verlag, Stuttgart.

FRISSE, E. (1977): Xylometrische und dendroklimatologische Untersuchungen über den Einfluß von Temperatur und Niederschlag auf Eichen und Buchen. Diss. Univ. Hamburg, $213 \mathrm{~S}$.

GAMS, H. (1932): Die klimatische Begrenzung von Pflanzenarealen und die Verteilung der hygrischen Kontinentalität. Z. Ges. Erdk. 4 : 56-68, 178-198.

GARELKOV, D. (1973): Biological productivity of some beech forest types in Bulgaria. In: College OF Life ScIENCES AND ACRICUlture (Hrsg.): IUFRO Biomass Studies. Univ. Maine, Orono, USA: 307-314.

GÄRTNER, R. \& STOLL, G. (1990): Weiserjahre in Baden-Württemberg. AFZ 45: 1163-1165.

GERKE, H. (1987): Untersuchungen zum Wasserhaushalt eines Kalkbuchenwald-Ökosystems und zur Wasserbewegung in flachgründigen Böden und im durchwurzelten Kalkgestein als Grundlage zur Modellentwicklung. Ber. Forsch.zentr. Waldökosysteme Göttingen A 27: $1-189$.

GHOLZ, H.L. (1982): Environmental limits on aboveground net primary production, leaf area, and biomass in vegetation zones of the pacific northwest. Ecology 63: 469-481.

Gholz, H.L., Fitz, F.K. \& WARUNG, R.H. (1976): Leaf area difference associated with oldgrowth forest communities in the western Oregon Cascades. Can. J. For. For. Res. 6: 49-57. 
GOLCHERT, H.J. (1981): Mittlere monatliche Globalstrahlungsverteilungen in der Bundesrepublik Deutschland. Metereol. Rdsch. 34: 143-151.

GörLITZ, G. (1992): Untersuchungen zum Wasser- und Elementumsatz der Streuschicht eines Eichen-Buchenwaldes. Unveröff. Dipl.Arb. Univ. Göttingen, 99 S.

GRANIER, A. (1985): Une nouvelle méthode pour la mesure du flux de sève brute dans le tronc des arbres. Ann. Sci. For. 42: 193-200.

GRANIER, A. (1987): Evaluation of Transpiration in a Douglas-fir stand by means of sap flow measurements. Tree Physiol. 3: 309-320.

Granier, A., Biron, P., Köstner, B., Gay, L.W. \& NAijar, G. (1996a): Comparisons of Xylem Sap Flow and Water Vapour Flux at the Stand Level and Derivation of Canopy Conductance for Scots Pine. Theor. Appl. Climatol. 53: 115-122.

Granier, A., Biron, P., Bréda, N., Pontailler, J.-Y \& Saugier, B. (1996b): Transpiration of trees and forest stands: short and long-term monitoring using sap flow methods. Global Change Biol. 2: 265-274.

GRANIER, A. \& BRÉDA, N. (1996): Modelling canopy conductance and stand transpiration of an oak forest from sap flow measurements. Ann. Sci. For. 53: 537-546.

Granier, A., Bréda, N., Biron, P. \& Villette, S. (1999): A lumped water balance model to evaluate duration and intensity of drought constraints in forest stands. Ecological Modelling 116: 269-283.

Granier, A., Biron, P. \& Lemoine, D. (2000): Water balance, transpiration and canopy conductance in two beech stands. Agr. For. Met. 100: 291-308.

Granier, A., BrÉDA, N., Loustau (2000a): A generic model of forest canopy conductance dependent on climate, soil water availability and leaf area index. Ann. Sci. For. 57: 755-765.

Granier, A., Ceschia, C., Damesin, E., Epron, D., Gross, P., Lebaube, S., Le Dantec, V., Le Goff, N., , Lemoine, D., , Lucot, E., OtTorini, J.M., Pontaillier, J.Y. \& SAugier, B. (2000b): The carbon balance of a young beech forest. Functional Ecology 14: 312326.

Granier, A. \& Loustau. D. (1994): Measuring and modelling the transpiration of a maritime pine canopy from sap-flow data. Agr. For. Met. 71: 61-81.

GRIER, C. C. \& RUNNING, S.W. (1977): Leaf area of mature northwestern forests: relation to site water balance. Ecology 58: 893-899.

GRISEBACH, A. (1872): Die Vegetation der Erde nach ihrer klimatischen Anordnung. Engelmann, Leipzig, $603 \mathrm{~S}$.

GROTE, R. \& SUCKOW, F. (1998): Integrating dynamic morphological properties into forest growth modelling. I. Effects on water balance and gas exchange. Forest Ecol. Manag. 112: 101-119. 
HACKe, U. \& SAUTER, J.J. (1995): Vulnerability of xylem to embolism in relation to water potential and stomatal conductance in Fagus silvatica $f$. purpurea and Populus balsamifera. J. Exp. Bot., Vol.46: 1177-1183.

Hamilton, G.J. \& Christie, J.M. (1971): Forest management tables (metric). In: forestry commission booklet. London, $34 \mathrm{~S}$.

HAGEMEIER, M. (2002): Funktionale Kronenarchitektur mitteleuropäischer Baumarten am Beispiel von Hängebirke, Waldkiefer, Traubeneiche, Hainbuche, Winterlinde und Rotbuche. Diss. Bot. 361, J. Cramer, 154 S.

Hare, P. D., Cress, W. A. \& Van Staden, J. (1998): Dissecting the roles of osmolyte accumulation during stress: Review. Plant, Cell and Env. 21: 535-553.

Harrington, R.A., Fownes, J.H., Meinzer, F.C. \& Scowcroft, P.G. (1995): Forest growth along a rainfall gradient in Hawaii: Acacia koa stand structure, productivity, foliar nutrients and water- and nutrient-efficiencies. Oecologia 102: 277-284.

Hatton, T.J. \& WU, H.I. (1995): Scaling Theory to extrapolate individual tree water use to stand water use. Hydrol Proc. 9: 527-540.

Haverkamp, R. \& Parlange, J.Y. (1986): Predicting the water-retention curve from particlesize distribution: 1. sandy soils without organic matter. Soil Science 142: 325-339.

HeIL, K. (1996): Wasserhaushalt und Stoffumsatz in Fichten- (Picea abies L. [Karst.]) und Buchenökosystemen (Fagus sylvatica L.) der höheren Lagen des Bayerischen Waldes . Diss. Univ. München, Forstwiss. Fak., 374 S.

Heimann, J. (1995): Xylemsaftfluß 40-jähriger Fichten (Picea abies L. [Karst.]) im Wassereinzugsgebiet der Langen Bramke, Harz. Diss. Univ. Göttingen, 148 S.

HeImOVAARA, T.J. (1993): Time domain reflectometry in soil science : theoretical backgrounds, measurements and models. Dissertation Univ. Amsterdam, $169 \mathrm{~S}$.

HeInKen, T. (1993): Phytosociological and historical investigations in beech woods and birchoak woods on pleistcene sandy soils without groundwater influence in Lower Saxony (NW Germany). In: Scripta Geobot. 21: 61-66.

HeInsDorf, D. \& Chrozon, S. (1997): Entwicklung der Belaubung mittelalter Buchenbestände in Nordostdeutschland von 1987-1996. Forst und Holz 52: 182-189.

HERBST, M. (1995): Stomatal behaviour in beech canopy: an analysis of Bowen ratio measurements compared with porometer data. Plant, Cell and Env. 18: 1010-1018.

Herbst, M., Eschenbach, CH. \& Kappen, L. (1999): Water use in neighbouring stands of beech (Fagus sylvatica L.) and black alder (Alnus glutinosa (L.) Gaertn.). Ann. For. Sci. 56: 107-120.

HeRTEL, D. (1999): Das Feinwurzelsystem von Reinbuchen- und Mischbeständen der Rotbuche: Struktur, Dynamik und interspezifische Konkurrenz. Diss. Botanicae 317, J. Cramer, $190 \mathrm{~S}$. 
Hertel, D. \& Leuschner, CH. (2002): A comparison of four different fine root production estimates with ecosystem carbon balance data in a Fagus-Quercus mixed forest. Plant and Soil 239: 237-251.

HIEGE, W. (1985): Wasserhaushalt von Forsten und Wäldern und der Einfluß des Wassers auf Wachstum und Gesundheit von Forsten und Wäldern: eine Literaturstudie . Bos en water 7a, Waterbeheer Natuur Bos en Landschap, Utrecht, 192 S.

Hinckley, T.M., Brooks, J.R., Cermak, J., Ceulemans, R., Kucera, J., Meinzer, F.C.\& RoBERTS, D.A. (1994): Water flux in a hybrid poplar stand. Tree Physiol. 14: 1005-1018.

Hofmann, G., Anders, S., Beck,W., Chrzon, S. \& Matthes, B. (1991): Buchenwälder und ihr Vitalitätszustand in Ostdeutschland. Beiträge für die Forstwirtschaft 25: 157-168.

Holbrook, N.M., \& ZWIENIECKI, A.A. (1999): Embolism repair and xylem pressures in plants: do we need a miracle? Plant Physiol. 120: 7-10.

HolmsgaARD, E. \& JENSEN, V. (1962): Influence of weather on growth and reproduction of beech. Commun. Inst. Forst. Fenni. 55, Heft 5: 1-5.

Huber, B., JAZEWITSCH, W. von, John, A. \& Wellenhofer W. (1949): Jahrringchronologie der Spessarteichen. Forstw. Cbl. Nr. 68: 706-715.

ISHIBASHI, M. \& TERASHIMA, I. (1995): Effects of continuous leaf wetness on photosynthesis: Adverse aspects of rainfall. Plant, Cell and Env. 18: 431-438.

JARVIS, P.G. (1976): The interpretation of the variations in leaf water potential and stomatal conductance found in canopies in the field. Phil. Trans. R Soc. Lond. ser. B 273: 593610.

JARVIS, P.G. \& MCNAUGHTON, K.G. (1986): Stomatal control of transpiration: scaling up from leaf to region. Adv. Ecol. Res. 15: 1-49.

JAZEWITSCH, W. VON (1953): Jahrringchronolgie der Spessart-Buchen. Forstw. Cbl. 72: 234-247.

JimÉnez, M.S., NADEZhdina, N., Cermak, J. \& Morales, D. (2000): Radial variation in sap flow in five laurel forest tree species in Tenerife, Canary Islands. Tree Physiol. 20: 11491156.

JONES, H.G. (1992): Plants and microclimate: a quantitative approach to environmental plant physiology. Cambridge Univ. Press., Cambridge, $428 \mathrm{~S}$.

Kelliher, F.M., Köstner, B.M.M., Hollinger, D.Y., Byers, J.N., Hunt, J.E., McSeveny, T.M., Meserth, R., WeIR, P.L. \& Schulze, E.D. (1992): Evaporation, xylem sap flow, and tree transpiration in a New Zealand broad-leaved forest. Agr. For. Met. 62: 53-73.

Kelliher, F.M., Leunig, R., Raupach, M.R. \& Schulze, E.-D. (1995): Maximum conductances for evaporation from global vegetation types. Agr. For. Met. 73: 1-16.

KERN, J.S. (1995): Evaluation of soil water retention models based on soil physical properties. Soil Sci. Soc. Am. J. 59: 1134-1141.

KIENAST, F. (1987): Jahrringe als ökologische Datenträger . Berichte Eidgenössische Anstalt für das forstliche Versuchswesen 292.51 S. 
Kirchner, M., Baumgarten, M., Matyssek, R., Dittmar, C., Fellner, R., Hager, H., Pasuthova, J., Reuther, M., Schume, H., Soukup, F., Werner, H. \& Braeutigam, S. (2000): Fallstudie Buche im Dreiländereck Böhmen Österreich Bayern. In: BAYERISCHES STAATSMINISTERIUM FÜR LANDESENTWICKLUNG UND UMWELTFRAGEN (Hrsg.): Materialien 151. $161 \mathrm{~S}$.

Koch, O. (2002): Wasserumsatz eines Buchenbestandes im Hainich. Unveröff. Diplomarbeit Univ. Göttingen, $81 \mathrm{~S}$.

Koide, R.T., Robichaux, R.H., Morse, S.R. \& Smith, C.M. (1989): Plant water status, hydraulic resistance and capacitance. In: PeArCy, R.W., Ehleringer, J.R., MoOney, H.A., Rundel, P.W. (Hrsg.): Plant Physiological Ecology. London, New York: 161-183.

KÖPPEN, W. (1901): Versuch einer Klassifikation der Klimate vorzugsweise nach ihren Beziehungen zur Pflanzenwelt. Geograph. Zeitschr. 6.

KÖRNER, CH. (1994): Leaf diffusive conductances in the major vegetation types of the globe. In: SChulze, E.-D., CALDWELl, M.M. (Hrsg.): Ecophysiology of photosynthesis. Ecological studies Vol. 100. Springer, Heidelberg: 463-490.

KÖSTNER, B. (2001): Evaporation and transpiration from forests in Central Europe - relevance of patch-level studies. Meteorol. Atmos. Phys. 76: 69-82.

Köstner, B., Alsheimer, M. \& Tenhunen, J.D. (1996a): Tree Canopy Transpiration at Different Sites of a Spruce Forest Ecosystem. Verhandlungen der Gesellschaft für Ökologie Bd. 26: 61-68.

Köstner, B., Biron, P., Siegwolf, R. \& Granier, A. (1996b): Estimates of Water Vapour Flux and Canopy Conductance of Scots Pine at the Tree Level Utilizing Different Xylem Sap Flow Measurements. Theor. Appl. Climatol. 53: 105-113.

Köstner, B., Granier, A. \& Cermak, J. (1998a): Sap flow measurements in forest stands methods and uncertainties. Ann. Sci. For. 55: 350-359.

Köstner, B., Falge, E., Alsheimer, M., Geyer, R. \& Tenhunen, J.D. (1998b): Estimating tree canopy water use via xylem sap flow in an old Norway spruce forest and a comparison with simulation-based canopy-transpiration estimates. Ann. Sci. For. 55: 125-139.

Köstner, B.M.M., Schulze, E.-D., Kelliher, F.M., Hollinger, D.Y., Byers, J.N., Hunt, J.E., McSeveny, T.M., Meserth, R. \& Weir, P.L. (1992): Transpiration and canopy condutance in a pristine broad-leaved forest of Nothofagus: an analysis of xylem sap flow and eddy correlation measurements. Oecologia 97: 350-359.

KOTAR, M. (1996): Volume and height growth of fully stocked mature beech stands in Slovenia during the past three decades. Growth trends in European forests: studies from 12 countries. European Forest Institute research report 5: 391-312.

Kowalik, P., Borghetti, M., Borselli, L., Magnani, F., SAnesi, G. \& Tognetti, R. (1997): Diurnal water relations of beech (Fagus Sylvatica L.) trees in the mountains of Italy. Agr. For. Met.84: 11-23.

Kozlowski, T. T. \& Pallardy, S.G. (1997a): Physiology of woody plants. Academic Press, San Diego, 411 S. 
Kozlowski, T. T. \& Pallardy, S.G. (1997b): Growth control in woody plants. Academic Press, San Diego, $641 \mathrm{~S}$.

KRAMER, H. (1982): Kurzfristige Zuwachsreaktionen bei Buche in Abhängigkeit von Witterung und verschiedenen Baummerkmalen. AFJZ 153: 57-67.

KrAmER, H. \& AKCA, A. (1995): Leitfaden zur Waldmesslehre. Sauerländer's Verlag, Frankfurt am Main: 1-266.

Kutsch, W.L., Herbst, M., Vanselow, R., Hummelshoj, P., Jensen, N.O. \& Kappen, L. (2001): Stomatal acclimation influences water and carbon fluxes of a beech canopy in northern Germany. Basic Appl. Ecol. 2: 265-281.

LAdEFoged, K. (1952): The periodicity of wood formation. Dan. Biol. Skr. 7: 1-98.

LAdefoged, K. (1963): Transpiration of forest trees in closed stands. Physiol. Plant. 16: 378-414.

LANDESAMTES FÜR UMWELtSChUtZ SACHSEN-ANHALT (2000): Karte der Potentiellen Natürlichen Vegetation von Sachsen-Anhalt, Erläuterungen zur Naturschutz-Fachkarte M. $1: 200.000$.

LANDSBERG, J.J. (1986): Experimental approaches to the study of the effects of nutrients and water on carbon assimilation by trees. Tree Physiol. 2: 427-444.

LANDWEHR, S. T. (1997): Photosynthese und Blattleitfähigkeiten von Altbuchen (Fagus sylvatica L.) an unterschiedlich wasserversorgten Standorten. Unveröff. Diplomarbeit, Syst.-Geobot. Inst. d. Univ. Göttingen, 129 S.

LANG, S. (1999): Ökophysiologische und anatomische Untersuchungen zum Saftfluß in verschiedenen Splintholzbereichen von Fagus sylvatica L.. Dissertation, Univ. Karlsruhe, $162 \mathrm{~S}$.

LARCHER, W. (1994): Ökophysiologie der Pflanze. Ulmer Verlag, Stuttgart, 394 S.

LAVAHUN, C. (1981): Unterer Muschelkalk und oberer Buntsandstein am Ostrand des Göttinger Waldes zwischen Herberhausen und Mackenrode (TK 4426 Ebergötzen). Unveröff. Diplomarbeit Geol. Paläont. Inst. Univ. Göttingen

Lebaube, S., Le Goff, N., Ottorini, J.-M. \& Granier, A. (2000): Carbon balance and tree growth in a Fagus sylvatica stand . Ann. For. Sci. 57: 49-61.

Lemoine, D. , Peltier, J.-P. \& MARigo, G. (2001): Comparative studies of the water relations and the hydraulic characteristics in Fraxinus excelsior, Acer pseudoplatanus and $A$. opalus trees under soil water contrasted conditions. Ann. For. Sci. 58: 723-731.

LEMoINe, D., Cochard, H. \& GRANIER, A. (2002): Within crown variation in hydraulic architecture in beech (Fagus sylvatica L): evidence for a stomatal control of xylem embolism. Ann. For. Sci. 59: 19-27.

Leuschner, C., Rode, M.W., Danner, E., Lübbe, K., Clauß, C., Margraf, S. \& Runge, M. (1993): Soil profile alteration and humus accumulation during heathland-forest succession in NW-Germany. Scripta Geobot. 21: 73-84. 
LEUSCHNER, CH. (1993): Patterns of soil water depletion under coexisting oak and beech trees in a mixed stand. Phytocoenologia 23: 19-33.

LEUSCHNER, CH. (1994): Walddynamik in der Lüneburger Heide: Ursachen, Mechanismen und die Rolle der Ressourcen. Habilitationsschrift Univ. Göttingen, 368 S.

LEUSCHNER, CH. (1998): Water extraction by fine roots in the forest floor of a temperate FagusQuercus forest. Ann. Sci. For. 55: 141-157.

LeusChNeR, CH. (1998a): Mechanismen der Konkurrenzüberlegenheit der Rotbuche. Ber. d. Reinh. Tüxen-Ges. 10: 5-18.

Leuschner, Ch., Backes, K., Hertel, D., Schipka, F., Schmitt, U., Terborg, O. \& Runge, M. (2001): Drought responses at leaf, stem and fine root levels of competitive Fagus sylvatica L. and Quercus petraea (Matt.) Liebl. trees in dry and wet years. Forest Ecology and management 149: 33-46.

Leuschner, CH., Rode, M.W. \& Heinken, T. (1993): Gibt es eine Nährstoff-Mangelgrenze der Buche im nordwestdeutschen Flachland? Flora 188: 239-249.

LÖSCH, R. (1994): Exchange of energy and vapor between plants and the atmosphere. Prog. Bot. 55: 79-95.

LÖSCH, R. (1999): Plant water relations. In: Esser, K., KAdEREIT, J.W., LÜTTGE, U. \& Runge, M. (Hrsg.): Prog. Bot. 60: 193-233.

Lösch, R. (2001): Wasserhaushalt der Pflanzen. Quelle \& Meyer Verlag, Wiebelsheim, 595 S.

Loustau. D., Domec, J-C. \& Bosc, A. (1998): Interpreting the variations in xylem sap flux density within the trunk of maritime pine (Pinus pinaster Ait.): application of a model for calculating water flows at tree and stand levels. Ann. Sci. For. 55: 29-46.

Loustau. D., Granier, A. (1993): Environmental Control of water flux through Maritime Pine (Pinus pinaster Ait.) . In: Borghetti, M., Grace, J., \& RASCHI, A. (Hsrg.): Water Transport in Plants Under Climatic Stress: 205-218.

Lu, P., Biron, P., BrÉDA, N. \& GRANier, A. (1996): Water relations of adult Norway spruce (Picea abies (L) Karst) under soil drought in the Vosges mountains: whole-tree hydraulic conductance, xylem embolism and water loss regulation. Ann. Sci. For. 53: 113-121.

LundBLAD, M. \& Lindroth, A. (2002): Stand transpiration and sapflow density in relation to weather, soil moisture and stand characteristics. Basic Appl. Ecol. 3: 229-243.

LuXMOORE, R.J. \& HufF, D.D. (1989): Water. In: JoHnson, D.W. \& VAN HoOK, R.J. (Hrsg.): Analysis of biogeochemical cycling processes in Walker Branch Watershed. Springer Verlag New York: 164-196.

Lyr, H., POlster, H. \& Fiedler, H.-J. (1967): Gehölzphysiologie. Fischer Verlag, Jena.

MADRIGAL, A. (1992): Selvicultura de hayedos. Investigacion agraria, Sistemas y recursos forestales, fuera de serie $\mathrm{N}^{\circ} 1$ : actas del congreso internacional del haya Vol I: 35-60.

MAGNANI, F. \& BorghetTI, M. (1995): Interpretation of seasonal changes of xylem embolism and plant hydraulic resistance in Fagus sylvatica. Plant, Cell and Env. 18: 689-696. 
Maherali, H. \& DeLuCiA, E. (2001): Influence of climate-driven shifts in biomass allocation on water transport and storage in ponderosa pine. Oecologia 129: 481-491.

Makowka, I., STICKAN, W. \& WorbeS, M. (1991): Jahrringbreitenmessung an Buchen (Fagus sylvatica L.) im Solling: Analyse des Klimaeinflusses auf den jährlichen Holzzuwachs. Ber. Forsch.zentr. Waldökosysteme Göttingen B 18, 158 S.

MAMMEN, E. (1952): Der Einfluss einiger Witterungsfaktoren auf Jahrringbreite und Spätholzbildung verschiedener Holzarten des gleichen nordwestdeutschen Standortes. Diss. Univ. Göttingen, 178 S.

MARGRAF, S. (1989): Vergleichende chemische und physikalische Charakterisierung von Bodenprofilen einer Calluna-Heide, eines Birken-Kiefernwaldes und eines EichenBuchenwaldes auf Sanden der Lüneburger Heide. Unveröff. Diplomarb. Univ. Göttingen, $98 \mathrm{~S}$.

Martin, T.A., Brown, K.J., Cermak, J, Ceulmans. R., Kucera, J., Meinzer, F.C., Rombold, J.S., Sprugel, D.G. \& Hinckley, T.M. (1997): Crown conductance and tree and stand transpiration in a second-growth Abies amabilis forest. Can. J. For. Res. 27: 797-808.

Martonne DE, E. (1925): Traité de Geographie physique. In : Notions générales climat hydrographie. Colin, Paris, $496 \mathrm{~S}$.

MAtzNeR, E. (1988): Der Stoffumsatz zweier Waldökosysteme im Solling. Ber. Forsch.zentr. Waldökosysteme Göttingen A 40, 217 S.

McNaughton, K.G. \& Jarvis, P.G. (1983): Predicting the effects of vegetation changes on transpiration and evaporation. In: KozLOWSKI, T.T. (Hrsg.): Water deficits and plant growth. Academic Press, New York, Vol. VII: 1-47.

Meiresonne L., Nadezhdin N., Cermak J., Van-Slycken J. \& Ceulemans R. (1999): Measured sap flow and simulated transpiration from a poplar stand in Flanders (Belgium). Agr. For. Met. 96: 165-179.

MeIWes, K.J. \& BeESE, F. (1988): Ergebnisse der Untersuchung des Stoffhaushaltes eines Buchenwaldökosystems auf Kalkgestein. In: Ber. Forsch.zentr. Waldökosysteme Göttingen B 9, 142 S.

Mencuccini, M. \& GRACE, J. (1995): Climate influences the leaf area, sapwood area ratio in Scots pine. Tree Physiol. 15: 1-10.

Mitscherlich, G. (1981): Wald, Wachstum und Umwelt, Bd. 2: Waldklima und Wasserhaushalt. Sauerländer's Verlag, Frankfurt am Main, 402 S.

MitsCherlich, G. (1981a): Wald, Wachstum und Umwelt, Bd. 3: Boden, Luft und Produktion. Sauerländer's Verlag, Frankfurt am Main, 352 S.

Mitscherlich, G., Moll, W., KÜNSTle, E. \& MAURER, P. (1966): Ertragskundlich-ökologische Untersuchungen im Rein- und Mischbestand. VII: Höhenwachstum und Zuwachs des Bestandes. AFJZ 137.

MONTEITH, J.L. (1981): Coupling of plants to the atmosphere. In: GRACE, J., FORD, E.D., JARVIS, P.G. (Hrsg.): Plants and their atmospheric environment. Blackwell, Oxford: 1-29. 
MuHS, A. (1997): Feinwurzelverteilung und Streuabbau an vier Buchenstandorten mit unterschiedlichem Wasserhaushalt. Unveröff. Diplomarb. Univ. Göttingen.

Nagel J., Albert M. \& Schmidt M. (2000): BWINPro. Niedersächsische Forstliche Versuchsanstalt, Abt. Waldwachstum, Göttingen.

NiederstadT F.G. (1987): Zum Wasserhaushalt von Buchen (Fagus sylvatica L.) auf unterschiedlich säurebelasteten Standorten. Unveröff. Diplomarbeit, Univ. Göttingen, $180 \mathrm{~S}$.

Ninnemets, U., Sober, A., Kull, O., Hartung, W. \& Tenhunen, J.D. (1999): Apparent controls of leaf conductance by soil water availability and via-light-acclimation of foilage structural and physiological properties in a mixed deciduous, temperate forest. Int. J. Plant. Sci. 160: 707-721.

OGINK-HENDRIKS, M.J. (1995): Modelling surface conductance and transpiration of an oak forest in the Netherlands. Agr. For. Met. 74: 99-118.

Oren, R., Ewers, B.E., Todd, P., Phillips, N. \& Katul, G. (1998): Water balance delineates the soil layer in which moisture affects canopy conductance. Ecol. Appl. 8: 990-1002.

Oren, R., Phillips, N., Katul, G., Ewers, B.E. \& Pataki, D.E. (1998a): Scaling sap flux and soil water balance and calculating variance: a method for partitioning water flux in forests. Ann. Sci. For. 55: 191-216.

Overdieck, D. \& Forstreuter, M. (1994): Evapotranspiration of beech stands and transpiration of beech leaves subject to atmospheric CO2 enrichment. Tree Physiol. 14: 997-1003.

PALZ, W. (Hrsg.) (1996): European solar radiation atlas: solar radiation on horizontal and inclined surfaces. Springer Verlag Berlin Heidelberg, 333 S.

Pataki, D.E., Oren, R., Katul, G. \& Sigmon, J. (1998): Canopy conductance of Pinus taeda, Liquidambar styraciflora and Quercus phellos und varying atmospheric and soil water conditions. Tree Physiol. 18: 307-315.

PAULE, L. (1992): Geographic variation and genetic diversity of the european beech (Fagus sylvatica L.) in europe. Investigacion agraria, Sistemas y recursos forestales, fuera de serie $\mathrm{N}^{\circ} 1$ : Actas del congreso internacional del haya Vol. I: 281-290.

PAUle, L. (1992a): Biochemische Untersuchungen zur Genetik von Waldbaumpopulationen. In: LANDESANSTALT FÜR FORSTWIRTSCHAFT NORDRHEIN-WESTFALEN (Hrsg.): Bericht über die 21. Internationale Tagung der Arbeitsgemeinschaft für Forstgenetik und Forstpflanzenzüchtung vom 22. bis 23. Juni 1992 in Arnsberg. Schriftenreihe der Landesanstalt für Forstwirtschaft Nordrhein-Westfalen; Sonderbd.

PeCK, A. \& MAYER, H. (1996): Einfluß von Bestandesparametern auf die Verdunstung von Wäldern. Forstw. Cbl. 115: 1-9.

Pellinen, P. (1986): Biomasseuntersuchungen im Kalkbuchenwald. Diss. Univ. Göttingen, $134 \mathrm{~S}$.

Peltier, J.P. \& MARigo, G. (1998): Water stress tolerance of Fraxinus Excelsior L.. Bull. Ecol. (Brunoy) 29: 399-402. 
Peuke, A.D., Schraml, C., Hartung, W. \& Rennenberg, H. (2002): Identification of drought-sensitive beech ecotypes by physiological parameters. New Phytol. 154: 373387.

Phillips, N., Oren, R. \& Zimmermann, R. (1996): Radial patterns of xylem sap flow in non-, diffuse- and ring-porous tree species. Plant, Cell and Env. 19: 983-990.

PhILliPS, N. \& OREN, R. (1998): A comparison of daily representations of canopy conductance based on two conditional time-averaging methods and the dependence of daily conductance on environmental factors. Ann. Sci. For. 55: 217-235.

PigotT, C.D. \& PigotT, S. (1993): Water as a determinant of the distribution of trees at the boundary of the mediterranean zone. J. Ecol. 91: 557-566.

Polster, H. (1967): Wasserhaushalt. In: LyR, H., Polster, H. \& Fiedler, H.-J. (Hrsg.): Gehölzphysiologie. Fischer Verlag, Jena.

Pretzsch, H. (1996): Growth Trends of Forests in Southern Germany. Growth trends in European forests : studies from 12 countries. European Forest Institute research report 5. Springer Verlag, Berlin Heidelberg:107-132.

Prodan, M. (1965): Holzmeßlehre. Sauerländer's Verlag, Frankfurt am Main, 644 S.

Prskawetz, M. \& LeXer, M.J. (2000): Evaluierung des LAI-2000 zur Ermittlung des Blattflächenindex in Buchenjungbeständen. AFJZ 171: 185-191.

Raftoyannis, Y. \& Radoglou, K. (2002): Physiological Responses of Beech and Sessile Oak in a Natural Mixed Stand During a Dry Summer. Ann. Bot. 89: 723-730.

Reich P.B., Walthers M.B. \& Ellsworth D.S. (1991): Leaf age and season influence the relationships between leaf nitrogen, leaf mass per area and photosynthesis in maple and oak trees. Plant, Cell and Env. 14: 251-259.

REICH, P.B. \& HiNCKLEY, T.M. (1989): Influence of pre-dawn water potential and soil-to-leaf hydraulic conductance on maximum daily leaf conductance in two oak species. Functional Ecology 3: 719-726.

Riederer, M. \& Schreiber L. (2001): Protecting against water loss. J. Exp. Bot., Vol.52: 2023-2032.

RoBERTS, J. (1983): Forest transpiration: a conservative hydrological process? J. Hydr. 66: 133-141.

RoBerts, J. \& Rosier, P.T.W. (1994): Comparative estimates of transpiration of ash and beech forest at a chalk site in southern Britain. J. Hydr. 162: 229-245.

Rode, M.W. \& Heinken, T. (1993): Der Einfluß der Vegetation auf die Nährstoffverteilung in stark versauerten, nährstoffarmen Böden der Lüneburger Heide. Scripta Geobot. 20: 21-38.

RÖHRIG, E. (1991): Seasonality. In: Ecosystems of the world 7: Temperate deciduous forests: 25-31. 
Roloff, A. (1985): Morphologie der Kronenentwicklung von Fagus sylvatica L. (Rotbuche) unter besonderer Berücksichtigung möglicherweise neuartiger Veränderungen. Diss. Forst. Fak. Univ. Göttingen.

RolofF, A. (1985a): Untersuchungen zum vorzeitigen Laubfall und zur Diagnose von Trockenschäden in Buchenbeständen. AFZ 40: 157-160.

RosenberG, A. (1995): Klimatische Einflüsse auf den Durchmesserzuwachs von Fichte (Picea abies [L.] Karst.), Rotbuche (Fagus sylvatica [L.]) und Eberesche (Sorbus aucuparia [L.], syn. Vogelbeere) in den Hochlagen des Sauerlandes. Diplomarbeit Univ. Göttingen, Forstwiss. Fachber., Inst. f. Waldbau, $98 \mathrm{~S}$.

RozAs, V. (2001): Detecting the impact of climate and disturbances on tree-rings of Fagus sylvatica L. and Quercus robur L. in a lowland forest in Cantabria, Northern Spain. Ann. For. Sci. 58: 237-251.

RUBNER, K. (1960): Die pflanzengeographischen Grundlagen des Waldbaus. Neumann Verlag, Radebeul, Berlin.

SALIENDRA, N.Z., Sperry, J.S. \& COMSTOCK, J.P. (1995): Influence of leaf water status on stomatal response to humidity, hydraulic conductance and soil drought in Betula occidentalis. Planta 196: 357-366.

SCHAAP, M.G. (1996): The role of soil organic matter in the hydrology of forests on dry sandy soils. Diss. Univ. Amsterdam, 145 S.

SchefFer, F. \& Schachtschabel, P. (1998): Lehrbuch der Bodenkunde. Enke Verlag, Stuttgart, $494 \mathrm{~S}$.

Schenk, J., Stickan, W. \& Runge, M. (1989): Belaubungsverlauf und Blattmerkmale von Buchen unter dem Einfluß von Kalkung und Stickstoffdüngung. Ber. Forsch.zentr. Waldökosysteme Göttingen A 49: 91-101.

Schlichter, T.M., Ploeg, R.R. \& Ulrich, B. (1983): Ein Simulationsmodell der Wasseraufnahme durch einen Buchenwald: Auswirkung von unterschiedlicher Wurzelbiomasse und -verteilung. Z. Pflanzenernähr. Bodenk. 146: 725-735.

SCHMiTT, U. (1993): Stand structure of early and late-successional forest communities in heathland-forest succession in NW Germany. Scripta Geobot. 21: 67-72.

SchOBER, R. (1951): Zum Einfluß der letzten Dürrejahre auf den Dickenzuwachs. Forstw. Cbl. 70: 204-228.

Schober, R. (1972): Die Rotbuche. Schriften der forstl. Fak. Univ. Göttingen 43,44, 333 S.

SCHOBER, R. (1995): Ertragstafeln wichtiger Baumarten bei verschiedener Durchforstung. Sauerländer's Verlag, Frankfurt am Main, 166 S.

Scholander, P.F. \& HAMmel, H.T. (1964): Hydrostatic pressure and osmotic potentials in leaves of mangroves and some other plants. Proc. natl. Acad. Sci. USA 51: 119-125.

Scholander, P.F., Hammel, H.T., Bradstreet, E.D. \& Hemmingsen, E.A. (1965): Sap pressure in vascular plants. Science 148: 339-346. 
Schraml, C. \& RennenberG, H. (2000): Sensitivität von Ökotypen der Buche. Forstw. Cbl. 119: 51-61.

SCHREIBER L., KIRSCH, T. \& RIEDERER, M. (1996): Transport properties of cuticular waxes of Fagus sylvatica L. and Picea abies L. (Karst) - estimation of size-selectivity and tortuosity from diffusion coefficients of aliphatic molecules. Planta 198: 104-109.

Schulte, M. (1992): Saisonale und interannuelle Variabilität des CO2-Gaswechsels von Buchen (Fagus sylvatica L.) - Bestimmung von C-Bilanzen mit Hilfe eines empirischen Modells. Diss. Univ. Göttingen, $160 \mathrm{~S}$.

SCHulze, E. D. (1970): Der CO2-Gaswechsel der Buche (Fagus sylvatica L.) in Abhängigkeit von Klimafaktoren im Freiland. Flora 159: 177-232.

SChulze, E. D. \& HALl, A.E. (1982): Stomatal responses, water loss and CO2 assimilation rates of plants in contrasting environments. In: LANGE, O.L., NoBel, P.S., Osmond, C.B., \& ZIEGLER, H. (Hrsg.): Encyclopedia of Plant Physiology, New Series Vol 12B. Springer Verlag, Berlin Heidelberg New York:181-230.

Schulze, E.D., Kelliher, F.M., KöRner, C., Lloyd, J. \& Leuning, R. (1994): Relationships Among Maximum Stomatal Conductance, Ecosystem Surface Conductance, Carbon Assimilation Rate and Plant Nitrogen Nutrition: A Global Ecology Scaling Exercise. Annu. Rev. Ecol. Syst. 25: 629-660.

SEIBT, G. (1981): Die Buchen- und Fichtenbestände der Probeflächen des Sollingprojektes der Deutschen Forschungsgemeinschaft. Schriften der forstl. Fak. Univ. Göttingen 72, 109 S.

SHIELDS, L.M. (1950): Leaf xeromorphy as related to physiological and structural influences. Bot. Rev. 16: 399-440.

Shuttleworth, W.J. (1989): Micrometeorology of temperate and tropical forest. Phil. Trans. R. Soc. London ser. B 324: 299-334.

Smith, D.M. \& Allen, S.J. (1996): Measurement of sap flow in plant stems. J. Exp. Bot., Vol.47, Nr.305: 1833-1844.

Sperry, J.S., Hacke, U.G., Oren, R. \& COMStock, J.P. (2002): Water deficits and hydraulic limits of water supply. Plant, Cell and Env. 25: 253-266.

Stickan, W., Schulte, M., Kakubari, Y., Niederstadt, F., Schenk, J. \& Runge, M. (1991): Ökophysiologische und biometrische Untersuchungen in einem Buchenbestand (Fagus sylvatica L.) des Sollings als ein Beitrag zur Waldschadensfoschung. Ber. Forsch.zentr. Waldökosysteme Göttingen B 18, 158 S.

StoJKo, S.M. (1991): Die ökologische Bestimmung der Vitalität der Rotbuche (Fagus sylvatica L.) an der osteuropäischen Grenze ihres Areals in der Ukrainischen SSR. 3. IUFROBuchensymposium, Zvolen 1991, $370 \mathrm{~S}$.

Strobel, J. (1997): Der Wasserhaushalt eines Buchenwaldes im mitteldeutschen Trockengebiet. Unveröff. Diplomarb. Univ. Göttingen, 113 S.

Sturm, N., Tenhunen, J.D. \& HARTUnG, W. (1996): Das Wirkungsgefüge Bodenwasserverfügbarkeit, Xylem-ABA-Konzentration und Bestandesleitfähigkeit - eine 
Freilanduntersuchung an Pinus sylvestris. Verhandlungen der Gesellschaft für Ökologie Bd.26: 79-83.

SwANSON, R.H. (1994): Significant historical developments in thermal methods for measuring sap flow in trees. Agr. For. Met. 72: 113-132.

SWINBANK, W.C. (1951): The measurement of heat and water vapor by eddies in the lower atmosphere. J. Metereol. 8: 135-145.

TERBORG, O. (1998): Die Kohlenstoffassimilation von Rotbuchen und Traubeneichen in einem Mischbestand in der Lüneburger Heide und deren Bedeutung für die interspezifische Konkurrenz . Diss. Univ. Göttingen, 109 S.

TESKeY, R.O. \& SHERIFF, D.W. (1996): Water use by Pinus radiata trees in a plantation. Tree Physiol. 16: 273-279.

THом, A.S. (1972): Momentum, mass, and heat exchange of the vegetation. Quart. J. Roy. Met. Soc. 98: 124-134.

Thom, A.S. \& Oliver, H.R. (1977): On Penman's equation for estimating regional evapotranspiration. Quart. J. Roy. Meteor. Soc. 103: 345-357.

ThOMAS, F.M. (2000): Growth and water relations of four deciduous tree species (Fagus sylvatica L., Quercus petraea [Matt.] Liebl., Q. pubescens Willd., Sorbus aria [L.] Cr.) occurring at Central-European tree-line sites on shallow cacareous soils: physiological reaction. Flora: 104-115.

Tognetti, S., Johnson, J.D. \& Michelozzi, M. (1995): The response of european beech (Fagus sylvatica L.) seedlings from two italian populations to drought and recovery. Trees 9: 348-354.

TOPP, G.C., DAVIS, J.L. \& ANNAN, A.P. (1980): Electromagnetic determination of soil water content: Measurement in coaxial transmission lines. Water Resour. Res. 16: 574-582.

Tschaplinski, T. J., Gebre, G.M. \& ShirshaC, T.L. (1998): Osmotic potential of several hardwood species as affected by manipulation of throughfall precipitation in an upland oak forest during a dry year. Tree Physiol. 18: 291-298.

Tuhkanen, S. (1980): Climatic parameters and indices in plant geography. Acta Phytogeogr. Suec. $67: 1-105$.

TURNER, N.C. (1988): Measurement of plant water status by the pressure chamber technique. Irrig. Sci. 9: 289-308.

TyReE, M.T. \& ChEUnG, Y.N.S. (1977): Resistance to water flow in Fagus grandifolia leaves. Can. J. Bot. 55: 2591-2599.

TYREE, M.T. \& EWERS, F.W. (1991): The hydraulic architecture of trees and other woody plants. New. Phytol. 119: 345-360.

TyreE, M.T. \& HAMmEL, H.T. (1972): The measurement of the turgor pressure and the water relations of plants by the pressure bomb technique. J. Exp. Bot., Vol.23: 267-282. 
Tyree, M.T. \& JARvis, P. G. (1982): Water in tissues and cells. In: LANGe, O.L., Nobel, P.S. OsMOND, C.B. \& ZIEGLER, H. (Hrsg.): Encyclopedia of plant physiology - Physiological Plant Ecology II, New Series 12B. Springer Verlag Berlin Heidelberg New York: 36-77.

Tyree, M.T., Salleo, S., Nardini, A., Lo Gullo, M.A. \& Mosca, R. (1999): Refilling of embolized vessels in young stems of laurel. Do we need a new paradigm? Plant Physiol. 120: $11-21$.

TYREE, M.T. \& SPERRY, J.S. (1988): Do woody plants operate near the point of catastrophic xylem dysfunction caused by dynamic water stress? Answers from a model. Plant Physiol.88: 574-580.

Uemura, A., Sishida, A.,Nakano, T., Terashima, I., Tanabe, H. \& Matsumoto, Y. (2000): Acclimation of leaf characteristics of Fagus species to previous-year and current-year solar irradiances. Tree Physiol. 20: 945-951.

UlRICH, B. (1981): Ökologische Gruppierung von Böden nach ihrem chemischen Bodenzustand. Z. Pflanzenernähr. Bodenk. 144: 289-305.

Vertessy, R.A., BenYon,R.G., O'Sullivan, S.K. \& GribBen, P.R. (1995): Relationships between stem diameter, sapwood area, leaf area and transpiration in a young mountain ash forest. Tree Physiol. 15: 559-567.

Vose, J.M. \& ALLEN, H.L. (1988): Leaf area, stem wood growth, and nutrition relationships in Loblolly Pine. For. Sci. 34: 547-563.

VOß, S. (1998): Belaubungsdichte und Blattmasse in Abhängigkeit von bodenchemischen Faktoren in verschiedenen Buchenwäldern Nordhessens. Unveröff. Diplomarbeit Univ./Gh. Kassel.

WALSH, R.P.D. \& Voight, P.J. (1977): Vegetation litter: an underestimated variable in hydrology and geomorphology. J. Biogeogr. 4: 253-274.

WALter, H. (1960): Einführung in die Phytologie III, 1. Standortslehre.

WAlter, H. \& BRecKle S.-W. (1991): Ökologie der Erde Bd. 1. Gustav Fischer Verlag, Stuttgart, $238 \mathrm{~S}$.

WEBER, E. (1980): Grundriß der biologischen Statistik. 652 S.

WenK, G. \& Vogel, M. (1992): Einfluß von Temperatur und Niederschlag auf den Verlauf des Radialzuwachses. Schriften der forstl. Fak. Univ. Göttingen 106: 206-215.

Wetlander, N.T. \& Ottosson, B. (1997): Influence of photosythetic photon flux density on growth and transpiration in seedlings of Fagus sylvatica. Tree Physiol. 17: 133-140.

WiLhelmi, T. VON (1959): Ein Testversuch über die Abhängigkeit des Dickenwachstums der Bäume von der Globalstrahlung und der Lufttemperatur. AFJZ 130: 204-209.

Willert, D.J., Matyssek, R. \& Herppich, W. (1995): Experimentelle Pflanzenökologie. Thieme Verlag, Stuttgart, 344 S.

WiLsON, K.B., BALDOCCHI, D.D. \& HANSON, B.J. (2000): Quantfying stomatal and non-stomatal limitation to carbon assimilation rate as a result of leaf aging and drought in mature deciduous tree species. Tree Physiol. 20: 787-797. 
WiLson, K.B., BALDOCCHI, D.D. \& HANSON, B.J. (2000a): Spatial and seasonal variability of photosynthetic parameters and their relationship to leaf nitrogen in a deciduous forest. Tree Physiol. 20: 565-578.

Wilson, K.B., Hanson, P.J., Mulholland, P.J., Baldocchi, D.D. \& Wullschleger, S.D. (2001): A comparison of methods for determining forest evapotranspiration and its components: sap-flow soil water budget eddy covariance and catchment water balance. Agr. For. Met. 106: 153-168.

WoldstedT, P. \& DuphORN, K. (1974): Norddeutschland und angrenzende Gebiete im Eiszeitalter. Koehler Verlag, Stuttgart, $500 \mathrm{~S}$.

WoOdward, F.I. (1987): Climate and plant distribution. Cambridge University Press, Cambridge.

Wullschleger, S.D., Meinzer, F.C. \& Vertessy, R.A. (1998): A review of whole plant water use studies in trees. Tree Physiol. 18: 499-512.

Wullschleger, S.D., Hanson, P.J. \& Tschaplinski, T.J. (1998a): Whole plant water flux in understory red maple exposed to altered precipitation regimes. Tree Physiol. 18: 71-79.

Wullschleger, S.D., Wilson, K.B. \& Hanson, P.J. (2000): Environmental control of whole plant transpiration, canopy conductance and estimates of the decoupling coefficient for large red maple trees. Agr. For. Met. 104: 157-168.

ZimMERMANN, N.E. \& KienAST, F. (1999): Predictive mapping of alpine grasslands in Switzerland: Species versus community approach. J. Veg. Sci. 10: 469-482. 


\section{Verzeichnis der Tabellen und Abbildungen im Text}

Tab. 2-1: $\quad$ Bodenchemische Kennwerte der Untersuchungsflächen $\quad 7$

Tab. 2-2: Bestandesstruktur der Untersuchungsflächen 9

Tab. 2-3: Niederschlagssummen auf den Untersuchungsflächen 13

Tab. 2-4: $\quad$ Mittlere Temperaturen auf den Untersuchungsflächen 13

Tab. 2-5: Monatssummen der Globalstrahlung auf den 15 Untersuchungsflächen

Tab. 2-6: Monatssummen des Wasserdampf-Sättigungsdefizits der Luft auf den 17 Untersuchungsflächen

Tab. 2-7: Feldkapazität und Nutzwasserkapazität auf den Untersuchungsflächen

Tab. 4-1: Blattflächenindices und morphologische Blattparameter in den Untersuchungsbeständen

Tab. 4-2: Holzvolumenvorrat und -zuwachs sowie Reisholzanteil in den Untersuchungsbeständen

Tab. 4-3: Mittelwerte der mittäglichen und maximalen stomatären

Blattleitfähigkeit in den Sonnenkronen der Untersuchungsbestände

Tab. 4-4: Relative kumulative Anteile der monatlichen Bestandestranspiration an der Jahrestranspiration der Untersuchungsbestände 1996

Tab. 5-1: Werte des Kontinentalitäts-Index nach ELLENBERG (1996)

Tab. 5-2: Kennwerte der Kontinentalität des Klimas auf den vier untersuchten Buchenstandorten

Tab. 5-3: Saisonale Mittelwerte des veränderten monatlichen Index der Kontinentalität auf den Untersuchungsflächen

Tab. 5-4: Mehrjährige Mittelwerte der Monatssummen der Globalstrahlung auf den Untersuchungsflächen Göttinger Wald und Solling, sowie für Stationen im mitteldeutschen Tiefland

Tab. 5-5: Trockenmasse lebender Feinwurzeln in den Untersuchungsbeständen 1996 und 1997

Tab. 5-6: Monatliche Mittelwerte der Nutzwassergehalte in $0-10 \mathrm{~cm}$ und $10-40 \mathrm{~cm}$ Bodentiefe

Tab. 5-7: Mittelwerte, Maxima und Minima der Nutzwasservorräte der Untersuchungsbestände in Mineralboden und organischer Auflage

Tab. 5-8: Schema der Verteilungsmuster von Bodenwasserverfügbarkeit und Feinwurzeldichte in den Untersuchungsbeständen

Tab. 5-9: Mittlere osmotische Potentiale bei Wassersättigung und bei Grenzplasmolyse in den Untersuchungsbeständen und nach Literaturangaben 
Tab. 5-10: Mittägliche und maximale stomatäre Blattleitfähigkeiten in den Untersuchungsbeständen und nach Literaturangaben

Tab. 5-11: Mittlere minimale und maximale Blattwasserpotentiale in den Untersuchungsbeständen und nach Literaturangaben

Tab. 5-12: Maximalwerte der täglichen Bestandestranspiraton und Jahressummen der Bestandestranspiration in den Untersuchungsbeständen und nach Literaturangaben

Tab. 5-13: Bestimmtheitsmaße der linearen und sigmoidalen

Beziehungen der Bestandestranspiration zu Globalstrahlung und Sättigungsdefizit der Luft

Tab. 5-14: Mittelwerte von Wasserhaushaltsparametern an Tagen mit und ohne Niederschlag

Tab. 5-15: Bestimmtheitsmaß der multiplen linearen Regressionen für die Beziehung der Bestandestranspiration zu Globalstrahlung, Sättigungsdefizit der Luft und Bodenwassergehalt

Tab. 5-16: Monatliche Mittelwerte der Bestandesleitfähigkeit auf den Untersuchungsflächen

Tab. 5-17: Bestimmtheitsmaß der multiplen linearen Regressionen für die Beziehung der Bestandesleitfähigkeit zum Bodenwassergehalt

Tab. 5-18: Bestimmtheitsmaß der Optimumfunktion zwischen der Bestandesleitfähigkeit und der Globalstrahlung 
Abb. 2-1: Topographische Lage der Untersuchungsflächen

Abb. 2-2: Monatliche Temperaturen und Niederschläge im langj. Mittel

Abb. 2-3: Globalstrahlung (kumulativ) auf den Untersuchungsflächen

Abb. 2-4: Wasserdampf-Sättigungsdefizit der Luft auf den Untersuchungsflächen

Abb. 2-5: Volumetrischer Wassergehalt der Streuauflage der Bestände in der Lüneburger Heide und im Solling

Abb. 2-6: Bodenmatrixpotential und volumetrischer Bodenwassergehalt in den Beständen Göttinger Wald, Lüneburger Heide und Solling

Abb. 2-7: Volumetrischer Bodenwassergehalt auf den Untersuchungsflächen 1996

Abb. 2-8: Bodenmatrixpotential auf den Untersuchungsflächen 1996

Abb. 2-9: Bodenmatrixpotential und volumetrischer Bodenwassergehalt in den Beständen Ziegelrodaer Forst, Göttinger Wald und in der Lüneburger Heide 1997

Abb. 2-10: Bodenmatrixpotential und volumetrischer Bodenwassergehalt im Bestand Solling 1997

Abb. 2-11: Matrixpotential-Wassergehalts-Beziehungen (Feld-pF-Kurven) der Böden auf den Untersuchungsflächen

Abb. 2-12: Nutzwasservorrat in Mineralboden und organischer Auflage in den Untersuchungsbeständen 1996

Abb. 3-1: Beispielkurve der Druck-Volumen-Analyse

Abb. 3-2: Beziehung der mittleren Saftflußrate zur Baumgrundfläche in den Untersuchungsbeständen

Abb. 4-1: Kronenraum-Höhenprofile des kumulativen Blattflächenindex

Abb. 4-2: Holzvolumenzuwachs in den Untersuchungsbeständen

Abb. 4-3: Mittlerer relativer Durchmesserzuwachs in den Untersuchungsbeständen

Abb. 4-4: Mittlere relative Durchmesserzuwachsraten in den Untersuchungsbeständen

Abb. 4-5: Osmotische Potentiale bei Wassersättigung und bei Grenzplasmolyse in den Untersuchungsbeständen im saisonalen Verlauf

Abb. 4-6: Mittlere osmotische Potentiale bei Wassersättigung und bei

Grenzplasmolyse in den Untersuchungsbeständen

Abb. 4-7: Saisonaler Verlauf des relativen Wassergehalts bei Grenzplasmolyse in den Untersuchungsbeständen

Abb. 4-8: Mittlerer relativer Wassergehalt bei Grenzplasmolyse in den Untersuchungsbeständen

Abb. 4-9: Ausgewählte Tagesgänge des Blattwasserpotentials in den 
Abb. 4-10: Saisonaler Verlauf der Tagesmaxima und -minima des Blattwasserpotentials in den Untersuchungsbeständen

Abb. 4-11: Saisonaler Verlauf der Tagesmaxima und -minima des Blattwasserpotentials in den Untersuchungsbeständen 1997

Abb. 4-12: Mittelwerte des maximalen Blattwasserpotentials in den Untersuchungsbeständen

Abb. 4-13: Mittelwerte des minimalen Blattwasserpotentials in den Untersuchungsbeständen

Abb. 4-14: Tagesgänge der Blattleitfähigkeit in der Sonnenkrone

Abb. 4-15: Saisonaler Verlauf der mittäglichen stomatären Blattleitfähigkeit in den Untersuchungsbeständen

Abb. 4-16: Kronen-Höhenprofile der Blattleitfähigkeit in den Beständen Ziegelrodaer Forst und Göttinger Wald

Abb. 4-17: Kronen-Höhenprofile der mittleren relativen Blattleitfähigkeit und des kumulativen Blattflächenindex im Ziegelrodaer Forst und im Göttinger Wald

Abb. 4-18: Beziehung der mittleren relativen Blattleitfähigkeit zum kumulativen LAI über verschiedene Höhenstufen des Kronenraums

Abb. 4-19: Höhenprofile der Blattleitfähigkeit im Kronenraum zu Beginn und Ende einer Trockenperiode

Abb. 4-20: Kronenraum-Höhenprofile der mittleren BlattleitfähigkeitsEinschränkung und des kumulativen Blattflächenindex

Abb. 4-21: Kronenraum-Höhenprofil der mittleren relativen BlattleitfähigkeitsEinschränkung gegenüber der maximalen Blattleitfähigkeit

Abb. 4-22: Tagesgänge der Saftflußrate einer Buche im Göttinger Wald im Verlauf einer Trockenperiode

Abb. 4-23: Tagesgänge der Xylem-Saftflußrate, der Globalstrahlung und des Sättigungsdefizits bei unterschiedlicher Witterung

Abb. 4-24: Tagessummen der Bestandestranspiration auf den Untersuchungsflächen 1996

Abb. 4-25: Monatssummen der Bestandestranspiration auf den Untersuchungsflächen 1996

Abb. 4-26: Kumulative Tagessummen der Bestandestranspiration auf den Untersuchungsflächen 1996

Abb. 4-27: Tagessumme der Bestandestranspiration im Bestand Göttinger Wald 1995

Abb. 5-1: Monatlicher Kontinentalitäts-Index der Untersuchungsflächen 1995-1997 sowie im langjährigen Mittel

Abb. 5-2: Blattleitfähigkeits- und Blattwasserpotentialwerte aus Tagesgangmessungen in den Untersuchungsbeständen 
morphologisch-bestandesstrukturellen Parametern in den Untersuchungsbeständen

Abb. 5-4: Lineare und sigmoidale Beziehungen der Bestandestranspiration zu Globalstrahlung und Sättigungsdefizit

Abb. 5-5: Vergleich der linearen Beziehungen zwischen der Tagessumme der Bestandestranspiration und Sättigungsdefizit der Luft an Tagen mit und ohne Niederschlag

Abb. 5-6: Saisonaler Verlauf der Bestandesleitfähigkeit auf den Untersuchungsflächen 1996

Abb. 5-7: Optimum-Beziehung der Tagesmittelwerte der Bestandesleitfähigkeit zur Tagessumme der Globalstrahlung in den Untersuchungsbeständen

Abb. 5-8: Beziehung der Bestandesleitfähigkeit zum Sättigungsdefizit der Luft in den Untersuchungsbeständen 


\section{Abkürzungsverzeichnis}

\begin{tabular}{|c|c|}
\hline $\mathrm{Ak}_{\mathrm{e}}$ & Kationenaustauschkapazität \\
\hline BHD & Brusthöhendurchmesser \\
\hline $\mathrm{E}$ & Bestandestranspiration \\
\hline gTG & Gramm Trockengewicht \\
\hline $\mathrm{g}_{\mathrm{c}}$ & Bestandesleitfähigkeit \\
\hline $\mathrm{g}_{\mathrm{s}}$ & stomatäre Leitfähigkeit \\
\hline $\mathrm{G}$ & Globalstrahlung \\
\hline GF & $\begin{array}{l}\text { Grundfläche } \\
\text { (Stammquerschnittsfläche) }\end{array}$ \\
\hline GW & Göttinger Wald \\
\hline $\mathrm{h}$ & Höhe \\
\hline LAI & $\begin{array}{l}\text { leaf area index } \\
\text { (Blattflächenindex) }\end{array}$ \\
\hline $\mathrm{LAI}_{\mathrm{kum}}$ & kumulativer leaf area index \\
\hline $\mathrm{LH}$ & Lüneburger Heide \\
\hline $\mathrm{n}$ & Stichprobenumfang \\
\hline n.s. & nicht signifikant \\
\hline $\mathrm{p}$ & Irrtumswahrscheinlichkeit \\
\hline PAR & $\begin{array}{l}\text { photosynthetic active radiation } \\
\text { (photosynthetisch aktive Strahlung) }\end{array}$ \\
\hline $\mathrm{r}$ & Korrelationskoeffizient \\
\hline $\mathrm{RWC}_{\mathrm{p}}$ & relativer Wassergehalt bei Grenzplasmolyse \\
\hline $\mathrm{SO}$ & Solling \\
\hline VPD & $\begin{array}{l}\text { vapour pressure deficit } \\
\text { (Wasserdampf-Sättigungsdefizit der Luft) }\end{array}$ \\
\hline $\mathrm{ZF}$ & Ziegelrodaer Forst \\
\hline$\Theta$ & volumetrischer Bodenwassergehalt \\
\hline$\pi_{\mathrm{o}}$ & osmotisches Potential bei Wassersättigung \\
\hline$\pi_{\mathrm{p}}$ & osmotisches Potential bei Grenzplasmolyse \\
\hline$\Psi$ & Bodenmatrixpotential \\
\hline$\Psi_{\max }$ & maximales Blattwasserpotential \\
\hline$\Psi_{\min }$ & minimales Blattwasserpotential \\
\hline$\varnothing$ & Mittelwert \\
\hline
\end{tabular}




\title{
Danksagung
}

\author{
Mein Dank gilt
}

- Christoph Leuschner für die Anregung zu dieser Untersuchung, sein immer offenes Ohr und die wohlgesetzte Mischung aus Ansporn und Geduld in der Betreuung dieser Arbeit

- Dietrich Hertel für den allzeit guten Rat in allen Fragen und Problemen und seine Sorgfalt und Ausdauer bei den Diskussionen der Etappen auf dem Weg zum Ziel

- Hanke, Katrin, Lars, Mechthild, Stella und Tom, die mit mir beim Installieren und Messen im Wald waren sowie Marc Hagemeier und ganz besonders Jörg Strobel für sein enormes Engagement auf der Untersuchungsfläche im Ziegelrodaer Forst.

- Heinz Coners für die nette außerbairisch-inländische Gemeinschaft in unserem Arbeitszimmer

- dem Endredaktionsteam: Carolin, Lars, Marina, Ros und Susanne

- der ganzen Institutsbesatzung in Weende, von der jede und jeder einzelne zu dem einmalig guten Arbeitsklima beigetragen hat, das mich jeden Tag aufs neue gerne in die Grisebachstraße 1 hat rausradeln lassen.

- und zuletzt aber nicht an letzter Stelle all jenen, die mit mir daran geglaubt haben, daß diese Arbeit vollendet wird. 


\section{Lebenslauf}

\section{Persönliche Angaben}

Name

Florian Schipka

Geburtsdatum

1.7.1967

Geburtsort

Würzburg

Staatsangehörigkeit deutsch

\section{Bildungsgang}

1973-1977 Grundschule in München

1977-1986 Wittelsbacher Gymnasium München

1986 Allgemeine Hochschulreife am Wittelsbacher Gymnasium München

1986-1988 Zivildienst in der Individuellen Schwerstbehindertenbetreuung München

1988-1991 Grundstudium Biologie an der Ludwig-Maximilians-Universität München

1991-1995 Hauptstudium Biologie an der Georg-August-Universität Göttingen

1995 Abschluß als Diplom-Biologe

1996-2002 Vorbereitung auf die Promotion 